\title{
Comprehensive Tobacco Control Policy Regimes and Population Health: Assessing Causal Loops
}

Stephanie J. Frisbee

West Virginia University

Follow this and additional works at: https://researchrepository.wvu.edu/etd

\section{Recommended Citation}

Frisbee, Stephanie J., "Comprehensive Tobacco Control Policy Regimes and Population Health: Assessing Causal Loops" (2010). Graduate Theses, Dissertations, and Problem Reports. 4594.

https://researchrepository.wvu.edu/etd/4594

This Dissertation is protected by copyright and/or related rights. It has been brought to you by the The Research Repository @ WVU with permission from the rights-holder(s). You are free to use this Dissertation in any way that is permitted by the copyright and related rights legislation that applies to your use. For other uses you must obtain permission from the rights-holder(s) directly, unless additional rights are indicated by a Creative Commons license in the record and/ or on the work itself. This Dissertation has been accepted for inclusion in WVU Graduate Theses, Dissertations, and Problem Reports collection by an authorized administrator of The Research Repository @ WVU.

For more information, please contact researchrepository@mail.wvu.edu. 


\title{
Comprehensive Tobacco Control Policy Regimes and Population Health: Assessing Causal Loops
}

\author{
Stephanie J. Frisbee, M.Sc, M.A. \\ Dissertation submitted to the Eberly College of Arts and Sciences at West Virginia University in \\ partial fulfillment of the requirements for the degree of:
}

\author{
Doctor of Philosophy \\ in \\ Political Science (Public Policy Analysis) \\ Department of Political Science
}
Donley T. Studlar, Ph.D., Chair
Robert D. Duval, Ph.D.
Michael S. Hendryx, Ph.D.
Susan Hunter, Ph.D.
John C. Kilwein, Ph.D.
Morgantown, West Virginia, U.S.A.
2010

Keywords: tobacco control policy, public policy, public health, smoking, population health

Copyright 2010 


\title{
ABSTRACT \\ Comprehensive Tobacco Control Policy Regimes and Population Health: Assessing Causal Loops
}

\author{
Stephanie J. Frisbee, M.Sc, M.A.
}

Tobacco products remain among the most controversial consumer products of all time: cigarettes are the only legal product that, when used as intended, are lethal. The global and individual burden attributable to the primary use of tobacco, or secondary or tertiary exposure to cigarette smoke, whether measured by morbidity, mortality, or economic costs, is substantial. With the combined efforts of scientific research, public health and policy advocates, the image and use of tobacco products has undergone profound change. However, while much has been achieved regarding the attitudinal, behavioral, and policy changes needed to diminish the individual, social, and economic costs of tobacco use, much remains to be yet accomplished if these adverse tobacco use impacts are to be further curtailed. There is considerable evidence that tobacco use is becoming highly concentrated in lower socio-economic groups and that the rate of decline in smoking is slowing. Further, as the tobacco epidemic emerges in the developing world, there is considerable interest ine applying the lessons learned in industrialized countries to developing countries, thereby truncating the tobacco epidemic and forgoing some of the enormous costs in countries least able to absorb such costs.

The unifying theme of the present work is an integration of the public health and political science perspectives on tobacco control so as to establish a more comprehensive framework of the underlying factors and elements interrelating tobacco use and tobacco control policy. A substantial challenge in developing such a framework is the complexity of the relationship between the two primary outcomes of interest. The relationships, including interdependencies and feedback mechanisms, are much more accurately characterized by a causal loop. This work presents an overview of the tobacco epidemic, a review of two very different literatures with different perspectives on the tobacco epidemic (public health literature and political and policy science), an empirical policy history analysis integrating the political and policy science viewpoint with the public health perspective on the evolution of the tobacco epidemic, and two quantitative analyses alternately supporting the interdependence and complex temporal relationship between tobacco control policy adoption and population health outcomes as well as the importance of societally-derived factors. An integrated conceptual model based on the causal loops of tobacco control policy and tobacco-related population health is then presented 
that incorporates the realms of population, governmental, judicial, public health, tobacco industry and other subsystems, and scientific communities. However, while this framework does assimilate the key elements and forces elucidated during the course of this work and integrates the political and policy science with the public health perspective, in truth this framework likely elicits more questions than it answers. The research questions and agendas and metrics proposed highlight both the strengths and deficiencies of the two perspectives. 
For my Jefferson, Nathaniel, and Amelia.

May I always be worthy of your unwavering love and support. 


\section{ACKNOWLEDGEMENTS}

I am sincerely grateful for all those who have supported me in this endeavor. Thank you to my many professors and instructors who have guided and, at times, pushed my academic development. I am also sincerely grateful to the members of my committee, Drs. Duval, Hendryx, Hunter, Kilwein, and Studlar, for their assistance and guidance both throughout my doctoral studies but also in the preparation of my dissertation. I also wish to acknowledge and thank Dr. Worsham for his counsel during my studies.

In particular, I wish to acknowledge and sincerely thank Dr. Studlar, my doctoral advisor and mentor. I consider myself to have been most fortunate to have met and worked with Dr. Studlar. He has encouraged, and then required and supported, my development, as a good mentor should. Much sincere thanks, Dr. Studlar, for all of your assistance, as well as your wisdom and humor. I aspire to develop into a worthy academic colleague. 


\section{TABLE OF CONTENTS}

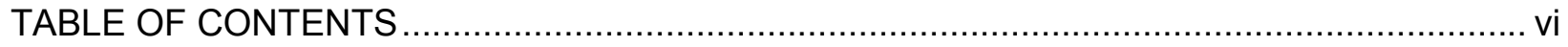

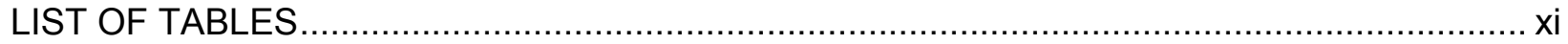

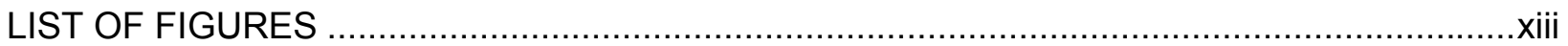

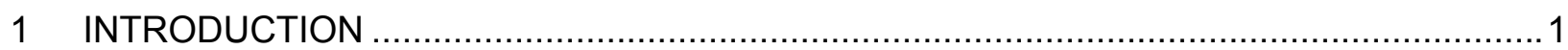

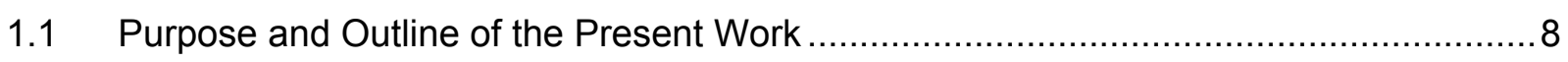

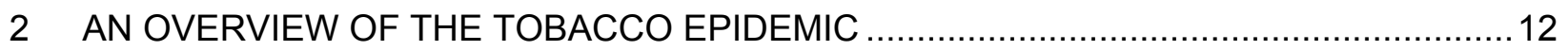

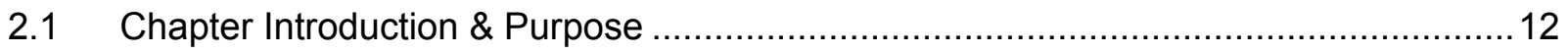

2.2 Models for Characterizing the Tobacco Epidemic in the Industrialized World ..............12

2.2.1 The Phases of Tobacco Control Model ........................................................12

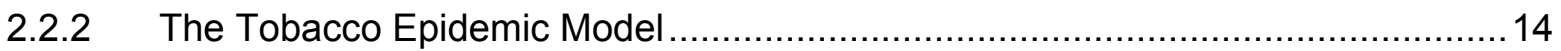

2.3 The Tobacco Epidemic in the United States ........................................................ 16

2.3.1 A Brief History of the Evolution of the Tobacco Epidemic in the United States .....16

2.3.2 Current Estimates of Smoking Related Population Health .................................20

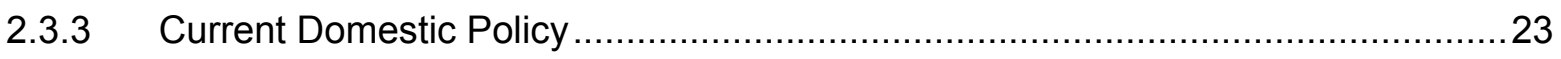

3 LITERATURE REVIEW: THE TOBACCO EPIDEMIC FROM THE PUBLIC HEALTH

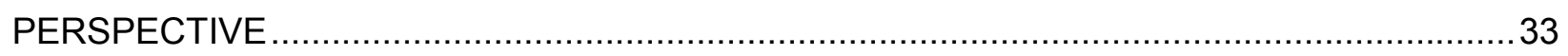

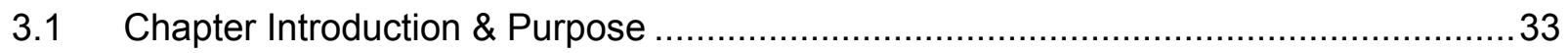

3.2 Tobacco Control Policy Best Practices....................................................................

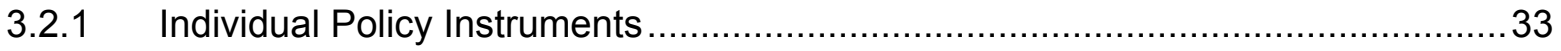

3.2.2 Comprehensive Tobacco Control and Tobacco Control Policy Regimes..............37

3.2.3 Evidence of the Effectiveness of State-Level Tobacco Control Policy Regimes ...45

3.2.4 International Cooperative Efforts to Enact Tobacco Control Policies ....................48

3.3 Universal Challenges to Enacting Tobacco Control Policies ……..............................55

3.3.1 A "Right" to Tobacco Control or a "Right" to Smoke? ............................................56

3.3.2 Debates about the Economic Rationale for Tobacco Control Policies ..................60

3.3.3 Final Comments on "Rights" in Light of Health Disparities and Social Justice ......64

3.3.4 The Universal and Ubiquitous Anti- Anti-Tobacco Arguments ............................65

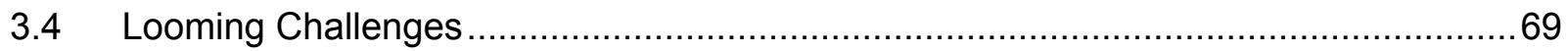

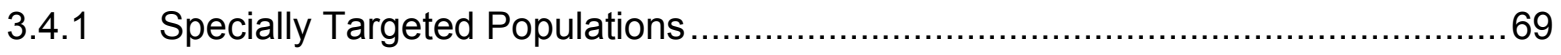


3.4.2 Alternative and Smokeless Tobacco Products and the Harm Reduction Debate .70

3.4.3 The Tobacco Harm Reduction Debate ..................................................... 72

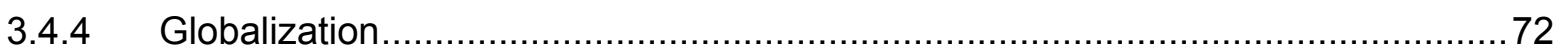

3.4.5 Tobacco-Control Challenges in the United States ....................................... 73

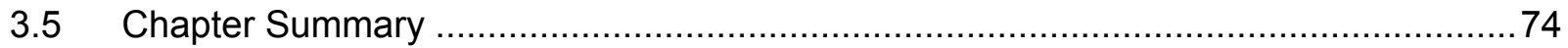

4 LITERATURE REVIEW: THE TOBACCO EPIDEMIC FROM THE POLITICAL AND

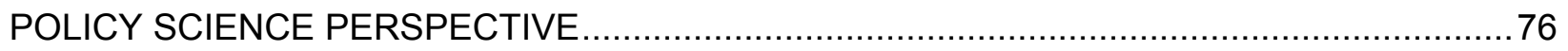

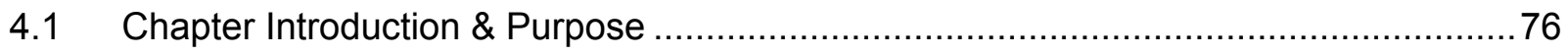

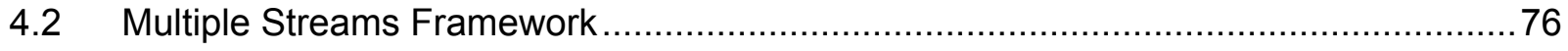

4.2.1 An Overview of the Multiple Streams Framework ........................................ 76

4.2.2 Application of the Multiple Streams Framework to Tobacco Control Policy ..........77

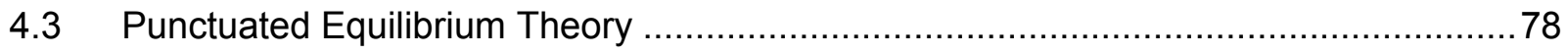

4.3.1 An Overview of Punctuated Equilibrium Theory ...................................... 78

4.3.2 Application of the Punctuated Equilibrium Theory to Tobacco Control Policy.......80

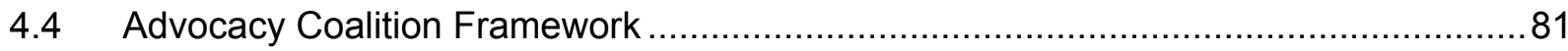

4.4.1 An Overview of the Advocacy Coalition Framework .......................................81

4.4.2 Application of the Advocacy Coalition Framework to Tobacco Control Policy ......81

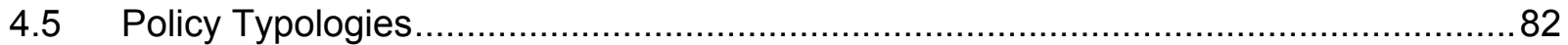

4.5.1 An Overview of Policy Typologies .................................................... 82

4.5.2 De-normalization, Morality Policy, and Tobacco Control Policy .........................83

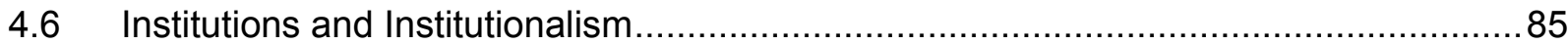

4.6.1 An Overview of the Role of Institutions and Institutionalism in Public Policy........ 85

4.6.2 Institutions, Institutionalism, and Tobacco Control Policy..................................87

4.7 Policy Learning, Diffusion, Transfer, and Convergence ......................................90

4.7.1 An Overview of Policy Learning, Diffusion, Transfer, and Convergence in Public Policy 90

4.7.2 Policy Learning, Diffusion, Transfer, Convergence, and Tobacco Control Policy .92

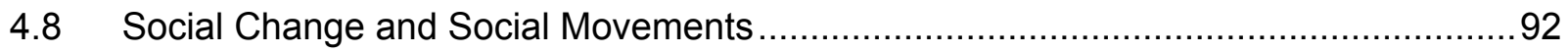

4.8.1 An Overview of Social Change in Public Policy .............................................92 
4.8.2 Tobacco Control Policy Adoption as a Social Movement .................................94

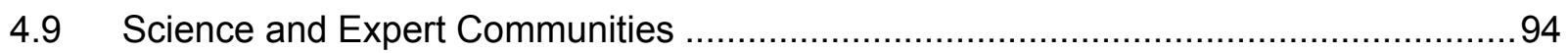

4.9.1 An Overview of Science and Expert Communities in Public Policy.....................94

4.9.2 Science and Expert Communities in Tobacco Control Policy.............................96

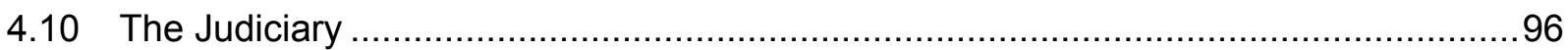

4.10.1 An Overview of the Role of the Judiciary in Public Policy ................................96

4.10.2 The Judiciary and Tobacco Control Policy .................................................... 98

4.11 The Political and Policy Science Perspective on Networks ...................................99

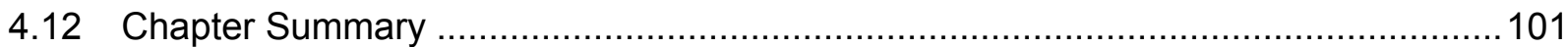

5 AN INTEGRATED POLICY HISTORY OF THE EVOLUTION OF THE TOBACCO EPIDEMIC IN THE UNITED STATES THROUGH THE LENS OF IDEAS, INTERESTS, AND INSTITUTIONS 102

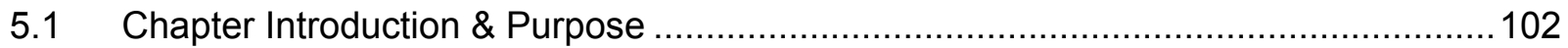

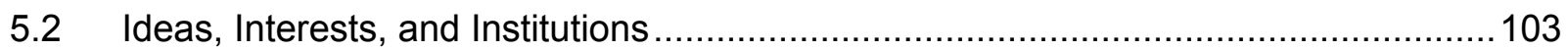

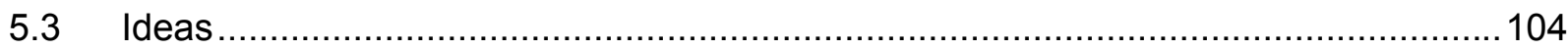

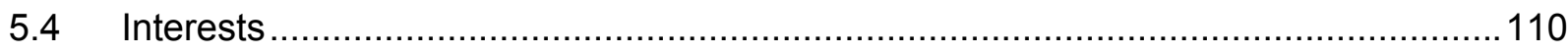

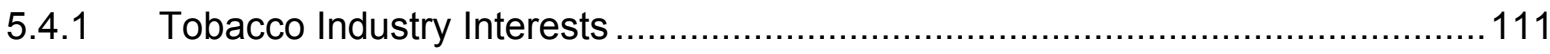

5.4.2 Public Health and State Advocacy Interests ......................................... 115

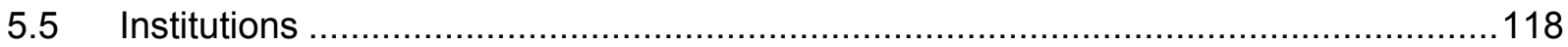

5.6 Ideas, Interests, and Institutions and Policy Change....................................... 121

5.6.1 Focusing Events \& Policy Entrepreneurs ........................................... 121

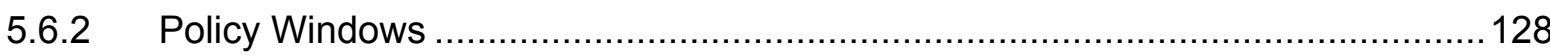

5.7 Chapter Summary \& Contribution................................................................ 133

6 ASSOCIATIONS BETWEEN TOBACCO CONTROL POLICIES, PROGRAMS, AND POPULATION TOBACCO-RELATED HEALTH IN THE U.S. STATES .............................. 134

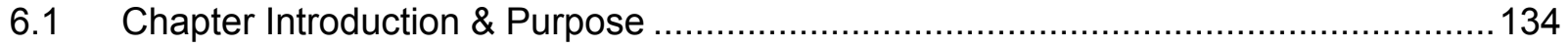

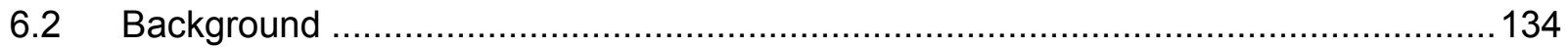

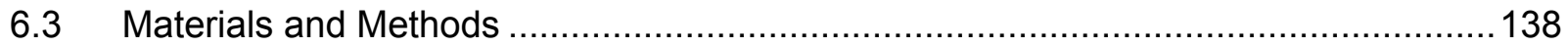

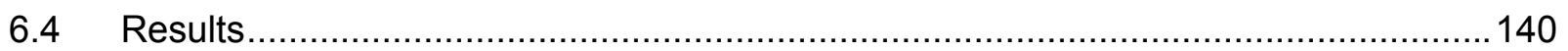

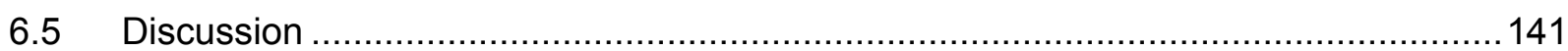

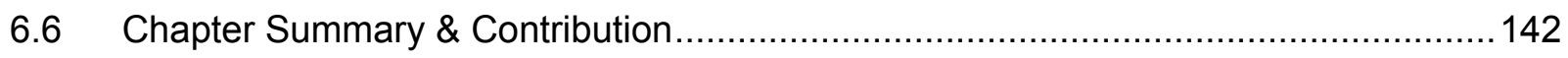


7 TOBACCO CONTROL POLICY AND RELATED POPULATION HEALTH OUTCOMES IN THE EUROPEAN UNION: ASSESSING THE IMPACT OF E.U. ACCESSION ON

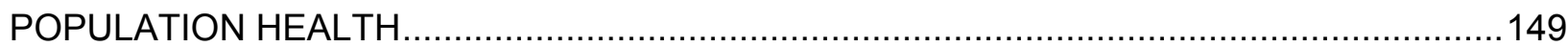

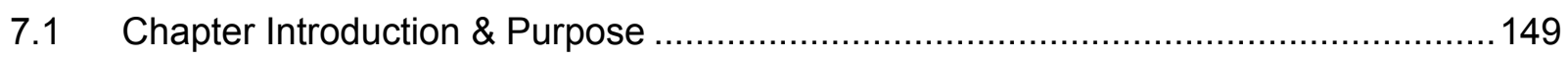

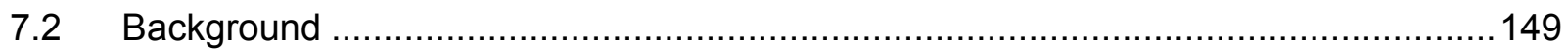

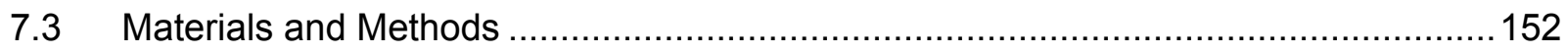

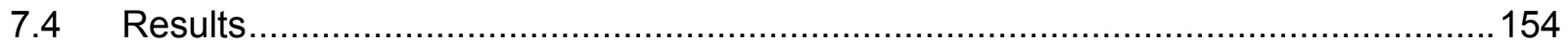

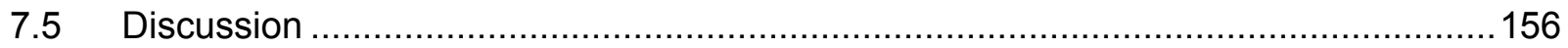

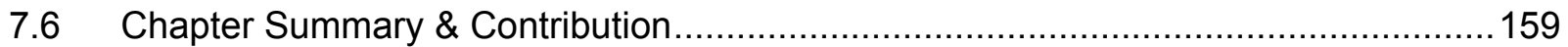

8 CONCLUSION (AND A CONCEPTUAL MODEL FOR UNDERSTANDING TOBACCO CONTROL POLICY AND TOBACCO-RELATED POPULATION HEALTH)..........................166

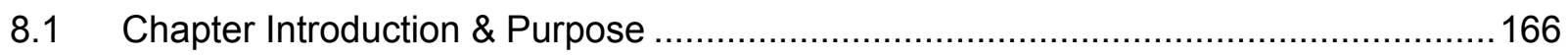

8.2 An Conceptual Model for Integrating the Social and Political Forces Affecting Policy Adoption and Population Health: A Causal Loop .......................................................167

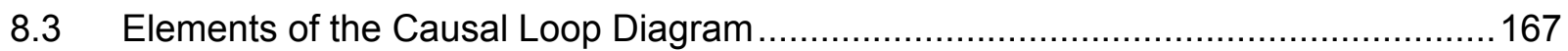

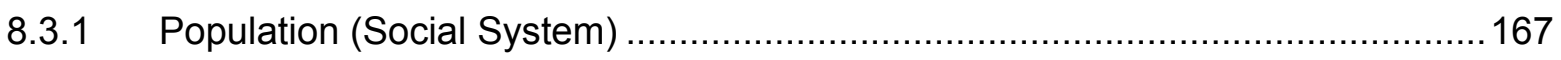

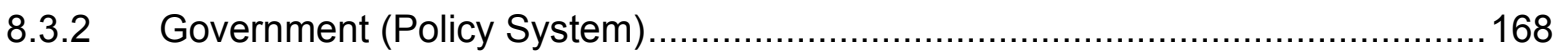

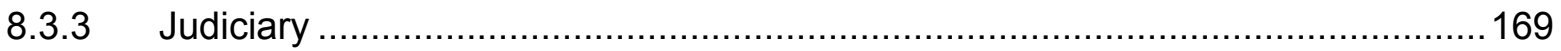

8.3.4 Tobacco Control and Public Health Infrastructure vs. Tobacco Industry

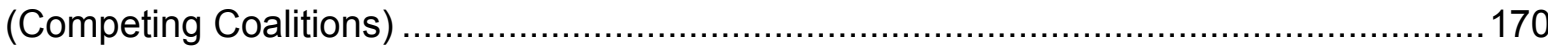

8.3.5 Scientific, Expert, and Epistemic Communities ……......................................170

8.4 Conclusions: Submissions to Political and Policy Science, and Public Health........... 170

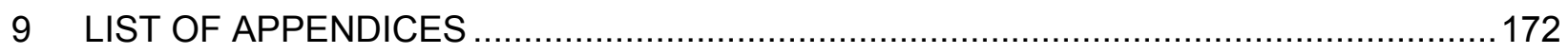

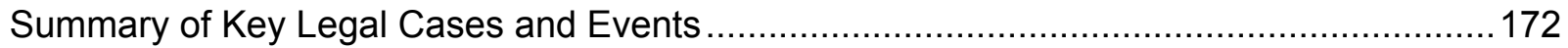

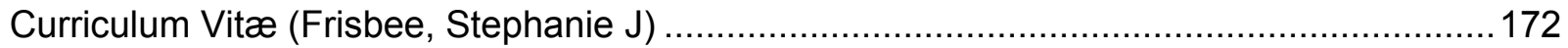

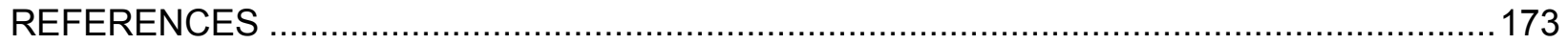

10 APPENDIX 1: SUMMARY OF KEY LEGAL CASES AND EVENTS ...........................206

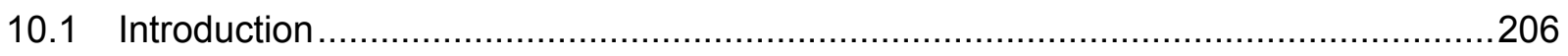

10.2 Suits with Individual Plaintiffs Claiming Personal Harm ........................................207

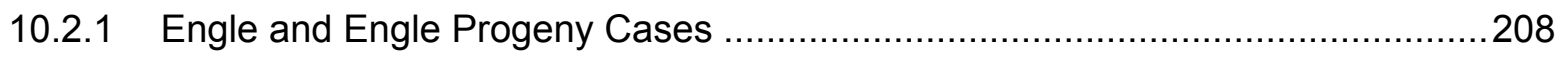

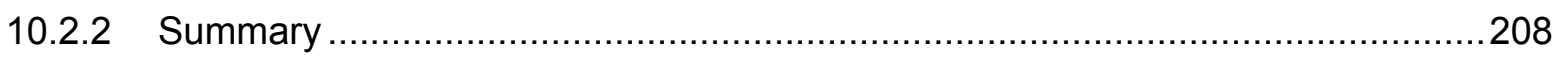

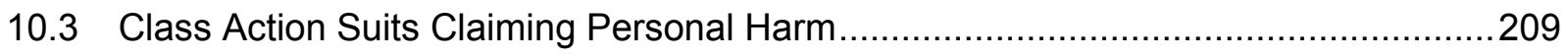


10.4 Suits Claiming Harm from Exposure to Secondhand or Environmental Tobacco Smoke 209

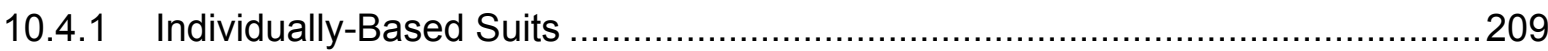

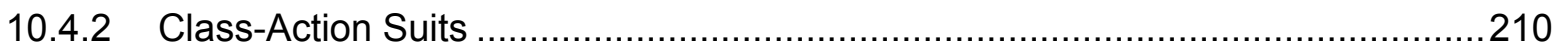

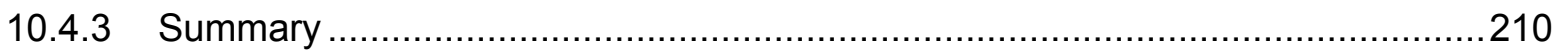

10.5 Suits Seeking Reimbursement for Tobacco-Attributable Expenses ........................210

10.5.1 The States Attorneys' General and the Master Settlement Agreement.............211

10.5.2 Master Settlement-Emulating Suits ................................................. 213

10.5.3 Master-Settlement Agreement Interpretation and Enforcement Suits ...............213

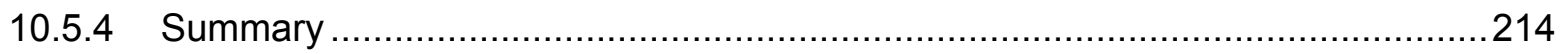

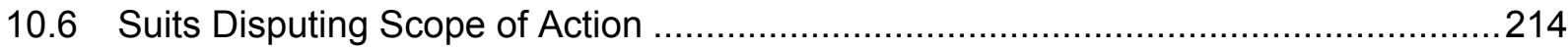

10.6.1 Suits Brought by Tobacco Companies ....................................................215

10.6.2 Suits Brought by the Government Against Tobacco Companies .....................226

11 APPENDIX 2: CURRICULUM VITÆE (FRISBEE, STEPHANIE J) .............................229 


\section{LIST OF TABLES}

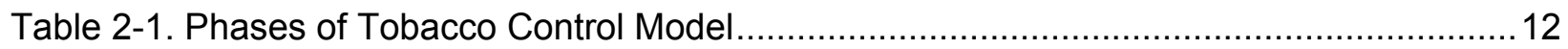

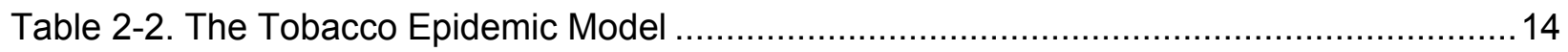

Table 2-3. Federal Tobacco-Related Legislation, Enacted ..................................................... 17

Table 2-5. Federal Regulations Affecting Tobacco Products and Use ................................... 18

Table 2-4. Federally-Enacted Legislation that was a "Missed Opportunity" for or Impeded

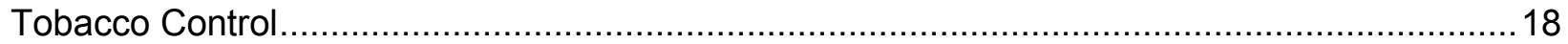

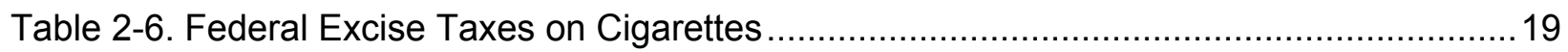

Table 2-7. Federal Agricultural Policies and Programs for Tobacco Farmers ..........................20

Table 2-8. State-Specific Smoking Prevalence and Smoking-Attributable .............................22

Table 2-9. Key Provisions of the Family Smoking Prevention and Tobacco Control Act of 2009 .

Table 2-10. Key Activities in the Inaugural Year of F.D.A. Tobacco Regulation .........................26

Table 2-11. Membership of the Interagency Committee on Smoking and Health........................30

Table 2-12. Summary of State-Level Tobacco Excise Tax and Enacted Tobacco-Control

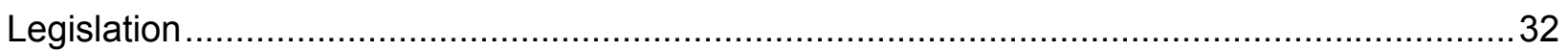

Table 3-1. Quantitative Estimates of the Effectiveness of Individual Tobacco Control Policy

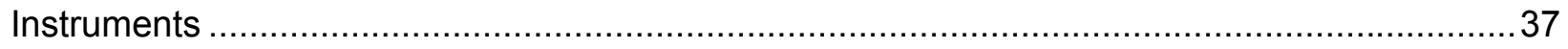

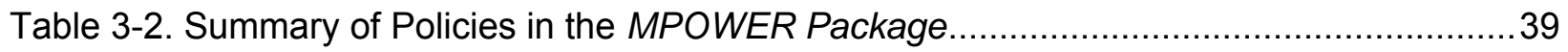

Table 3-3. CDC-Recommended Surveillance and Evaluation Metrics Based on MPOWER

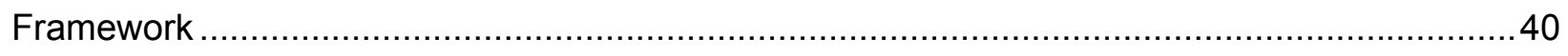

Table 3-4. Tobacco Control Policy Regime Components ........................................................... 41

Table 3-5. Articles of the Framework Convention on Tobacco Control ....................................51

Table 3-6. "Myths" and "Realities" in the Tobacco Control Debate ............................................66

Table 3-7. Economic "Myths" and "Realities" in the Tobacco Control Debate ..........................67

Table 3-8. Libertarian Perspective on the "Myths" and "Realities" in the Tobacco Control Debate

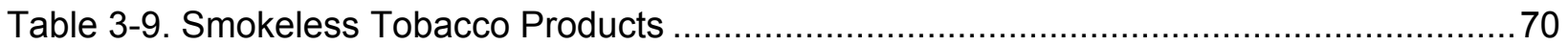

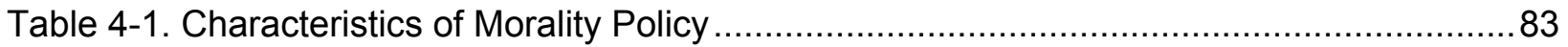

Table 5-1. Smoking and Tobacco-Related Reports of the U.S. Surgeon General, 1964-2007 106

Table 5-2. Overview of the Development of Anti-Tobacco Groups and Coalitions ...................116

Table 5-3. Summary of Seminal Legal Cases Discussed in Appendix 1 ................................120

Table 5-4. List of Failed Tobacco Control Legislation (1989-2010) ..................................... 130 
Table 6-1. Descriptive Characterization of Tobacco Control Policies During Study Timeframes

Table 6-2. Descriptive Characterization of Continuous Variables During Study Timeframes ... 145 Table 6-3. Univariate Association (A.N.O.V.A. Analysis) Between Smoking Prevalence and Tobacco Control Policy Adoption During Different Study Timeframes 146

Table 7-1. Comparisons and Changes in Structural and Institutional Metrics (1990/1994 to 2000/2004) in Existing E.U. Countries and 2004 \& 2007 E.U. Accession Countries ..... 160

Table 7-2. Comparisons and Changes in Price and Policy Metrics (1990/1994 to 2000/2004) in

Existing E.U. Countries and 2004 \& 2007 E.U. Accession Countries 161

Table 7-3. Comparisons and Changes in Population Health Outcome Metrics (1990/1994 to 2000/2004) in Existing E.U. Countries and 2004 \& 2007 E.U. Accession Countries ..... 162

Table 7-4. Results for Regression Analysis 163

Table 10-1. Summary of Key Components of the Master Settlement Agreement 211 


\section{LIST OF FIGURES}

Figure 1-1. Population Smoking Prevalence in OECD Countries, 1960-2009.....

Figure 1-2. Initial Conceptualization of a Comprehensive Framework Illustrating a Causal-Loop

Relationship Between the Social and Political Factors of Tobacco Control..............................9

Figure 2-1. Trend in Prevalence of Current Smokers, Adults and High School Students, 1965-

2007 16

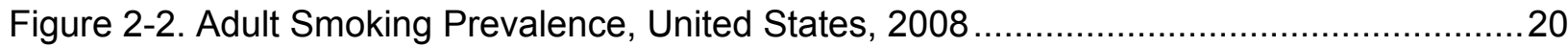

Figure 2-3. Smoking Prevalence in OECD Countries, 2004-2006 .......................................23

Figure 2-4. Schematic Representation of the National Tobacco Control Program ....................29

Figure 4-1. Advocacy Coalition Framework Flow Diagram ............................................... 82

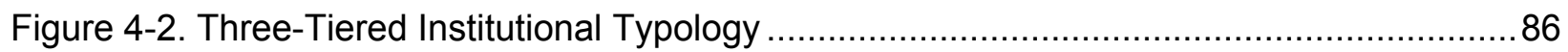

Figure 5-1. Overview of Results Regarding Knowledge and Attitudes about the Harmful Effects

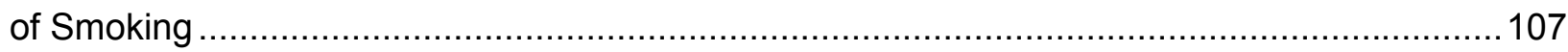

Figure 5-2. Schematic Representation of Current Anti-Tobacco Coalition Networks ...............117

Figure 7-1. Range of the Percent Change in Smoking Prevalence from 1990-94 to 2000-04 in

Individual Existing and Accession E.U. Countries .................................................... 164

Figure 7-2. Comparison of Existing E.U., Accession E.U., and European-Neighborhood

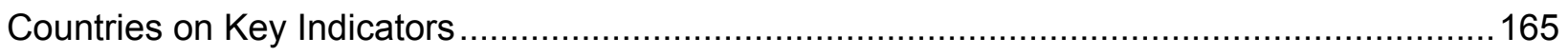

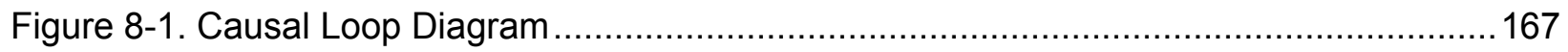




\section{INTRODUCTION}

Tobacco products remain among the most controversial consumer products of all time. As many others have previously highlighted, cigarettes are the only legal product that, when used as intended, are lethal. Alternately stated, there is no safe level of exposure to tobacco, tobacco smoke, or tobacco smoke particles. [U.S. Department of Health and Human Services, Office of the Surgeon General, 2006] Further, the global and individual burden attributable to the primary use of tobacco, or secondary or tertiary exposure to cigarette smoke, whether measured by morbidity, mortality, or economic costs, is substantial. Smoking has been causally linked to multiple cancers, coronary heart disease, stroke, obstructive lung diseases, infertility, and Sudden Infant Death Syndrome (SIDS). [Centers for Disease Control and Prevention, 2009] Exposure to secondhand smoke, also called "passive smoking" or environmental tobacco smoke, is causally linked to heart disease and cancer, and, in children, ear infections, exacerbation of asthma and other respiratory symptoms and infections, and increased risk for SIDS. [Centers for Disease Control and Prevention, 2010] Additionally, recent reports have documented that residual tobacco smoke on surfaces, including clothing, furniture, vehicle surfaces, and skin, reacts with ambient nitrous acid to form carcinogenic substances, resulting in yet another exposure route, a "third-hand" route, to the deleterious effects of tobacco products. [Sleiman, Gundel, Pankow, Jacob, Singer, \& Destaillats, 2010] In the United States, it is estimated that each pack of cigarettes sold represents a $\$ 10.47$ loss in direct (medical care) and indirect (productivity) costs and that there are 5.1 million years of potential life lost annually due to cigarette smoking. [Centers for Disease Control and Prevention, 2009] From 2000-2004, the total economic losses in the United States attributable to cigarette smoking were $\$ 193$ billion (\$96 billion direct medical expenses, and $\$ 97$ billion in indirect lost productivity). [Centers for Disease Control and Prevention, 2009] Further, annual mortality in the United States attributable to smoking is estimated at 443,000, including almost 50,000 deaths annually from secondhand smoke. [Centers for Disease Control and Prevention, 2009] Globally, the World Health Organization estimates that tobacco causes 5 million deaths annually and, by 2030, the annual tobacco-attributable mortality will climb to 8 million annually, resulting in one billion cumulative deaths in the $21^{\text {st }}$ century. [World Health Organization, 2008] More notably, of the 1.1 billion people worldwide who currently smoke, $80 \%$ live in low- and middle-income countries and these same low- and middle-income countries are projected to experience more than $70 \%$ of the predicted one billion $21^{\text {st }}$ century cigarette-related deaths. [Jha, 2009] Thus, tobacco is amongst the leaders in global all-cause mortality, is most assuredly the leading cause of 
preventable death [World Health Organization, 2008], and is increasingly a barrier to overcoming health disparities both within and between countries.

The nature and magnitude of the adverse health, economic, and societal effects of tobacco have emerged through the efforts of almost a century of scientific research. Combined with the efforts of public health and policy advocates, the image and use of tobacco products has undergone profound change. Starting with the Agricultural Adjustment Act of 1933, the U.S. government (Department of Agriculture) provided price supports for tobacco farmers in exchange for agreed-upon acreage and production quotas. Further, in a practice that started in World War I and continued until the 1975, the U.S. military distributed cigarettes as part of rations for military personnel (formal military tobacco control efforts did not begin until 1986). [Smith \& Malone, 2009] Thus, in the 1950s tobacco in general and cigarettes specifically were widely used and accepted products, promoted and endorsed by physicians and the government alike. However, there has been a monumental paradigm shift in the perception, regulation, and use of these products in the last half century such that these products have become marginalized, if not de-normalized. While comparative data prior to 1960 are difficult to obtain, Figure 1-1 demonstrates the substantial decline in smoking prevalence in OECD countries since the middle of the $20^{\text {th }}$ century. Whereas in many countries half or almost half of their population were daily smokers in 1960 , by the start of the $21^{\text {st }}$ century the vast majority of OECD countries

Figure 1-1. Population Smoking Prevalence in OECD Countries, 1960-2009

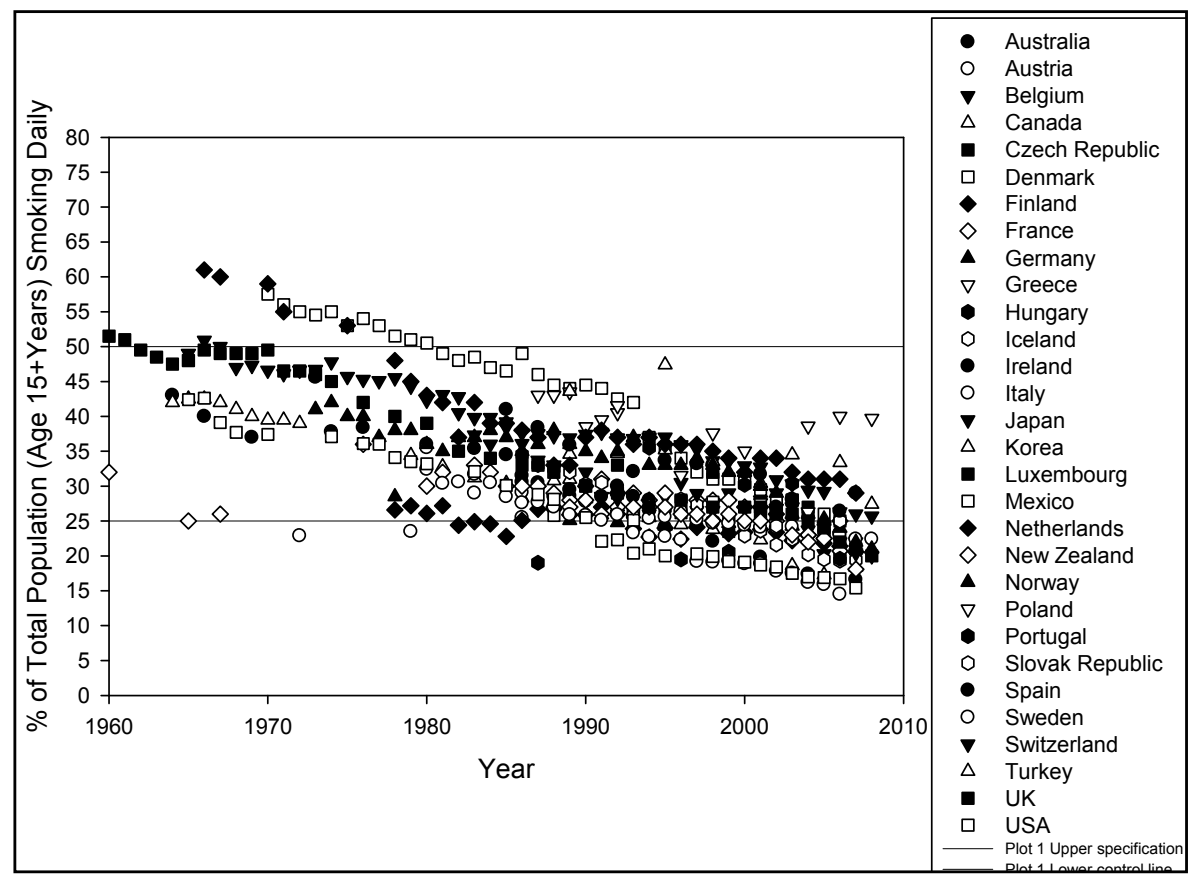

Data Source: OECD Health Statistics, 2009 
had halved that - i.e., $\leq 25 \%$ of the total population were daily smokers - and the prevalence of daily smokers continues to decline. Further, though also with the caveat that comparative or standardized data are not readily available, surveys from the Gallup., Inc. ${ }^{\circledR}$ have reported that in 1999, 92\% of Americans believed that smoking caused lung cancer [Morales, L; Gallup, Inc., 2008], that $56 \%$ of adults in 2008 thought that secondhand smoke was harmful compared to $36 \%$ in 1995 [Morales, L; Gallup, Inc., 2008], and that 54\% of adults in 2005 supported smoking bans in restaurants compared to $17 \%$ in 1987. [Moore, D W; Gallup, Inc., 2005]. Further still, the United States has developed and implemented what is regarded as one of the most restrictive tobacco control policy regimes in the world today. [Studlar, 2010]

This paradigm shift in attitudes, behavior, and policy has been achieved through multidisciplinary efforts sustained over multiple generations. Basic and population (epidemiology) sciences have identified the causal biologic mechanisms for tobacco-related morbidity and mortality as well as the social burden of tobacco use. Public health scientists, including health economists, have developed and quantified the effectiveness of various tobacco prevention and abatement strategies. Psychologists and medical professionals have contributed to the understanding of effective strategies to change individual attitudes and behaviors, including the treatment of nicotine addiction. Sociologists have documented changes in the social dynamics and perceptions of smoking, the tobacco industry, and the responsibility of government to delineate and protect the rights of individuals from the harmful effects of tobacco. And finally, political scientists have studied and reported on how various political structures, forces, and dynamics shape and affect the adoption of tobacco control policies. That is, this sustained, multidisciplinary effort has been, though perhaps unintentionally, Heclo's "CODA" - the combination of both case study and programmatic analysis contributing to analytic realism. [Heclo, 1972]

However, while much has been achieved in the United States and other industrialized countries regarding the attitudinal, behavioral, and policy changes needed to diminish the individual, social, and economic costs of tobacco use, much remains to be yet accomplished if these adverse tobacco use impacts are to be further curtailed. The fact remains that, despite decades of effort and advocacy, tobacco use still places an enormous burden on societies. The most recent estimates from the CDC attest to this: 46.6 million Americans are current smokers and an additional 88 million, including $54 \%$ of children 3-11 years of age, are exposed to secondhand smoke; and there continue to be approximately 443,000 tobacco-attributable deaths and 8.6 million tobacco-related illnesses annually. [Centers for Disease Control and 
Prevention, National Center for Chronic Disease Prevention and Health Promotion, Office on Smoking and Health, 2010] Additionally, estimates have suggested that smoking-attributable expenses averaged $11 \%$ of state Medicaid expenditures, or a total of $\$ 22$ billion nationwide, in 2004 [Armour, Finkelstein, \& Fielbelkorn, 2009], and that between 1995-2015 tobacco-related Medicare expenses will be $\$ 800$ billion. [Department of Health and Human Serivces, Centers for Medicaid and Medicare Services, 2010] Further, there is considerable evidence that tobacco use is becoming highly concentrated in lower socio-economic groups (smoking prevalence is approximately $25 \%$ in those with a high school education or less, or $50 \%$ of all current smokers, compared to $6 \%$ in those with a graduate degree), and that the rate of decline in smoking is slowing (the smoking prevalence in the U.S. was estimated at $20.9 \%$ in 2005 and $20.6 \%$ in 2009; in high school students, between 1999-2003 smoking prevalence declined from $36 \%$ to $22 \%$, but between 2003-2009 declined from $22 \%$ to $20 \%$ ), both of which are disquieting trends. [Centers for Disease Control and Prevention, National Center for Chronic Disease Prevention and Health Promotion, Office on Smoking and Health, 2010] Stated more starkly, it is likely that the next $10 \%$ of smoking prevalence will be more difficult and intransigent to eliminate than the previous $10 \%$ of population smoking prevalence as tobacco use becomes socially and politically entrenched in socioeconomic and geo-demographic clusters that are traditionally more difficult to reach and less responsive to conventional health promotion and health education messages and public health policy arguments. Counter-acting the decline in the gains from public health advocacy and policy change efforts will require an increase in the efficiency of these efforts not necessarily of the endorsed programmatic or policy solutions themselves, but of the efforts to enact these evidence-based programs and policies. Thus, increasing the efficiency of these programmatic and policy enactment efforts will implicitly require a much clearer and more precise understanding of the factors that will facilitate (or impede) a given jurisdiction in the adoption of strategies to reduce smoking prevalence and consumption, including the implementation of comprehensive tobacco control policies.

Neither the changing nature of the challenge [Centers for Disease Control and Prevention, National Center for Chronic Disease Prevention and Health Promotion, Office on Smoking and Health, 2010], [Tynan, et al., 2010], [Mendez, 2010] nor the need to adjust the approach to policy change have gone unnoticed by the public health community. In particular, two approaches are being advanced within the public health community: the need to take a more systems-based approach to tobacco control; and the need to develop a more 
sophisticated understanding of (and approach to) the political side of tobacco control policy enactment.

"Systems" approaches are not new. In political science, for example, David Easton, whose scholarship began in the 1950s, is generally regarded as a pioneer in the development of a comprehensive ("systems") approach to the study of political systems. (E.g., [Easton, 1957]) The application of such systematic approaches is, however, relatively recent in the biomedical sciences, including public health, disciplines which, by their nature and tradition, tend towards focus on hypothesis-driven, reductionist research questions designed to identify specific mechanisms (or risks). In public health, with its close relationship to and shared origin with epidemiology, such an approach has often (though not always) translated into research and policy solutions targeted at changing individual behavior. However, in a post-epidemiologic transition era where societal burdens of disease increasingly come from chronic, not acute, illnesses, individually-based methods, particularly when absent consideration of the environments in which such individual behaviors are occurring, have much less impact on improving the public's health. [McKinlay \& Marceau, 2000] As a recent editorial in the American Journal of Public Health observed,

"Systems modeling has been gaining increasing acceptance among the public health community, which is recognizing its value in addressing the complex nature of problems that affect the health of the population."

From: [Mendez, 2010]

In tobacco control, a concerted - and federally (NIH) initiated -- effort to develop a focused research effort on systems approaches to tobacco control was prompted by the "Initiative on the Study and Implementation of Systems", and particularly the National Cancer Institute publication Greater than the Sum: Systems Thinking in Tobacco Control in 2007. [Best, et al., 2006], [National Cancer Institute, 2007] The stated purpose of these efforts have been to identify feedback loops between components within the system [Mabry, Marcus, Clark, Leischow, \& Mendez, 2010], and

"Is it possible to understand the interplay of factors that both sustain and potentially disrupt tobacco use?" and "What structures and functions are essential for both understanding that complexity and improving our efforts in tobacco control?"

From: [Marcus, Leischow, Mabry, \& Clark, 2010] 
In further support of the effort to encourage a systems-based approach to tobacco control policy research, the full issue of the July 2010 American Journal of Public Health was dedicated to studies using a systems framework to investigate various aspects of tobacco control including adolescent smoking, cessation, diffusion of policies and adoption of the Framework Convention on Tobacco Control, and social networks among others. Episodes such as these federally-sponsored initiatives and editorial foci highlight the growing recognition of the importance of and need for systematic approaches to understanding the elements and factors, and how they relate and interact, that affect both tobacco use and tobacco control policy.

The second of the approaches being advanced as necessary to improve the efficiency of tobacco control efforts is the development of a more sophisticated command of the political side of tobacco control policy enactment. The public health community has been criticized by members of its own as well as the policy science establishment for what is interpreted as a deficient understanding, acknowledgment, or willingness to work within (or a combination of all three) the political system that ultimately enacts policy. From within the public health community, the failure of the McCain Bill in 1998 has been forwarded as an exemplary illustration of these deficiencies in the public health community. [McKinlay \& Marceau, 2000], [McKinlay \& Marceau, 2000] It is not unreasonable to postulate that some of this perceived inability to master the political aspects of tobacco control stems from elementary principles of the discipline of public health, particularly the emphasis of and reliance on science and scientific evidence for the development of evidence-based policies. In contrast, the political system and the policy process has been described as,

“...the culture of politics where policy development is not linear but highly contingent, often unpredictable, and dependent upon convincing people to recognize the existence of a problem and the best way to resolve it. Outcomes result from building majorities, not from scientific expertise."

From: [Rudder \& Fritschler, 2009]

As alternately stated by others, public health is ultimately a political issue:

"Science can identify solutions to pressing health problems, but only politics can turn most of those solutions into reality."

From: [Oliver, 2006]

That the "best" ("evidence-based") policy solutions become compromised during the policy and political - process is often viewed with disbelief in the public health community, and antithetical to the rationally-based scientific process at the core of much of public health. As has 
been previously described, the response from the public health community to the long delays in enacting evidence-based policy, or outright policy failures (e.g., the McCain Bill defeat by Motion of Cloture in 1998) has not been to engage in the compromising, bargaining, or power-sharing aspect of the political process, but rather to re-frame the issue into starkly "good" vs. "evil" terms and as a "war" against the tobacco industry with smokers (and those exposed to secondhand smoke) its victims. [Larsen, 2008] An archetypal example of this stance is articulated in the recent Government of Ontario's 2011-2016 tobacco control strategy which, in addition to having as its vision "a tobacco-free Ontario by 2030 ", states,

"Treating the tobacco as a "normal" legitimate industry undermines the efforts by the government and health organizations to safeguard the health of Ontarians from tobacco products.... The tobacco industry should not be considered either normal or legitimate. The government of Ontario's new strategy needs to incorporate a plan of action for de-normalization and delegitimizing the industry."

From: [Ontario Tobacco Strategy Advisory Group, 2010]

And,

"The tobacco industry tries to frame the problem of tobacco use as "a consumer choice." This could not be further from the truth. The addiction to tobacco takes away any choice the consumer has to not use tobacco products."

From: [Ontario Tobacco Strategy Advisory Group, 2010]

This strategy has been characterized by some as being anti-political - beyond the scope of normal politics because one of the participants is corrupt, illegitimate, or beyond moral reach implying that the public health community, by its choice of framing of tobacco use and the tobacco industry, is necessarily disqualifying the democratic process itself and the possibility that,

“...they can ignore how citizens might want to set the limits of public health intervention."

From: [Larsen, 2008]

That is, despite calls from within the public health community itself to develop competencies and strategies so as to engage the democratic, political process [McKinlay \& Marceau, 2000], [Milio, 1985], [Oliver, 2006], the public health community continues with a strategy that likely so precludes such engagement. 
Thus, in synthesizing these two lines of reasoning, a framework that combines the social process of tobacco use as well as the political and policy processes of tobacco control and policy implementation is sought. A comprehensive - "systematic" - framework must necessarily combine the public health perspective, with its focus on in science-based arguments and development of evidence-base policies and emphasis on the outcome of reductions in smoking prevalence, and the political science perspective, with its focus on understanding the elements of the policy process and using policy process theories to explain the policy adoption and emphasis on the outcome of policy adoption. Interestingly, despite the longstanding tobacco control efforts, it has been observed that,

"...it is remarkable how underdeveloped the interaction between the two regimes really is."

From: [Larsen, 2008]

That is, this is an area ripe for both conceptual and quantitative development which the present work, in parts, attempts to address.

\subsection{Purpose and Outline of the Present Work}

The unifying theme of the present work is an integration of the public health and political science perspectives on tobacco control so as to establish a more comprehensive framework of the underlying factors and elements interrelating tobacco use (outcome of prevalence) and tobacco control policy (outcome of policy adoption). A substantial challenge in developing such a comprehensive framework, however, it is the complexity of the relationship between the two primary outcomes of interest - tobacco use (prevalence) and policy adoption. There is both conceptual [Marmor \& Lieberman, 2004] and quantitative [Chaloupka \& Saffer, 1992] evidence that the causal relationship between these two outcomes is neither unidirectional nor linear.

"Factors other than government policy - especially shifts in social norms have influenced that decline, but those norms have themselves been directly and indirectly influenced by government policies. In short, tobacco consumption has become, in part, a political outcome.... These respective tobacco-control regimes emerge as largely consistent with broader public attitudes about the importance of health and "well-being," but we have less confidence about whether such attitudes influence the development of control legislation, or if the direction of causation is reversed."

From: [Marmor \& Lieberman, 2004]

That is, the relationships, including interdependencies and feedback mechanisms, are much more accurately characterized by a causal loop. 
Figure 1-2. Initial Conceptualization of a Comprehensive Framework Illustrating a Causal-Loop Relationship Between the Social and Political Factors of Tobacco Control

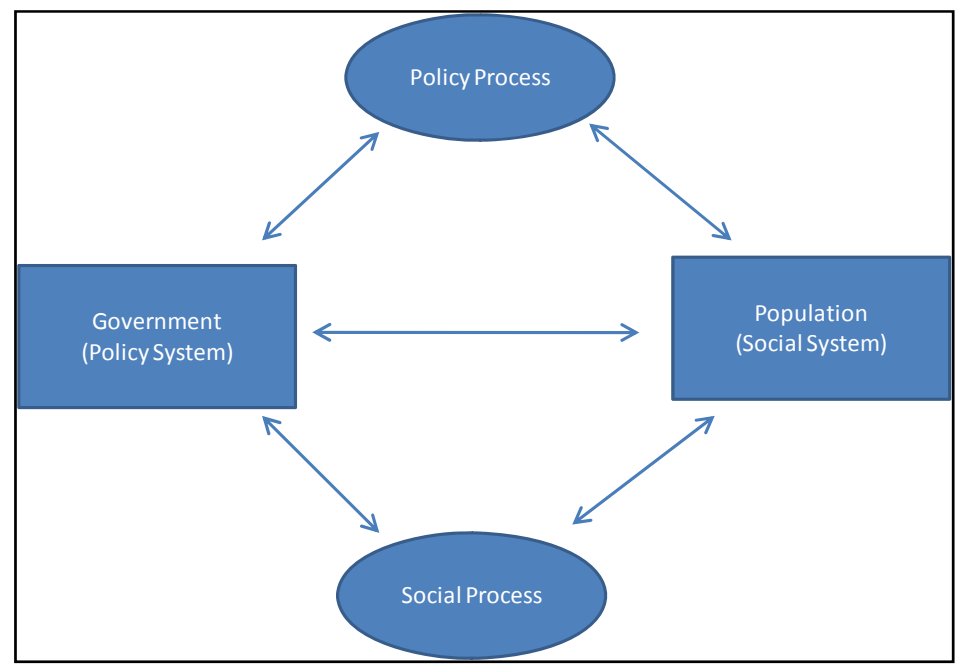

As a starting point, then, a comprehensive framework can initially be conceptualized as shown in Figure 1-2. What remains is identifying the elements within this causal loop and establishing a better understanding of the nature of these causal loop associations between the social and political forces influencing tobacco control. Thus, the conceptualization represented in Figure 1-2 will be re-visited at the end of the present work after an examination of the tobacco epidemic from both the public health and political science perspectives, and primary investigations into the nature of the associations between elements of this causal loop diagram.

Broadly, then, the research questions posed by the present work are:

R1: What are the fundamental elements that are part of this causal loop diagram?

R2: What is the nature of the relationship between tobacco control policies and tobacco control policy regimes and tobacco-related population health?

R3: What are the research questions that arise from this causal loop model?

While central-level tobacco use and tobacco control policy in the United States is the primary focus of the current work, it would be detrimental to exclude valuable information from statelevel and / or international (mostly industrialized countries) activities and studies, and thus these will be included as appropriate to increase both the rigor and generalizability of the current work. To address these research questions, the present study will follow the course of study outlined below. 
- The tobacco epidemic in the industrialized world will be described in overview. Specifically, two models that describe the tobacco epidemic model will be detailed. The current state of the tobacco epidemic and tobacco control policies in the United States will also be described, including both the current smoking prevalence as well as the current, relevant tobacco control policies.

- The tobacco control literature will be reviewed from the public health perspective. This review will include: defining tobacco control policies and tobacco control policy regimes; the current understanding of "best practices", or "evidence-based, in tobacco control policies; a description of ongoing coordinated, international efforts to combat the global tobacco epidemic and enact these "best practices" tobacco control policies; and the universal and emerging challenges facing tobacco control activities will be identified and briefly discussed.

- The tobacco control literature will be reviewed from the policy science perspective. This review will include: how theories of the policy process, especially the agendasetting theories (Multiple Streams Framework, Punctuated Equilibrium Theory, and the Advocacy Coalition Framework), have been applied to explain tobacco control policy adoption and evolution; tobacco control policy adoption as explained by theories of policy learning, diffusion, transfer, conversion, and networks; the impact of social change, including elements of issue framing, on tobacco control policy adoption; the importance of policy type (typology) on tobacco control policy; the influence of institutions and institutionalism on tobacco control policy adoption; the role of scientific communities and experts in the development and adoption of tobacco control policy; and, finally, how the courts and legal proceedings have influenced on tobacco control policy.

- An investigative policy history analysis will be conducted on the evolution of tobacco control policy in the United States. This policy analysis will use Heclo's ideasinterests-institutions framework. [Heclo H. , 1994]

- Two quantitative investigations will be presented, one based on the U.S. states and the second in the European Union, interrogating factors influencing tobacco control policy adoption.

- Finally, the conceptual framework presented in Figure 1-2 will be re-visited. The findings from the previous chapters, both the reviews of literature and the empirical chapters, will be integrated and the elements of the framework expanded and the 
framework itself refined. Subsequent research questions arising from this framework will be discussed.

Acquiring a better understanding the elements of and relationship between the elements in this causal loop is important, from the political and policy science perspective, because of how this knowledge will broaden a generalizable understanding of the policy process in other policy areas. From the public health perspective, acquiring a better understanding the elements of and relationship between the elements in this causal loop is important if efforts to combat the tobacco epidemic in the industrialized world are to become more efficient. Of additional importance though not the direct purpose of the present work, if the lessons learned about combating the tobacco epidemic in the industrialized world are to be efficiently and effectively transferred to the developing world thereby averting much of the tobacco epidemic, which is the implicit focus of public health efforts such as the Framework Convention on Tobacco Control among others, a more precisely calibrated understanding of the factors causally affecting tobacco control policy adoption is needed. 


\section{AN OVERVIEW OF THE TOBACCO EPIDEMIC}

\subsection{Chapter Introduction \& Purpose}

The purpose of this chapter is to simply provide an overview of the tobacco epidemic in the industrialized world. Two models that describe the tobacco epidemic model will be detailed. Additionally, the current state of the tobacco epidemic and tobacco control policies in the United States will be described, including both the current smoking prevalence as well as the current, relevant tobacco control policies.

\subsection{Models for Characterizing the Tobacco Epidemic in the Industrialized World}

The tobacco epidemic in the industrialized world has evolved over the last $60+$ years, during which time tobacco evolved from a widely used and little regulated product to one that is now used by less than a quarter of the American population and is highly regulated. It is not surprising, then, that models developed to characterize the tobacco epidemic have developed stages based on chronologic demarcations in public health parameters and policy approaches. Two models based on the historic evolution of the tobacco epidemic in the United States and other industrialized countries, the Phases of Tobacco Control model and the Tobacco Epidemic Model, are described below.

\subsubsection{The Phases of Tobacco Control Model}

The Phases of Tobacco Control is a six-stage model that demarcates the tobacco epidemic based on the type of tobacco control policy regime. [Studlar, 2002], [Studlar, 2008] The six phases are outlined in Table 1-2.

In Phase I, cigarettes in particular evolved rapidly from a niche product to a much more widely used consumer product due to the development of the automatic cigarette making machine and its subsequent widespread use by James B. Duke, the portable safety match, reliable packaging, and extensive advertising. The U.S. federal government did not pursue any restrictive policies, rather deferring action, if any, to the states. Tobacco products were the

Table 2-1. Phases of Tobacco Control Model

\begin{tabular}{|ccc|}
\hline Phase & Timeframe & Title/Description \\
\hline Phase I & $1884-1914$ & Consolodation of the Cigarette Industry and Early Controversies \\
Phase II & $1914-1950$ & Era of Good Feeling; Cigarettes Promoted by Governments \\
Phase III & $1950-1964$ & The Gathering Storm of Health Concerns \\
Phase IV & $1964-1984$ & Regulatory Hesitancy \\
Phase V & $1984-2008$ & Tobacco as Social Menace \\
Phase VI & The Future & Neoprohibitionism versus harm reduction? \\
\hline
\end{tabular}

Source: [Studlar, 2008] 
target of some temperance movements and some states enacted product bans, though most states did not implement any restrictive policies.

The second phase, encompassing both World Wars, marked a substantial expansion in the use of cigarettes. Cigarettes were regarded as the lesser of three moral sins available to troops (the other two being alcohol and prostitution) and so their use was promoted by the government. Thus, cigarettes acquired a de facto image of being patriotic and socially acceptable.

In the third phase, credible scientific evidence began to emerge that raised concern about deleterious health effects, particularly lung cancer. Some popular media outlets began to cover these stories and additional research was supported by private organizations such as the American Cancer Society. Despite the mounting evidence however, government policy remained lax, with few restrictions and some, but not substantial, taxation.

In the fourth phase, a series of government-sponsored reports were published from multiple countries, including the United Kingdom and Canada, and culminated in the 1964 U.S. Surgeon General's Report. [U.S. Department of Health, Education, and Welfare, 1964] These reports served to review the scientific evidence linking tobacco to adverse health outcomes and then to affirm and endorse that tobacco caused various diseases and even mortality. Thus, while the tobacco industry could discredit and so deflect the conclusions of individual studies, this task became much more difficult when it was the position of multiple governments that the cumulative evidence supported that tobacco caused cancer, among other diseases (though this did not deter them from so trying). Despite these now-endorsed scientifically-based positions, government policy to reduce tobacco consumption and smoking prevalence remained largely impotent. While some package labeling requirements were enacted, lax federal taxation policies (which were not increased between 1951 and 1982) resulted in cigarettes becoming more affordable over time. It was not until the early 1980 s and the publication of several exposé-type books and articles in the popular media that the course in both public opinion and policy finally began to change.

In the fifth phase, scientific evidence regarding the health hazards of secondhand smoke as well as the addictiveness of nicotine changed the tone of the public and policy discourse. More, increasingly restrictive tobacco control policies were enacted and social attitudes toward both smoking and the tobacco industry became increasingly negative. This phase also saw multiple, additional Surgeon General's reports, increased legal activity directed against tobacco 
companies, including that by the state Attorneys General, and the Master Settlement Agreement.

The sixth and final phase, with yet to be determined activities and results, foreshadows the looming challenge for tobacco control activists pursuant to alternate and so called "reduced risk" tobacco products, products that tobacco companies are increasingly developing as smoking prevalence (and industry revenues) in industrialized countries continue to decline.

\subsubsection{The Tobacco Epidemic Model}

The Tobacco Epidemic Model was proposed based on the study of the historic patterns in five key metrics of the tobacco epidemic (smoking prevalence, cigarette consumption, lung cancer rates, smoking attributable death, and tobacco control activities) in industrialized countries such as the United States, Canada, and the United Kingdom. [Lopez, Collishaw, \& Piha, 1994] The characteristics of each stage of the Tobacco Epidemic model, based on these five metrics, are described in Table 2-2.

In Stage I, male and female smoking prevalence starts at very low levels but begins to rise rapidly though few, if any, tobacco related deaths are evident. In Stage II, male smoking

Table 2-2. The Tobacco Epidemic Model

\begin{tabular}{|c|c|c|c|c|}
\hline & Stage I & Stage II & Stage III & Stage IV \\
\hline $\begin{array}{c}\text { General } \\
\text { Characterization }\end{array}$ & The beginning & Expansion to widespread use & $\begin{array}{l}\text { Beginning of both abatement and the } \\
\text { "real" health consequences }\end{array}$ & Decline and denormalization \\
\hline Prevalence (Male) & $\begin{array}{l}\text { Low }(<15 \%) \text { in early stage but rising } \\
\text { rapidly in atter stage }\end{array}$ & May reach $50 \%-80 \%$ & $\begin{array}{l}\text { Peaks in early stage (often at } \approx 60 \% \text { ) } \\
\text { then declines in latter stage to } \approx 40 \%\end{array}$ & Continues to decline, though slow ly \\
\hline Prevalence (Female) & $\begin{array}{l}\text { Very low due to traditional socio- } \\
\text { cultural factors }(<5 \%-10 \%)\end{array}$ & $\begin{array}{l}\text { Lags male prevalence, but rises } \\
\text { rapidly }\end{array}$ & $\begin{array}{l}\text { Peaks in mid-stage (often at } \approx 35 \% \text { - } \\
45 \% \text { ) and then decreases to a period } \\
\text { of long plateau; distribution of female } \\
\text { smoking typically highly skew ed,w ith } \\
\text { much higher prevalence in younger } \\
\text { w omen (often } \approx 40 \%-50 \% \text { ) but much } \\
\text { low er in older w omen (often }<10 \% \text { ) }\end{array}$ & Continues to decline, though slow ly \\
\hline Consumption & Low ( $<500$ cigs/person/year) & $1000-3000$ cigs/person/year & $\begin{array}{l}3000-4000 \text { cigs/person/year in males } \\
\text { and } 1000-2000 \text { cigs/person/year in } \\
\text { females }\end{array}$ & Not specified \\
\hline $\begin{array}{l}\text { Lung Cancer Rate } \\
\text { (Male) }\end{array}$ & Rare & $\begin{array}{l}\text { Rapid rise from } 5 / 100,000 \text { to } \\
50 / 100,000\end{array}$ & $\begin{array}{l}\text { Peak in latter stage at } \approx 110- \\
120 / 100,000\end{array}$ & $\begin{array}{l}\text { Rates decline, possibly as much as } \\
20 \% \text { from their peak }\end{array}$ \\
\hline $\begin{array}{l}\text { Lung Cancer Rate } \\
\text { (Female) }\end{array}$ & Rare & $\approx 8-10 / 100,000$ & $25-30 / 100,000$ & Not specified \\
\hline $\begin{array}{l}\text { Smoking Mortality } \\
\text { (Male) }\end{array}$ & $\begin{array}{l}\text { Not yet evident in early stage, but a } \\
\text { few cases emerging tow ard the latter } \\
\text { stage }\end{array}$ & $\begin{array}{l}\text { By latter stage, } \approx 10 \% \text { of all-cause } \\
\text { mortality is attributable to smoking }\end{array}$ & $\begin{array}{l}\text { Rapid rise to latter stage when } 25 \% \text { - } \\
30 \% \text { of all-cause mortality is } \\
\text { attributable to smoking }\end{array}$ & $\begin{array}{l}\text { Peaks early in stage often at } \approx 30 \% \text { - } \\
35 \% \text { of all-cause mortality, then } \\
\text { progressively declines }\end{array}$ \\
\hline $\begin{array}{l}\text { Smoking Mortality } \\
\text { (Female) }\end{array}$ & Not yet evident & Still very low & $\begin{array}{l}\text { Low but rising to latter stage } w \text { hen } \\
\approx 5 \% \text { of all-cause mortality is } \\
\text { attributable to smoking }\end{array}$ & $\begin{array}{l}\text { Rises rapidly during this stage, though } \\
\text { its eventual peak depends upon the } \\
\text { peak in female smoking prevalence; } 2 \text { - } \\
3 \text { decades into stage the eventual } \\
\text { peak could reach } \approx 20 \%-25 \% \text { of all- } \\
\text { cause mortality then begin to decline }\end{array}$ \\
\hline Policy & $\begin{array}{l}\text { No control policies; agricultural } \\
\text { support policies likely }\end{array}$ & $\begin{array}{l}\text { Control activities sporadic and not well } \\
\text { developed; lack of public and political } \\
\text { support in part due to yet poorly } \\
\text { understood risks }\end{array}$ & $\begin{array}{l}\text { Conditions for control policies become } \\
\text { more favorable; smoke free public } \\
\text { places and transportation are among } \\
\text { the first enacted but smoke-free } \\
\text { w orkplaces not yet common; media } \\
\text { important in enacting policies; smoking } \\
\text { is becoming socially not as acceptable }\end{array}$ & $\begin{array}{l}\text { Increased "demand" for legislation that } \\
\text { provides for smoke-free personal } \\
\text { environments; policies needed to } \\
\text { support nicotine-addicted smokers } \\
\text { who w ant to quit; social differences in } \\
\text { smoking prevalence persist; continued } \\
\text { changes in social climate need to be } \\
\text { supported }\end{array}$ \\
\hline Duration & $\approx 20$ years & $\approx 20-30$ years & $\approx 20-30$ years & $20+$ years \\
\hline
\end{tabular}

Source: [Lopez, Collishaw, \& Piha, 1994] 
prevalence rises rapidly and reaches levels far higher than that for females, reaching as high as $50 \%-80 \%$ of the male population. By the end of this stage, tobacco-attributable illness and deaths rise rapidly, accounting for $10 \%$ of all male deaths. Tobacco control activities in this stage are poorly developed, if present at all, and cessation and cessation support activities are uncommon. In Stage III, the prevalence of male smoking peaks and then begins to decline. The prevalence of female smoking plateaus later in this stage and then also begins to decline, though smoking prevalence among younger women can reach levels close to that of males. Knowledge of smoking health hazards becomes more widespread, yet because of the latency between exposure and tobacco-related illness and death, during this stage the incidence and prevalence of tobacco-attributable disease continues to rise rapidly and peaks at $25 \%-30 \%$ of male mortality, with tobacco-proportionate mortality even higher in the middle-age groups. However, as knowledge of smoking hazards spreads, the receptivity for tobacco control increases and such activities become more organized and successful, and tobacco control policies become more comprehensive. In Stage IV, the final stage of this epidemic model, smoking prevalence for both genders continues to decline at slow but similar rates, but smoking-attributable death rates remain high $-30 \%-35 \%$ of all female deaths and $40 \%-45 \%$ of male deaths in middle age. While smoking-attributable male death rates begin to decline at the latter phases of this stage, smoking-attributable female death rates continue to rise, reflective of female smoking prevalence peaking after that for males. An important focus of tobacco control activities becomes ensuring smoke-free environments, including smoke-free workplaces. Likewise, smoking cessation efforts expand, though socio-economic differences in smoking prevalence and smoking-attributable death continue.

Both the Phases of Tobacco Control and the Tobacco Epidemic Model are natural history models based on the unfolding of the tobacco epidemic in the United States and Canada (the former model, which, since its original introduction, has been updated to include most industrialized democracies - see [Studlar, 2005], [Studlar, 2009]) and, more broadly, industrialized countries that included the United States (the latter model). While the models have a slightly different emphasis as the basis for differentiating between the different phases of the epidemic, both models span the 100+ years over which the tobacco epidemic has unfolded in industrialized countries. Additionally, both models have in common that tobacco control activities do not begin in earnest for at least 75 years after the beginning of the epidemic, a time after which male smoking prevalence in particular has already peaked, often at more than half of the male population, and thus when the consequences of decades of expanding and unchecked smoking and subsequent lung cancer and other morbidities and smoking-attributable 
mortality are first being felt. That is, in both models, tobacco control policies are enacted too late to avoid the substantial individual and societal costs attributable to tobacco use. Avoiding these costs, then, is contingent upon earlier enactment of tobacco control policies to shorten the duration of model stages or avoid them altogether. Thus, the success of policy diffusion efforts from the industrialized countries to developing countries, many of which are still early in the first stages of the tobacco epidemic will be paramount if the enormous societal costs of tobacco use in the developing countries, arguably those countries least able to absorb such avoidable costs, are to be evaded.

\subsection{The Tobacco Epidemic in the United States}

\subsubsection{A Brief History of the Evolution of the Tobacco Epidemic in the United States}

The history of smoking prevalence in the United States is succinctly described in Figure 2-1. While smoking prevalence was not routinely and systematically prior to 1960 as it is now by the Centers for Disease Control and Prevention, it is estimated that smoking prevalence in the United States was at or near $50 \%$ during the middle of the $20^{\text {th }}$ century. As shown in Figure 2-1, smoking prevalence has steadily declined though it is noted that neither the proportion of adult smokers or high school students reached the desired goals established as part of the C.D.C.'s Healthy People 2010 initiative.

Figure 2-1. Trend in Prevalence of Current Smokers, Adults and High School Students, 1965-2007

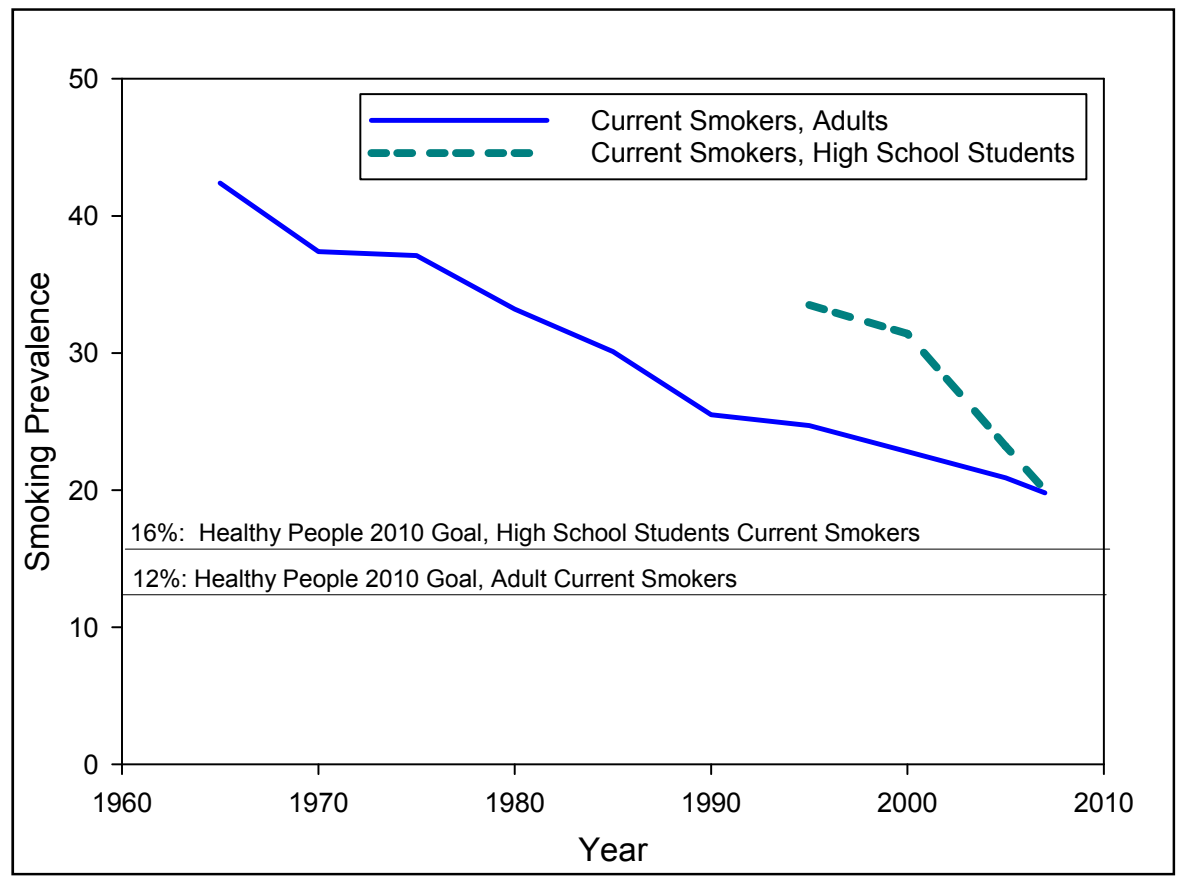

Source: [Centers for Disease Control and Prevention, 2009] 
With regard to the development of tobacco control policies, the competing interests and balances in these policies have been those of the tobacco industry, including tobacco farmers and others in hospitality industries, who have wanted as few restrictions as possible on the sale and distribution of cigarettes and the indefinite continuation of agricultural supports for tobacco farmers and international trade promotion for their products, and public health advocates, who have wanted if not the outright ban of tobacco products, then substantial restrictions and regulations on the sale, advertisement, and distribution of tobacco products with the objective being the abatement of current and prevention of future societal harm and costs due to the consumption of tobacco. In the U.S. federalist system, tobacco control policies have been part of the decision agenda and implemented at multiple venues, including at the federal-, state-, and local- levels. Central-level policy making can be grouped into four categories: legislation

Table 2-3. Federal Tobacco-Related Legislation, Enacted

\begin{tabular}{|c|c|c|}
\hline Year & Title / Authority & Summary \\
\hline 1914 & $\begin{array}{l}\text { Federal Trade Commission } \\
\text { (FTC) Act of } 1914\end{array}$ & $\begin{array}{l}\text { - Provided provisions to prevent unfair and deceptive practices in commerce } \\
\text { - Act used multiple times to curtail misleading advertising and claims, especially on cigarette } \\
\text { packages } \\
\text { - Amended } 1938\end{array}$ \\
\hline 1965 & $\begin{array}{l}\text { Federal Cigarette Labeling and } \\
\text { Advertising Act of } 1965\end{array}$ & $\begin{array}{l}\text { - Required a package warning label (“Caution: Cigarette Smoking May Be Hazardous to Your } \\
\text { Health"; other text/warning prohibited) but not a warning label on advertisement } \\
\text { - Required that the FTC and Department of Health, Education, and Welfare to report to Congress } \\
\text { annually on cigarette advertising and promotion practices and the health consequences of } \\
\text { smoking, respectively }\end{array}$ \\
\hline 1969 & $\begin{array}{l}\text { Public Health Cigarette } \\
\text { Smoking Act of } 1969\end{array}$ & $\begin{array}{l}\text { - Required new package warning (“Caution: The Surgeon General Has Determined that } \\
\text { Cigarette Smoking Is Dangerous to Your Health"; other text/warning prohibited) } \\
\text { - Prohibited cigarette advertising on television and radio } \\
\text { - Preempted states and localities from regulating or prohibiting cigarette advertising or promotion } \\
\text { for health reasons }\end{array}$ \\
\hline 1973 & Little Cigar Act of 1973 & - Banned little cigar advertising on television and radio \\
\hline 1984 & $\begin{array}{l}\text { Comprehensive Smoking } \\
\text { Education Act of } 1984\end{array}$ & $\begin{array}{l}\text { - Required rotating health warning labels on cigarette packages and advertisements ("Surgeon } \\
\text { General's Warning: Smoking causes lung cancer, heart disease, emphysema, and may } \\
\text { complicate pregnancy"; "Surgeon General's Warning: Quitting smoking now greatly reduces } \\
\text { serious risks to your health"; "Surgeon General's Warning: Smoking by pregnant women may } \\
\text { result in fetal injury, premature birth, and low birth weight:; "Surgeon General's Warning: } \\
\text { Cigarette smoke contains carbon monoxide") } \\
\text { - Other text/warning labels were preempted } \\
\text { - Required DHHS to submit biennial reports on smoking and health } \\
\text { - Created the Federal Interagency Committee on Smoking and Health } \\
\text { - Required cigarette manufacturers to provide a brand-specific, confidential list of ingredients }\end{array}$ \\
\hline 1984 & Cigarette Safety Act of 1984 & $\begin{array}{l}\text { - Designed to determine the feasibility of developing cigarettes less likely to ignite upholstery and } \\
\text { mattresses }\end{array}$ \\
\hline \multirow[t]{6}{*}{1986} & $\begin{array}{l}\text { Comprehensive Smokeless } \\
\text { Tobacco Health Education Act } \\
\text { of } 1986\end{array}$ & $\begin{array}{l}\text { - Required three rotating health warning labels and advertisements (“This product may cause } \\
\text { gum disease and tooth loss"; "This product may cause mouth cancer"; "This product is not a } \\
\text { safe alternative to cigarettes" }\end{array}$ \\
\hline & & - Preempted other text/warning labels \\
\hline & & - Prohibited advertising on television and radio \\
\hline & & - Required DHHS and FTC to submit reports to Congress \\
\hline & & \\
\hline & & $\begin{array}{l}\text { - Required DHHS to conduct a public information campaign on the health hazards of smokeless } \\
\text { tobacco }\end{array}$ \\
\hline 1987 & Public Law 100-202 & - Banned smoking on domestic air flights of 2 hours or less \\
\hline 1989 & Public Law 101-164 & - Banned smoking on domestic air flights of 6 hours or less \\
\hline 1992 & $\begin{array}{l}\text { Synar Amendment to the } \\
\text { Alcohol, Drug Abuse, and } \\
\text { Mental Health Administration } \\
\text { (ADAMHA) Reorganization Act } \\
\text { of } 1992\end{array}$ & - Required all states to adopt and enforce restrictions on sales of tobacco to minors \\
\hline 1994 & Pro-Children Act of 1994 & - Required all federally-funded children's services to become smoke-free \\
\hline 2009 & $\begin{array}{l}\text { Family Smoking Prevention } \\
\text { and Tobacco Control Act of }\end{array}$ & - Granted FDA authority to regulate tobacco products \\
\hline
\end{tabular}

Source: [Centers for Disease Control and Prevention, 2010] 
affecting the sale, distribution, or marketing of tobacco products; regulation affecting the sale, distribution, or marketing of tobacco products; excise taxes on tobacco products; and policies and programs affecting tobacco farmers. In Tables 2-3 \& 2-4, seminal federal legislation affecting tobacco control is summarized. In Table 2-3, it can be seen that while there was some limited-scope activity immediately following the 1964 Surgeon General's report, it was not until 1984 that the first comprehensive, federal legislation was enacted. Further, it was not until 1992 with the Synar Amendment that there was a central-level policy to restrict tobacco sales to children.

The information in Table 2-4 summarizes central-level legislation that either could have been or was intentionally not extended to cigarettes or tobacco products resulting in "missed opportunities" for tobacco control. This information thus represents governmental "non-

Table 2-5. Federally-Enacted Legislation that was a "Missed Opportunity" for or Impeded Tobacco Control

\begin{tabular}{|c|c|c|}
\hline Year & Title / Authority & Summary \\
\hline 1960 & $\begin{array}{l}\text { Federal Hazardous } \\
\text { Substances Labeling Act } \\
\text { (FHSA) of } 1960\end{array}$ & $\begin{array}{l}\text { - Authorized FDA to regulate hazardous substances } \\
\text { - In } 1963 \text {, the FDA set forth its interpretation that tobacco did not meet criteria for "hazardous" } \\
\text { under the Act, pending the } 1964 \text { Surgeon General's report }\end{array}$ \\
\hline 1970 & $\begin{array}{l}\text { Controlled Substances Act of } \\
1970\end{array}$ & $\begin{array}{l}\text { - Designed to prevent abuse of drugs, narcotics, and other addictive substances } \\
\text { - Specifically excluded tobacco from the definition of a "controlled substance" }\end{array}$ \\
\hline 1972 & $\begin{array}{l}\text { Consumer Product Safety Act } \\
\text { of } 1972\end{array}$ & $\begin{array}{l}\text { - Transferred authority granted FDA under FHSA to the Consumer Product Safety Commission } \\
\text { (CPSC) } \\
\text { - Did not include tobacco or tobacco products in the definition of "consumer products" }\end{array}$ \\
\hline 1976 & $\begin{array}{l}\text { Amendment to the Federal } \\
\text { Hazardous Substances } \\
\text { Labeling Act of } 1960\end{array}$ & $\begin{array}{l}\text { - In response to a petition from the American Public Health Association to the CPSC requesting a } \\
\text { maximum level of tar in cigarettes }(21 \mathrm{mg}) \text {, Congress amended the FHSA to specifically } \\
\text { exclude tobacco and tobacco products being considered a "hazardous substance" }\end{array}$ \\
\hline 1976 & Toxic Substances Act of 1976 & $\begin{array}{l}\text { - Act to "regulate chemical substances and mixtures which present an unreasonable risk of injury } \\
\text { to health or the environment" } \\
\text { - Tobacco or tobacco products not included in definition of "chemical substances" }\end{array}$ \\
\hline
\end{tabular}

Source: [Centers for Disease Control and Prevention, 2010]

Table 2-4. Federal Regulations Affecting Tobacco Products and Use

\begin{tabular}{|c|c|c|}
\hline Year & Title / Authority & Summary \\
\hline 1967 & FCC & $\begin{array}{l}\text { - Fairness Doctrine - attempted to ensure that coverage of controversial issues (in this case } \\
\text { cigarettes) by a broadcast station was balances and fair; required that stations broadcasting } \\
\text { cigarette commercials donate air time to anti-smoking messages }\end{array}$ \\
\hline 1971 & FCC & - Under the Fairness Doctrine, anti-smoking messages ended when cigarette advertising ended \\
\hline 1973 & Civil Aeronautics Board & - Required no-smoking sections on all commercial air flights \\
\hline 1975 & Department of Defense & - Discontinued cigarettes in K- and C-rations for soldiers and sailors \\
\hline 1987 & DHHS & - Established smoke-free environment at all facilities \\
\hline 1992 & FTC & $\begin{array}{l}\text { - First enforcement action against Pinkerton Tobacco (under Comprehensive Smokeless } \\
\text { Tobacco Health Education Act) claiming that the Pinkerton logo appeared illegally during a } \\
\text { television broadcast }\end{array}$ \\
\hline 1993 & WIC (Congress) & - Smoke-free environment at all facilities \\
\hline 1993 & EPA & - Classified environmental tobacco smoke as a Class A carcinogen (known human carcinogen) \\
\hline 1994 & OSHA & $\begin{array}{l}\text { - Announced proposed legislation to prohibit smoking in workplaces, except in designated, } \\
\text { separately ventilated rooms }\end{array}$ \\
\hline 1994 & Department of Defense & - Established smoke-free environment at all facilities \\
\hline 1995 & President Clinton / FDA & $\begin{array}{l}\text { - Announced planned regulations (by FDA) to restrict the sale, distribution, and marketing of } \\
\text { tobacco products, especially to minors }\end{array}$ \\
\hline 1997 & $\begin{array}{l}\text { President Clinton/Executive } \\
\text { Order }\end{array}$ & - Established smoke-free environments at all federal facilities \\
\hline
\end{tabular}

Source: [Centers for Disease Control and Prevention, 2009] 
decisions" in tobacco control policy.

Central-level regulations governing specific aspects of tobacco products or use are summarized in Table 2-5. Of particular note is the Fairness Doctrine by the F.C.C., used to both broadcast and then stop broadcasting anti-smoking messages on network television. Also, it was not until 1997 that federal workplaces were declared to be smoke-free environments.

Federal excise taxes on cigarettes are summarized in Table 2-6. Since 1950, federal excise taxes have undergone long periods of inactivity (no increases) resulting in extended time during which the real price of cigarettes fell. There was a 30-year lag between the 1951 levy and the subsequent increase in 1982 and, since then, federal excise taxes on cigarette have been increased approximately every 10 years. The most recent increase, signed by President Obama in 2009 , raised the federal tax on a pack of cigarettes to $\$ 1.01$. Combined with the most recent information on state excise taxes [Centers for Disease Control and Prevention, 2010], which in 2009 averaged \$1.37 per pack, the "average" combined federal and state excise tax for cigarettes in the United States is $\$ 2.38$. As a comparison, in 2009 the Canadian federal excise tax for cigarettes was CDN\$1.70 per pack and an average provincial excise tax of CDN\$3.43, resulting an "average" combined federal and provincial excise tax of CDN\$5.13 per pack. [Tran, 2009]

Finally, federal agricultural support programs for tobacco farmers are summarized in Table 2-7. A comprehensive set of support programs including price supports, crop insurance, and crop research and marketing began in 1933 under the Agricultural Adjustment Act of 1933. [Womach, 2005] With the Fair and Equitable Tobacco Reform Act of 2004, these agricultural support programs were discontinued and the Tobacco Transition Payment Program, created by the 2004 Act, was implemented to support tobacco farmers in transition to a free market system and will continue until 2014. [Farm Service Agency, 2005]

Table 2-6. Federal Excise Taxes on Cigarettes

\begin{tabular}{|c|c|c|}
\hline Year & Title / Authority & Summary \\
\hline 1951 & Revenue Act of 1951 & - $8 \phi$ per pack (from $7 \not \phi$ per pack with the justification to help fund the Korean War) \\
\hline 1982 & $\begin{array}{l}\text { Tax Equity and Fiscal } \\
\text { Responsibility Act of } 1982 \\
\text { (P.L. 97-248) }\end{array}$ & - Increased to $16 \not$ per pack \\
\hline 1990 & $\begin{array}{l}\text { Revenue Reconciliation Act of } \\
1990 \text { (P.L. 101-508) }\end{array}$ & $\begin{array}{l}\text { - Two-stage increase: on Jan. } 1 / 1991 \text { to } 20 \phi \text { per pack and an additional } 4 \phi \text { per pack increase (to } \\
\text { a total of } 24 \phi \text { per pack) on Jan } 1 / 1993\end{array}$ \\
\hline 1997 & $\begin{array}{l}\text { Balanced Budget Act of } 1997 \\
\text { (P.L. 105-33) }\end{array}$ & $\begin{array}{l}\text { Two stage increase: on Jan } 1 / 2000 \text { by } 10 \not \text { per pack to } 34 \phi \text { per pack and an additional } 5 \phi \text { per } \\
\text { pack to } 39 \phi \text { per pack on Jan } 1 / 2002\end{array}$ \\
\hline 2009 & $\begin{array}{l}\text { Insurance Reauthorization Act } \\
\text { of } 2009\end{array}$ & $\begin{array}{l}\text { - Increase to } \$ 1.01 \text { (from } 39 \phi \text { ) per pack } \\
\text { - Revenue to be used to fund SCHIP health insurance program } \\
\text { program, but the initial bill (HR } 946 \text { ) was vetoed by President Bush. The final bill (P.L. 110-173) } \\
\text { did re-authorize SCHIP but without an increase in tobacco taxes. }\end{array}$ \\
\hline
\end{tabular}

Source: [Talley, 2002] 
Table 2-7. Federal Agricultural Policies and Programs for Tobacco Farmers

\begin{tabular}{|cll|} 
Year & \multicolumn{1}{|c|}{ Title I Authority } & \multicolumn{1}{c}{ Summary } \\
\hline 1933 & $\begin{array}{l}\text { Agricultural Adjustment Act of } \\
1933\end{array}$ & $\begin{array}{l}\text { - Administered through the US Department of Agriculture Farm Service Agency } \\
\text { - In exchange for adhering to production quotas, tobacco farmers received price supports, } \\
\text { nonrecourse loans through the Commodity Credit Corporation }\end{array}$ \\
& & $\begin{array}{l}\text { - Additional elements of support included federal crop insurance, tobacco inspection and grading, } \\
\text { tobacco research, and extension education among others }\end{array}$ \\
2004 & $\begin{array}{l}\text { Fair and Equitable Tobacco } \\
\text { Reform Act of } 2004 \text { (P.L. 108- } \\
\text { 357) }\end{array}$ & $\begin{array}{l}\text { - Quota owners and farm operators compensated for capital losses and loss of future support } \\
\text { (funded by a } \$ 9.6 \text { billion over } 10 \text { years funded via an assessment on tobacco manufacturers } \\
\text { and importers }\end{array}$ \\
\hline
\end{tabular}

Source: [Womach, 2005], [Farm Service Agency, 2005]

\subsubsection{Current Estimates of Smoking Related Population Health}

Estimates from the C.D.C.'s National Health Interview Survey project that $20.6 \%$ of adults were current smokers in 2008. [Dube, Asman, Malarcher, \& Carabollo, 2009] As shown in Figure 2-2, more men than women smoke and a socioeconomic gradient is apparent, with substantially higher rates of smoking in those with fewer years of education compared to those with graduate education, and those below the poverty line compared to those above the poverty line. In youth, results from the C.D.C.'s 2007 Youth Risk Behavior Survey estimated that 8.1\% of high school students were current frequent smokers (smoked cigarettes on at least twenty of the last thirty days), $20.0 \%$ were current smokers (smoked cigarettes on at least one of the last thirty days), and $50.3 \%$ had ever tried cigarettes. [Centers for Disease Control and Prevention, Office on Smoking and Health, Division of Adolescent and School Health, National Center for Chronic Disease Prevention and Health Promotion , 2008] As previously shown in Figure 2-1

Figure 2-2. Adult Smoking Prevalence, United States, 2008

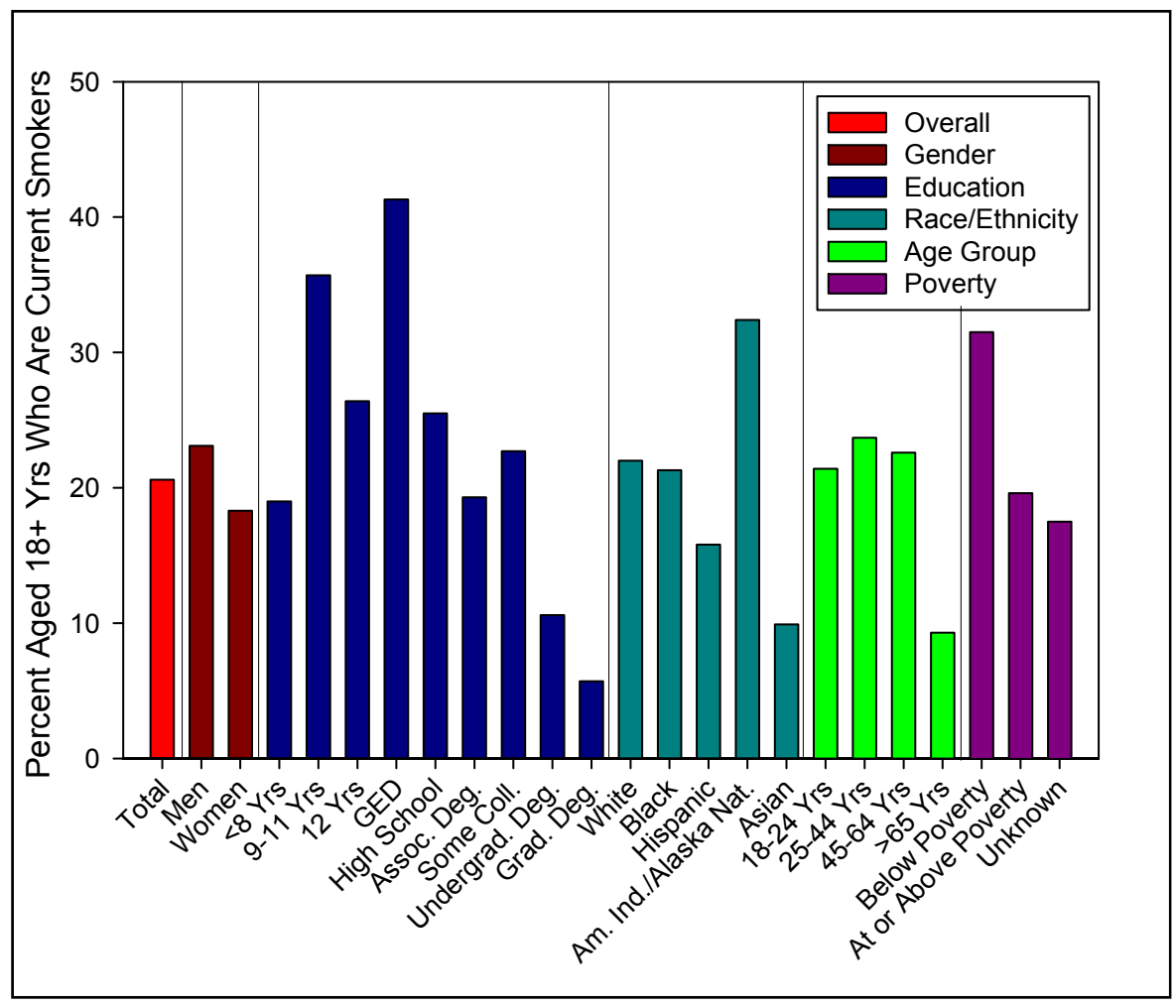

Source: [Dube, Asman, Malarcher, \& Carabollo, 2009] 
and discussed in the Introduction, while adult smoking prevalence decreased from $42.4 \%$ in 1964 to $19.8 \%$ in 2007 and smoking in high school students decreased to $20 \%$ in 2007 , the rate of decline in smoking prevalence has slowed and neither rates are projected to reach the Healthy People 2010 goals of $12 \%$ and $16 \%$ respectively. [Centers for Disease Control and Prevention, 2009]

Current adult and youth smoking prevalence and adult smoking-attributable mortality rates for individual states are presented in Table 2-8. [Centers for Disease Control and Prevention, 2010] Utah (9.3\%) followed by California (14.0\%), New Jersey (14.8\%), and Maryland (14.9\%) had the lowest proportion of adult current smokers in 2008 while Missouri (25.0\%), Kentucky (25.2\%), Indiana (26.0\%), and West Virginia (26.5\%) has the highest proportion of adult current smokers with West Virginia having almost 3-times (2.85) the proportion of adult smokers compared to Utah. Utah also had the lowest proportion of youth current smokers $(6.5 \%)$ followed by Hawaii $(6.8 \%)$, California $(6.9 \%)$, and the District of Columbia (7.2\%). Oklahoma (13.3\%), Arkansas (14.5\%), Wyoming (14.9\%), and Kentucky $(15.9 \%)$ had the highest proportion of youth current smokers with Kentucky having almost 2.5times (2.45) the proportion of youth smokers compared to Utah. Similarly, Utah also had the lowest smoking-attributable adult mortality rate (138.3 per 100,000) followed by Hawaii (167.6), Minnesota (215.1), and North Dakota (225.0) while the highest levels of smoking-attributable adult mortality rates were observed in Mississippi (333.6 per 100,000), Nevada (343.7), West Virginia (344.3), and Kentucky (370.6) with Kentucky again having almost 3-times (2.68) the smoking-attributable mortality rate of Utah. 
To provide comparison and international perspective, the smoking prevalence in O.E.C.D. countries, averaged over 2004-2006 where data were available, is shown in Figure 23. During this time period, only Sweden had a lower proportion of its population aged $15+$ years who smoked daily $-15.5 \%$ in Sweden compared to $16.9 \%$ in the United States. Six of twentyseven countries reported that less than $20 \%$ of their population were daily smokers, and sixteen of twenty-seven reported that less than $25 \%$ of their population were daily smokers.

Table 2-8. State-Specific Smoking Prevalence and Smoking-Attributable

\begin{tabular}{|c|c|c|c|}
\hline State & $\begin{array}{c}\text { Adult Smoking } \\
\text { Prevalence, } 2008\end{array}$ & $\begin{array}{c}\text { Youth Smoking } \\
\text { Prevalence, 2006-2007 }\end{array}$ & $\begin{array}{l}\text { Adult Smoking-Attributable } \\
\text { Mortality Rate (per } 100,000 \text { ) }\end{array}$ \\
\hline Alabama & 22.1 & 12.0 & 317.5 \\
\hline Alaska & 21.5 & 9.7 & 270.4 \\
\hline Arizona & 15.9 & 10.6 & 247.4 \\
\hline Arkansas & 22.3 & 14.5 & 323.7 \\
\hline California & 14.0 & 6.9 & 235.0 \\
\hline Colorado & 17.6 & 10.3 & 237.6 \\
\hline Connecticut & 15.9 & 9.8 & 238.3 \\
\hline Delaware & 17.8 & 9.3 & 280.9 \\
\hline District of Columbia & 16.2 & 7.2 & 249.9 \\
\hline Florida & 17.5 & 9.5 & 258.8 \\
\hline Georgia & 19.5 & 10.0 & 299.4 \\
\hline Hawaii & 15.4 & 6.8 & 167.6 \\
\hline Idaho & 16.9 & 8.9 & 237.4 \\
\hline Illinois & 21.3 & 10.2 & 263.1 \\
\hline Indiana & 26.0 & 11.8 & 308.9 \\
\hline lowa & 18.8 & 11.7 & 248.0 \\
\hline Kansas & 17.9 & 11.9 & 262.7 \\
\hline Kentucky & 25.2 & 15.9 & 370.6 \\
\hline Louisiana & 20.5 & 11.0 & 299.8 \\
\hline Maine & 18.2 & 11.4 & 289.8 \\
\hline Maryland & 14.9 & 8.8 & 261.9 \\
\hline Massachusetts & 16.1 & 9.5 & 249.4 \\
\hline Michigan & 20.5 & 10.7 & 281.9 \\
\hline Minnesota & 17.6 & 11.7 & 215.1 \\
\hline Mississippi & 22.7 & 9.4 & 333.6 \\
\hline Missouri & 25.0 & 11.8 & 307.8 \\
\hline Montana & 18.5 & 12.2 & 276.0 \\
\hline Nebraska & 18.4 & 11.0 & 235.8 \\
\hline Nevada & 22.2 & 10.2 & 343.7 \\
\hline New Hampshire & 17.1 & 9.8 & 272.4 \\
\hline New Jersey & 14.8 & 9.1 & 239.5 \\
\hline New Mexico & 19.4 & 11.8 & 234.0 \\
\hline New York & 16.8 & 8.2 & 246.1 \\
\hline North Carolina & 20.9 & 10.8 & 298.4 \\
\hline North Dakota & 18.1 & 12.4 & 225.6 \\
\hline Ohio & 20.1 & 12.9 & 299.1 \\
\hline Oklahoma & 24.7 & 13.3 & 332.1 \\
\hline Oregon & 16.3 & 9.7 & 263.3 \\
\hline Pennsylvania & 21.3 & 11.8 & 259.0 \\
\hline Rhode Island & 17.4 & 11.3 & 266.8 \\
\hline South Carolina & 20.0 & 11.8 & 293.4 \\
\hline South Dakota & 17.5 & 12.5 & 239.2 \\
\hline Tennessee & 23.1 & 13.0 & 325.0 \\
\hline Texas & 18.5 & 9.5 & 273.1 \\
\hline Utah & 9.3 & 6.5 & 138.3 \\
\hline Vermont & 16.8 & 11.3 & 247.5 \\
\hline Virginia & 16.4 & 11.0 & 267.0 \\
\hline Washington & 15.7 & 9.7 & 261.0 \\
\hline West Virginia & 26.5 & 12.6 & 344.3 \\
\hline Wisconsin & 19.9 & 12.2 & 244.2 \\
\hline Wyoming & 19.4 & 14.9 & 283.1 \\
\hline
\end{tabular}

Source: [Centers for Disease Control and Prevention, 2010] 
Figure 2-3. Smoking Prevalence in OECD Countries, 2004-2006

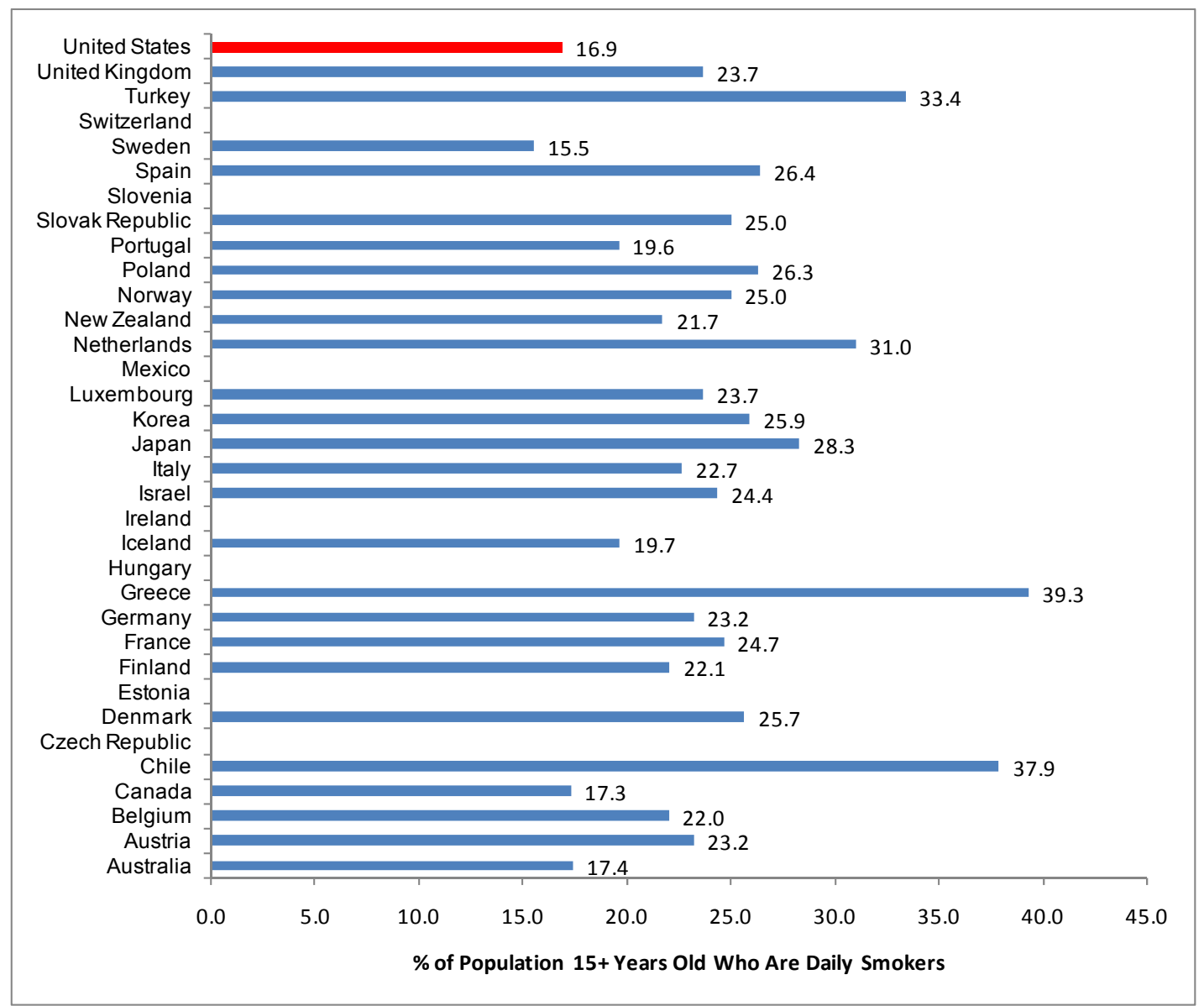

Data Source: OECD Heatlh Statistics, 2010

\subsubsection{Current Domestic Policy}

There are three components to the current U.S. tobacco control policy at the centrallevel: taxation, enacted legislation, and bureaucratic infrastructure.

\subsubsection{Central-Level Taxation}

As part of Children's Health Insurance Program (C.H.I.P.) Reauthorization Act of 2009 (Public Law No. 111-3), the central-level tobacco excise tax was raised to $\$ 1.01$, a $\$ 0.62$ increase from the previous excise tax of $\$ 0.39$. The excise-tax increase was included as a revenue provision of the bill, meaning that the excise tax was "paying for" the CHIP reauthorization and program expansion. Per the provisions in the Bill, the excise tax covers cigars, cigarettes, cigarette papers and tubes, smokeless tobacco, pipe tobacco, roll-your-own tobacco, and also taxes floor stocks of tobacco products. The Bill, and tax increase, was effective April 1, 2009. 


\subsubsection{Legislation}

The current central-level tobacco control legislation is the Family Smoking Prevention and Tobacco Control Act of 2009 (Public Law No. 111-31). The Act represents the most comprehensive single piece of tobacco control legislation enacted at the central-level in the United States and creates a new regulatory scheme for tobacco products within the F.D.A.; thus, this Act represents the culmination of regulatory and legislative attempts begun in 1995 (and the subsequent 1996 F.D.A. Final Rule). Very similar versions of this Act were introduced in the $108^{\text {th }}$ Congress, passed by the Senate in 2004, and passed by the House in 2008. [Redhead \& Burrows, 2009] The current Act, sponsored by Rep. Waxman (D-CA), was passed by the House on April 2, 2009 (H.R. 1256; H.Rept. 111-58, part 1 and 2), by the Senate on May 20, 2009 (S. 982), and signed by President Obama on June 22, 2009. [Redhead \& Burrows, 2009], [Congressional Research Service, 2009]

A central function of this Act was to amend the Federal Food Drug and Cosmetic Act to provide the Secretary of Health and Human Services, through the F.D.A., the jurisdiction and responsibility to regulate tobacco products, which the F.D.A. originally asserted in 1996 but was overturned by the Supreme Court in F.D.A. v. Brown and Williamson Tobacco Corp. The key provisions of the Act are summarized in Table 2-9. While the F.D.A. is prohibited from banning nicotine in tobacco products or the products themselves, they were authorized with a broad scope of authority to develop regulations for the manufacture, distribution, sale, and marketing of tobacco products subject to the consideration of both individual and population health. Components of the Act were implemented in September 2009 and, as required in the Act, the F.D.A. issued "Regulations Restricting the Sale and Distribution of Cigarettes and Smokeless Tobacco to Protect Children and Adolescents" which became effective on June 22, 2010. [U.S. Food and Drug Administration, 2010] However, this 2010 Final Rule did not include the restrictions on outdoor advertising included in the 1996 Final Rule in order to permit additional study and public comment in light of the Supreme Court Ruling in Lorillard Tobacco Co. et al. v. Reilly, Attorney General of Massachusetts et al, No. 00-0596. [U.S. Food and Drug Administration, 2010] As was anticipated, this Act has already been challenged in court (Smoking Everywhere, Inc., and Sottera, Inc., d/b/a NJOY v. U.S. Food and Drug Administration et al. Civil Case No. 09-771 (RJL). 
Finally, in June 2010 the F.D.A. issued a review reporting on the first year of activities pursuant to the implementation of the Act in June 2009. Key among these activities was the creation of the National Center for Tobacco Products which identifies its mission as the

Table 2-9. Key Provisions of the Family Smoking Prevention and Tobacco Control Act of 2009

\begin{tabular}{|c|c|}
\hline Topic & Description \\
\hline Allowable Scope of Activity & $\begin{array}{l}\text { Secretary/FDA may: } \\
\text { - } \quad \text { Restrict sale or distribution of products to protect public health } \\
\text { - } \quad \text { Restrict advertising and promotion consistent with the First Amendment } \\
\text { - } \quad \text { Alter label requirements to promote better understanding of risk of use of tobacco products } \\
\text { - } \quad \text { Adopt product standards that reduce the yield of nicotine and reduce or eliminate other product components } \\
\text { - } \quad \text { Conduct product testing } \\
\text { - Can recall or ban a product that poses unreasonable risk of substantial harm }\end{array}$ \\
\hline Disallowed Scope of Activity & $\begin{array}{l}\text { Secretary/FDA may not: } \\
\text { - } \quad \text { Ban cigarettes/tobacco products } \\
\text { - } \quad \text { Require reduction of nicotine content to zero } \\
\text { - } \quad \text { Require written or oral prescription to obtain products } \\
\text { - } \quad \text { Prohibit face-to-face sales in retail outlets } \\
\text { - } \quad \text { Publicly disclose trade secrets or other confidential information }\end{array}$ \\
\hline Infrastructure & $\begin{array}{l}\text { Secretary/FDA must create: } \\
\text { - } \quad \text { Center for Tobacco Products to implement Act } \\
\text { - } \quad \text { Technical support office for small manufacturers } \\
\text { - } \quad \text { Tobacco Products Scientific Advisory Committee } \\
\quad \text { Expert Panel }\end{array}$ \\
\hline Preemption & $\begin{array}{l}\text { - Federal agencies, states, political subdivisions, Indian tribes etc., may enact additional or stricter measures, } \\
\text { including excise taxes, except for those relating to product manufacturing standards, adulteration and labeling, } \\
\text { and modified risk tobacco products } \\
\text { States and localities can impose specific bans on the time, place, or manner of advertising or promotion but not } \\
\text { the content of such advertisements }\end{array}$ \\
\hline $\begin{array}{l}\text { Product and Manufacturing } \\
\text { Standards }\end{array}$ & $\begin{array}{l}\text { Requires that tobacco manufacturers: } \\
\text { - Submit a list of ingredients (and quantity) for each product } \\
\text { - Submit the form and content of nicotine in each product } \\
\text { - } \quad \text { Submit a list of "harmful constituents" (as defined by the Secretary/FDA) in each product } \\
\text { - Submit all documents that relate to health, toxicologic, physiologic, or behavioral effects of tobacco products, } \\
\text { additives, or components } \\
\text { - } \text { Register annually with the Secretary/FDA } \\
\text { Comply with manufacturing standards, including uniform standard for ingredients, to be established by the } \\
\text { - Secretary/FDA } \\
\text { Foreign/tobacco importers must register with the Secretary/FDA and reasonably comply with requirements to } \\
\text { establish that product content and manufacture conform with standards to be set by the Secretary/FDA }\end{array}$ \\
\hline New Products & $\begin{array}{l}\text { - } \quad \text { Pre-market approval for all new products } \\
\text { - The Secretary/FDA must develop a pre-market approval process that includes health information }\end{array}$ \\
\hline Amendment of Previous Acts & $\begin{array}{l}\text { - Amends the Federal Cigarette Labeling and Advertising Act such that labeling requirements are those developed } \\
\text { by the Secretary/FDA } \\
\text { - Amends the Comprehensive Smokeless Tobacco Health Act of } 1986 \text { such that labeling requirements for } \\
\text { smokeless tobacco products are the same as those developed by the Secretary/FDA for cigarettes }\end{array}$ \\
\hline $\begin{array}{l}\text { Re-issue of } 1996 \text { FDA Final } \\
\text { Rule }\end{array}$ & $\begin{array}{l}\text { The Secretary/FDA is required to re-issue the Final Rule as issued by the FDA in } 1996 \text { with some minor revisions. The } \\
\text { rule requires: } \\
\text { - Ban on sales of tobacco products to those }<18 \text { years of age } \\
\text { Ban on packs with }<20 \text { cigarettes } \\
\text { - } \quad \text { Significant limitations on sales from vending machines or self-service displays } \\
\text { - Bans free samples of cigarettes; limits distribution of smokeless tobacco } \\
\text { Bans brand-name sponsorship for sporting, musical, or cultural events or sponsorship of any team or group } \\
\text { participating therein } \\
\text { Bans gifts of cigarettes/tobacco products or gifts for buying cigarettes/tobacco products } \\
\text { - Bans use of music in audio ads (i.e., words only) } \\
\text { Bans sale or distribution of branded non-tobacco products (e.g., hats, t-shirts) } \\
\text { Restricts advertising, bans outdoor advertising within } 1000 \text { feet of schools }\end{array}$ \\
\hline Modified Risk Tobacco Products & $\begin{array}{l}\text { - A modified risk product may be commercially marketed if: 1) it significantly reduces tobacco-related harm for } \\
\text { tobacco users; and 2) have population benefits for both smokers and non-smokers when evaluated as actually } \\
\text { used by consumers } \\
\text { - A product not labeled or marketed as a modified risk product may be sold for five years if: 1) it would promote } \\
\text { public health; and 2) the product is expected to benefit the health of the population } \\
\text { - Post-market surveillance is to be conducted on all reduced risk products with reports annually }\end{array}$ \\
\hline $\begin{array}{l}\text { Specific Requirements -- } \\
\text { Additives }\end{array}$ & - All flavorings, natural or artificial, such as vanilla, clove, orange etc., are banned with the exception of menthol \\
\hline $\begin{array}{l}\text { Required Action - Further Study } \\
\text { Mandated }\end{array}$ & $\begin{array}{l}\text { - Expert Panel shall study health implications of raising minimum age to purchase tobacco products } \\
\text { - Tobacco Products Scientific Advisory Committee shall study and report on: 1) the effects of altering nicotine } \\
\text { content including whether there is a point at which dependence / addiction is not induced; 2) the health impact on } \\
\text { the use of menthol; } 3 \text { ) the nature and health impact of dissolvable tobacco products }\end{array}$ \\
\hline $\begin{array}{l}\text { Required Action - Public } \\
\text { Disclosure }\end{array}$ & - The Secretary/FDA must publish annually a list of harmful or potentially harmful products in each tobacco product \\
\hline Miscellaneous Stipulations & $\begin{array}{l}\text { - } \quad \text { Tobacco manufacturers may not in any way use FDA regulation to construe that tobacco products are safe } \\
\text { - Secretary/FDA required to issue regulations mandating use of color graphic health warning labels }\end{array}$ \\
\hline
\end{tabular}

Source: [Congressional Research Service, 2009] 
protection of "public health by issuing and enforcing tobacco product regulations and educating the public about the dangers of tobacco use". [U.S. Food and Drug Administration, 2010] Additional key activities in the first year of F.D.A. jurisdiction in tobacco control are listed in Table 2-10 and include the issuance of multiple rules and final guidance as well as the development of the infrastructure and networks the F.D.A. will need to fully implement all provisions of the 2009 Act.

\subsubsection{The Tobacco Control Bureaucracy - Structural Support for Tobacco Control}

With the implementation of the Family Smoking Prevention and Tobacco Control of 2009, the United States now has three central-level formal, bureaucratic agencies responsible for tobacco control and prevention policies. The F.D.A., through the National Center for Tobacco Products, is responsible for developing, forwarding, and enforcing, through provisions

Table 2-10. Key Activities in the Inaugural Year of F.D.A. Tobacco Regulation

\begin{tabular}{|c|c|}
\hline Area & Activities \\
\hline Protecting Kids & $\begin{array}{l}\text { - } \text { Announced and enforced ban on flavored cigarettes }(9 / 2009) \\
\text { Re-issued } 1996 \text { Final Rule }(3 / 2010) \text {. Provisions included: } \\
\text { - National minimum age of } 18 \text { to purchase tobacco products } \\
\text { - Banned sales of packs <20 cigarettes } \\
\text { - Banned distribution of free samples of tobacco products } \\
\text { - Banned event sponsorship } \\
\text { Banned vending machine sales in all but adult-only facilities }\end{array}$ \\
\hline $\begin{array}{l}\text { Establishing a Science } \\
\text { Base }\end{array}$ & $\begin{array}{l}\text { - Issued guidance for industry on registration and product listing for owners and operators of } \\
\text { - } \quad \text { Issuestic tobacco establishments (11/2009) } \\
\text { - } \quad \text { gstablished Tobacco Products Scientific Advistory Committee (TPSAC) }(11 / 2009) \text { with first } \\
\text { meeting in } 3 / 2010 \text {. Members of the TPSAC are: JM Samet (Chair) and CL Stark (Acting } \\
\text { Designated Federal Official), NL Benowitz, MS Clanton, DK Hatsukami, JD Heck, PN } \\
\text { Henderson, GN Connolly, KL DeLeeuw, LA Hamm Jr., JE Henningfield, JH Lauterbach, M } \\
\text { Wakefield } \\
\text { - Appointed Cpt. D Ashley as Director, Office of Science }(6 / 2010)\end{array}$ \\
\hline $\begin{array}{l}\text { Regulating Tobacco } \\
\text { Products }\end{array}$ & $\begin{array}{l}\text { - } \quad \text { Announced ban on flavored and candy-like tobacco products (9/2009). Warning letters issued to } \\
\text { - } \quad \text { Issultiple companies in violation of ban. } \\
\text { additives } \\
\text { - Issued final guidance regarding registration requirements for tobacco product manufacturers } \\
\text { - } \quad \text { Issued tobacco products } \\
\text { documents relating to health, toxicological, behavioral, or physiologic effects of current or future } \\
\text { tobacco products, and their contents (ingredients, components, additives of products and } \\
\text { smoke) } \\
\text { - Issued letters to industry requesting information about perception and use of dissolvable } \\
\text { tobacco products } \\
\text { Issued draft guidance regarding enforcement for regulations restricting sale and distribution of } \\
\text { - } \quad \text { Bebacco products to youth. Regulation became enforceable on } 6 / 22 / .2009 \text {. } \\
\text { tobacco products. Regulation that package and advertising warning labels rotate quarterly } \\
\text { became enforceable on } 6 / 22 / / 2009 \text {. } \\
\text { - Issued guidance on use of the terms "light", "mild", "low" etc } \\
\text { Issued guidance to solicit public comment and feedback on how FDA will develop and publish } \\
\text { information on harmful or potentially harmful constituents in tobacco products }\end{array}$ \\
\hline Communication & - Held seven listening sessions in fall 2009 \\
\hline Stakeholders & $\begin{array}{l}\text { - } \quad \text { Created Center website } \\
\text { - } \quad \text { Established small business office } \\
\text { - } \quad \text { Caunched call center for consumers and stakeholders } \\
\text { - } \quad \text { Opontrol Act and FDA's public health role } \\
\text { - } \quad \text { Pres. } \\
\text { - } \quad \text { confenten multiple public dockets to allow public to provide information, research, ideas, feedback } \\
\text { - Began retailer education campaign about advertising and sales to youth }\end{array}$ \\
\hline
\end{tabular}

Source: [U.S. Food and Drug Administration, 2010] 
in the Family Smoking Act, the manufacture, distribution, sale, and marketing of tobacco products. The C.D.C., through the Office for Smoking and Health, is responsible for tobacco prevention and control. The smaller Interagency Committee on Smoking and Health coordinates tobacco education and control activities within and between central-, state-, and local-level government and private agencies

The Office for Smoking and Health, originally established in 1965, has two principle programmatic efforts: the National Tobacco Control Program and global tobacco control programs whose main collaborative effort, the Global Tobacco Surveillance System (G.T.S.S.), was established to facilitate the development of standardized and internationally comparative surveillance data on variety of tobacco issues (e.g., tobacco use, exposure to secondhand smoke, etc.). These programmatic foci are supported by four units and three branches within the Office: Global Tobacco Control Unit; Resource Management Unit; Policy, Planning, and Coordination Unit which also includes a Planning Team and a Senior Policy Advisor; Health Communications Branch which also includes an Information Resources, Development and Implementation, and a Media team; Epidemiology Branch which includes an Evaluation, Surveillance, Research, and Data Analysis and Survey Support team; and a Program Services Branch which includes two program support teams. [Centers for Disease Control and Prevention, 2009]

The National Tobacco Control Program (N.T.C.P.), created in 1999, coordinates, supports, and funds national and state-level prevention and control efforts. The N.T.C.P. identifies the following as its goals, components, and activity areas:

Goals:

1. Eliminate exposure to secondhand smoke

2. Promote quitting among adults and youth

3. Prevent initiation among youth

4. Identify and eliminate disparities among population groups

Components:

1. Population-based community interventions

2. Counter-marketing

3. Program policy/regulation

4. Surveillance and evaluation

Activity areas:

1. Clean indoor air policy

2. Tobacco use treatment 
3. Access by minors

4. Advertising and promotion

5. Economic approaches (excise taxes)

6. Mass media and counter-advertising

7. Synergistic effects (changing of social norms)

From: [Centers for Disease Control and Prevention, 2010], [Wisotzky, Albuquerque, Pechacek, \& Park, 2004]

Funding for state-level tobacco control programs is provided from the National Center for Chronic Disease Prevention and Health Promotion at the C.D.C. to the reciprocal offices mirrored in state departments or bureaus for public health. The N.T.C.P. thus functions to coordinate and support the activities of fifty state-level tobacco prevention and control programs, as well as programs in the District of Columbia, eight other U.S. territories and jurisdictions, and seven tribal support centers. [Centers for Disease Control and Prevention, 2010] Additionally, the N.T.C.P. funds six national-level networks intended to target specific minority or at-risk communities. Currently, the funded national networks focus on African-Americans, American Indians/Alaska Natives, Asian Americans/Pacific Islanders, Hispanics/Latinos, lesbian/gay/bisexual/transgender communities, and low socioeconomic groups and include: APPEAL PROMISE Network (Asian Pacific Partners for Empowerment, Advocacy, and Leadership); National African American Tobacco Prevention Network; National Latino Tobacco Control Network; The National LGBT Tobacco Control Network; Break Free Alliance; and the National Native Commercial Tobacco Abuse Prevention Network. [National Networks for Tobacco Control and Prevention] 
Figure 2-4. Schematic Representation of the National Tobacco Control Program

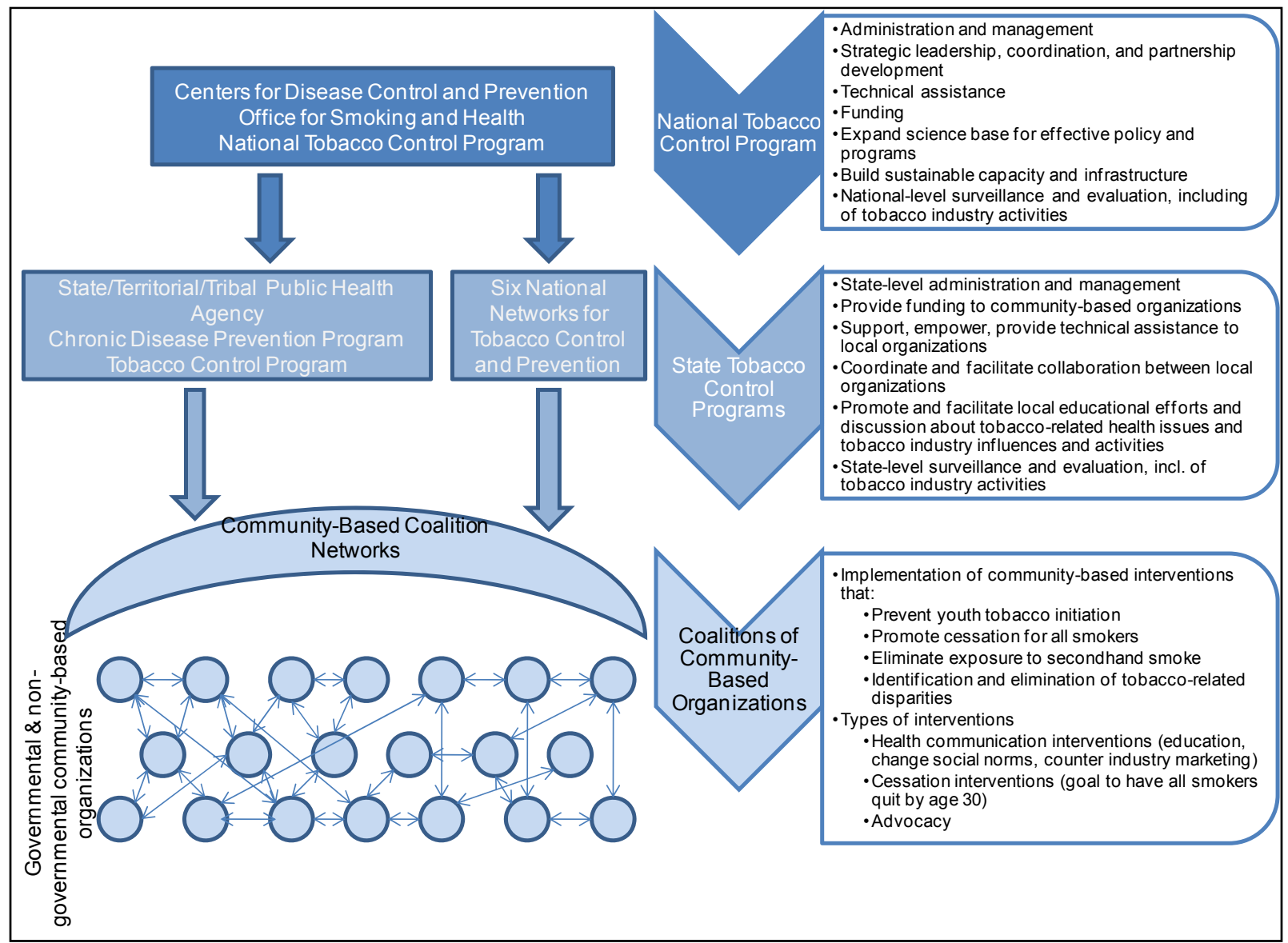

Sources: [Centers for Disease Control and Prevention, 2009], [Centers for Disease Control and Prevention, 2010], [Centers for Disease Control and Prevention, 2007], [Centers for Disease Control and Prevention, 2007]

The N.T.C.P. utilizes a community-based model with the goal of producing lasting changes in social norms for tobacco by implementing economic, regulatory, and comprehensive evidence-based programs projected to have the largest population impact. [Centers for Disease Control and Prevention, 2007] The foundation for the implementation of the N.T.C.P.'s community-based model is the development and support of networks of coalitions comprised, in turn, of myriad community-based organizations. [Centers for Disease Control and Prevention, 2007] The benefits of a coalition structure are multifold. Importantly, non-governmental, community-based organizations can engage in activities, particularly policy advocacy and lobbying, not allowable by government agencies. Additional benefits of a coalition infrastructure include: representation of community diversity; synergy of resources and efforts; expansion of public support to sustain tobacco control programs; diversity in membership to propagate and amplify community mobilization; policy advocacy; changing social norms by advocating for and promoting pro-health values; membership diversity implies broad community representation and thus imparts credibility leading to community buy-in; broad and diverse coalition membership reduces duplication of effort within a community and promotes collaboration and leveraging of 
Table 2-11. Membership of the Interagency Committee on Smoking and Health

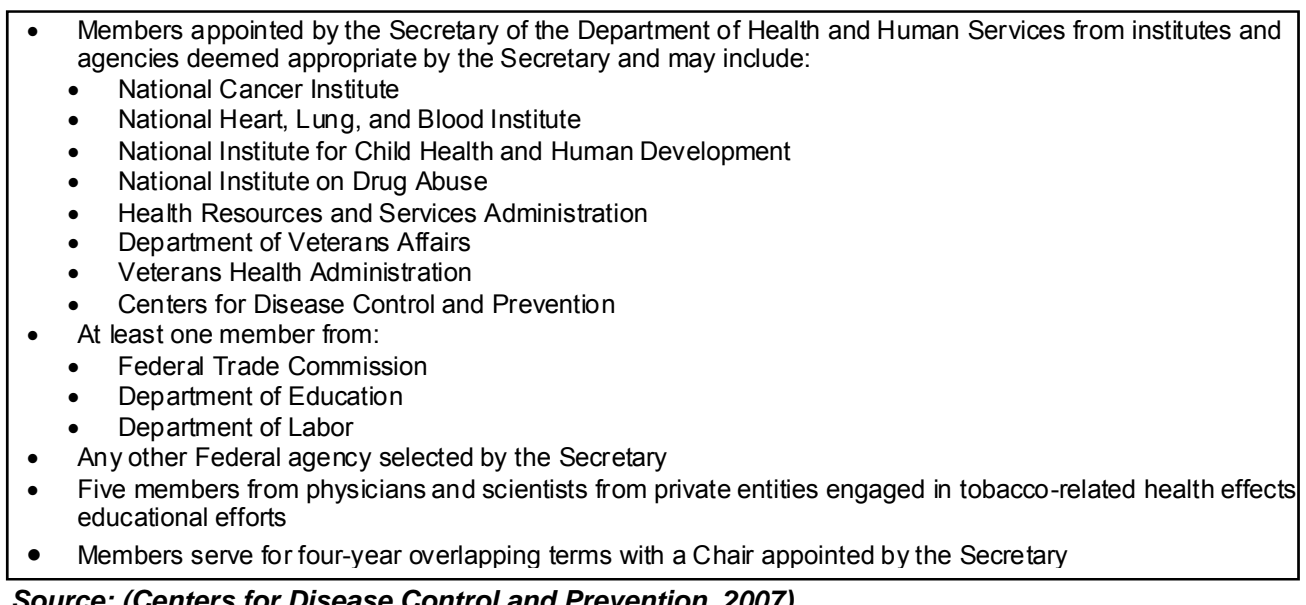

talents and capital, both economic and human; and more effectual efforts to counter-act tobacco industry practices. [Centers for Disease Control and Prevention, 2007] Thus, the N.T.C.P. is hierarchical in nature with the Office for Smoking and Health and the N.T.C.P. providing strategic, organizational, technical, and scientific support as well as funding to state agencies. The state agencies subsequently function similarly for the coalitions of community-based organizations. This structure, including the functions of each organization level, is depicted in Figure 2-4. The community-based model of coalitions thus results in overlapping networks community-based organizations that collaborate and coordinate resources to implement the N.T.C.P. recommended interventions, programs, and policies.

Finally, the last and smallest component of the central-level tobacco control and prevention structure is the Interagency Committee on Smoking and Health. Created as part of the Comprehensive Smoking Education Act of 1984, the Committee consists of representatives from multiple agencies within the Department of Health and Human Services as well as other central-level government departments (full membership of the Committee is specified in Table 2-11). [Centers for Diseaes Control and Prevention, 2009] The Interagency Committee serves to advise the Secretary for Health and Human Services on the coordination of tobacco research and educational programs, and other tobacco-related activities with other central-, state-, and local-level government and private agencies. [Centers for Diseaes Control and Prevention, 2009] Specifically, the Committee is accountable to the Secretary for Health and Human Services through the Director of the C.D.C. and is required report biennially to Congress on educational efforts by both central-level government and private agencies to improve public knowledge about the tobacco-related health effects and the effects of such efforts (i.e., the public's level of knowledge thereof). [Centers for Disease Control and Prevention, 2007] 


\subsubsection{State-Level Taxation and Legislation}

In addition to central-level policies, states also establish tobacco control policies which are summarized in Table 2-12. [Centers for Disease Control and Prevention, 2010] As of December $31,2009,58.8 \%$ of states had smoke-free workplace laws, $54.9 \%$ had smoke-free restaurant statutes, and $43.1 \%$ required smoke-free bars. In 2007, 49.0\% of state Medicaid programs covered pharmaceutical nicotine replacement therapy for all enrollees and another $25.5 \%$ of states covered such therapies for some enrollees; $17.6 \%$ of states did not cover any pharmaceutical nicotine replacement therapy. In 2009 , approximately $25 \%$ of states had some form of preemption for advertising and promotion, meaning that local jurisdictions were not allowed to enact stricter regulations than those enacted at the state-level. Also, by December 31,2009 , almost half $-49.0 \%$-- of states had minimum price laws. At the same point in time, the average state excise tax was $\$ 1.33 \pm \$ 0.12$ (SE), ranging from $\$ 0.07$ in South Carolina to $\$ 3.46$ in Rhode Island; $25 \%$ of states had excise taxes equal to or in excess of $\$ 2.00$. Finally, using the recommended expenditures established for each state by the C.D.C., total actual expenditures on tobacco control programs were estimated as percent of recommended expenditures. In 2007 , the average percent of recommended expenditures was $25.5 \% \pm 3.21 \%$ (SE), ranging from $1.1 \%$ of recommended expenditures in Tennessee to $85.5 \%$ of recommended expenditures in Maine. Fourteen states spent less than $10 \%$ of recommended levels with the lowest spending states being Tennessee, Mississippi, Missouri, Michigan, Texas. Only seven states spent in excess of $50 \%$ of recommended levels with the highest spending states being Hawaii, Alaska, Wyoming, Delaware, and Maine. 
Table 2-12. Summary of State-Level Tobacco Excise Tax and Enacted Tobacco-Control Legislation

\begin{tabular}{|c|c|c|c|c|c|c|c|c|c|c|c|c|}
\hline State & $\begin{array}{l}\text { 100\% Smoke-Free } \\
\text { Indoor Air Laws, } \\
12 / 21 / 2009 \\
\text { (Worksites) }\end{array}$ & $\begin{array}{l}\text { 100\% Smoke-Free } \\
\text { Indoor Air Laws, } \\
12 / 21 / 2009 \\
\text { (Restaurants) }\end{array}$ & $\begin{array}{l}\text { Medicaid FFS } \\
\text { Coverage for } \\
\text { Tobacco } \\
\text { Dependence } \\
\text { Treatments, 2007 } \\
\text { (Medications) }\end{array}$ & $\begin{array}{l}\text { Medicaid FFS } \\
\text { Coverage for } \\
\text { Tobacco } \\
\text { Dependence } \\
\text { Treatments, 2007 } \\
\text { (Counseling) }\end{array}$ & $\begin{array}{l}\text { Prevalence of } \\
\text { Households with No- } \\
\text { Smoking Rules, } \\
2006-2007 \text { (\%) }\end{array}$ & $\begin{array}{l}\text { Tobacoo Counter- } \\
\text { Marketing Media } \\
\text { Intensity, per } \\
\text { Quarter, 2008 } \\
\text { (TRPs - Youth) }\end{array}$ & $\begin{array}{l}\text { Tobacoo Counter- } \\
\text { Marketing Media } \\
\text { Intensity, per } \\
\text { Quarter, 2008 } \\
\text { (GRPs - Adult } \\
\text { Households) }\end{array}$ & $\begin{array}{c}\text { Local Advertising } \\
\text { and Promotion Laws } \\
\text { Allowed, 12/31/2009 } \\
\text { (Display) }\end{array}$ & $\begin{array}{c}\text { Local Advertising } \\
\text { and Promotion Laws } \\
\text { Allowed, 12/31/2009 } \\
\text { (Promotion) }\end{array}$ & $\begin{array}{c}\text { State Cigarette } \\
\text { Excise Tax per } \\
\text { Pack, 12.31/2009 }\end{array}$ & $\begin{array}{l}\text { Percentage of } \\
\text { Recommended } \\
\text { Tobacco Control } \\
\text { Investment, } 2007\end{array}$ & $\begin{array}{c}\text { Minimum Price } \\
\text { Law for } \\
\text { Cigarettes, } \\
12 / 31 / 2009\end{array}$ \\
\hline Alabama & No & No & No & No & 73.8 & 0 & 0 & Yes & Yes & 0.425 & 3.7 & No \\
\hline Alaska & No & No & Some & All & 79.5 & & & Yes & Yes & 2 & 70.7 & Yes \\
\hline Arizona & Yes & Yes & No & Pregnant Only & 82.6 & 23 & 111 & Yes & Yes & 2 & 38.2 & No \\
\hline Arkansas & Yes & No & Some & All & 65.1 & 49 & 52 & Yes & Yes & 1.15 & 44.3 & Yes \\
\hline California & No & No & All & No & 87.6 & 138 & 670 & Yes & Yes & 0.87 & 19.2 & No \\
\hline Colorado & Yes & Yes & All & Pregnant Only & 82.6 & 118 & 344 & Yes & Yes & 0.84 & 48.7 & No \\
\hline Connecticut & No & No & No & No & 79.5 & 50 & 59 & Yes & Yes & 3 & 7 & Yes \\
\hline Delaware & Yes & Yes & All & No & 77.5 & & & Yes & Yes & 1.6 & 79.4 & Yes \\
\hline District of Columbia & Yes & Yes & All & No & 73.7 & 20 & 118 & Yes & Yes & 2.5 & 10 & Yes \\
\hline Florida & Yes & Yes & Some & No & 84 & 321 & 1183 & Yes & Yes & 1.339 & 3.1 & No \\
\hline Georgia & No & No & No & No & 79.2 & 0 & 0 & Yes & Yes & 0.37 & 2.7 & No \\
\hline Hawaii & Yes & Yes & All & No & 83.7 & 134 & 1003 & Yes & Yes & 2.6 & 66.6 & No \\
\hline Idaho & No & Yes & All & No & 87.3 & 14 & 99 & Yes & Yes & 0.57 & 12.8 & No \\
\hline Illinois & Yes & Yes & All & No & 73.8 & 14 & 146 & Yes & Yes & 0.98 & 6.3 & No \\
\hline Indiana & No & No & All & All & 66.2 & 266 & 722 & No & No & 0.995 & 15.3 & Yes \\
\hline lowa & Yes & Yes & Some & Pregnant Only & 72.4 & 249 & 969 & Yes & Yes & 1.36 & 21 & Yes \\
\hline Kansas & No & No & Some & No & 75.5 & 29 & 138 & Yes & Yes & 0.79 & 7.5 & No \\
\hline Kentucky & No & No & No & Pregnant Only & 60.9 & 0.5 & 1 & No & No & 0.6 & 6 & Yes \\
\hline Louisiana & Yes & Yes & Some & No & 74.7 & 62 & 157 & Yes & No & 0.36 & 17.2 & Yes \\
\hline Maine & Yes & Yes & Some & All & 75.8 & 1 & 11 & Yes & Yes & 2 & 85.5 & No \\
\hline Maryland & Yes & Yes & Some & All & 81.5 & 22 & 171 & Yes & Yes & 2 & 32.2 & Yes \\
\hline Massachusetts & Yes & Yes & All & All & 80.3 & 76 & 433 & Yes & Yes & 2.51 & 11.4 & Yes \\
\hline Michigan & No & No & Some & All & 70.9 & 37 & 151 & No & Yes & 2 & 2.1 & No \\
\hline Minnesota & Yes & Yes & All & All & 79.3 & 15 & 67 & Yes & Yes & 1.23 & 39.2 & Yes \\
\hline Mississippi & No & No & All & Pregnant Only & 72.7 & 0 & 0 & No & No & 0.68 & 1.4 & Yes \\
\hline Missouri & No & No & No & No & 69.5 & 2 & 8 & Yes & Yes & 0.17 & 1.7 & No \\
\hline Montana & Yes & Yes & All & No & 79.4 & & & Yes & Yes & 1.7 & 57.3 & Yes \\
\hline Nebraska & Yes & Yes & No & No & 76.7 & 106 & 631 & Yes & Yes & 0.64 & 20.3 & Yes \\
\hline Nevada & Yes & Yes & All & No & 81.7 & 4 & 18 & No & No & 0.8 & 14.6 & No \\
\hline New Hampshire & No & Yes & All & Pregnant Only & 80.7 & & & Yes & Yes & 1.78 & 5.9 & No \\
\hline New Jersey & Yes & Yes & All & No & 82 & & & Yes & Yes & 2.7 & 10.4 & Yes \\
\hline New Mexico & Yes & Yes & All & All & 76.7 & 80 & 253 & Yes & Yes & 0.91 & 38.9 & No \\
\hline New York & Yes & Yes & Some & No & 75.3 & 395 & 2389 & Yes & Yes & 2.75 & 34.8 & Yes \\
\hline North Carolina & No & No & All & No & 73.1 & 308 & 549 & No & No & 0.45 & 16 & No \\
\hline North Dakota & Yes & No & Some & All & 74.8 & 0 & 0 & Yes & Yes & 0.44 & 47.1 & No \\
\hline Ohio & Yes & Yes & All & No & 66.7 & 11 & 26 & Yes & Yes & 1.25 & 32.1 & Yes \\
\hline Oklahoma & No & No & All & All & 71 & 2 & 37 & No & No & 1.03 & 25.8 & Yes \\
\hline Oregon & Yes & Yes & All & All & 84.8 & 60 & 363 & Yes & Yes & 1.18 & 11.1 & No \\
\hline Pennsylvania & Yes & No & All & All & 71.5 & 93 & 556 & Yes & Yes & 1.6 & 20.5 & Yes \\
\hline Rhode Island & Yes & Yes & No & All & 77.9 & & & Yes & Yes & 3.46 & 14.6 & Yes \\
\hline South Carolina & No & No & All & No & 75 & 6 & 105 & No & No & 0.07 & 5.4 & No \\
\hline South Dakota & Yes & Yes & Some & No & 76.7 & 23 & 218 & Yes & No & 1.53 & 15.7 & Yes \\
\hline Tennessee & Yes & No & No & No & 68.9 & 0 & 1 & No & No & 0.62 & 1.1 & Yes \\
\hline Texas & No & No & Some & No & 81.3 & 0 & 0.5 & Yes & Yes & 1.41 & 2.3 & No \\
\hline Utah & Yes & Yes & All & Pregnant Only & 90.6 & 1070 & 4766 & No & No & 0.695 & 35.6 & No \\
\hline Vermont & Yes & Yes & All & No & 75.4 & & & Yes & Yes & 2.24 & 61.8 & No \\
\hline Virginia & No & No & All & Pregnant Only & 79.1 & 65 & 135 & Yes & Yes & 0.3 & 14.1 & No \\
\hline Washington & Yes & Yes & Pregnant Only & Pregnant Only & 87 & 255 & 575 & Yes & No & 2.025 & 42.6 & Yes \\
\hline West Virginia & No & No & Pregnant Only & All & 62.6 & 68 & 289 & No & Yes & 0.55 & 24.1 & No \\
\hline Wisconsin & No & No & Pregnant Only & All & 72.5 & 30 & 119 & No & No & 2 & 17.8 & Yes \\
\hline Wyoming & No & No & Pregnant Only & All & 70.2 & & & Yes & Yes & 0.6 & 78.2 & No \\
\hline
\end{tabular}

Data Source: [Centers for Disease Control and Prevention, 2010] 


\section{LITERATURE REVIEW: THE TOBACCO EPIDEMIC FROM THE PUBLIC HEALTH PERSPECTIVE}

\subsection{Chapter Introduction \& Purpose}

The purpose of this chapter is to provide a review of the existing, scientific tobacco control literature from the public health perspective. This review will include: defining tobacco control policies and tobacco control policy regimes; the current understanding of "best practices", or "evidence-based, in tobacco control policies; a description of ongoing coordinated, international efforts to combat the global tobacco epidemic and enact these "best practices" tobacco control policies; and the universal and emerging challenges facing tobacco control activities will be identified and briefly discussed.

\subsection{Tobacco Control Policy Best Practices}

In both the natural history models discussed in Chapter 2, the Phases of Tobacco Control Model and the Tobacco Epidemic Model, tobacco control policies do not emerge until four-five decades after the beginning of the epidemic when the health and economic effects of tobacco use become patent after the prolonged latency period between [cumulative] tobacco exposure and disease. Further, because of this latency between exposure and the onset of tobaccorelated disease, the delay of policy implementation until after the entrenchment of addiction to tobacco use results, as described in the Tobacco Epidemic Model, in sustained and substantial adverse societal costs despite gradual, decreasing smoking prevalence. This section describes the contemporary understanding of evidence-based tobacco control policy, the evidence base for which has been predominantly established in industrialized countries, thus defining the terms "comprehensive tobacco control policy" and "tobacco control policy regime".

\subsubsection{Individual Policy Instruments}

The evidence base for tobacco control policies has accumulated over the past 3-plus decades from ecologic studies, natural experiments, as well as controlled or quasi-experimental intervention trials at the individual, community, and population level. Substantiation for this substantial body of evidence is two-fold: the Cochrane Library and population-based simulation models.

The Cochrane Library is a collection of six different databases that functions as a repository for peer-reviewed systematic reviews based on the international evidence for myriad health topics. A keyword search on "tobacco" in the Cochrane library yields more than 2,200 
entries (53 entries in the Cochrane Database of Systematic Reviews, 35 reviews of other types, 2,037 entries in the Cochrane Central Register of Controlled Trials, 36 entries in the Cochrane Methodology Register, 13 entries in the Health Technology Assessment Database, and 94 entries in the National Health Service (U.K.) Economic Evaluation Database), which cumulatively summarize and integrate the evidence from many thousand individual studies conducted in countries and for time periods according to criteria for that review. (Search conducted on 6/6/2010 at [The Cochrane Collaboration])

Additionally, a sufficient body of scientific knowledge on the relative effectiveness of tobacco control policies is available to permit the development of at least two formal simulation models. SimSmoke, developed by the Pacific Institute for Research and Evaluation with David T. Levy, Ph.D. as the Senior Scientist, was originally developed with evidence from trials and studies conducted in the United States but more recently has been adapted for international application. [Pacific Institute for Research and Evaluation], [Levy, Cho, Kim, Park, Suh, \& Kam, 2010] SimSmoke uses smoking rates and smoking-attributable deaths as its primary endpoints and permits the projection of policy effectiveness (i.e., reduction in smoking rates) based upon characteristics of the population to whom the policy will be applied (e.g., baseline smoking rates, and relative proportions of gender, age, and ethnicity) as well as characteristics of the policy itself (e.g., duration of advertising campaign, magnitude of tax increase, etc.). An alternate simulation model, the Tobacco Policy Model with Tammy O. Tengs, Sc.D. as the principal developer, uses quality-adjusted life years (QALYs) as the primary endpoint. The Tobacco Policy Model uses U.S. census-based data (and demographic projections), stratified by both age and gender, to model the effects of reductions in smoking initiation, increases in cessation, and reductions in relapse in different age groups and genders on QALYs gained over a specified time period. [Tengs, Osgood, \& Lin, 2001] Because of the use of QALYs as the specified endpoint, projections from this model are necessarily pre-disposed to emphasize the importance of prevention of initiation in younger age-groups.

Tobacco control policies have been variously categorized, but are generally considered to have three principal objectives:

- Preventing smoking initiation in youth and adolescents and smoking entrenchment in young adults. Because the vast majority of smokers begin smoking as teenagers and the entrenchment of the habit and addiction to nicotine occurs between the ages of 18-24 years, policies that inhibit and 
otherwise prevent experimentation with smoking during high school are paramount, though success of these policies will not noticeably impact population smoking prevalence for as long as 15 years (smaller proportion of the larger population).

- Promoting smoking cessation in current smokers. Most studies suggest that approximately $75 \%$ of current smokers want to quit and, for most smokers, multiple quit attempts are needed before successful cessation is achieved (smokers report an average of 4.1 quit attempts and former smokers report an average of 6.1 quit attempts). [Jones, J M; Gallup, Inc., 2006] Thus, providing access to behavioral and pharmacologic-based efficacious cessation support treatments is key to averting the associated health and economic consequences of smoking, and immediately affecting population smoking prevalence. [Levy, Mabry, Graham, Orleans, \& Abrams, 2010]

- Protecting non-smokers from exposure to tobacco smoke or tobacco smoke particles. As the scientific evidence overwhelmingly supports, exposure to secondhand smoke also causes multiple, negative health effects. [U.S. Department of Health and Human Services, Office of the Surgeon General, 1986] Thus, the protection of non-smokers from involuntary exposure to environmental tobacco smoke with smoke-free air policies has become a fundamental element of tobacco control programs.

To achieve these policy objectives and counter tobacco industry activities, jurisdictions implement tobacco control policies broadly grouped as:

- Taxation. Excise taxes levied at the central (national) or state level based on either ad valorum (added to the price based as a percentage of the value) or flatrate formulas.

- Protection. Typically termed "clean air" policies, these groups of policies are designed to protect non-smokers from exposure to "involuntary" or "environmental" tobacco smoke.

- Education. Policies and programs designed to inform the public of the addictiveness and health consequences of smoking and, more recently, the actions of the tobacco industry.

- Regulation. Policies that affect the manufacture, sale, and distribution of tobacco products, including package labeling, requiring health warning labels, prohibition 
of product sales to minors, and restriction of advertising and promotional practices including event sponsorship and advertisements in magazines and on billboards.

- Cessation support. Individually-based interventions to help current smokers break their nicotine addiction and quit smoking is increasingly recognized as both a moral imperative as well as a practical necessity to immediately affect population smoking prevalence rates. [Levy, Mabry, Graham, Orleans, \& Abrams, 2010]

As discussed above, there is a substantial body of scientific evidence quantifying the effectiveness of various policies in different jurisdictions across time periods and demographic strata, though a complete summary of these studies is beyond the scope and purpose of the present study. For the purposes of the discussion here, the comparative, quantitative effectiveness of different policies will be summarized based on the foundation evidence for SimSmoke. [Levy, Chaloupka, \& Gitchell, 2004] As shown in Table 3-1, taxes and clean indoor air laws have the largest, consistent, and quantifiable effects on smoking prevalence when policies are considered as individual instruments.

Selection of policy instruments is influenced by the desired evaluation time frame. For example, a recent study using SimSmoke demonstrated that a policy goal of substantial, shortterm (3-5 years) reduction in smoking prevalence requires a mix of policies designed to increase the quit rates in adult smokers (as opposed to policies designed to reduce initiation rates in adolescents and young adults), including tax increases, media campaigns, and smoke free air policies and must also necessarily require substantial support for cessation programs. [Levy, Mabry, Graham, Orleans, \& Abrams, 2010] In contrast, consideration of benefit over a longer (generation) timeframe results in selection of policies with more emphasis on prevention of smoking initiation in adolescents (when most begin smoking) and smoking entrenchment in young adults, in whom cumulative life-long benefit will result in greater population QALYs. [Tengs, Osgood, \& Lin, 2001], [Tengs, Osgood, \& Chen, 2001] 
Table 3-1. Quantitative Estimates of the Effectiveness of Individual Tobacco Control Policy Instruments

\begin{tabular}{|c|c|c|}
\hline Policy Type & Quantitative Effectiveness & Summary of Evidence \\
\hline Cloon Jndoor Air I our & $\begin{array}{l}\text { - Starting at an assumed baseline of } \$ 4.00 \text {, a } \$ 1.00 \\
\text { price increase }(25 \%) \text { reduces smoking prevalence by } \\
7 \% \text { in } 3 \text { years, and by up to } 14 \% \text { over a longer time } \\
\text { period (as effects of marginally higher decreases in } \\
\text { prevalence in younger, more price-sensitive smokers } \\
\text { have a larger impact on estimates of population-wide } \\
\text { smoking prevalence ) }\end{array}$ & $\begin{array}{l}\text { Price elasticity estimates range from }-0.3 \text { to }-0.5 \\
\text { Price effects include lower initiation rates, higher } \\
\text { cessation rates, and lower consumption for those } \\
\text { continuing to smoke } \\
\text { Price elasticities are generally higher in adolescents } \\
\text { and young adults, and in lower income groups }\end{array}$ \\
\hline Clean Indoor Air Laws & $\begin{array}{l}\text { - Comprehensive bans, with strong enforcement and } \\
\text { media publicity, reduce smoking prevalence by } 11 \% \text {, } \\
\text { with } 7 \%-8 \% \text { attributable to worksite bans and } 2 \%-3 \% \\
\text { attributable to restaurant bans; partial bans are } \\
\text { estimated to be } 50 \% \text { as effective }\end{array}$ & $\begin{array}{l}\text { Bans protect non-smokers from harmful exposure, } \\
\text { reduce opportunities to smoke, and support smoke- } \\
\text { free social norms } \\
\text { States with comprehensive bans have } 5 \%-20 \% \text { lower } \\
\text { per capita consumption and } \approx 10 \% \text { lower prevalence } \\
\text { In companies, quit rates are } 10 \%-15 \% \text { higher in firms } \\
\text { with compared to those without bans }\end{array}$ \\
\hline Advertising Restrictions & $\begin{array}{l}\text { - Comprehensive advertising bans reduce prevalence } \\
\text { by } 4 \% \text { and initiation by } 6 \% \text {; partial bans reduce the } \\
\text { effectiveness to a } 2 \% \text { reduction in both initiation and } \\
\text { prevalence }\end{array}$ & $\begin{array}{l}\text { Advertising bans and restrictions reduce the } \\
\text { opportunities for tobacco companies to create } \\
\text { attractive and favorable images of smoking }\end{array}$ \\
\hline Product Labeling & $\begin{array}{l}\text { - Large, graphic warning labels may reduce smoking } \\
\text { prevalence by } 2 \% \text { and increase cessation rates by } \\
2 \%\end{array}$ & $\begin{array}{l}\text { Recall of the presence of content of text-based } \\
\text { warning labels is low; recall increases with more } \\
\text { prominent and graphic warning labels }\end{array}$ \\
\hline Mass Media Policies & $\begin{array}{l}\text { - Well-funded and long-term campaigns can reduce } \\
\text { prevalence by up to } 7 \% \text { when combined with other } \\
\text { policies } \\
\text { Youth-oriented campaigns can reduce youth } \\
\text { prevalence by } 6.5 \% \text { but have a smaller impact on } \\
\text { population-wide prevalence rates }\end{array}$ & $\begin{array}{l}\text { - } \quad \text { Media campaigns are more effective when combined } \\
\text { with other policies } \\
\text { - } \quad \text { Affectiveness depends upon scale and duration } \\
\text { and tested messages aimed at different } \\
\text { sociodemographic groups }\end{array}$ \\
\hline $\begin{array}{l}\text { School Education } \\
\text { Programs }\end{array}$ & $\begin{array}{l}\text { SimSmoke does not attribute any quantifiable effect } \\
\text { of school education programs on population smoking } \\
\text { prevalence }\end{array}$ & $\begin{array}{l}\text { Earlier school-based programs focused on educating } \\
\text { students about the harmful effects of smoking; more } \\
\text { recent programs use a life-skills approach educating } \\
\text { students on resisting smoking initiation as well as the } \\
\text { sociopolitical culture of tobacco use } \\
\text { - The CDC recommends school-based programs, } \\
\text { including "booster" programs, though evidence } \\
\text { regarding effectiveness is mixed }\end{array}$ \\
\hline Youth Access Enforcement & $\begin{array}{l}\text { Policies with strong enforcement, strict penalties, and } \\
\text { community support can reduce youth prevalence up } \\
\text { to } 25 \% \text {, but these effects can take up to } 15 \text { years to } \\
\text { be detected in adult prevalence rates }\end{array}$ & $\begin{array}{l}\text { - Many youth get tobacco from non-retail sources such } \\
\text { as the "black market", theft, older peers and siblings, } \\
\text { and parents } \\
\text { Effectiveness of strict access policies thus depend } \\
\text { upon the extent to which market sources are } \\
\text { substituted by non-market sources }\end{array}$ \\
\hline $\begin{array}{c}\text { Access to Cessation } \\
\text { Treatments }\end{array}$ & $\begin{array}{l}\text { - With broad treatment coverage, cessation programs } \\
\text { increase quit rates by } 25 \% \text { leading to a } 2 \% \text { reduction } \\
\text { in prevalence in } 5 \text { years and a } 3.5 \% \text { reduction in } \\
\text { prevalence in } 10 \text { years }\end{array}$ & $\begin{array}{l}\text { Access to insurance-covered cessation programs } \\
\text { increase their use, and use of cessation programs } \\
\text { double-to-quadruple success rates }\end{array}$ \\
\hline Telephone Quit Lines & $\begin{array}{l}\text { Telephone quit lines can be very effective for those } \\
\text { who call, but detectable population-wide effects are } \\
\text { minimal (participation is often }<5 \% \text { of all smokers) }\end{array}$ & $\begin{array}{l}\text { - Quit lines are convenient and, when used, evidence } \\
\text { supports effectiveness in all age groups and gender } \\
\text { Quit lines are most effective when advertised as part } \\
\text { of mass media campaign }\end{array}$ \\
\hline
\end{tabular}

Source: [Levy, Chaloupka, \& Gitchell, 2004]

\subsubsection{Comprehensive Tobacco Control and Tobacco Control Policy Regimes}

A comprehensive tobacco control program is one that consists of a combination of individual policy instruments. Specifically, comprehensive tobacco control policies simultaneously address multiple or all of the principal objectives (prevention of initiation, promotion of cessation, protection from secondhand smoke) with policy instruments from multiple or all of the broad policy groups (taxation, clean air policies, education, regulation, cessation support). For example, a jurisdiction's comprehensive tobacco control program might include: effective levels of taxation (balancing initiation prevention and cessation against smuggling incentives); public anti-tobacco education campaigns; implementation and enforcement of laws preventing youth access; restrictions on tobacco advertising; widespread adoption of smoke-free air laws; support for cessation programs, including training of healthcare 
professionals and access support for individuals; and school-based prevention programs. [Wakefield \& Chaloupka, 2000]

The evolution from a "comprehensive tobacco control program" to a "tobacco control policy regime" is subtle and rarely discussed in the public health literature, the regime construct being more familiar to the political science field. One such study, from the political science tradition, defines policy regimes as the cumulative policies and programs used by governments to control tobacco and identifies "hands-off", "low-control", "moderate-control", "high-control", and "prohibitionist" regimes. [Marmor \& Lieberman, 2004] However, in the operationalization of their definition and categorization of countries included in their study, the authors conflated several important policy distinctions made in the public health literature and used what the authors termed a "rough-and-ready three-point scale". [Marmor \& Lieberman, 2004] Still, it is entirely possible to develop a definition for a tobacco control policy regime by fusing the political science concept of the aggregate set of government policies and programs and the public health programmatic frameworks forwarded by the World Health Organization and the Centers for Disease Control and Prevention.

In 2008, the World Health Organization forwarded the MPOWER Package, a set of six, evidence-based policies (groups of policies) regarded as the requisite foundation to effectively counter the tobacco epidemic. [World Health Organization, 2008] MPOWER is the acronym for these groups of policies, which are described in Table 3-2. This report emphasizes the implementation and enforcement of these collective policies in order to prevent smoking initiation and entrenchment in adolescents and young adults, assist current smokers in cessation, and prevent exposure in non-smokers. The difference between "comprehensive policy" and the "policy regime" advanced in the MPOWER Package is the inclusion of surveillance and monitoring and the expectation for the simultaneous implementation of all policies in the MPOWER framework. The 2008 report also highlighted, though briefly, the underfunding of tobacco control programs both in personnel and the financing of program activities. The report estimated that for countries reporting data $(n=89), 95 \%$ of global tobacco control spending was done in high-income countries and that global tobacco tax revenues exceeded by 500 -times spending on tobacco control activities. Further, while $74 \%$ of the countries submitting data $(n=174)$ reported a national tobacco control agency, of the 86 countries submitting staffing data, $55 \%$ of the 604 total, global staff were in six high-income countries resulting in an average of 3.4 full-time equivalent staff in $93 \%$ of the countries. This underfunding, including the large disparity between high- and low-income countries, was again 
Table 3-2. Summary of Policies in the MPOWER Package

\begin{tabular}{|c|c|c|}
\hline Component & Definition & Description \\
\hline $\bar{M}$ & $\begin{array}{c}\text { "Monitor tobacco use and prevention } \\
\text { policies" }\end{array}$ & $\begin{array}{l}\text { Track several indicators prevalence, impact of policy interventions, and } \\
\text { tobacco industry activity (marketing, promotion, lobbying) } \\
\text { Data on prevalence and program effectiveness should be available based } \\
\text { on age, gender, race and geographic jurisdictions } \\
\text { - Effective dissemination of findings from surveillance and monitoring } \\
\text { programs }\end{array}$ \\
\hline$P$ & "Protect people from tobacco smoke" & $\begin{array}{l}\text { - Complete ban on all indoor smoking (no "designated" indoor smoking } \\
\text { areas) } \\
\text { - Strong enforcement of bans, including strong penalties for violations } \\
\text { Bans are most effectively implemented in conjunction with mass media } \\
\text { campaigns }\end{array}$ \\
\hline $\mathrm{O}$ & "Offer help to quit tobacco use" & $\begin{array}{l}\text { - Substantial and meaningful access to evidence-based, culturally } \\
\text { appropriate cessation programs for the estimated } 3 / 4 \text { current smokers } \\
\text { wishing to quit } \\
\text { Three-pronged approach to cessation support includes incorporation into } \\
\text { primary care (thus must include training and support for primary healthcare } \\
\text { workers), well-staffed and well advertised quit lines, and availability of low } \\
\text { cost pharmacologic therapy to treat nicotine addiction (nicotine } \\
\text { replacement therapy) }\end{array}$ \\
\hline W & "Warn about the dangers of tobacco" & $\begin{array}{l}\text { Anti-tobacco media and educational campaigns conducted by the } \\
\text { government or NGOs to warn of the health hazards and addictiveness of } \\
\text { tobacco use and support a socially unacceptable and negative image for } \\
\text { tobacco use (campaigns conducted by the tobacco industry have been } \\
\text { shown to be ineffective or to increase tobacco use) } \\
\text { Use of large, graphic warning labels on packages and advertising, which } \\
\text { are more effective than text-only warnings }\end{array}$ \\
\hline $\mathrm{E}$ & $\begin{array}{l}\text { "Enforce bans on tobacco advertising, } \\
\text { promotion, and sponsorship" }\end{array}$ & $\begin{array}{l}\text { - Comprehensive ban on advertising in all media formats and promotion for } \\
\text { any event and at point-of-sale } \\
\text { - Strict and strong enforcement, particularly of activities aimed at } \\
\text { adolescents and young adults }\end{array}$ \\
\hline $\mathrm{R}$ & "Raise taxes on tobacco" & $\begin{array}{l}\text { - Product-specific excise tax (i.e., in addition to any value-added tax that } \\
\text { applies to broad categories of goods) that is both strictly enforced and } \\
\text { regularly adjusted for inflation } \\
\text { To avoid "substitution effects", all tobacco products should be taxed } \\
\text { similarly }\end{array}$ \\
\hline
\end{tabular}

Source: [World Health Organization, 2008]

discussed in the 2009 report along with stronger recommendations for the structure of centrallevel tobacco control programs, though the report did not make minimum funding or staffing recommendations. [World Health Organization, 2009]

The MPOWER Package from the World Health Organization had a global perspective and focused its analysis and recommendations at central-level governments. In contrast, the C.D.C.'s National Tobacco Control Program, originally developed in 1999 but revised multiple times since, forwards a multi-level approach that includes activities at the central-, state-, and local-level jurisdictions. [Centers for Disease Control and Prevention, 2010], [Wisotzky, Albuquerque, Pechacek, \& Park, 2004] The C.D.C. has also published a series of three "best practices" reports to disseminate the rationale and implementation for this national program: Best Practices for Comprehensive Tobacco Control Programs, Best Practices User Guide: Coalitions - State and Community Intervention, and Best Practices User Guide: Youth Engagement - State and Community Intervention. [Centers for Disease Control and Prevention, 2007], [Centers for Disease Control and Prevention, 2007], [Centers for Disease Control and Prevention, 2010] 
Considered integratively and collectively, the C.D.C.'s framework is premised on a central-level agency that develops and supports a state- and community-level infrastructure developed around coalition networks; it is these coalition networks that are the programmatic functional units of the tobacco control policy regime. Compared to the MPOWER framework, the C.D.C.'s recommendations are far more prescriptive regarding the structure, content, and programmatic activities of these networks. Further, the C.D.C. makes explicit recommendations for structural and programmatic funding levels for the overall and each component of the policy regime, estimated using formulas developed and made publicly available by the C.D.C., that account for: overall population demographics and demographic strata; smoking prevalence; population socioeconomic factors such as proportion living near the poverty level, education level, and the proportion receiving publicly subsidized health insurance; geographic size; the number of local health units; infrastructure costs such as cost of living and labor costs; and the cost and complexity of conducting programs (e.g., mass media campaigns) to reach target populations (e.g., youth, racial minorities). As forwarded by the C.D.C., the four goals for a tobacco control policy regime are the prevention of tobacco use initiation in adolescents and young adults, the promotion and support for cessation among current smokers, the protection and eventual elimination from exposure to secondhand smoke, and the identification and elimination of tobacco-related disparities in the population, all of which are achieved through state and community interventions, health communication interventions, cessation interventions, surveillance and evaluation, and administration and management. [Centers for Disease Control and Prevention, 2007] The C.D.C. has recently published a standard for central - and statelevel surveillance and evaluation programs based on the MPOWER framework, complete with suggested metrics (summarized in Table 3-3) for each activity area. [Centers for Disease Control and Prevention, 2010]

Table 3-3. CDC-Recommended Surveillance and Evaluation Metrics Based on MPOWER Framework

\begin{tabular}{|cll|}
\hline Component & \multicolumn{1}{c|}{ Recommended Metrics } \\
\hline "Monitor tobacco use and prevention & - & \multicolumn{1}{c|}{ Current smoking among adults } \\
policies" & - Past month cigarette use among youth \\
"Protect people from tobacco smoke" & - Smoking-attributable adult mortality \\
& - State smoke-free policy \\
"Offer help to quit tobacco use" & - Percent of smokers calling Quitline \\
& - Medicaid coverage for counseling and medications \\
"Warn about the dangers of tobacco" & - Households with no-smoking rules \\
& - Tobacco counter-marketing media intensity \\
"Enforce bans on tobacco advertising, & - State allows local advertising and promotion laws (no preemption) \\
promotion, and sponsorship" & - Retail environment tobacco licensure \\
"Raise taxes on tobacco" & - Amount of cigarette excise tax \\
& - Minimum price law \\
&
\end{tabular}

Source: (Centers for Disease Control and Prevention, 2010) 
So, while the specifics of the C.D.C.'s National Tobacco Control Program and its subsequent implementation recommendations have clearly been developed for and tailored to the United States, the substance of these programs and recommendations are not without substantial generalizability to jurisdictions beyond the United States. Further, these

\section{Table 3-4. Tobacco Control Policy Regime Components}

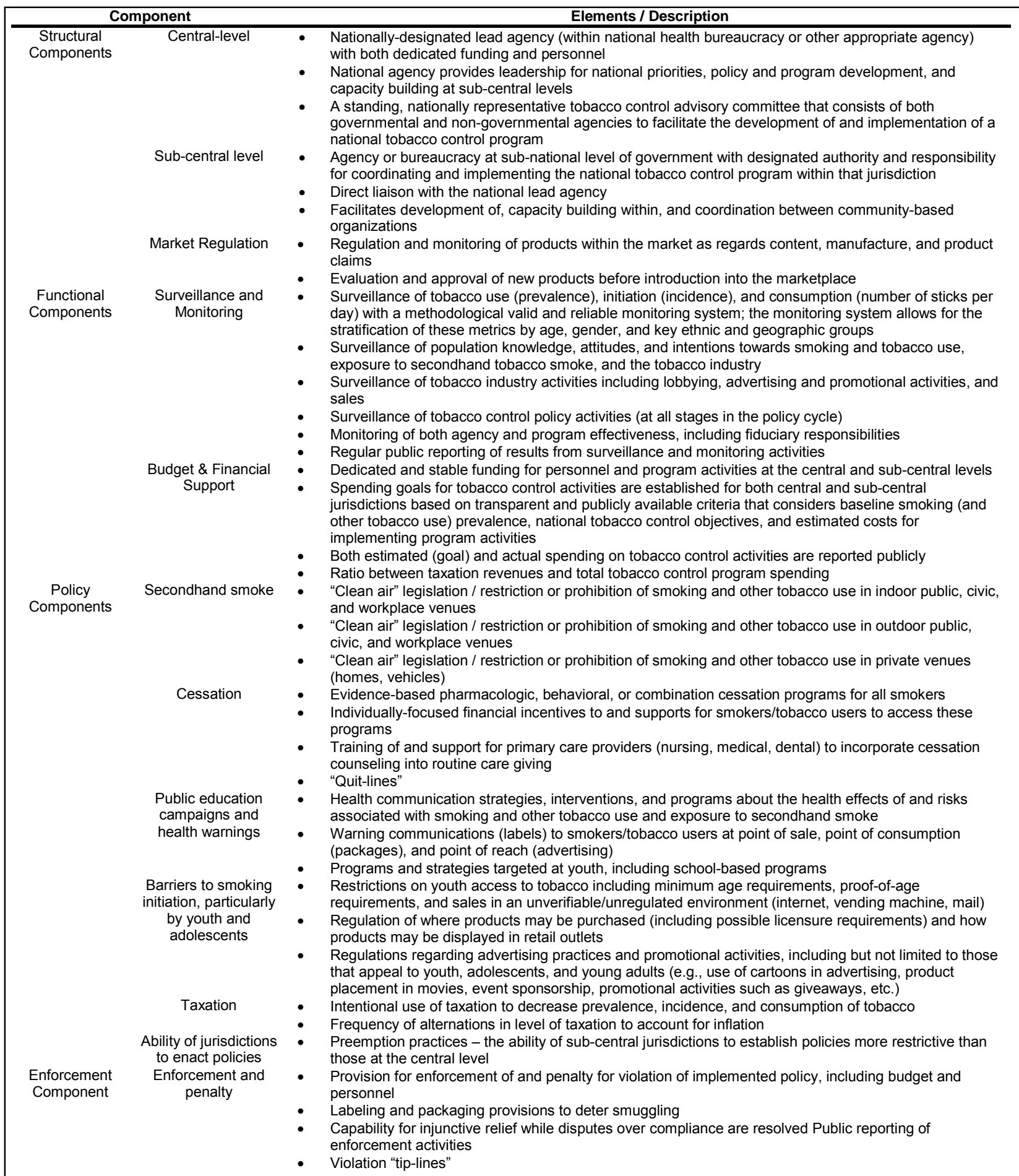


recommendations both complement and build upon the MPOWER framework. What emerges, then, as a definition for a "tobacco control policy regime" is the orientation of a jurisdiction's cumulative policy activity regarding the reduction and elimination of tobacco-attributable disease and death in the population within that jurisdiction. The components to be considered when determining the type of tobacco control policy regime in a given jurisdiction at a given point in time are summarized in Table 3-4. These components are advanced based on a synthesis of the World Health Organization's MPOWER Package and supporting materials, as well as the C.D.C.'s National Tobacco Control Program and supporting materials. Thus, these components are an amalgamation of the structural and policy best practices from these organizations. As is seen in this table, the important distinction between "comprehensive tobacco policy" and a "tobacco control policy regime" is the consideration of the structural elements including central leadership, sub-central networks, and the support for policies and programs such as budgeting and surveillance and evaluation. The intent of identifying these criteria is not to define, in a dichotomous manner, whether a jurisdiction does or does not have a tobacco control policy regime, but rather to identify the dimensions to consider when characterizing the nature of the tobacco control policy regime in a given jurisdiction at a given point in time. Ideally, the nature of a jurisdiction's tobacco control policy regime can be differentiated along a meaningful continuum, implying the need for scaling and measurement. The quantification of tobacco control policy regimes is discussed in the next section.

\subsubsection{Quantifying Tobacco Control Policy Regimes}

As the policy solutions to combating the tobacco epidemic have evolved from single policy instruments to a set of policy instruments (comprehensive tobacco control policy) to multiple policy instruments supported by an infrastructure that includes personnel, financial, and surveillance and evaluation (tobacco control policy regime), a parallel problem of the measurement and characterization of these policy regime configurations has also emerged. From an administrative and research perspective, the ability to meaningfully discriminate between such different policy regime configurations across different jurisdictions and time periods requires a quantification methodology. The approach in reports and studies to date that have characterized or needed to quantify policy regime configurations has typically been one of three possible solutions. In the first approach, a list of policy elements is generated and jurisdictions are then evaluated with a series of dichotomous (yes/no or checkmarks) or nominal (e.g., no/minimal/moderate/complete) scores for each of the policy criteria. These analyses thus approximate a compendium of a jurisdiction's status (or that for multiple jurisdictions) on a 
catalog of policy elements and, while some policy elements such as taxation lend themselves to quantification, the evaluation of most policy elements is categorical. [Centers for Disease Control and Prevention, 2010], [World Health Organization, 2008], [World Health Organization, 2009] Consequently, the consideration of individual policy elements in this approach means that a single, cumulative score for an "overall" comparison remains elusive. Additionally, the set of and definitions for the individual policy elements considered are rarely consistent across reports or over time, making comparisons difficult. In the second approach, a grouping or grading system is created that accounts for the cumulative set of policy instruments which categorizes jurisdictions into similar groups or assigns a report-card-like grade. [Marmor \& Lieberman, 2004], [American Lung Association, 2009] However, while this approach considers the cumulative set of policy instruments and thus attempts to differentiate between policy regimes, the methodology is typically study/report-specific and so the rigor and generalizability of the grouping methodology is unclear. Further, because the grouping or grading system remains categorical in nature, statistical analyses are limited to those accommodating such categorical variables and thus comparisons across time and jurisdictions are again difficult. In the third approach, an attempt to establish interval quantification of policy regime configurations is made by developing a policy score. [Joossens \& Raw, 2006], [Studlar, Christensen, \& Frisbee, 2009], [Studlar, Christensen, \& Sitasari, 2011] While some analytic utility is gained for that study, the scoring methodology is typically not rigorous, and the inclusion of policy elements as well as the definition, point assignment, and weighting for policy elements varies between studies. Thus, the challenge for all three of these commonly employed approaches is that comparison across and between studies and reports is very limited due to non-standardized approaches to the inclusion of policy elements, data sources, and scoring and weighting of policy elements.

Within the existing literature, four attempts have been made to develop a standardized policy scoring system: the Assessment of the Comprehensiveness of Tobacco Control Laws Scale (A.C.T.-L.) [Klonoff, et al., 1998], the Measuring Activities of Tobacco Control (M.A.To.C.) score [Thyrian \& John, 2006], the Tobacco Control Scale (T.C.S.) [Joossens \& Raw, 2006], and a rating systems for youth access to tobacco laws in U.S. states [Alciati, et al., 1998], though these scores have not been widely applied or cited. The A.C.T.-L. is a 55-item questionnaire designed to score city- and county-level anti-smoking ordinances, and the score has environmental tobacco, advertising, and youth access subscales. The methodologic development of the A.C.T.-L. was reported in the original study, including the validity and 
reliability, though the score was not applied to specific jurisdictions. [Klonoff, et al., 1998] Also, the original report has only been cited by three other studies in PubMed, one of which was a non-tobacco study and a second was the study developing the M.A.To.C. score, and the score itself has not been applied in a study indexed in PubMed. The M.A.To.C. score consists of the self-reported (by country experts) responses to a series of thirty questions, also identified and developed by a group of experts, and the original study reported the results of the application of the score to fourteen European countries. [Thyrian \& John, 2006] The M.A.To.C. score has been cited by two other studies in PubMed, one of which applied the reported M.A.To.C. scores in subsequent analysis. [Thyrian \& John, 2006] Finally, the T.C.S. score is a country-based expert survey, developed based on expert opinion as to policy element content and weighting, with an overall score (a total of 100 points) and sub-scale scores for price, public place bans, spending on public information campaigns, advertising bans, package health warnings, and cessation treatment. [Joossens \& Raw, 2006] The original report, in addition to reporting the methodology for the score development, also reported the T.C.S. scores for thirty European countries based on surveys administered in 2005 and there has been a subsequent report that updated these 2005 country-based scores. [Joosens \& Raw, 2008] The T.C.S. has been cited by nine other studies indexed in PubMed, one of which applied the reported TCS scores in subsequent analysis and was the same study which also cited the M.A.To.C. score. [Thyrian, Panagiotakos, Polychronopoulos, West, Zatonski, \& John, 2008] Finally, a rating system was developed to score states on youth access laws using statutes compiled in the National Cancer Institute's State Cancer Legislative Database (S.C.L.D.) which was comprised of a score based on a five-point rating of nine different youth access-oriented policy elements. [Alciati, et al., 1998] However, it is unclear that this ranking system has been applied outside this National Cancer Institute database. For both the M.A.To.C. and T.C.S. scores, the use of non-public datasets (i.e., the use of self-report surveys of selected country experts administered by the authors of the study) has substantially limited the applicability of the score by other researchers to other jurisdictions or time periods, and the reliance on country-based expert self-reporting raises concerns about score reliability when there is a personnel change in those country-based experts.

Thus, there remains a large gap and need in the literature. The absence of a theoretically rigorous and statistically valid and reliable mechanism to quantify the nature of a jurisdiction's tobacco control policy regime at a given time point has undoubtedly impeded the conduct of both temporal and comparative studies. So, while such a quantification method - a 
score - does not yet exist, it is possible to identify at least some of the ideal criteria for such a score. Accordingly, it is forwarded that an ideal score would have the following characteristics:

- Be applicable to both research and administrative (e.g., public health agencies, health advocacy groups) settings;

- Have both a transparent and publicly available scoring system, and be based on publicly available data so that researchers and agencies alike could apply the score across jurisdictions and time periods;

- Be applicable to different types of jurisdictions with equal validity and reliability (e.g., a country, a state or province, or a county or city), implying that the selection of and definitions for content (policy elements) would need to be meaningful both across jurisdictions and time;

- While being theoretically, methodologically, and statistically sound, also be feasible and reasonable to implement and track in a wide variety of settings and jurisdictions;

- Have both a total score, and sub-scale scores for key areas of interest such as advertising and youth smoking, among others

- Selection of content (policy elements) be theoretically based, as well as the scoring and weighting system.

For any scoring system, the simultaneous achievement of these criteria will not be without substantial challenge, in particular the last criteria of a theoretic foundation for both content and weighting. Whereas much of the evidence for policy effectiveness has been gathered from studies of individual policies, much less is understood about interaction effects between individual policy elements, [Levy, Bauer, \& Hye-ryeon, 2006] and the directionality of the causal relationship between policy and population health outcome (prevalence), particularly as regards temporality, is also ambiguous. [Marmor \& Lieberman, 2004] Regardless and despite these challenges, development of a method to validly and reliably quantitatively characterize the nature of a tobacco control policy regime remains both a significant need in the field and an area suitable for research and development.

\subsubsection{Evidence of the Effectiveness of State-Level Tobacco Control Policy Regimes}

In industrialized countries, where the investment has been made in policy development and adoption as well as well as the personnel and surveillance and evaluation to support population tobacco control programs, it is consistent with the above discussion to consider these states to have a tobacco control policy regime. Thus, comparative evaluations can be conducted to 
assess the relative effectiveness of these policy regimes. Within the United States, because each state administers its own tobacco control program (as discussed previously, with funding and coordination through the N.T.C.P. at the C.D.C. and additional funding from state M.S.A. settlement agreements as well as taxation) and the role of the U.S. central government has been comparatively sluggish, each state can be considered to have its own tobacco control policy regime thus permitting between-state comparative studies comparing features of either the state tobacco control programs and / or adopted policies and measures of state population health (e.g., smoking prevalence).

In the United States, California (1989) followed by Massachusetts (1993), Arizona (1994), Oregon (1996), and Florida (1997) were the first states to implement state-level tobacco control programs. [Siegel, 2002], [Wakefield \& Chaloupka, 2000] Several reports, using case-study methodology, have reported on the results from individual state-level programs, particularly results for the "early adopters" - California, Massachusetts, Arizona, Oregon, and Florida. In a review of published reports (scientific, peer-reviewed studies as well as state-issued reports), one study concluded that despite differences in program strategies and approaches, the statelevel programs were associated with a decline in adult smoking prevalence as well as a change in the "factors" influencing teen smoking. [Wakefield \& Chaloupka, 2000] In a review of the California and Massachusetts programs, another study reported a reduction in cigarette consumption but no measureable impact on smoking initiation by adolescents. [Siegel \& Biener, 1997] In a follow-up study evaluating the California, Massachusetts, Arizona, Oregon, and Florida programs, the same research group concluded that these state-level programs could be very effective in improving population health but that results were highly contingent upon sustained, adequate funding and the intensity and aggressiveness of program activities. [Siegel, 2002] Finally, in a more recent review of case study reports of the California, Massachusetts, Florida, and Sydney/Melbourne (Australia) tobacco control programs, the author concluded that there was strong evidence to support the effectiveness of these state-level programs, though the author noted the challenges of accounting for wide variation in program funding over time. [Pierce, 2007]

Population-based analyses have also been undertaken. In a study applying the S.C.L.D. score (described above, [Alciati, et al., 1998]), scores calculated quantifying state-level youth access-focused policies in 1996 were found to correlate to the state tobacco excise tax (positive), the proportion of the state living in rural areas (negative), leadership in the state legislature (negative for Republican-controlled houses), and the prevalence of teen smoking in 
1997 as estimated by C.D.C.'s Youth Behavioral Risk Factor Survey (Y.R.B.S.). [Luke, Stamatakis, \& Brownson, 2000] In another study using youth smoking prevalence estimates from the Monitoring the Futures Project collected as part of the Institute for Social Research at the University of Michigan, state-level per capita tobacco control expenditures were found to be negatively associated with smoking prevalence and consumption. [Tauras, et al., 2005] In a study using a quasi-experimental design, similar results were reported in adults: per capita expenditures on state-level tobacco control programs were negatively associated with adult smoking prevalence. [Farrelly, Pechacek, Thomas, \& Nelson, 2008] Finally, in another study utilizing data from the Monitoring the Futures Project, cigarette price was found to be positively associated with cessation in teens as were youth access laws. [Tworek, et al., 2010]

The body of literature quantitatively documenting the effectiveness of these state-level tobacco control programs (policy regimes) is not as robust and the results have been, as other studies have acknowledged [Tworek, et al., 2010], more equivocal than perhaps anticipated. This likely has myriad explanations, including the underdevelopment of both the technical aspects as well as the theoretical underpinnings of these studies. As discussed previously, inclusion of the policy elements within the tobacco control programs is based on the effectiveness of these policies typically established in single-intervention trials and little is understood about either the interactions between individual policy elements or the temporal relationships between policy and a population health outcome. Moreover, and also discussed in the Introduction, in these studies the directionally in the causal association is typically assumed to be from policy to health outcome when, in fact, that may not be accurate - or at least an oversimplification. [Marmor \& Lieberman, 2004] Further, because a validated quantification method for characterizing tobacco control policy regimes is not available (discussed above), these studies typically treat all state tobacco control programs similarly ("yes/no" or "yes/no" to a series of specific policy elements), or per capita spending is substituted as a measure of policy comprehensiveness or vigor. That is, assessment of these state-level programs has generally not distinguished between policy adoption and aspects of implementation, spending and programmatic activities, or other aspects of programmatic activities such as intensity, aggressiveness, or structural characteristics or functional capacity. While statistical techniques such as network analysis are now being applied to the evaluation of the organizational characteristics of state-level tobacco control programs and networks of the associated community-based coalitions [Krauss, Meuller, \& Luke, 2004], [Harris, Luke, Burke, \& Meuller, 2008] these analyses and the results from them are still nascent. Thus, substantial scholarship 
remains to develop more rigorous assessment methodologies for these state-level tobacco control programs so as to elucidate the most effective program structures and processes to elicit the best population health outcomes.

\subsubsection{International Cooperative Efforts to Enact Tobacco Control Policies}

While the gradual decline in smoking prevalence in industrialized countries has resulted in shrinking markets for tobacco companies (though not profitability), global trade liberalization, the collapse of the U.S.S.R. and dissolution of the Soviet bloc, economic unification in Europe (European Union), and global trade agreements have resulted in the opening of new markets for tobacco companies, and transnational tobacco companies have capitalized on these new market opportunities. [Collin, Lee, \& Bissell, 2002] As discussed in the Introduction, while tobacco consumption has decreased by approximately $50 \%$ in the last $20-30$ years in countries such as the United States, the United Kingdom, and Canada, both prevalence and consumption have increased substantially in developing countries such that these countries now account for $80 \%$ of global smokers. [Jha, 2009] Further, whereas nearly $70 \%$ of the 100 million tobaccorelated deaths in the $20^{\text {th }}$ century occurred in high-income countries, it has been forecast that $70 \%$ of the projected 1 billion tobacco-related deaths in the $21^{\text {st }}$ century will occur in low- and middle-income countries. [Jha, 2009] Tobacco companies have aggressively pursued the emerging markets in these developing countries. For example, research using tobacco industry documents on the activities of transnational tobacco companies in central and eastern European countries shortly after the collapse of the communist regimes has reported evidence for tactics such as an explosion of advertising, often targeted at women and children, in societies previously unaccustomed to the promotion of consumer goods and often without existing tobacco control policies or the capacity to quickly implement such policies. [Zatonski, 2003], [Lipand, 2007], [Szilagyi, 2006] Such evidence has resulted in a clear recognition that coordinated global tobacco control efforts are needed to counter a sophisticated, global tobacco industry.

Such international tobacco control efforts began as early as the 1960s. Specifically, the $19671^{\text {st }}$ World Conference on Tobacco or Health (W.C.T.O.H.) held in New York City, NY is often considered the inaugural event in a formal, global tobacco control effort. These World Conferences have been held triennially since 1967, hosted by different countries worldwide. The purpose of these international forums has been and remains the facilitation of policy learning and diffusion, particularly by creating the structure (networks) through which such learning and diffusion can occur, and the promotion and dissemination of globally-focused 
research and evidence on epidemiology, tobacco industry activities, and policy effectiveness. While other international forums have developed since the first W.C.T.O.H., such as the AsiaPacific Conferences on Tobacco or Health (A.Pa.C.T.), the European Conferences on Tobacco or Health (E.C.To.H.), the Society for Research on Nicotine and Tobacco (S.R.N.T.), and the World Cancer Congress (U.I.C.C.), the W.C.T.O.H. remains the preeminent international meeting for tobacco control. Further, while facilitation of policy implementation to combat the tobacco control epidemic in industrialized countries was the focus of early conferences, expansion to include efforts to facilitate such policy implementation in low- and middle-income countries has occurred over time. As forwarded previously (Introduction), truncating or averting stages of the tobacco epidemic in developing countries has evolved to become the implicit, primary objective of international tobacco control policy efforts. Despite the challenges in organizing and hosting these conferences, not limited to funding, logistics, and industry attempts to undermine the conferences [Muggll \& Hurt, 2003], several global initiatives have developed as a result of these conferences, the Framework Convention on Tobacco Control chief among them.

The World Health Organization's Framework Convention on Tobacco Control (F.C.T.C.) was initially conceptualized in the 1990s by a small group of American academic researchers and public health advocates, with very early support from Health Canada, and was proposed as a resolution at the $9^{\text {th }}$ World Conference on Tobacco or Health in Paris in October 1994 and again at the World Health Organization's World Health Assembly in 1996. [Roemer, Taylor, \& Lariviere, 2005] The process from the initial proposal of using the constitutional authority of the World Health Organization to develop a legally binding treaty to the formal adoption of the F.C.T.C. spanned almost a decade and consisted of multiple working groups, intergovernmental negotiating bodies, draft resolutions, and negotiations and revisions to these draft resolutions. [World Heath Organization, 2010], [Warner, 2008] The F.C.T.C. was adopted by the World Health Assembly in May 2003 and came into effect in February 2005. The Convention had 168 signatories (signed before June 29,2004 ) representing $91.8 \%$ of the world's population, and currently has 169 parties (countries legally bound to enact the provisions of the F.C.T.C.; signatory countries through domestic ratification, and non-signatory countries through accession or succession) representing $86.6 \%$ of the world's population, and 183 participants (signatories and / or parties) representing $94.89 \%$ of the world's population. [Framework Convention Alliance, 2010] Of the original 168 signatory countries, fourteen have not yet ratified the treaty (notably, the United States being one of these countries) and of the parties to the Framework, 
fifteen were not original signatories (i.e., became party to the Framework through accession $(n=14)$ or succession $(n=1))$. [Framework Convention Alliance, 2010]

As stated in Article 3 of the F.C.T.C., the objective of the Convention is:

"The objective of this Convention and its protocols is to protect present and future generations from the devastating health, social, environmental and economic consequences of tobacco consumption and exposure to tobacco smoke by providing a framework for tobacco control measures to be implemented by the Parties at the national, regional and international levels in order to reduce continually and substantially the prevalence of tobacco use and exposure to tobacco smoke."

From: [World Health Organization, 2003]

A complete list of the Articles of the Convention is outlined is Table 3-5. As evidenced from this list, the major content areas to be addressed by F.C.T.C. include: measures to reduce the demand for tobacco, including taxation, education and public awareness, and advertising and package labeling; measures to reduce youth access to tobacco; global strategies to counteract smuggling; and elimination of exposure to secondhand smoke. 
Table 3-5. Articles of the Framework Convention on Tobacco Control

\begin{tabular}{|c|c|}
\hline \multicolumn{2}{|l|}{ I: Introduction } \\
\hline Article 1 & Use of Terms \\
\hline Article 2 & $\begin{array}{l}\text { Relationship between this Convention and other agreements and legal } \\
\text { instruments }\end{array}$ \\
\hline \multicolumn{2}{|c|}{ II: Objective, guiding principles and general obligations } \\
\hline Article 3 & Objective \\
\hline Article 4 & Guiding Principles \\
\hline Article 5 & General Obligations \\
\hline \multicolumn{2}{|c|}{ III: Measures relating to the reduction of demand for tobacco } \\
\hline Article 6 & Price and tax measures to reduce the demand for tobacco \\
\hline Article 7 & Non-price measures to reduce the demand for tobacco \\
\hline Article 8 & Protection from exposure to tobacco smoke \\
\hline Article 9 & Regulation of the contents of tobacco products \\
\hline Article 10 & Regulation of tobacco products disclosure \\
\hline Article 11 & Packaging and labeling of tobacco products \\
\hline Article 12 & Education, communication, training and public awareness \\
\hline Article 13 & Tobacco advertising, promotion and sponsorship \\
\hline Article 14 & Demand reduction measures concerning tobacco dependence and cessation \\
\hline \multicolumn{2}{|c|}{ IV: Measures relating to the reduction of the supply of tobacco } \\
\hline Article 15 & Illicit trade in tobacco products \\
\hline Article 16 & Sales to and by minors \\
\hline Article $17^{*}$ & Provision of support for economically viable alternative activities \\
\hline \multicolumn{2}{|l|}{ V: Protection of the environment } \\
\hline Article 18 & Protection of the environment and health of persons \\
\hline \multicolumn{2}{|l|}{ VI: Questions related to liability } \\
\hline Article 19 & Liability \\
\hline \multicolumn{2}{|c|}{ VII: Scientific and technical cooperation and communication of information } \\
\hline Article 20 & Research, surveillance and exchange of information \\
\hline Article 21 & Reporting and exchange of information \\
\hline Article 22 & $\begin{array}{l}\text { Cooperation in the scientific, technical and legal fields and provision of related } \\
\text { expertise }\end{array}$ \\
\hline \multicolumn{2}{|c|}{ VIII: Institutional arrangements and financial resources } \\
\hline Article 23 & Conference of the Parties \\
\hline Articles 24 & Secretariat \\
\hline Articles 25 & $\begin{array}{l}\text { Relations between the Conference of the Parties and intergovernmental } \\
\text { organizations }\end{array}$ \\
\hline Article 26 & Financial resources \\
\hline \multicolumn{2}{|l|}{ IX: Settlement of disputes } \\
\hline Article 27 & Settlement of disputes \\
\hline \multicolumn{2}{|c|}{ X: Development of the Convention } \\
\hline Article 28 & Amendments to this Convention \\
\hline Article 29 & Adoption and amendment of annexes to this Convention \\
\hline \multicolumn{2}{|l|}{ XI: Final Provisions } \\
\hline Article 30 & Reservations \\
\hline Article 31 & Withdrawal \\
\hline Article 32 & Right to vote \\
\hline Article 33 & Protocols \\
\hline Article 34 & Signature \\
\hline Article 35 & Ratification, acceptance, approval, formal confirmation or accession \\
\hline Article 36 & Entry into force \\
\hline Article 37 & Depositary \\
\hline Article 38 & Authentic texts \\
\hline
\end{tabular}

Source: [World Health Organization, 2003]

The first global initiative to address a non-communicable disease, the F.C.T.C. is often referenced as the first global health treaty, though it is actually not a treaty (an instrument explicit in its terms and required actions at the time of approval) but a framework convention (an instrument that identifies the overall objectives and specific content areas to be addressed and the process for developing the specific protocols for implementation after approval). [Warner, 
2008] That is, by becoming party to the Convention, countries agreed to participate in the negotiation process and to implement the protocols developed and agreed to as part of that negotiation process. The negotiation and protocol approval process is conducted under the auspices of the Conference of the Parties (C.O.P.), a body created by the F.C.T.C. itself and of which all parties to the F.C.T.C. are members with voting privileges, which has the authority to conduct and oversee the proscribed negotiations as well as adopt protocols and annexes to the Convention. [Warner, 2008] The F.C.T.C. in general, and the negotiation and protocol adoption process specifically, is also supported by groups such as the Framework Convention Alliance, a group of non-governmental organizations and health advocacy groups that has provided technical and other support to the F.C.T.C. from a very early stage in the process. [Warner, 2008] To date, the C.O.P. has approved guidelines for Articles 5.3, 8, 11, and 13 and has active work groups creating guidelines for implementation for Articles 9, 10, 12, 14, 17, and 18. [World Health Organization, 2010] The intent for the Article guidelines is that they form a "minimum standard" for tobacco control legislation which party countries must enact domestically.

Because of the format as a framework convention rather than a treaty, the adoption of the F.C.T.C. by the World Health Organization in 2003 signified the end of one series of complex negotiations and the beginning of another series of international negotiations to establish the specific terms and protocols for global tobacco control. As one would anticipate in a process with 168-183 countries each with specific circumstances and interests, the negotiation of the F.C.T.C. and the subsequent protocols and guidelines, domestic ratification, and implementation of domestic policy has been a complex and challenging process with many obstacles. In the consensus-based negotiations of the F.C.T.C., multiple studies have reported on the ability of individual countries to weaken or otherwise influence the requirements of the Articles. Of particular note have been studies of Japan's actions to weaken F.C.T.C. language [Assunta \& Chapman, 2005], and allusions to obstreperous tactics on the part of the United States and attempts to unduly influence final Convention language. [Warner, 2008], [Collin, Lee, \& Bissell, 2002] The World Health Organization has also not been without criticism, particularly stemming from perceived insufficient conflict of interest standards that have been manipulated and used advantageously by the tobacco industry. [Godlee, 2000]

Predictably, the tobacco industry has been incontestably opposed to the F.C.T.C. and numerous studies have documented industry tactics to undermine, weaken, and otherwise impede F.C.T.C. negotiations, development of Convention guidelines, and implementation of 
domestic policies in party countries. The reported tactics to impede the development of the F.C.T.C. have included: lobbying and pressuring countries to either not participate in negotiations or advocating to weaken Convention Articles; advocating for an agreement based on voluntary codes of conduct rather than regulation; threatening to withdraw support for domestic government programs if countries participated (this tactic was particularly employed in developing countries, including those emerging from post-Soviet regimes, where transnational tobacco companies often contributed financially to, e.g., health and education budgets as a means of exerting influence); refusing to comply with implemented regulations; implicitly supporting smuggling; and exploitation of the negotiation process so as to impede progress. [Collin, Lee, \& Bissell, 2002] Studies have also reported on "Project Cerberus", an effort by British American Tobacco, Philip Morris, and Japan Tobacco International between 1999-2001, to develop, propose, and advocate for a global voluntary regulatory code so as to make the F.C.T.C. unnecessary. [Mamudu, Hammond, \& Glantz, 2008] Tobacco industry tactics have also included a particular focus on creating and / or exploiting economic fears in countries with a domestic tobacco agricultural sector or those which rely on tobacco industry contributions to domestic (non-tobacco) programs. To accomplish this, analysis of tobacco industry documents have reported on attempts to undermine economic impact estimates by the World Bank by commissioning industry-sponsored reports and studies [Mamudu, Hammond, \& Glantz, 2008] and creating economic fears by producing and distributing projections for the job and economic losses attributable to implementing the F.C.T.C. or other domestic tobacco control measures. [Otanez, Mamudu, \& Glantz, 2009] In the European Union and the United Kingdom, studies have also reported that the tobacco industry is attempting to create tension between F.C.T.C. guidelines, particularly Article 5.3, which proscribes tobacco industry consultation or involvement in negotiations except when strictly necessary, and perceptions about existing E.U. standards for "good governance" and "better regulation" so requiring industry participation in policy negotiation, with the eventual goal to substantially weaken the effectiveness of the F.C.T.C. [Smith, Gilmore, Fooks, Collin, \& Weishaar, 2009]

Ratification of the F.C.T.C. and implementation of subsequent domestic policy has been and will continue to be challenging, particularly in developing countries which often have neither the legal framework nor the legislative sophistication to implement the Article guidelines in a timely or effective fashion. [Owusu-Dabo, McNeill, Lewis, Gilmore, \& Britton, 2010] The tobacco industry has been adept at exploiting these vulnerabilities by influencing both legislators and the legislative process in developing countries to weaken the impact of the F.C.T.C., Article 
guidelines, and domestic policy. [Samet, Wipfli, Perez-Padilla, \& Yach, 2006], [Meija, Schoj, Barnoya, Flores, \& Perez-Stable, 2008], [Albuja \& Daynard, 2009] Thus, while the process to establish the specific F.C.T.C. Article guidelines continues with substantial work remaining, the ultimate ability of the F.C.T.C. to combat the global tobacco epidemic will likely substantially depend upon the successful and sustained technical and strategic support for the drafting and implementation of meaningful domestic tobacco control policies in developing countries.

Two other international tobacco control efforts require mention both because of their scope and association to the F.C.T.C.: the International Tobacco Control Policy Evaluation Project (I.T.C. Project) and the Global Tobacco Surveillance System (G.T.S.S.). The I.T.C. Project was initiated in 2002 in four countries (Australia, Canada, the United Kingdom, and the United States), though it has since expanded to more than a dozen countries. [Fong, G T; Cummings, K M; Shopland, D R; for the ITC Collaboration, 2006] A survey, the I.T.C. Project is designed to assess the psychosocial and behavioral effects of F.C.T.C. policies and is based on psychosocial and health communications theoretical and conceptual models. [Fong, et al., 2006] Further, it is designed as a parallel prospective longitudinal cohort study of adult smokers and non-smokers (in some countries) with a sampling plan based on a quasi-experimental design. [Thompson, et al., 2006] With standardized questionnaires and implementation methodology, the ITC Project allows opportunities for intra-country longitudinal comparisons and inter-country comparisons not previously available. To date, the I.T.C. Project has resulted in more than fifty studies indexed in PubMed on topics ranging from population attitudes towards specific tobacco control policies to intentions to and predictors of cessation.

Finally, the G.T.S.S. began in 1998 as a collaboration between the C.D.C., the Canadian Public Health Association, and the World Health Organization which had recently launched its Tobacco Free Initiative. The G.T.S.S. was explicitly designed to establish standardized and internationally comparative surveillance data on issues such as tobacco use, exposure to secondhand smoke, exposure to tobacco advertising or promotion, and cessation. [The GTSS Collaborative Group, 2006] In order to develop such a comparative data repository, a key task of the G.T.S.S. has been to develop a series of standardized questionnaires, sampling methodologies, and field procedures implementable in the now $190+$ countries that contribute data to the G.T.S.S. [Warren, et al., 2009], [Global Tobacco Surveillance System Collaboration Group, 2005]. The G.T.S.S. has developed into four modules: the Global Youth Tobacco Survey (G.Y.T.S., the first module implemented), the Global School Personnel Survey (G.S.P.S.), the Global Health Professions Student Survey (G.H.P.S.S.), and the Global Adult 
Tobacco Survey (G.A.T.S.). [Warren, et al., 2009] The G.T.S.S. has resulted in multiple peerreviewed research publications as well as atlas-type compendiums and data reports with webbased access to results. [Centers for Disease Control and Prevention, 2009]

The F.C.T.C. in particular, but also companion efforts such as the I.T.C. Project and the G.T.S.S., are part of the emerging field of global health governance. The origins of global health governance are derived from the normative expansion of human rights to include "health". [Gable, 2007] Fundamentally, it has been recognized that without health individuals cannot advocate for or benefit from their other human rights. [Gable, 2007] The right to health was first explicitly delineated in the 1948 United Nations Universal Declaration of Human Rights [United Nations Office of the High Commissioner for Human Rights, 1948] and then expanded upon in the 1966 International Covenant on Economic, Social, and Cultural Rights. [United Nations Office of the High Commissioner for Human Rights, 1966] Hence, efforts to advance global health through global health governance can be interpreted as advancing human rights and addressing issues of social justice by ameliorating global health disparities. Two additional, important functions for global health governance, including the requisite structures and processes, have been identified: a mechanism to mount effective and timely responses to global infectious disease outbreaks such as SARS, H1N1, HIVIAIDS [Taylor, 2004], [Gostin \& Hodge, Global health law, ethics, and policy, 2007], [Dressler \& Marks, 2006]; and as a means to present a countervailing force against globalized economic regimes and the unequal and unjust distribution of economic benefits that often results from the international trade agreements that support such regimes. [Dressler \& Marks, 2006], [Thomas \& Weber, 2004] Thus, while the language of the F.C.T.C. does not itself directly invoke human rights, the connection to human rights, global public health, reduction of global health disparities, and counteracting the effects of the globalization of "big tobacco" has been clearly recognized. [Dressler \& Marks, 2006]

\subsection{Universal Challenges to Enacting Tobacco Control Policies}

Currently, tobacco products and their use are legal in all countries throughout the world. Recently, the only country to attempt to fully ban the possession and use of tobacco, Bhutan, reversed their 2004 ban in 2009 due to widespread difficulties in enforcement and the development of a black market despite what might be considered conditions advantageous to a successful ban (small, isolated, and mountainous country and low smoking prevalence). [Joosens, 2009], [Government of Bhutan, 2009] Further, in the United States polls suggest that only $17 \%$ of the population supports an outright ban on tobacco products. [Jones, J M; Gallup, Inc., 2009] By definition, tobacco control policies aim to decrease demand for cigarettes and 
other tobacco products by directly influencing the behavior of current or future smokers. As such, tobacco control policies also necessarily have an economic impact on those growing, manufacturing, distributing, or selling an otherwise legal product. That is, the fundamental paradox of tobacco control policies is the ambition to ban the use of a legal product but not the product itself. This paradox has resulted in debate, and often conflict, about the appropriate role of government, the legal and moral basis for tobacco control policy, an acceptable balance between individual and property rights, and even about the balance between different individual rights. The issues raised in these debates will be discussed in this section.

\subsubsection{A "Right" to Tobacco Control or a "Right" to Smoke?}

In the United States, the 1938 Supreme Court ruling in United States v. Carolene Products Company [United States v. Carolene Products Company, 1938] is often cited as the legal, jurisprudential basis for the regulation of tobacco products. [Byrd, Shapiro, \& Schiedermayer, 1989] In this ruling, the Court established different standards for the judicial review of legislation: regulation of economic (property) rights could be assumed to be constitutional provided that a sound rationale was provided by the legislature, but legislative regulation of civil or personal rights (e.g., life, liberty) would be subjected to a much stricter standard of judicial review. [Powell, 1982], [Funston, 1975] That is, the Court effectively created a hierarchy of rights wherein personal or civil rights have primacy over property rights and are so afforded more protection. Thus, an appeal to the protection of personal and human rights has evolved as a legal rationale to advance tobacco control policies.

As discussed above, the United Nations explicitly identified a right to health as a fundamental human right in 1948:

\section{Universal Declaration of Human Rights, Article 25}

"25.1 Everyone has the right to a standard of living adequate for the health and well-being of himself and of his family, including food, clothing, housing and medical care and necessary social services, and the right to security in the event of unemployment, sickness, disability, widowhood, old age or other lack of livelihood in circumstances beyond his control."

From: [United Nations Office of the High Commissioner for Human Rights, 1948]

In this Article, the instrumental value of health is clearly recognized as fundamental to achieving equality in the realization of human rights. In 1966, the United Nations continued conceptual extension human rights to include a right to health: 
International Covenant on Economic, Social and Cultural Rights, Article 12

"12.1 The States Parties to the present Covenant recognize the right of everyone to the enjoyment of the highest attainable standard of physical and mental health.

12.2 The steps to be taken by the States Parties to the present Covenant to achieve the full realization of this right shall include those necessary for:

a. The provision for the reduction of the still-birth rate and of infant mortality and for the healthy development of the child;

b. The improvement of all aspects of environmental and industrial hygiene;

c. The prevention, treatment and control of epidemic, endemic, occupational and other diseases;

d. The creation of conditions which would assure to all medical service and medical attention in the event of sickness."

From: [United Nations Office of the High Commissioner for Human Rights, 1966]

In Article 12.1, the right to both physical and mental health is explicitly affirmed. Further, Article 12.2 identifies the obligations of the State to protect and advance not only individual health but also public health. In subsequent comments pursuant to the International Covenant on Economic, Social and Cultural Rights, the United Nations further advanced these rights and obligations with increasingly prescriptive language regarding what States ought to do to protect these rights including, for example, necessary characteristics of health care systems (though ultimately this International Covenant is yet functionally unenforceable). [Kinney, 2001]

So, while the right to health is not an enforceable right in the realm of international law, within the United States (and other countries as well) the protection of health, now understood as a fundamental human or personal right with precedence over property rights, has been advanced as sound rationale, the standard established by the U.S. Supreme Court in United States v. Carolene Products Company, for tobacco control policies. The emergence and accumulation of scientific evidence establishing causal links between tobacco use and exposure and morbidity and mortality has given substantial credibility to the use of the human rights framework as the basis for this [U.S.] Court-standard of sound rationale. Insofar as a person has a right to health (a human or personal and civil right) which is accorded greater consideration and protection than the right of another to smoke (a property right or legally protected interest), a hierarchy also established by the U.S. Supreme Court in United States $v$. Carolene Products Company, protection of non-smokers from exposure to secondhand or 
environmental tobacco smoke, established by scientifically valid evidence as having negative health effects and increasing mortality risk, policies restricting or banning smoking particularly indoors have thus been framed as protection of human rights. [Oriola, 2009], [Katz, 2006], [Dressler \& Marks, 2006] The human rights framework, in conjunction with the specific rights and obligations advanced in the 1989 United Nations Convention on the Rights of the Child [United Nations General Assembly, 1989], has also been applied as the foundation of rational basis for policies protecting children from exposure to secondhand smoke, enticement to use tobacco products, and employment in or exploitation (child labor) in tobacco agriculture or manufacturing industries. [Dressler \& Marks, 2006], [World Health Organization, 2001]

Despite legitimate appeal to protection of the human right to health, tobacco products remain legal as does their use, and thus tobacco control policies necessarily limit personal liberty to obtain and use these legal products. [Pope, 2000] The legal principles which serve as justification to limit personal freedom with a tobacco control policy, which is substantively distinguished from the public explanations forwarded for a given policy, are those of the limiting harm to others, the harm principle, or limiting the harm to oneself, the principle of either soft or hard paternalism. [Pope, 2000], [Oriola, 2009] The harm principle, widely regarded as the most legitimate basis for governments to limit individual autonomy and with a longstanding legal and philosophical tradition, presupposes that an individual's right to liberty and autonomy is justifiably abridged so as to prevent harm to others. [Pope, 2000] Thus, some tobacco control policies that limit an individual's liberty to use tobacco, whose use results in known negative (harmful) health consequences for those exposed to secondhand smoke, can clearly be justified with the harm principle, for example indoor smoking bans. [Oriola, 2009] However, there must necessarily be limits to the harm principle, particularly in the understanding of what constitutes a reasonable or sufficient harm to warrant limitations on liberty, or there is a risk for a limitless, normative expansion in the conception of harm to include justification for virtually any government liberty-limiting action. [Pope, 2000] It is possible to argue that there are some instances, such as transient exposure to secondhand smoke outdoors, where the harm to others is not of sufficient magnitude or risk to warrant limitations on liberty with the harm principle, and thus other justifications are sought. [Pope, 2000]

In using the principle of paternalism, the state justifies limitations on individual liberty through coercive policies to protect one's life, health, and / or safety because an individual is deemed to not have sufficient knowledge, maturity, or voluntary autonomy to make an informed and sound decision (soft paternalism), or solely to protect the individual from the harmful 
consequences of an otherwise informed and autonomous choice (hard paternalism). [Oriola, 2009], [Pope, 2000] The transition in legal justification from the harm principle to the principle of paternalism unavoidably entails increased scrutiny and increased criticism from those philosophically more aligned with civil libertarianism, who regard any government liberty-limiting intervention defended as being in the government-deemed individual's best interest with profound skepticism. While policies justified with the principle of soft paternalism to protect vulnerable populations, such as tobacco control policies protecting children from secondhand smoke or those designed to prevent smoking initiation in children and adolescents (legal "minors"), and policies justified by the harm principle are generally accepted by civil libertarians [Hospers, 1980], paternalistic policies limiting the liberties of adults are much more controversial. [Hospers, 1980], [Oriola, 2009], [Pope, 2000] The debate about the acceptability of paternalistic tobacco control policies, and the demarcation between tolerable and insupportable, is made more complex by two issues: the uniqueness of tobacco products as the only consumer product whose use as intended irrefutably results in harm to both the user and exposed non-users; and whether the decision to smoke is truly informed (and whether package warning labels fulfill this standard) and autonomous and, subsequently, whether continued use given the addictive qualities of nicotine is autonomous. [Pope, 2000]

These debates are by no means settled, in part because the concept and understanding of "harm" continues to evolve in legal, political, and public spheres and tobacco control advocates have long understood the importance of acquiring additional, scientific evidence to further quantify "harm". [Byrd, Shapiro, \& Schiedermayer, 1989] However, tobacco control advocates are not of uniform opinion or certainty on the utility of rights-based arguments to build public and political support for tobacco control policies. [Fox \& Katz, 2005], [Jacobson \& Banerjee, 2005], [Katz, 2006] The trepidation is partially due to the tobacco industry's successful framing of tobacco control advocates as "Health Nazis" who infringe upon "smokers' rights" such that it is tobacco control advocates who may be perceived as being on the antirights side of the debate [Katz, 2006], though it is noted that the use of "rights" in this context confounds, likely intentionally, common language understanding with technical definition of rights to obscure the difference between a fundamental human right and a legally protected interest. [Dressler \& Marks, 2006] The tactical challenges of using rights-based arguments vis à vis the tobacco industry aside, the invocation of rights as a reason to enact tobacco control policies necessarily raises fundamental, philosophical questions including: 
"Who has the right to rank health in the hierarchy of social norms or goods? What authority, if any, is there for the state to permit or prohibit behaviors that will likely bear on health? What sanctions can attach to healthharming behavior? What health-affecting entitlements are there, and how are they ensured?"

From: [Coggon, 2009]

How a particular country or society answers these questions is deeply rooted in philosophical, cultural, and political traditions, as well as constitutional and case law jurisprudence. How such traditions vary between countries or change over time, and how such differences and changes affect the adoption of tobacco control policies is not well understood and remains an area needing additional research inquiry. It seems evident, though, and certainly within the United States, that rationalization of tobacco control policies based solely on rights-based arguments is difficult and likely inadequate due to practical challenges (i.e., effective counter-arguments forwarded by the tobacco industry), and that rights-based arguments appealing to the harm principle alone likely do not meet judicial standard for sound rationale while rights-based arguments appealing to paternalism plausibly meet with stronger judicial (and political) scrutiny. There is also an uncomfortable logical inconsistency and policy conundrum in rights-based justifications for tobacco control policies: if tobacco products so violate fundamental human rights to health, cause sufficient harm, and so interfere with informed and autonomous decision making, then why are these products not banned? Hence, there must also be additional rationale for tobacco control policies.

\subsubsection{Debates about the Economic Rationale for Tobacco Control Policies}

Included in the normative expansion of the understanding of the harm caused by cigarettes have been the economic costs to society caused by the use of or exposure to tobacco products. As stated previously, the C.D.C. has estimated an economic cost of $\$ 10.46$ associated with each pack of cigarettes sold, an estimate which includes direct medical expenses and indirect economic losses such as lost productivity. [Centers for Disease Control and Prevention, 2009] Tobacco taxes thus function dually to reduce demand and to recover some of the tobacco-related costs, particularly those attributable to tobacco-related medical

care. However, neither the body of literature estimating these costs to society nor the literature on tobacco taxes are without controversy.

The majority of studies estimating the economic costs to society have been conducted in the United States and largely estimate costs associated with primary use of cigarettes (i.e., costs associated with exposure to secondhand smoke or due to use of non-cigarette tobacco 
products much less common). Further, the estimation of such costs is methodologically complex, and so estimates vary depending upon: the dataset; whether a prevalence or incidence approach is used; whether costs for only specific tobacco-related diseases are considered or all medical costs are included; the methods underlying the determination of the disease and mortality risk ratios and attributable fractions; the scope of costs considered (i.e., medical costs alone, or additional costs such as insurance, pension costs, or years of life lost); whether payment inputs as well as expenditures are considered (i.e., the considerate of socalled "net" vs. "gross" costs); as well as statistical methodologies, which have evolved over time. [Max, 2001] Most studies concur on the direction, though not on the magnitude, of the annual, direct smoking-attributable medical costs: smokers have higher annual medical costs than do never-smokers (and, in some studies, than former-smokers as well), and are estimated to account for anywhere from $6 \%-9 \%$ to $12 \%-14 \%$ of medical expenditures. [Max, 2001], [Warner, 2003], [Warner, Hodgson, \& Carroll, 1999], [Hodgson, 1992], [Hayashida, et al., 2010], [Fellows, Trosclair, Adams, \& Rivera, 2002]

However, when the lifetime costs of smokers vs. non-smokers are considered, reported study results are far more equivocal. A Swiss study first queried whether the shorter lifespan of smokers compensated for the higher medical costs incurred during their lifetime. [Leu \& Schaub, 1983] Two oft-cited American studies concluded that while smokers' medical expenditures impose costs on society, these expenditures are recuperated in foregone pension and nursing home payments due to early mortality, resulting in a so-called "death benefit". [Manning, Keeler, Newhouse, Sloss, \& Wasserman, 1989], [Viscusi, 1995] But a critique of the estimation methods used in these studies has focused on the costs that were and were not considered: while non-smokers have higher pension and nursing home costs than smokers (because smokers die at a younger age) that make up for or exceed their lower medical expenditures, these studies did not account for the larger inputs made into these systems by non-smokers (through taxation over a longer lifespan) which negates, according to this critique, any "death benefit". [Warner, Hodgson, \& Carroll, 1999] Further, additional studies have indicated that the observed balance in "net" vs. "gross" lifetime expenditures (the "net" expenditures accounting for lower pension outlays due to shorter lifespan) is influenced by several methodologic considerations. First, the importance of whether the study differentiates between never- vs. former- vs. current- vs. always-smokers and how the outlays and inputs for each are apportioned is highlighted by the observed "quitting ill" phenomenon in which the medical crisis that motivated cessation results in substantially elevated medical costs in these 
individuals, who are now, though only recently, non-smokers, in the short- to mediumtimeframe. [Warner, 2003] Second, whether the amount of smoking (i.e., packs per day) is considered as evidence suggests that medical expenditures increase with the amount smoked. [Hodgson, 1992] Third, whether costs other than medical expenditures, such as health status or quality of life, are considered. [Hayashida, et al., 2010] Finally, which disease-related costs are considered as attributed to smoking and whether gender and the age at time of cessation is considered. [Rasmussen, Prescott, Sorensen, \& Sogaard, 2004], [Rasmussen, Prescott, Sorensen, \& Sogaard, 2005] The wide variability in methodologic approaches and findings suggests that this topic is not yet resolved but rather remains controversial, and conclusions from individual studies are highly dependent upon the aforementioned methodologic details. [Max, 2001], [Warner, 2003] Finally, regardless of the questionable ethical legitimacy for doing so, the tobacco industry has cited results from the industry-favorable studies, while ignoring contrary studies and methodologic complexities, to argue against enacting tobacco control policies on the basis that smoking is cost-effective because of the "death benefit". [Pellegrini, 2001] At a minimum, the tobacco industry has effectively created controversy around this issue.

Taxation is a prominent and ubiquitous tobacco control policy and is justified as a means to recover some of the smoking-attributable medical expenditures and to affect a price-induced reduction in demand. Beyond ideologically-based "no tax is a good tax" criticisms, high levels of tobacco taxation are contentious because of the intersection of poverty, price elasticities and concerns about tax regressivity. Both within the United States and globally, there is substantial evidence that tobacco use is increasingly becoming a characteristic of lower socioeconomic classes. [World Health Organization, 2004] In the United States, there is evidence that the social disparity in smoking prevalence has increased since the 1998 Master Settlement Agreement [Franks, et al., 2007], and studies have reported associations such as increased food insecurity in poor households with a smoker compared to poor households without a smoker. [Armour, Pitts, \& Lee, 2008] Given this socioeconomic gradient, any tax on tobacco products, a consumption good, will necessarily be regressive (a larger proportion of total income in lower socioeconomic strata is spent on consumption and thus any consumption tax tends to regressivity), which is compounded by the higher smoking prevalence in these lower socioeconomic strata. [Remler, 2004] So, increasing levels of tobacco taxation could be understood as nevertheless beneficial if such tax increases differentially induced poorer smokers to quit. However, evidence for higher price elasticity (in absolute value terms) amongst lower socioeconomic groups is unclear. [Regidor, Pascual, \& Gutierrez-Fisac, 2007] Evidence 
supports that adolescent and young adult smokers are the most price elastic. [Grossman \& Chaloupka, 1997], [Franz, 2008], [Tauras, 2004] In adults however, observations from epidemiologic studies that social disparities in smoking prevalence have increased despite repeated price increases [Franks, et al., 2007], [Regidor, Pascual, \& Gutierrez-Fisac, 2007] as well as from studies making direct estimates of elasticities [Gospodinov \& Irvine, 2009] have suggested that demand may actually be more inelastic in lower socioeconomic groups. Reporting oppositional results, other studies have suggested higher price elasticity amongst lower socioeconomic strata. [Siahpush, Wakefield, Spittal, Durkin, \& Scollo, 2009], [Farrelly \& Engelen, 2008], [Thomas, et al., 2008] It is noted that the concern is not the effectiveness of tobacco taxation to affect a decrease in both prevalence and consumption at the populationlevel, but whether these effects are distributed evenly throughout all sociodemographic groups in a population; on the latter point the answer is yet uncertain.

The varied results may, in part, be due to the time perspective taken as studies have demonstrated short-term price inelasticity with cross-price effects (i.e., reduced consumption or substitution with cheaper or "gray-market" goods) but much higher price elasticity in the long run. [Becker, Grossman, \& Murphy, 1994], [Hyland, et al., 2005] A possible explanation for these varied observations is that the probability of cessation (calculated or interpreted as a price elasticity) after a tax increase is dependent upon the ability to access cessation support to assist in overcoming nicotine addiction. Individuals in upper socioeconomic strata are more likely to be able to access such cessation supports of their own accord while individuals in lower socioeconomic strata are more likely to require social and/or monetary support to obtain these supports. Thus, important ethical questions arise about tobacco taxation related to social equity and social justice, notably: 1) How must taxation policies be constructed so as to ensure reduction not entrenchment or exacerbation of social disparities; and 2) If provision of cessation support is key to minimizing social gradients in taxation effects, is it ethical for jurisdictions to raise taxes without providing commensurate cessation support (in extension, then, should Medicaid be required to provide cessation support)? [Feldman, 2001], [Feldman, 2009] The importance of support for cessation in promoting social equity in tobacco use reduction, both within countries and globally, has been noted as a moral imperative and the absence of it as a mandate in the F.C.T.C. has been a source of particular criticism of the Framework. [Meier \& Shelley, 2006], [Meier B. M., 2005] 
Thus, as with rights-based arguments the economic rationale for and policy instruments used in tobacco control are not incontrovertible, and each jurisdiction must address these issues and debates when enacting tobacco control policies.

\subsubsection{Final Comments on "Rights" in Light of Health Disparities and Social Justice}

Appeals to and arguments about human rights and the human right to health, the harm principle and legal paternalism, concerns about the regressivity of taxes, and unease regarding the use of social stigmatization and de-normalization to promulgate tobacco control policies conflux when tobacco use and tobacco control policies are considered in the context of social disparities in health. As has already been discussed, the use of tobacco is increasingly concentrating along social gradients such that, either within a country or between countries, tobacco users are from lower socioeconomic strata or poorer countries. Thus, in addition to the arguments already presented, tobacco use and tobacco control policy debates become yet more complicated when social justice and related issues are considered. Many have argued that comprehensive and aggressive tobacco control policies, including the F.C.T.C., are imperative (with some allusions to moral imperatives) to advance human rights (right to health), reduce social disparities, and so promote social justice. [Wilson \& Thomson, 2005], [Healton \& Nelson, 2004], [Crow, 2005], [Crow, 2004] But if tobacco use is concentrating along social gradients, it is not unreasonable to query if tobacco control policies need to be adjusted to account for the different needs and concerns of these socioeconomic strata. Strategies such as de-normalization and social stigmatization is considered by some to aggravate rather than diminish health disparities and social injustice [Bell, Salmon, Bowers, Bell, \& McCullough, 2010] and the social justice concerns about excise tax regressivity have already been discussed. Additional concerns include the intentional targeting of these disadvantaged social strata by tobacco companies [Barbeau, Leavy-Sperounis, \& Balbach, 2004] as well as the structure of non-tax tobacco control policies. Specifically, individuals in lower socioeconomic strata typically have fewer individual (human), social, and economic capital resources which affects one's ability to access or effectively use cessation treatment, for example, and lower health literacy which affects one's ability to read and understand package and advertising warning labels, for example. [Weiss \& Smith-Simone, 2010], [DiClemente, Delahanty, \& Fiedler, 2010] Accordingly, if tobacco control policy is to be used as a way to reduce health disparities, the perspectives and needs of individuals in of lower socioeconomic strata must be considered and accommodated if social justice is to be truly advanced. 
In summary, what has been presented in these subsections is the philosophical basis for opposition to tobacco control policies both domestically and internationally. While the concerns presented here have been framed within the context of U.S. legal standards and evidence, the fundamental issues of limitations on liberties, protections of human rights, and values are ubiquitous and so are universal challenges to implementing tobacco control policies. These are also arguments and concerns that have been effectively forwarded by the tobacco industry worldwide as barriers to implementing tobacco control policies. How these arguments or a society's legal framework affect public or political opinion or policy adoption across jurisdictions or time periods is not well understood and remains an area to be explored.

\subsubsection{The Universal and Ubiquitous Anti- Anti-Tobacco Arguments}

The now decades-long debates in the political and public arenas over tobacco control policies have facilitated the development of a series of common arguments for and against these policies. As these arguments have persisted, they have become somewhat familiar and entrenched within the population and resistant to change. Many of these arguments have been recycled again and again in different jurisdictions at different time periods in response to the policy debate of that time and place. Their perseverance is likely due to their populist appeal and face validity, even if their premises or conclusions are not supported by fact. Anthologies of these arguments have, at various times, been compiled and presented in either academic or popular literature. Summaries of the arguments presented in three such publications are presented in Tables 3-6-3-8. In the first publication summarized in Table 3-6, from a decidedly pro-tobacco control perspective, twelve anti-tobacco control "myths" are summarized and rebuttal arguments are given for each of these "myths". [Frieden \& Blakeman, 2005] In the second publication summarized in Table 3-7, from a more neutral perspective, the "myths" about the economic implications of tobacco and tobacco control as argued by both the tobacco industry and tobacco control communities are presented along with the "reality" - i.e., the "truth" as supported by scientific studies - underlying the arguments. [Warner, 2000] In the third publication summarized in Table 3-8, from a decidedly libertarian and anti-tobacco control perspective, common arguments against the need or justification for tobacco control are presented. [Sullum, 1998] 
Table 3-6. "Myths" and "Realities" in the Tobacco Control Debate

\begin{tabular}{|c|c|}
\hline "Myth" & "Reality" I Rebuttal \\
\hline $\begin{array}{l}\text { "People have free choice whether or not } \\
\text { to smoke" }\end{array}$ & $\begin{array}{l}\text { - } \quad \text { Free will is subverted by advertising and nicotine addiction } \\
\text { - } \quad \text { In } 2002 \text {, tobacco industry spent } \$ 12.5 \text { billion on advertising and promotion in the } \\
\text { US ( }>18 X \text { spending on tobacco control) } \\
\text { - } \quad \text { Nicotine is highly addictive, a fact known and manipulated by tobacco companies } \\
\text { - } \quad \text { Children, below the legal age of consent, are not legally competent to make } \\
\text { informed and rational decisions about whether to smoke }\end{array}$ \\
\hline "Everyone knows how bad smoking is" & $\begin{array}{l}\text { - There is a general awareness that smoking isn't healthy, but there is much less } \\
\text { knowledge about specific risks beyond lung cancer (e.g., heart disease, gender- } \\
\text { specific risks) } \\
\text { Evidence that knowledge of risks varies from country to country and even within a } \\
\text { country across different population strata (e.g., rural vs. urban) }\end{array}$ \\
\hline "Just a few cigarettes a day can't hurt" & $\begin{array}{l}\text { - } \quad \text { Relationship between tobacco use and lung cancer is relatively linear } \\
\text { But, relationship between exposure and cardiovascular disease is not, and } \\
\text { negative health effects start at very low doses and rise rapidly }\end{array}$ \\
\hline "'Light' cigarettes are less harmful" & $\begin{array}{l}\text { - There is no standard definition to what "light" means } \\
\text { - Tobacco companies insist that the term is intended to refer to perceived taste and } \\
\text { not to tar or nicotine content } \\
\text { - Any meaningful difference between regular and "light" cigarettes is lost due to } \\
\text { compensatory behaviors }\end{array}$ \\
\hline $\begin{array}{l}\text { "It is easy to stop smoking: if people } \\
\text { want to quit they will" }\end{array}$ & $\begin{array}{l}\text { - } \\
\text { - Nicotine addiction makes cessation difficult } \\
\text { addictive potential } \\
\text { - } \quad \text { Most smokers attempt quitting annually } \\
\text { - Only } 7 \% \text { of smokers who attempt quitting without assistance succeed }\end{array}$ \\
\hline "Cessation medications don't work" & $\begin{array}{l}\text { - Pharmacologic therapy double the chances of success, and combination therapy } \\
\text { can increase change of success beyond that }\end{array}$ \\
\hline "Once a smoker always a smoker" & - $\quad$ More than $50 \%$ of Americans who have smoked have quit \\
\hline $\begin{array}{l}\text { "Smokers may die earlier, but all they } \\
\text { lose are a couple of bad years at the end } \\
\text { of life" }\end{array}$ & $\begin{array}{l}\text { - Average smokers loses } 14 \text { years of life, } 95 \% \text { of that time in non-smokers is spent } \\
\text { without disability }\end{array}$ \\
\hline $\begin{array}{l}\text { "Environmental tobacco smoke may be a } \\
\text { nuisance, but it isn't deadly" }\end{array}$ & $\begin{array}{l}\text { - The negative health effects of exposure to secondhand smoke as been well } \\
\text { documented, including substantial increased risk for both respiratory and lung } \\
\text { disease }\end{array}$ \\
\hline "Tobacco is good for the economy" & $\begin{array}{l}\text { - As supported by analyses done by the World Bank, a complete evaluation of both } \\
\text { the costs and benefits of tobacco in the economy shows that the net effect of } \\
\text { tobacco on the economy } \\
\text { - For example, analysis in the US shows that elimination of tobacco from the } \\
\text { economy would result in a net increase of } 130,000 \text { jobs }\end{array}$ \\
\hline $\begin{array}{l}\text { "We've already solved the tobacco } \\
\text { problem" }\end{array}$ & $\begin{array}{l}\text { While smoking prevalence is and has been declining in the developed world, about } \\
20 \% \text { of the population in developed countries still smoke and globally and } \\
\text { estimated } 1 \text { billion people will die this century from smoking related causes }\end{array}$ \\
\hline $\begin{array}{l}\text { "The tobacco industry no longer markets } \\
\text { to kids or undermines public health } \\
\text { efforts" }\end{array}$ & $\begin{array}{l}\text { The fiduciary responsibility of the tobacco companies - to preserve and expand } \\
\text { profits - is orthogonal to being supportive of and compliant with tobacco control } \\
\text { policies } \\
\text { - Magazine ads for the } 3 \text { most popular brands reach } 80 \% \text { of children in the US } \\
\text { - Adolescents } 12-17 \text { are twice as likely as adults to have been exposed to tobacco } \\
\text { advertising }\end{array}$ \\
\hline
\end{tabular}

Source: [Frieden \& Blakeman, 2005] 
Table 3-7. Economic "Myths" and "Realities" in the Tobacco Control Debate

\begin{tabular}{|c|c|}
\hline "Myth" & "Reality" I Rebuttal \\
\hline $\begin{array}{l}\text { Tobacco Industry: The cultivation and } \\
\text { manufacture of tobacco is crucial to the } \\
\text { country's economy and tobacco control } \\
\text { will result in job losses, lost tax revenue, } \\
\text { and trade deficits }\end{array}$ & $\begin{array}{l}\text { - While } 33 \text { million people farm tobacco worldwide, most do it part time / in } \\
\text { addition to other crops } \\
\text { - Half of all global tobacco farmers are in China ( } 15 \text { million) followed by India } \\
\text { ( } 3.5 \text { million) and is a meaningful portion of the economy in another half-dozen } \\
\text { countries } \\
\text { - In the vast majority of countries, tobacco manufacturing is }<1 \% \text { of } \\
\text { manufacturing employment } \\
\text { In the US, only } 1.6 \% \text { of jobs in the six-state "tobacco bloc" come from tobacco } \\
\text { farming or manufacturing, and only } 1 \% \text { of income comes from tobacco in } \\
\text { almost half of all US } \\
\text { This argument assumes that economic presence equates to economic } \\
\text { dependence, even though most studies show that jobs lost to tobacco control } \\
\text { or lost manufacturing/growing would be reallocated } \\
\text { A tobacco control program that does not include an increase in tobacco excise } \\
\text { taxes will result in lost revenue }\end{array}$ \\
\hline $\begin{array}{l}\text { Tobacco Industry: Tobacco control will } \\
\text { cause severe hardships in other industries } \\
\text { (e.g., restaurants) }\end{array}$ & $\begin{array}{l}\text { - No empirical evidence to support that bar / restaurant smoking bans result in } \\
\text { lost business } \\
\text { Bans - and supporting studies - criticized by restaurants and bars, but no } \\
\text { contrary evidence has been presented } \\
\text { - Advertising bans result in industry-specific job losses but studies by the } \\
\text { advertising industry suggest that these are gross but not net job losses }\end{array}$ \\
\hline $\begin{array}{l}\text { Tobacco Industry: Increases in tobacco } \\
\text { excise taxes cause increases in } \\
\text { smuggling and so result in lost } \\
\text { government revenue }\end{array}$ & $\begin{array}{l}\text { Estimates in developed countries support that a } 10 \% \text { increase in taxes will } \\
\text { result in a } 4 \% \text { decrease in consumption, and estimates from developing } \\
\text { countries approximate an } 8 \% \text { decrease in consumption for a } 10 \% \text { increase in } \\
\text { taxes thus net government revenues should always increase with a tax } \\
\text { increase; this is further supported by the absence of any studies suggesting } \\
\text { the contrary } \\
\text { Smuggling is a legitimate concern and is often supported by the tobacco } \\
\text { industry, but there are established anti-smuggling measures that can largely } \\
\text { combat the practice }\end{array}$ \\
\hline $\begin{array}{l}\text { Tobacco Industry: Tobacco taxes are } \\
\text { fundamentally unfair because they are } \\
\text { regressive not progressive, and unfairly } \\
\text { burden the poor }\end{array}$ & $\begin{array}{l}\text { - Tax is likely regressive, though a tax increase is likely less regressive because } \\
\text { evidence suggests that poorer smokers are more price sensitive } \\
\text { - Concerns about regressivity can be overcome of a portion of the tax increase } \\
\text { is dedicated to cessation }\end{array}$ \\
\hline Tobacco Control Advocates: & - This is likely true \\
\hline $\begin{array}{l}\text { Governments hypocritically promote } \\
\text { tobacco control and subsidize tobacco } \\
\text { growing, with the latter undermining health } \\
\text { and tobacco control efforts }\end{array}$ & $\begin{array}{l}\text { While the economic importance of tobacco agriculture and manufacturing has } \\
\text { decreased over time, more than anything the price support system in the US } \\
\text { that started in the 1930s has created an entrenched political establishment } \\
\text { with a vested interest to oppose tobacco control }\end{array}$ \\
\hline $\begin{array}{l}\text { Tobacco Control Advocates: Advances in } \\
\text { tobacco control in developed countries } \\
\text { has caused tobacco companies to move } \\
\text { into developing countries, thus advances } \\
\text { in developed countries "cause" hardship in } \\
\text { developing countries }\end{array}$ & $\begin{array}{l}\text { - While compelling, the argument is not logical from a profit-maximizing } \\
\text { perspective: companies go where there are profits to be made } \\
\text { While correlated with declining tobacco consumption in developed countries, } \\
\text { tobacco industry expansion in developing countries is more causally } \\
\text { associated by globalization of trade and rising consumer income in these } \\
\text { countries sufficient to support purchasing of their product } \\
\text { - Tobacco companies are still profitable in developed countries }\end{array}$ \\
\hline $\begin{array}{l}\text { Tobacco Control Advocates: Advertising } \\
\text { and promotion is the principal determinant } \\
\text { of smoking, especially of smoking } \\
\text { initiation by adolescents and young adults } \\
\text { vs. } \\
\text { Tobacco Industry: Tobacco advertising } \\
\text { has no effect on tobacco consumption - } \\
\text { their only function is between-brand } \\
\text { competition / marketshare }\end{array}$ & $\begin{array}{l}\text { - Advertising and promotional activities clearly increase consumption, as is well } \\
\text { understood by the tobacco industry } \\
\text { - However, per the } 1989 \text { Surgeon General's report, the exact magnitude of the } \\
\text { impact on smoking and / or smoking initiation is not known and possibly } \\
\text { unknowable, though population-wide studies show that complete advertising } \\
\text { and promotional bans reduce consumption by } 6 \% \\
\text { - Advertising is not the principal reason for smoking initiation in adolescents and } \\
\text { young adults - peer and parental behavior are stronger predictors of smoking } \\
\text { initiation }\end{array}$ \\
\hline
\end{tabular}

Source: [Warner, 2000] 
Table 3-8. Libertarian Perspective on the "Myths" and "Realities" in the Tobacco Control Debate

\begin{tabular}{|c|c|}
\hline "Myth" & "Reality" I Rebuttal \\
\hline "The tobacco companies hid the truth & - $\quad$ Concerns about smoking date back to the 1600 s \\
\hline $\begin{array}{l}\text { about the hazards and addictiveness of } \\
\text { cigarettes from the American public" }\end{array}$ & $\begin{array}{l}\text { - Scientific evidence began to emerge in the } 1930 \text { s and has received } \\
\text { consistent attention since the } 1950 \text { s }\end{array}$ \\
\hline "Tobacco is tobacco" & $\begin{array}{l}\text { Evidence suggests that cigars, pipes, and smokeless tobacco are much less } \\
\text { dangerous and so the same level of restriction [as cigarettes] is not justified }\end{array}$ \\
\hline "People smoke because of advertising" & $\begin{array}{l}\text { - Evidence suggests that advertising affects which brand people smoke, not if } \\
\text { they smoke } \\
\text { Per the } 1989 \text { Surgeon General's report, there is no "definitive answer to the } \\
\text { basic question of whether advertising and promotion increase the level of } \\
\text { tobacco consumption" }\end{array}$ \\
\hline "Smoking imposes costs on society" & $\begin{array}{l}\text { - Smokers die earlier than non-smokers and so medical costs are offset, per } \\
\text { study results by Viscusi, and RAND }\end{array}$ \\
\hline $\begin{array}{l}\text { "Secondhand smoke poses a grave } \\
\text { threat to bystanders" }\end{array}$ & $\begin{array}{l}\text { - The evidence about the health effects of secondhand smoke is not as } \\
\text { conclusive as the evidence about the health effects of smoking } \\
\text { - There is no evidence that secondhand smoke reduces life expectancy }\end{array}$ \\
\hline \multirow[t]{2}{*}{$\begin{array}{l}\text { "If secondhand smoke really is } \\
\text { dangerous, smoking ought to be banned } \\
\text { everywhere, except in private } \\
\text { residences" }\end{array}$} & $\begin{array}{l}\text { - Most epidemiologic evidence suggests that exposure to secondhand smoke } \\
\text { is most dangerous when it is a home-based exposure } \\
\text { - That home smoking bans aren't part of legislation suggest a concern for } \\
\text { property rights }\end{array}$ \\
\hline & $\begin{array}{l}\text { But why aren't the property rights of others - such as private employers, } \\
\text { restaurant and bar owners etc - given equal consideration? } \\
\text { Private property owners should be able to establish their own police and } \\
\text { market forces allowed to establish equilibrium }\end{array}$ \\
\hline \multirow{2}{*}{$\begin{array}{l}\text { "States have a right to demand } \\
\text { compensation from tobacco companies } \\
\text { for the costs of treating smoking-related } \\
\text { diseases under Medicaid" }\end{array}$} & $\begin{array}{l}\text { - Focusing on recovering medical care costs ignores the net benefit from } \\
\text { shorter life spans and so states' claims are unfounded }\end{array}$ \\
\hline & $\begin{array}{l}\text { - Why are cigarettes singled out for such compensation and why do states not } \\
\text { also pursue compensation from manufacturers of other "harmful" products } \\
\text { such as alcoholic beverages, fatty foods etc } \\
\text { - The makers and consumers of cigarettes should not be punished because } \\
\text { "politicians decided to pay for health care with taxpayers' money" }\end{array}$ \\
\hline "The tobacco companies have been & - Nicotine has not been a secret \\
\hline $\begin{array}{l}\text { secretly manipulating the nicotine in } \\
\text { cigarettes to keep smokers hooked" }\end{array}$ & $\begin{array}{l}\text { Nicotine-free cigarettes were introduced in the } 1920 \text { s, and reduced nicotine } \\
\text { and tar brands in the 1950s } \\
\text { Ways that manufacturers have provided consistent nicotine in products has } \\
\text { long been discussed in trade journals }\end{array}$ \\
\hline "Smoking is 'a pediatric disease"" & $\begin{array}{l}\text { While most smokers start as teenagers, the vast majority of smokers are } \\
\text { - Whilts } \\
\text { While smoking raises the risk of certain diseases it is a behavior - } \\
\text { something people choose to do - and not a disease }\end{array}$ \\
\hline $\begin{array}{l}\text { "Once people have started smoking, } \\
\text { nicotine addiction prevents them from } \\
\text { stopping" }\end{array}$ & $\begin{array}{l}\text { - There are about as many former smokers as there are current smokers, so } \\
\text { this position is insupportable }\end{array}$ \\
\hline
\end{tabular}

Source: [Sullum, 1998]

These tables have summarized the point/counter-point arguments commonly employed in tobacco control policy debates both domestically and internationally. Subsequent research studies have become available in the time since these studies (Tables 3-6-3-8) were published, thus altering the interpretation of some of the information supporting the arguments of the authors. Nonetheless, it is clear that both tobacco control advocates and tobacco control opponents can and have creatively interpreted and presented some data to support what, at times, feels like "positions" rather than reasoned arguments. These arguments arise, fundamentally, from the orthogonal philosophical interpretation of liberty-limiting tobacco control policies: public health and tobacco control advocates feel that the limitations on liberty are justified by the health and economic costs, whereas opponents do not. It is not likely that such philosophical divides will be bridged, and thus such debates and arguments are likely to persist. 


\subsection{Looming Challenges}

In the preceding sections, the philosophical arguments challenging tobacco control policy implementation were presented. Tobacco control policy also faces a series of specific challenges, many of which are related to market dynamics and a creative industry that shifts products and tactics in order to sustain profitability. These issues and challenges will be briefly discussed here.

\subsubsection{Specially Targeted Populations}

As has been previously discussed, a substantial gradient both within (domestically) and between countries (globally) has developed such that smoking is increasingly concentrated in lower socioeconomic social strata. [Franks, et al., 2007], [World Health Organization, 2004] Within the U.S., the Appalachian region has been reported as a sociogeographic cluster with the correlated variables of high smoking prevalence, low income/high poverty, and low policy coverage [Ferkeitch, Liber, Pennell, Nealy, Hammer, \& Berman, 2010] as well as a much higher probability that children will be exposed to secondhand smoke [Singh, Siahpush, \& Kogan, 2010], a known risk for increased likelihood that of smoking uptake [Greenland, Liu, Kiefe, Yunis, Dyer, \& Burke, 1995] and so continue smoking-related disparity cycles. This evolving gradient has differentially affected the social context of smoking and so the normative behaviors within these socioeconomic strata [Paul, Ross, Bryant, Hill, Bonevski, \& Keevy, 2010], further aggravating concerns about the entrenchment of discrepancies in health equality. So, whether the gradient in smoking is causative, symptomatic, or highly correlative with other causal factors, the socioeconomic disparity in smoking and health is concerning from both a social justice perspective and a practical perspective because of the additional challenges in realizing cessation and preventing initiation in populations with lower levels of education and social and economic resources.

Smoking rates in women, and particularly adolescent girls, is also a concern and challenge facing the public health community. While tobacco companies have long had genderspecific products and advertising campaigns, a recent report has documented new advertising campaigns promoting "purse packs", pink colored cigarettes, and branded cellphone "bling", among others, in highly read fashion magazines. [American Cancer Society Cancer Action Network, American Heart Association, American Lung Association, Robert Wood Johnson Foundation, Campaign for Tobacco-Free Kids, with funding from the Robert Wood Johnson Foundation, 2009] Globally, some reports have found that smoking in adolescent girls now exceeds that in women. [Warren, et al., 2008] These challenges highlight the need for specific 
and prescriptive policy, vigilant compliance monitoring and enforcement of existing policy, and the need for particular attention to young women who represent a strong market growth opportunity for tobacco companies.

\subsubsection{Alternative and Smokeless Tobacco Products and the Harm Reduction Debate}

As summarized in Table 3-9, there are numerous forms of tobacco products other than cigarettes with which tobacco or tobacco-like doses of nicotine can be consumed. In the United States, population estimates from the C.D.C. indicate that $3.3 \%$ of all adults $(6.5 \%$ of men and $0.4 \%$ of women) and $7.9 \%$ of all high school students (13.4\% in males and $2.3 \%$ in females) are smokeless tobacco users, with higher use rates in young white males, American Indians/Alaska natives, southern and north-central states, and lower socioeconomic status employment occupations or unemployed. [Centers for Disease Control and Prevention, 2009] Moist snuff has the largest U.S. market share (approximately 73\%) followed by loose leaf chewing tobacco (approximately 24.1\%). [Centers for Disease Control and Prevention, 2009] Use of smokeless tobacco products has been reported to increase the risk for the development of oral, esophageal, pancreatic and lung cancers to varying degrees, though somewhat inconsistently

Table 3-9. Smokeless Tobacco Products

\begin{tabular}{|c|c|c|}
\hline Type & Forms & Description \\
\hline Chewing Tobacco† & $\begin{array}{l}\text { Loose leave } \\
\text { Plug } \\
\text { Twist }\end{array}$ & $\begin{array}{l}\text { - Consumed by placing between the foil pouch } \\
\text { (loose leaf), leaf-wrapped packet (plug) or rope } \\
\text { (twist) between cheek and gums }\end{array}$ \\
\hline Snuff† & $\begin{array}{l}\text { Moist } \\
\text { Dry } \\
\text { Sachets }\end{array}$ & $\begin{array}{l}\text { - } \quad \text { Powder (dry) can be inhaled } \\
\text { - Most users put a "pinch" or "dip" (moist) or } \\
\text { sachet between cheek/lips/teeth and gums } \\
\text { - Snus, a Swedish moist snuff, has recently been } \\
\text { introduced in the US }\end{array}$ \\
\hline $\begin{array}{l}\text { Electronic Cigarettes } \\
\text { (sometimes "e-cigarettes" } \\
\text { or "e-cigs) } \ddagger\end{array}$ & $\begin{array}{l}\text { Electronic device that looks and feels like } \\
\text { a cigarette but does not burn tobacco }\end{array}$ & $\begin{array}{l}\text { - Device has a small battery-run electronic device } \\
\text { that produces a warm vapor mist of nicotine that } \\
\text { is inhaled } \\
\text { - } \quad \text { End of device "glows" like a cigarette } \\
\text { - Flavorings can be added } \\
\text { - Device comes with replacement cartridges; } \\
\text { nicotine dose can be varied }\end{array}$ \\
\hline $\begin{array}{l}\text { Betel Quid (sometimes } \\
\text { "gutka", "ghutka", "gutkha")* }\end{array}$ & $\begin{array}{l}\text { Commercially in tins, foil packets, or } \\
\text { sachets }\end{array}$ & $\begin{array}{l}\text { Betel quid is a combination of betel leaf, areca } \\
\text { nut, slaked lime, and sometimes with tobacco } \\
\text { added } \\
\text { - } \quad \text { Gutka is the commercial form of the product } \\
\text { Both are chewed or sucked on (saliva can be } \\
\text { swallowed or spit) } \\
\text { - Regional and ethnic origins in Indian sub- } \\
\text { continent, Asia, and Pacific Islands } \\
\text { Product is said to have stimulant and relaxant } \\
\text { effects }\end{array}$ \\
\hline $\begin{array}{l}\text { Water-pipes (sometimes } \\
\text { "hooka", "shisha", "goza", } \\
\text { "narghile", "hubble } \\
\text { bubble")¥ }\end{array}$ & $\begin{array}{l}\text { Tobacco packets and device are acquired } \\
\text { separately }\end{array}$ & $\begin{array}{l}\text { - Tall, upright device } \\
\text { Tobacco is heated (vaporized) in a chamber } \\
\text { then smoke is inhaled after passing through a } \\
\text { chamber of water } \\
\text { - Regional and ethnic origins in India and Arabic } \\
\text { countries }\end{array}$ \\
\hline Hard-form & $\begin{array}{l}\text { Lozenges, tables, tabs, strips, sticks, } \\
\text { other candy-like configurations }\end{array}$ & - $\quad$ Sucked similar to candy \\
\hline
\end{tabular}

Sources: †(Centers for Disease Control and Prevention, 2009]; $¥$ [Etter, 2010]; * [Centers for Disease Control and Prevention, 2009]; ¥ [Knishkowy \& Amitai, 2005], [Dugas, Tremblay, Low, Cournoyer, \& O'Loughlin, 2010]; [Gartner, Hall, Vos, Bertram, Wallace, \& Lim, 2007] 
internationally and dependent upon the study and study population [Boffetta, Hecht, Gray, Gupta, \& Straif, 2008], and preeclampsia in pregnant women. [Centers for Disease Control and Prevention, 2009] Potential cardiovascular effects associated with smokeless tobacco use are unclear primarily due to lack of study. [Arabi, 2006] Generally, the population-wide health effects of smokeless tobacco products are believed to be less than those for smoking. [Boffetta, Hecht, Gray, Gupta, \& Straif, 2008] Use of betel quid or gutka has been associated with increased risk for precancerous oral lesions and oral and esophageal cancers. [Centers for Disease Control and Prevention, 2009] However, the potential health effects of alternative, nontobacco products such as electronic cigarettes are largely unknown because they are both new products and largely unregulated, though a few countries have banned them outright. [Etter, 2010] Lastly, while population studies on the effects of hookah or water-pipe smoking have not been conducted, a content analysis of the inhaled smoke from water-pipes suggests toxicity as high if not higher than cigarette smoke, though it is acknowledged that the tobacco used in such pipes is not well standardized. [Knishkowy \& Amitai, 2005]

As the public and private implementation of smoking bans (i.e., in public and private worksites, public and private indoor and outdoor spaces, and home and car bans) spread, smokeless and alternate tobacco products are often viewed - or portrayed - as a means to continue tobacco use without violating regulations and so its use is expected to grow. [Arabi, 2007] Tobacco companies have developed and introduced new products and promotional campaigns to take advantage of this potentially expanding market opportunity. [Mejia \& Ling, 2010] Additionally, new products can often be introduced without the manufacturing regulations or tobacco control policy restrictions intended for cigarettes, as illustrated by electronic cigarettes [Etter, 2010] and hookah bars, both of which have proliferated in many states and the latter whose operation is not well regulated and which is becoming associated with college-age "party" activities including co-use of other illicit drugs and binge drinking. [Knishkowy \& Amitai, 2005], [Dugas, Tremblay, Low, Cournoyer, \& O'Loughlin, 2010], [Lyon, 2008] Thus, for the public health community, the challenges of smokeless and alternate tobacco products are twofold. The first challenge is practical: gathering and having access to sufficient, reliable data to make informed policy decisions and having a policy infrastructure that can adapt and respond to rapidly changing market conditions. The second challenge is philosophical: with some evidence that some of these products have fewer health effects, should they be promoted as part of a cessation strategy or would the risk of such a promotion of these products be either ineffective or unethical - as some have queried, "a gateway to smoking or a bridge to quitting"? 
[Arabi, 2007] On this latter challenge, smokeless and alternate tobacco products are fully embroiled in the "tobacco harm reduction debate" that is ongoing in the public health community.

\subsubsection{The Tobacco Harm Reduction Debate}

At the core of this debate is whether smokeless and alternate tobacco products represent a legitimate nicotine replacement product that will facilitate ultimate complete cessation, or whether smokers will simply substitute one product for another. Some studies report clear health benefits of switching to snuff, snus in particular [Hall \& Gartner, 2009], [Gartner, Hall, Vos, Bertram, Wallace, \& Lim, 2007], and endorse the use of smokeless and alternate tobacco products as a policy tool in tobacco harm reduction. [Rodu \& Godshall, 2006] However, many raise concerns about simple product substitution, dual-product use, or the relative effectiveness of these products over existing strategies for cessation inducement and nicotine replacement therapies. [McKee \& Gilmore, 2007], [Lambe, 2007], [Mumford, Levy, Gitchell, \& Blackman, 2005] Other studies have suggested that the population health benefits of promoting smokeless tobacco as part of a tobacco harm reduction strategy, after using simulation modeling to account for different use patterns, would be negligible. [Mejia, Ling, \& Glantz, 2010]

There is a notable lack of consensus within the public health and tobacco control community [Martin, Warner, \& Lantz, 2004], and many studies enumerate the need for additional, reliable information about: the products themselves including toxicologic profile; physiologic effects; epidemiologic effects and risks; impacts on individual behavioral patterns; population levels of knowledge about the products; legal and ethical challenges and concerns in product regulation; short-term vs. long-term effects of use and on overall probability of cessation; and understanding the demographic, socioeconomic, and/or sociogeographic clusters with greater risk or greater possible benefit from the products. [Hatsukami, et al., 2002], [Savitz, Meyer, Tanzer, Mirvish, \& Lewin, 2006] As has been previously pointed out, a substantial challenge to systematically addressing these issues in the United States has been the lack of a tobacco regulatory agency [Zeller, M; Hatsukami, D; and the Strategic Dialogue on Tobacco Harm Reduction Group, 2009], though this may have been resolved with the recent authority given to the F.D.A. in the Family Smoking Prevention and Tobacco Control of 2009.

\subsubsection{Globalization}

The tobacco industry's use of globalization, especially trade agreements, to expand and develop new markets has been well documented. [Zatonski, 2003], [Szilagyi, 2006], [Shaffer, 
Brenner, \& Houston, 2005] By design and intent, international trade agreements reduce the barriers to the flow of goods and services as well as the ability of individual states to regulate or impede the trade of products, including tobacco. Globalization has also been credited with the rising income in many countries, which makes tobacco products more affordable. [Collin, Lee, \& Bissell, 2002] In addition to trade, the development and access to the internet has substantially advanced the globalization of communication, information, and culture and some reports have documented tobacco industry use of new media venues such as Facebook ${ }^{\odot}$ to advertise and promote their products. [Freeman \& Chapman, 2010] As was discussed above, a primary reason to develop the F.C.T.C. was to combat the globalization of the tobacco epidemic, which includes the globalization of markets and marketing, and such studies highlight the importance of a savvy, globalized response to a savvy, globalized, and motivated industry.

\subsubsection{Tobacco-Control Challenges in the United States}

Two challenges facing U.S. tobacco control efforts merit brief discussion. The first challenge is unique to neither the U.S. nor this policy area: maintaining funding for tobacco control programs. The C.D.C. reports that the tobacco industry spent \$34 million / day or \$12.4 billion in 2006 on the advertising and promotion of cigarettes [Centers for Disease Control and Prevention, 2009] and \$354 million in 2006 on the advertising and promotion of smokeless tobacco products, an increase from $\$ 251$ million in 2005. [Centers for Disease Control and Prevention, 2009] In the face of industry perpetually aspiring to obtain new customers and new markets, tobacco control efforts can never be "over" or "done" if goals to protect and promote public health, reduce health disparities, and advance human rights and social justice are to be achieved. Thus, the tobacco control program activities as well as the funding and infrastructure that supports them must remain intact and the efforts to maintain the necessary funding and infrastructure must be sustained possibly perpetually and against ubiquitous and enduring fiscal pressures for such funding to be used elsewhere. Such challenges are emphasized by a recent report from the C.D.C. estimating that $\$ 24.4$ billion were available to states in 2008 from tobacco taxes and payments from legal settlements, yet states only spent $3 \%$ of those funds on their tobacco control programs, not even reaching the $15 \%$ of revenues recommended by the C.D.C.. [Centers for Disease Control and Prevention, 2010] This challenge is clearly recognized within the tobacco control community and efforts to both bring attention to and develop strategies for sustainability are not uncommon. [Wisotzky, Albuquerque, Pechacek, \& Park, 2004], [Stoner \& Foley, 2006], [Carver, Reinert, \& Range, 2007] 
Finally, in a white paper released in 2001 Philip Morris announced that they would support F.D.A. regulation of tobacco products provided that: a) cigarettes were regulated as a unique product and not a medical device; b) regulation did not lead to prohibition; c) regulations aimed at harm reduction do not reduce product-derived pleasure or enjoyment; d) communication about reduced risk products should not encourage smoking or discourage quitting; e) that regulations should address warning labels such that adults are fully informed about the risks associated with the product's use; and f) that tobacco products remain legal products (i.e., not banned) or made, through regulated removal or addition of specified ingredients, so unpalatable as to induce cessation. [Redhead \& Burrows, 2009] This represented a reversal from all of Philip Morris' previous positions opposing such regulation (even though the white paper emphasizes that it did not), including the 1996 F.D.A. Final Rule that first asserted F.D.A. jurisdiction over tobacco, and a split within the tobacco industry as all other tobacco companies remain opposed to F.D.A. regulation of tobacco. [Redhead \& Burrows, 2009] Philip Morris' unfeigned motivation to support F.D.A. regulation of tobacco is not known, but suppositions include capitalizing on their size to capture marketshare from competitors, improve their public image, enhance its legitimacy, and an effort for a weaken-from-within strategy. [Redhead \& Burrows, 2009], [McDaniel \& Malone, 2005] Regardless of their "new" tactic of cooperation, tobacco control advocates are generally wary of this cooperation and are concerned about the implications for and attempts to weaken tobacco control policies and programs. [McDaniel \& Malone, 2005]

\subsection{Chapter Summary}

This chapter has presented a review of the tobacco epidemic from the public health perspective. However, this review did not focus on the evidence establishing the biologic causal link between exposure to tobacco and adverse health outcomes nor the very large, and ever growing, body of public health literature establishing and advancing the understanding of tobacco control policy "best practices" - i.e., that body of literature representing the cumulative evidence for the effectiveness for various tobacco control programs and policies and the specific circumstances surrounding the implementation of those programs and policies. Rather, this review, after a overview of the evidence for tobacco control policy "best practices", focused on public health-lead efforts to enact these policies. That is, this chapter emphasized the public health community's extension of the positivist dimension of tobacco control policy (evidence for program and policy effectiveness) into the normative sphere: the reasoning that the deleterious health outcomes, social costs, and untoward conduct of the tobacco industry is sufficient to warrant and justify the position that these effective policies should therefore be universally 
adopted. Thus, this chapter examined the transition from tobacco control policies to tobacco control policy regimes and both the domestic and international efforts to adopt such policy regimes, including the World Health Organization's Framework Convention on Tobacco Control. This review also discussed universal challenges to implementing tobacco control policy regimes, especially the challenge of balancing different types of individual rights as well as that of the public's interest and health with these different types of individual rights. Other, common arguments both for and against tobacco control policies were also discussed, including arguments regarding measuring the true "cost" of tobacco use and lifespan issues, economic dependencies, and libertarian vs. paternalistic perspectives on the balance between individual choice and public health. Finally, pending challenges for the tobacco control policy community were discussed, including the growing intra- and inter-country concentration of tobacco use in already marginalized populations (impoverished, lower socio-economic strata, visible minorities) and the yet-unresolved debate over tobacco harm reduction products and the efficacy as well as the ethical dilemmas posed by the promotion of these products as a means to abate the tobacco epidemic.

The public health community has contributed much to the tobacco control literature. This perspective, in particular, has been largely responsible for the development of effective tobacco control programs and policies and it has been well documented that there have been barriers and challenges to the adoption and implementation of comprehensive tobacco control policies. However, beyond the legerdemain of the tobacco industry in manipulating a faulty political process for unseemly gains [the dominant viewpoint in the public health perspective], the public health literature has contributed comparatively little to explanations for how and why the policy process has worked in the pursuit of tobacco control policy adoption. This is the focus of the next chapter. 


\section{LITERATURE REVIEW: THE TOBACCO EPIDEMIC FROM THE POLITICAL AND POLICY SCIENCE PERSPECTIVE}

\subsection{Chapter Introduction \& Purpose}

Whereas a substantial portion of the tobacco control scholarship from within the public health community, as befits its origins and focus (understanding and improving the public's health), has centered on the elucidating and documenting causal mechanisms between smoking and health (both morbidity and mortality) as well as establishing an evidence base for effective programmatic (ultimately policy) interventions, the more common focus of tobacco policy scholarship from the political and policy science perspective has been understanding and explaining the factors influencing tobacco control policy adoption. That is, existing political and policy theories and frameworks have been applied to tobacco control policy to understand, from a more expansive (and positivist) perspective, the factors that have influenced the evolution of the tobacco epidemic and have facilitated or impeded the adoption of tobacco control policy. Thus, the purpose of this chapter is to review these theories and frameworks, how they have been applied to the tobacco epidemic, and the important findings from these studies. This review will include: theories of the policy process, especially the agenda-setting theories Multiple Streams Framework, Punctuated Equilibrium Theory, and the Advocacy Coalition Framework, that have been applied to inform tobacco control policy adoption; the role of science and expert communities in the tobacco control policy process; the influence of the courts and legal proceedings on the tobacco control policy process; the importance of policy type (typology) on tobacco control policy adoption; how institutions and institutionalism explains tobacco control policy adoption; the impact of social change, including elements of issue framing, on tobacco control policy adoption; how policy learning, diffusion, transfer, and convergence explains tobacco control policy adoption; and the political and policy science perspective on the importance of networks in facilitating policy adoption.

\subsection{Multiple Streams Framework}

\subsubsection{An Overview of the Multiple Streams Framework}

Kingdon's Multiple Streams Framework [Kingdon, 1984] is a model of the policy process, the agenda setting and decision making stages in particular, that was developed as an extension of the "garbage can" models of choice. [Cohen, March, \& Olsen, 1972]; [Zahariadis, 2007] Kingdon's Framework consists of three streams - the Problem Stream, Policy Stream, and Politics Stream - which he viewed as flowing separately and with substantial independence through the policy process. In the Problem Stream are the conditions and problems facing 
society and, in turn, policy makers. Problems are brought to the attention of the public and policy makers through various mechanisms including the research and reporting on various indicators, feedback from existing policies or programs, the media, and focusing events. Within the Problem Stream, it is the attention on the problem, which is as or more important than the nature of the problem itself, that influences the policy process. Kingdon envisioned the Policy Stream as a milieu or "soup" of different ideas and policy solutions that compete for the attention and favor of (and ultimate acceptance and adoption by) policy subsystems. Policy ideas in this stream are usually generated by specialists in that topic area and often, rather than being generated as the "best" solution to address a problem, are a solution that benefits, protects, or promotes the interest of the group that the specialist represents. The Politics Stream consists of three sub-streams: the national mood, pressure-group campaigns, and administrative or legislative turnover. The national mood refers to public opinion of and public pressure for a particular government action. Pressure-group campaigns include the activities of interest groups that act either in the public arena or within a particular policy subsystem, including political action committees and industry lobby groups. Administrative or legislative turnover refers to changes in the members of Congress or the White House that may impact the ideological predisposition of the legislative, executive (including bureaucracies), or judicial branches of the government. Policy choices are made when policy entrepreneurs, powerful individuals or groups (or those acting on their behalf), are able to manipulate preferences, perceptions, and situations and "link" the three streams. Kingdon described a "policy window" or "window of opportunity" as the linking of the three streams by a policy entrepreneur resulting in a policy decision. The Multiple Streams Framework is particularly adept at understanding policy processes that are ambiguous due to any combination of fluid participation, unclear or problematic preferences, unclear technology, and ambivalence. [Zahariadis, Comparing three lenses of policy choice, 1998]

\subsubsection{Application of the Multiple Streams Framework to Tobacco Control Policy}

In a search of both public health and the political science literatures, two studies were identified that applied the Multiple Streams Framework in order to explain the adoption of tobacco control policy. The Multiple Streams Framework was used to conduct a policy analysis of the factors influencing - and challenging - the adoption of smoke free ordinance in Lexington, KY. [Greathouse, Hahn, Okoli, Warnick, \& Riker, 2005] In analyzing more than two years of activities in each of the streams, the authors identified several critical factors (including building a strong coalition of supporters, and a comprehensive strategy that included a wealth of 
information and a strong legal team) that enabled the eventual enactment of the ordinance in a pro-tobacco jurisdiction.

In another study, the authors provided an overview of the Multiple Streams Framework and how it can be broadly applied to understand the adoption of tobacco control policies (generally) in California. [Blackman, 2005] Thus study was designed to provide nurses with a better understanding of the policy process, with tobacco control as a case example.

In summary, the systematic application of the Multiple Streams Framework has not been widely employed in tobacco control policy studies. When it has, its apparent utility has been the flexibility and so relative ease of organizing considerable information from many, disparate sources and types, often over a substantial duration of time, into a coherent narrative. Key concepts from the Multiple Streams Framework, specifically policy entrepreneurs and policy windows, have been frequently used in tobacco control studies as well as other policy areas. Thus, it is likely that these elements have been the key contributions of this Framework to the theoretical understanding of causal contributors of policy change. However, the explanatory value of the Framework and policy entrepreneurs and windows aside, it is unclear that the Multiple Streams Framework is able to predict, in contrast to retrospectively explain, policy change and so its ability to identify causal forces in the policy adoption process is unclear.

\subsection{Punctuated Equilibrium Theory}

\subsubsection{An Overview of Punctuated Equilibrium Theory}

Punctuated Equilibrium Theory (P.E.T.) [Baumgartner \& Jones, 1993], [Baumgartner \& Jones, 2007] was developed, at least in part, as an oppositional view to the prevailing, pedantic view of the policy process as a series of ordered, logical stages: policy making was frequently not ordered and logical but rather dynamic, with periods of frenetic activity after long periods of seeming inactivity. In this way, P.E.T. was among the first theories to emphasize the longitudinal nature of policy making (or at least policy analysis), rather than static, crosssectional approaches. In the longitudinal view of the Punctuated Equilibrium Theory, policy areas cycle through prolonged periods of relatively minor activity followed by a period "punctuation" - of significant activity, which then cycles back to a prolonged period of much lower inactivity. The underlying factors influencing this cycling between equilibrium / pseudoequilibrium and punctuation, then, also cycle through their own characteristic phases. In pseudo-equilibrium, those favored by the status quo fiercely defend the status quo, and the benefits being derived from it. Negative feedback mechanisms and policy monopolies 
established by policy sub-systems ensure an incremental approach to policy change, if any. Further, favored elites exert their dual-faces of power to ensure that only favorable issues reach the agenda and unfavorable issues are kept from the agenda. [Bachrach \& Baratz, 1962] In displacing pseudo-equilibrium, there is an expansion and mobilization of interest [Schattschneider, 1960] and progression through the issue-attention cycle, [Downs, 1972] and the issue begins to escape the control of the policy monopoly or subsystems, which in turn begin to collapse. If the favored elite cannot re-establish pseudo-equilibrium, negative feedback mechanisms give way to self-propelling positive feedback mechanisms, ensuring further collapse of the status quo. In such a scenario (failure to re-establish pseudo-equilibrium), there is rapid change as mobilization continues and policy monopolies and subsystems collapse. Involvement in and control over and issue becomes very fluid as there is competition not only to influence policy decisions but also to establish power and favor in new programs or subsystems that are likely to result from policy change; this is similar to or corresponds with a policy window, with ample opportunities for policy entrepreneurs, from the Multiple Streams Framework. [Kingdon, 1984] Finally, activity decreases and the dynamics of pseudo-equilibrium are re-established with or without actual policy change.

In moving through the phases of P.E.T., there is a differentiation between attention and activity, and issues that achieve "agenda status." An issue can have attention or generic activity paid it in any realm during any policy phase. However, an issue having achieved "agenda status" is one that is on the public agenda (an issue acknowledged by the broader population as requiring action), the formal agenda (being acted upon within the formal structures of government), or the decision agenda (an issue about to be acted upon). While achieving status on the public agenda is not always required (but frequently needed) for all policy changes, achieving formal and decision agenda status. An issue's "policy image," first described in by P.E.T. as how that issue or policy is understood and discussed, is a key determinant in how or if an issue "moves through" the various agendas and / or cycles through the phases of the P.E.T.. Thus, the P.E.T. envisages that a fundamental component of cycling from pseudo-equilibrium to punctuation is the competition to control or define the policy image. In attempt to control the policy image and re-define pseudo-equilibrium, then, actors are mobilized so as to offer competing, stronger policy images. Understanding policy change requires that one appreciates the factors affecting the dynamics attempting to change or maintain the policy image and thus the status quo. These factors can include characteristics of the issue itself, the context including both micro- and macro-political factors, and the actors and the venues. That is, the 
P.E.T. suggests that understanding the causes leading to policy change requires and understanding for the magnitude of underlying factors as well as the relative mix of these factors, and how they are changing over time.

\subsubsection{Application of the Punctuated Equilibrium Theory to Tobacco Control Policy}

In considering the Punctuated Equilibrium Theory, a fundamental question is whether tobacco control policy making has followed the characteristic pattern of pseudo-equilibrium followed by punctuations. Using data from the Agendas Project, analysis by Baumgartner and Jones documented this pattern of policy making within the federal government. [Baumgartner \& Jones, 1993] These results were echoed in a later study that analyzed Congressional committee hearings for evidence of subsystem dynamics, including positive and negative feedback. [Worsham, 2006] In analyzing information from 1945-2005 on the number and types of committees holding tobacco-related hearings, the types of witnesses testifying at these hearings, and legislative sponsorship, the author concluded that the pre-1964 Surgeon General's Report agricultural-dominated policy subsystem largely persisted through the 1980s, with evidence for substantial negative feedback and a relatively stable policy image. However, beginning in the 1990s, the policy image began to change and competition over the policy image (the previously overlooked health aspect) combined with legislative policy entrepreneurs initiated positive feedback, disrupting the previously stable policy subsystems. As of 2005 , the close of the study, author concluded that [pseudo-] equilibrium had not yet been re-established and so the final outcome was not yet apparent. [Worsham, 2006]

In contrast, other studies have suggested that tobacco control policy making at the statelevel does not necessarily follow the expected P.E.T. patterns. [Givel M., 2006], [Givel M., 2008] Rather than demonstrating "cycling" -- periods of pseudo-equilibrium with [relatively] stable policy images and subsystems followed by positive feedback and disruption of the policy subsystem - the author of these studies argued that state-level policy making exhibited several different patterns (e.g., linear, oscillating, exponential) but not the punctuated pattern predicted by the P.E.T.. [Givel M., 2008], [Givel M., 2006]

Thus, there has not been consensus as to whether tobacco control policymaking has or has not followed the pattern predicted by the P.E.T.. As with the Multiple Streams Framework, key concepts from the P.E.T., specifically positive and negative feedback, subsystems, and policy images, have been used widely within tobacco control policy as well as other policy areas, often without the systematic application of the full P.E.T. framework. The P.E.T. has also, as with the Multiple Streams Framework, provided a "lens" through which to organize and 
interpret considerable information into a reasoned explanation for the course of tobacco control policymaking. From this perspective, then, Punctuated Equilibrium Theory faces a similar challenge as the Multiple Streams Framework in that it its ability to predict, rather than retrospectively explain, causal forces in policy adoption is unclear.

\subsection{Advocacy Coalition Framework}

\subsubsection{An Overview of the Advocacy Coalition Framework}

As with the P.E.T., the Advocacy Coalition Framework (A.C.F.) expounds a far more complex version of policy making compared to a "stages" paradigm. [Sabatier \& Jenkins-Smith, 1999], [Sabatier \& Weible, 2007] A fundamental premise of the A.C.F. is that policy making is sufficiently complex so as to necessitate that the processes and activities associated with policy making occur in a policy subsystem with expertise sufficient for efficient, effective, and informed policy decision making; in the A.C.F., it is this subsystem that is the primary unit of study and analysis. That is, the A.C.F. places substantial emphasis on the role of experts and scientific and technical information in the policy making process. Further, the A.C.F. forwards that groups - coalitions - coalesce around common deep core beliefs, fundamental, steadfast, and normative beliefs about how the world "should" operate. These coalitions, which the A.C.F. forwards are more expansive than traditional "iron triangles" and can include legislators, bureaucrats from all levels of government, scientists and other content or technical experts such as consultants, members of the media, and interest groups, pool and marshal resources, including human and other forms of capital, in an effort to translate their deep core and policy values into policy, thereby dominating the policy subsystem. As multiple coalitions typically exist within a given subsystem, the competition within the bounds of the existing rules and system for resources, strategic advantage, and ultimate dominance of the subsystem (i.e., ability to translate policy values into policy) transpires over years or decades, and thus the timeframe for the A.C.F. is substantial. [Sabatier \& Jenkins-Smith, 1999], [Sabatier \& Weible, 2007], [Weible, Sabatier, \& McQueen, 2009] A diagram depicting the key elements of the A.C.F. is shown in Figure 4-1.

\subsubsection{Application of the Advocacy Coalition Framework to Tobacco Control Policy}

Two Japanese-based studies employed the A.C.F. to identify the emergence of a second coalition - health advocates - to compete with the existing coalition - pro-tobacco - and alter the dynamics of policy making in the subsystem in order to enact tobacco control policies. [Sato, 1999], [Sato, Araki, \& Yokoyama, 2000] 
Figure 4-1. Advocacy Coalition Framework Flow Diagram

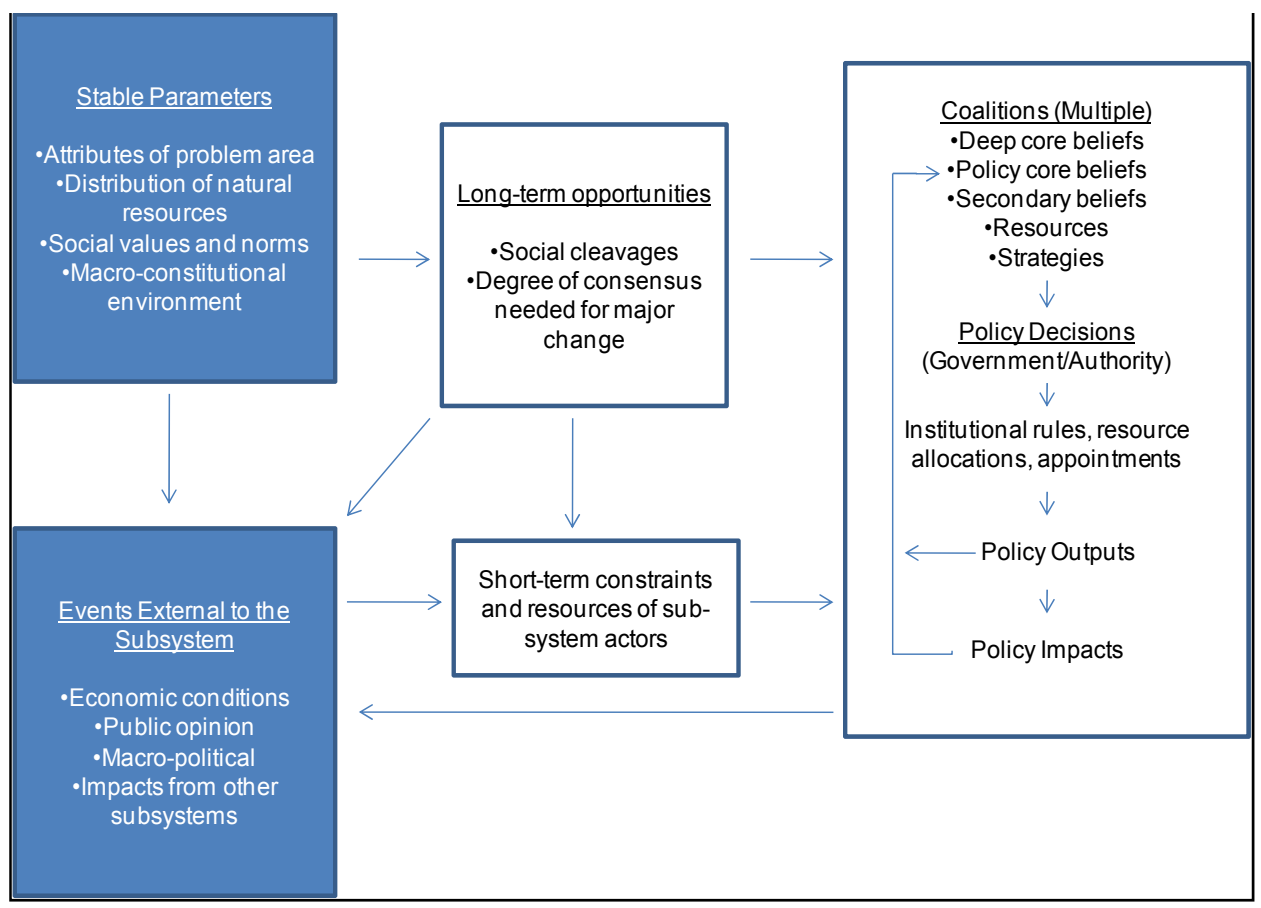

Source: Adapted from [Weible, Sabatier, \& McQueen, 2009]

Of the three agenda setting frameworks and theories discussed here, the A.C.F. is the most detailed regarding the elements and factors influencing the dynamics of policy subsystems (and, thus, policy change). However and despite the apparent relevance of the Advocacy Coalition Framework to tobacco control policy, few studies have systematically applied the A.C.F. to investigations aimed at explaining or understanding the adoption of tobacco control policies. Future comparative studies might use the A.C.F. to explore how differences in coalition resources or strategic decisions affect their ability to influence tobacco control policy adoption, though a likely barrier to such studies will be the comparable data needed (and the current paucity thereof) to perform such empirical analyses.

\subsection{Policy Typologies}

\subsubsection{An Overview of Policy Typologies}

Categorizing issues according to various characteristics or dimensions has been an important tool for political scientists in their quest to understand - and ultimately predict - how policy decisions are made. In this area of scholarship, Lowi's typology is often regarded as seminal. [Lowi, 1964] In his typology, Lowi forwarded a system that divides policy and agenda setting into three distinct arenas, each with its own politics and power structures: 1) the distributive arena of highly individualized decisions benefitting predominately individuals; 2) the regulatory arena that targets largely entire sectors and creates clear winners and losers by benefiting one sector at the expense of the other; and 3) the redistributive arena in which an 
entire social class is targeted with policy(ies) in an attempt to achieve equal possession. As envisioned by Lowi, the policy type ordains the politics, not vice versa. [Lowi, 1964]

Morality policy has been forwarded as an extension of Lowi's prominent three-category policy typology and has been variously defined as social regulation [Tatalovich, R; Daynes, B W; (Eds.), 1998] or the redistribution of values. [Meier K. J., 1999] And while the specific boundaries of a distinct typology have been elusive [Smith K. B., 2002], [Mooney, 2000], a series of characteristics of morality policy have been discussed (Table 4-1). In evaluating the characteristics outlined here, and has been discussed by others, tobacco control policy does partially overlap with dimension of morality policy [Studlar, 2008] and thus tobacco control policy can be examined within the context of the typology of morality policy.

\subsubsection{De-normalization, Morality Policy, and Tobacco Control Policy}

Part of the opposition to tobacco control policy is based solely on its policy typology. Tobacco control policies are partially regulatory in nature and use command and control regulations, economic incentives, and information to influence and modulate individual behavior. [Licari \& Meier, 1997] The motivation for tobacco growers, manufacturers, and sellers to resist the tobacco control policies which are intended to reduce the demand for their otherwise legal product is obvious: naked economic self-interest. The subsequent collective actions directed toward the political establishment and policy making systems are thus predictable. The broader resistance to tobacco control policy within populations, however, is less intuitive and is plausibly attributable to another of tobacco control policy's typology: morality policy and the related strategy of de-normalization.

To the extent that tobacco control policies are framed - or interpreted - as being about right vs. wrong behavior, giving preferential treatment to one social group at the expense of another group, or infringing upon core values, as predicted for policies with a morality

Table 4-1. Characteristics of Morality Policy

\begin{tabular}{|c|c|}
\hline Author & Characteristics of Morality Policy \\
\hline Meier (1999) & $\begin{array}{l}\text { - Redistribution of values } \\
\text { - Redistribution of state-accepted values onto those state-defined as perverse results in the socie } \\
\text { - } \quad \text { Valus elevation of some and social status reduction for others } \\
\text { - }\end{array}$ \\
\hline Mooney (2000) & $\begin{array}{l}\text { - Fundamental conflict between significant groups over core values, or "first principles", about } \\
\text { what is right and wrong } \\
\text { - Characteristics of morality policy issues are 1) technical simplicity, 2) high public salience } \\
\text { because they threaten basic values, and 3) are more likely than other policy types to have high } \\
\text { levels of participation and engagement because of their technical simplicity and salience }\end{array}$ \\
\hline Smith (2002) & $\begin{array}{l}\text { - Taxonomic classification based on patterns of political behavior identifies } 1 \text { ) higher levels of } \\
\text { participation, 2) weak role for experts, } 3 \text { ) low levels of compromise, and 4) higher probability of } \\
\text { judicial resolution of conflict }\end{array}$ \\
\hline
\end{tabular}


dimension, levels of public participation in policy debates and conflict in these debates rises. Thus, the components of tobacco control policy most likely to be considered as being morality policy are not the policy elements justified with the harm principle or even soft paternalism, but rather those policy elements perceived as being hard paternalism. Further, the emphasis on the morality dimension in tobacco control policy has changed with the framing of the issue over time and, arguably, between different advocacy groups. [Studlar, 2008] An emphasis on and the use of de-normalization substantially amplifies the morality policy dimension. Generically, denormalization is a process whereby normative standards for a particular action or behavior are changed. The evolving emphasis on socially normative behavior in public health can be traced to the epidemiologic transition and the shift from the leading causes of death being attributable to infectious disease to the leading causes of death being attributable to chronic disease with substantial causal contribution from social and behavioral determinants. [Cappuccio, 2004] Social marketing has thus developed as a central feature of health promotion and healthy public policy, and has as a core function the creation - changing - of social norms for acceptability and desirability of particular individual behaviors and influence those behaviors in order to combat chronic disease. [Gordon, McDermott, Stead, \& Angus, 2006], [Grier \& Bryant, 2005] Denormalization is thus a specific type of social marketing and tactic that emphasizes the unacceptability and undesirability of certain behaviors. Within the context of tobacco control policy, the tobacco industry as well as smoking and, to some extent smokers, have been the target of de-normalization tactics such as exclusion from F.C.T.C. negotiations (tobacco industry), reducing the number of places where the activity is acceptable (smoking and smokers), and an increasingly negative depiction in the media and publications (tobacco industry, smoking, and smokers). [Studlar, 2002] However, de-normalization has been controversial - adopted explicitly by some tobacco control programs (e.g., [Ontario Tobacco Strategy Advisory Group, 2010]), but substantially de-emphasized by others because of the associated risk [Studlar, 2002] even though there is some evidence linking de-normalization with increased cessation in adult smokers. [Hammond, Fong, Zanna, Thrasher, \& Borland, 2006] To the extent that tobacco control policy emphasizes the unacceptability of smoking, smokers, or the tobacco industry, then, it invokes the morality dimension of the policy and the ensuing conflict over values and social preference. The allusions about the policy and its proponents (public health advocates) are thus not only about paternalism but also about economic and spatial social exclusion. [Feldman, 2009] The latter concern is particularly relevant given the addictive nature of smoking and the increasing concentration of smokers in lower socioeconomic social strata. [Bell, Salmon, Bowers, Bell, \& McCullough, 2010] 
Thus, the morality dimension of tobacco control policy is a source of important secular opposition to these policies, economic and public health justifications aside, and the creation of sympathy for the "persecuted" minority (tobacco users and the tobacco industry). Further, while [American] federalism is structured such that local policy solutions can be developed to resolve conflict and reflect local preferences in morality-policy issues, the increasing nationalization of policy and interjection of the federal courts, as has been the case in tobacco control policy, has interrupted this locally-based balance thereby increasing tension. [Mooney, 2000] This tension created by loss of local control can also be seen on an international level, where the F.C.T.C. can be interpreted as, if not in content but in aspiration, a global prohibition regime that formally promotes substitution of local policy solutions for global policy convergence consistent with the values and economic interests of the dominant members of the international community. [Nadelmann, 1990] Thus, the F.C.T.C. is part global public health governance and part global paternalism and would be expected to engender similar resistance internationally as do such policies domestically.

\subsection{Institutions and Institutionalism}

\subsubsection{An Overview of the Role of Institutions and Institutionalism in Public Policy}

Institutionalism (and neo-institutionalism) is to political science is what Donabedian's structure-process-outcome axiom [Donabedian, 1966] is to public health and health care. An innovator in the field of health care quality improvement, Donabedian was an early scholar and leader and advocate for the adaptation of the rigorous quality assessment and improvement processes developed in industrial settings to health care delivery. His simple, but adroit and profound postulate has become the foundation for the field: one cannot understand or improve upon outcomes without understanding the processes and structures from which they arise. Translated to the policy process, policies (outcomes) are the products of policy processes which occur within the rules and institutions (structures) that are an integral, all-encompassing part of the fabric of communities and societies.

While there is not a single, succinct definition for "institutions" or "institutionalism", [Offe, 2006] the construct can be broadly understood as the fundamental structures and fabric of society existing along a spectrum of proximity to the policy making process itself. While institutions may initially be created to solve fundamental organizational needs of societies including the provision of public goods, [Moe, 2006] once created institutions to not remain neutral, benign entities but rather morph into actors within the society and the policy making process itself, becoming agents of power distribution [Immergut, 2006], [Offe, 2006], [Moe, 
2006] within the society thereby defining the boundaries for government capability and shaping and creating the very expectations of the society itself. [Offe, 2006] In acknowledging the myriad form, functions, and effects of institutions, the construct can by depicted as "layers" as shown in Figure 4-2. These tiers encompass the broadest social and governmental structures and institutions including cultural values and beliefs (tier 1), institutionalized policy regimes (tier 2 ), and the structures and institutions closest to the policy making process (tier 3) such as judicial review, aspects of legislative organization and voting rules, and entrenchment of social cleavages.

Early $20^{\text {th }}$ century scholarship conceptualized institutions as formal, legal entities whose activities were largely confined to their constitutionally assigned responsibilities [March \& Olsen, 1984] though this perspective, whether pluralist, elitist, or statist, left many policy choices unexplained. [Immergut, 2006] New, or neo-, institutionalism has emerged in an attempt to rectify these explanatory deficiencies, though neo-institutionalism largely rejects the rational actor paradigms at the foundation of institutionalism, contending that institutions are more complex than such models can explain. [Selznick, 1996] Rather neo-institutionalism replaces the rational-actor or 'logic of consequences and rational calculation' paradigm of individual behavior with the 'logic of appropriateness', [Olsen, 2001] a situationally-dependent paradigm based on 'rules' incorporated through socialization. [March \& Olsen, 1984] Thus, neoinstitutionalism recognizes that institutions are simultaneously cause and effect, which greatly complicates analytic assumptions of exogeneity, temporal and historic ordering, and institutional

Figure 4-2. Three-Tiered Institutional Typology

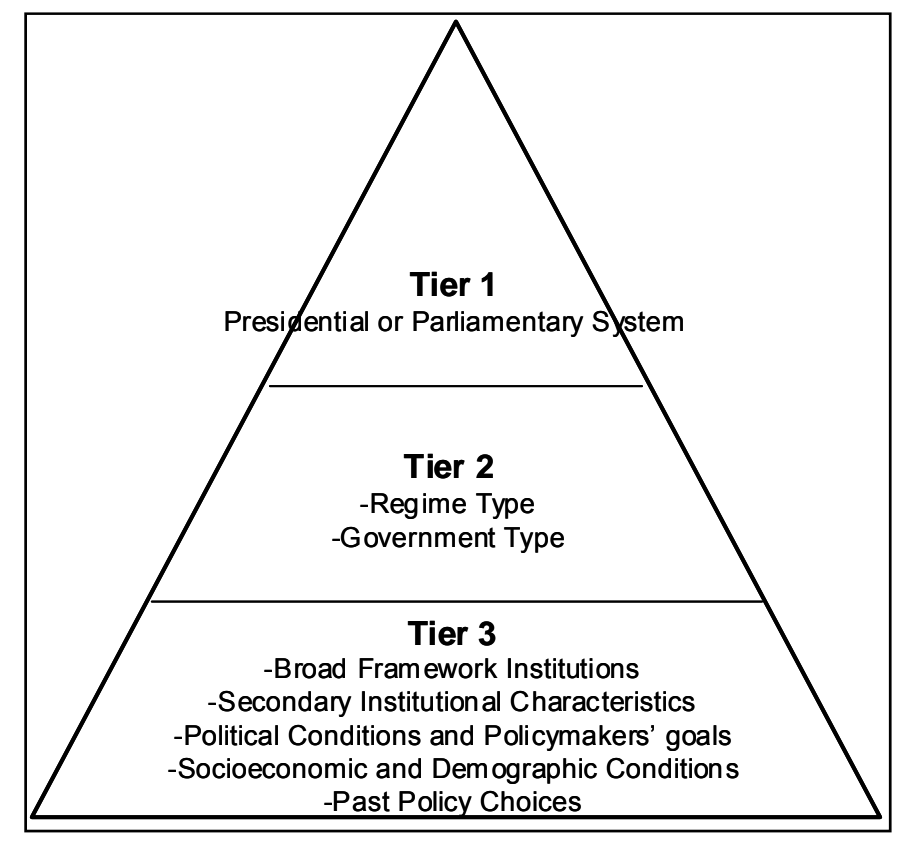

Source: Adapted from (Weaver \& Rockman, 1995) 
ability to affect social normative standards (leading to additional analytic complications especially for longitudinal studies). [March \& Olsen, 1984]

\subsubsection{Institutions, Institutionalism, and Tobacco Control Policy}

As regards tobacco control policy, two aspects of institutionalism have received particular research attention: venues and federalism.

Venues, while institutions, are also inextricably linked to Punctuated Equilibrium Theory. As described in P.E.T.,

"Policy venues are the institutional locations where authoritative decisions are made concerning a given issue. Policymaking authority is not automatically assigned to particular venues...Just as images may change over time, so may issues fall within several venues."

From: [Baumgartner \& Jones, 1993]

This is the "venue shopping" described in P.E.T. That is, just as there can be efforts to change a policy image, so too can there be efforts to change the venue in which policy decisions are made. Venue shopping, thus, is closely associated with mobilization, positive feedback mechanisms, and changing policy images. These associations were empirically demonstrated in a study of tobacco control policy adoption in Scotland, where the author reported that a change in the policy image (rooted in a shift in attention from the Scottish Executive to the Scottish Parliament) caused the change in venue - the decision for devolution from the U.K. to Scotland - was a key factor in facilitating the adoption of legislation banning smoking in public places in Scotland. [Cairney, 2007]

Changing policy venues - venue shopping - can be a valuable strategic choice not only because it necessarily implies mobilization and issue expansion, but also because different venues often have different procedural rules and norms, also part of the broader construct of institutionalism, that govern the decision making process within those venues. The importance of such institutional rules was documented in an analysis of tobacco control policy making in New Sound Wales, New Zealand where the authors reported that reforms giving additional powers to legislative councils and committees as well the influence to backbenchers were by factors in successful policy adoption. [Hooker \& Chapman, 2006] Additionally, a change of institutions - venue shopping - is not necessarily limited to different venues within the same country or jurisdiction. Thus the globalization of tobacco control policy, through efforts such as those of the European Union, have been discussed by some as being, at least in part, venue 
shopping. [Princen, 2004] (Using similar criteria, the F.C.T.C. could also be considered, at least in part, a venue-shopping effort, though the F.C.T.C. is not discussed in this study.])

Federalism is a form of governmental and institutional organization wherein multiple levels or layers jurisdictions have constitutionally protected policy making authority. Federalism, such as in the United States (central/national vs. states) and Canada (central/national vs. provinces), is distinguished from a unitary system, such as in Britain, in which only one legislative body has the authority to create policy. However, all federalist systems are not homogeneous as it does not imply uniform institutional arrangements, either structurally or functionally. Many mid-range theories and constructs have been developed, such as regulatory federalism, discretionary federalism, parliamentary federalism, presidential federalism, and executive federalism among others, to articulate the various forms of power-sharing arrangements and relationships between the different jurisdictional policy making levels (central/national, state/province, and substate/province such as counties). [Kelemen, 2000], [Studlar, 2010] So, while federalism (or unitarism) is a constitutional choice for a specific form of government, the specific form of federalism (e.g., permissive or regulatory federalism) evolves over years (generations) of dual or multifaceted (not always shared, and not infrequently competitive) policy making and the implicit balance of power that emerges from this collective policy making history and experience. Further, these balances of power - form of federalism - can vary between policy areas and can also change over time as, for example, institutional arrangements or interest group involvement changes.

The multiple levels of policymaking authority in federalist systems also necessarily imply multiple levels of institutions and so opportunities for venue shopping with the related issue expansion, mobilization of interest, etc. Several studies have focused on the impact of these institutional layers and venue shopping in federalist systems on tobacco control policy adoption. In a study of tobacco control policy adoption within individual states, the authors reported on several institutional characteristics, including the professionalism of the state legislature and government ideology, which impacted the between-state or local-to-state diffusion of tobacco control policies. [Shipan \& Volden, 2006] In a case-study evaluation of the Master Settlement Agreement, another author noted that it was federalism-permitted venue shopping that facilitated the states' attorneys general to not only creatively engage the judicial system but also to "shop" within the judicial system to find a venue -court - most favorable to their cause (Michael Moore, the state attorney general for Mississippi and the first to file a suit against the tobacco companies, and Richard Scruggs, a tort lawyer acting on behalf of the state, 
intentionally selected a judge-ruled chancery court so as to avoid a jury trial (juries had never, at that point, ruled against tobacco companies)). [Derthick, 2001] Interestingly, this author also commented that, while the initial venue-change to the courts was clearly consistent with federalism, the ultimate result of the negotiated Master Settlement Agreement, which used a contractual arrangement to impose de facto tobacco control policy, was likely inconsistent with the federalist principles of the Founding Fathers as it circumvented the traditional, democratic policy making process in its imposition of de facto policy. [Derthick, 2001]

Finally, federalism, with its constitutionally derived layers of policy making jurisdiction, is often compared to multi-level governance, an evolving theory attempting to explain the dynamics of policy making in an increasingly globalised world where countries willingly cede some level of their policy making sovereignty to transnational agreements and organizations, because of their functional similarities - multiple layers of governance, jurisdictions, and venues. Development of multi-level governance as a theory and an applied construct has proceeded particularly in response to the evolution of policy making in European Union, with its expanding competencies and, therefore, acquis communautaire, and scholarship on advancing its theoretical underpinnings continues. [Bulmer, 1994], [Bolleyer \& Borzel, 2010] Within tobacco control policy, studies comparing federalist systems or federalist systems to systems of multilevel governance, such as the European Union or the F.C.T.C., have been conducted. In comparing federalist systems with very different structural and power-sharing characteristics yet very similar tobacco control policy regimes and tobacco-related population health outcomes (Canada and the United States), the author reasoned that the flexibility of federalism can permit similar policy outcomes despite very different institutional processes because of how institutional arrangements can vary and adapt both between jurisdictions but also temporally within a given jurisdiction. [Studlar, 2010] In analyzing the evolution of tobacco control policy within the European Union, one study concluded that the expansion of the European Union's competencies to tobacco control, thereby instituting an arrangement of multi-level governance, had the effect of opening new policy venues to tobacco control policy advocates, with a functional effect typically ascribed to federalism, which in turn facilitated the development and eventual adoption of tobacco control policy by the European Union. [Mamudu \& Studlar, 2009] However, because multi-level governance is a still-evolving construct, its explanations for tobacco control policy adoption have, at times, found to be yet complete particularly when contrasted to the explanatory (and more fully developed) capacity of federalism. [Asare, Cairney, \& Studlar, 2009] 


\subsection{Policy Learning, Diffusion, Transfer, and Convergence}

\subsubsection{An Overview of Policy Learning, Diffusion, Transfer, and Convergence in Public Policy}

Viewed most broadly, the policy learning, diffusion, transfer (and borrowing) are related concepts wherein a policy enacted in one jurisdiction becomes enacted in another. As related concepts, differences in definitions are subtle:

- Policy transfer is the emulation of the policies, programs, institutions, or other policy apparatus from one jurisdiction or time point in another jurisdiction or time period; [Dolowitz \& Marsh, 1996]

- Policy diffusion is the spread of policy innovations (new policy solutions) from one jurisdiction to another; [Shipan \& Volden, 2008]

- Policy learning is the process whereby a jurisdiction facing a similar policy problem observes the policy solution in another jurisdiction, determines if that solution is successful, and is more likely to adopt a similar policy solution if it is deemed a successful and appropriate policy solution. [Shipan \& Volden, 2008]

Similarly, policy convergence is the tendency over time, often through policy learning, diffusion, or transfer, for jurisdictions to adopt increasingly similar policies, programs, and institutional arrangements. [Bennett, 1991] Rose differentiated between "learning" or "transfer" to achieve a politically-motivated policy short-cut and a genuine, analytically based "lesson drawing", which he defined as a distinctive type of program that draws upon foreign experience so as to permit knowledge extraction in order to inform a solution to a domestically based problem. [Rose, 2007] Core to successful lesson drawing, then, is understanding under what circumstances the foreign program succeeds and to what extent can that program be successfully applied domestically. The incentive for lesson drawing increases with problem solving urgency, where problems can appear due to changes in national or international circumstances, or because of a successful challenge of the status quo, including current assumptions, and ability to forward that the possibility for better solutions exist. That is, the foreign example(s) is/are successfully forward as a benchmark or best practice (or at least 'better' practice) in comparison to the existing, domestic solution. Such lessons, or benchmarks, can be drawn from historical examples, though this is inherently limited, or from different but contemporary geographic jurisdictions, near of far, similar or dissimilar. Further, there are an increasing number of forums - national, international, global, continental, or regional - for government officials, policymakers, and scientists that are designed to facilitate both awareness of the opportunity to learn about 
foreign lessons. Within tobacco control, the F.C.T.C. and the World Conferences on Tobacco or Health, among others, are quintessential such examples.

That the F.C.T.C. and W.C.To.H. conferences are deliberate forums to promote policy learning, transfer, and ultimately convergence is consistent with ideas developed from the political science perspective where some have asserted that policy transfer is not a random process. [Bennett, 1997] Rather, lessons are shared and reverberate ("ripple") through policy communities both formally and informally and jurisdictions can be motivated into policy transfer for rational reasons of lesson drawing, quasi-rational reasons of solution searching, less-rational legitimation, or harmonization. As research studies have reported on the circumstances of policy transfer, learning, and diffusion, models differentiating between different types and characteristics of such diffusion have been developed. Berry and Berry have conducted important scholarship in this area, articulating a framework of distinct diffusion and innovation forms, as described below. [Berry \& Berry, 2007], [Berry, 1994]

\section{1) Diffusion Models}

a) National Interaction Model - models of diffusion that are based national communication networks among and between state policymakers, bureaucrats, and public-sector employees regarding public sector programs and their successes or failings. The probability a state will adopt a certain program is proportional to the number of interactions State $X$ has had interactions with the already-adopted-in State $Y$.

b) Regional Diffusion Model - Adoption of policies across states is dependent upon geographic proximity - aka 'neighbor' or 'near neighbor' models.

c) Leader-Laggard Models - A state (or country) takes on the role of 'leader', and is thus pre-disposed to becoming a policy innovator, whereas other states take on the role of 'laggard', thus being pre-disposed to be an adoptor.

d) Isomorphism Models - Models that emphasize "likeness of states" (vs. geographic proximity) in their probability that a state will adopt a policy. That is, states look to other like states for their policy cues.

e) Vertical Influence Models - Models that suggest that diffusion from national to state levels are more important than horizontal diffusion across jurisdictions of similar 'rank' (e.g., municipality to municipality etc).

2) Internal Determinants Models - These models suggest that internal factors, such as the political, economic, or social environment within a state are the key factors 
determining whether a policy will be adopted. Definition of the dependent variable is key in these models, as it has significant implications for framing the research question (and subsequent analyses).

3) Unified Innovation Models that Include Elements of Diffusion and Internal Determinants - This is a model forwarded by Berry and Berry that functionally includes all variables, including internal determinants, resources, motivation, and elements from diffusion models including neighbors etc, into one analytic model. Analytically the model relies heavily upon event history analysis. As with many areas of political science, data availability is often a limiting factor.

\subsubsection{Policy Learning, Diffusion, Transfer, Convergence, and Tobacco Control Policy}

Not unexpectedly, policy learning, transfer, and diffusion have been used to explain the spread of tobacco control policies between jurisdictions. Earlier studies reported diffusion of tobacco control policies through jurisdictions in Canada and the United States and the role of advocacy groups in facilitation the policy diffusion. [Studlar, 1999] Later studies contributed additional empirical support to the importance of epistemic and transnational advocacy groups in facilitation policy learning and transfer. [Studlar, 2006], [Studlar, 2005] However, despite efforts such as the F.C.T.C. and other international tobacco control advocacy efforts, tobacco control policies have by no means been universally adopted. While some studies continue to emphasize the importance of advocacy networks for successful policy transfer and adoption, [Wipfli, Fujimoto, \& Valente, 2010] results from other studies suggest that other issues, such as the policy image and ideas and institutional arrangements are also key factors in policy transfer. [Cairney, 2009], [Studlar, 2007] That is, the transition from knowledge transfer to successful policy transfer (adoption) remains a political one.

\subsection{Social Change and Social Movements}

\subsubsection{An Overview of Social Change in Public Policy}

A view of public policy is that it is the tool by which societies chose to engage their government to deploy scarce public resources in order to reach a public solution to a problem it faces. And so, if public policies are the means which a society distributes its resources and public policy making the process by which a society affords and controls access to the decision making (resource allocation) process producing those policies, public policies and the public policy making process are the means by which a society apportions its values. To the extent that one accepts this view of public policy, it follows that a change in public policy, absent a fundamental change in the policy making process itself, reflects a change in either: a) the 
society's understanding or view of the problem; b) the society's view of whether the problem should be addressed publicly or privately; or c) the society's view of how [public] resources should be allocated to address the problem. That is, policy change can be interpreted as a change within the society - a social change, including as regards the society's values and preferences for resource allocation.

While some scholars rebuff socially-based explanations as being too naïve, (e.g., [Steinmo, 1994]) social and cultural values have nonetheless emerged as either complements to or alternates for other explanations such as institutionalism. [Steinmo, 1994], [Kurdle \& Marmor, 1981] In using social and cultural explanations, cross-sectional comparative studies attribute differences in policy regimes to differences in some combination of the three factors identified above (understanding or view of the problem, preference for a public or private solution, values informing resource allocation to address the problem). Likewise, in longitudinal studies, changes in policy or policy regimes are attributed to changes in some combination of these factors. Castles' and Obinger's "Families of Nations" or Epsing-Andersen's "Worlds of Welfare Capitalism" are illustrations of explanations for differences in patterns of public and social welfare policy regimes attributable to differences in cultural and fundamental social values. [Castles \& Obinger, 2008], [Epsing-Andersen, 1990] Also within the realm of social explanations are causal stories [Stone, 1989] and social constructions, [Schneider \& Ingram, 1993] which are fundamental to how a society understands or views a problem and, conceivably, its preference for a public or private solution to the problem. It is acknowledged, that neither social constructions nor causal stories are likely discrete from the policy images of the Punctuated Equilibrium Theory. Conceptual overlaps aside, it is straightforward to understand how either changes (longitudinal) or differences (comparative or cross-sectional) in the perceptions of power ("weak" or "strong") or construction ("positive" or "negative") altering categorization as "advantaged", "contenders", "dependents", or "deviants" in the social construction paradigm, [Schneider \& Ingram, 1993] or how similar changes in actions ("purposeful" or "unguided") or consequences ("intended" or "unintended") leading to an adjustment in the perceived classification as "mechanical cause", "accidental cause", "intentional cause", or "inadvertent cause" in the causal story paradigm [Stone, 1989] could affect a fundamental shift in a society's understanding of the problem or its preference for a public solutions. 


\subsubsection{Tobacco Control Policy Adoption as a Social Movement}

In tobacco control policy, social explanations have been forwarded to account for adoption of tobacco control policies and changes in tobacco control policy regimes. The changing and selective framing of tobacco control policies has been examined and the success of public health advocates in framing public smoking bans as protecting "innocent" victims has been forwarded as a key factor in the spread of smoke-free policies. [Larsen, 2010] Additionally, Nathanson in particular has contributed substantial scholarship to elucidating and reporting on various elements of social change that have contributed to the substantial changes in tobacco control policy regimes in developed countries. In particular, Nathanson notes that particularly in the fragmented American context, the work of grass-roots advocacy groups to re-frame smoking, the tobacco industry, and the need for and role of tobacco control policy has been essential in affecting the sea-changes in tobacco control policy regimes. [Nathanson, 2007] Further, Nathanson also concludes that the substantial declines in smoking prevalence are primarily attributable to the transformation of smoking from social acceptable to socially unacceptable due to the efforts of health-related social movements. [Nathanson, 1999], [Nathanson, 2005] However, while these empirical studies have identified the importance of social movements and social change, rigorous quantitative studies have to be conducted so as to better understand the relative importance of preferences for public vs. private solutions compared to cultural values.

\subsection{Science and Expert Communities}

\subsubsection{An Overview of Science and Expert Communities in Public Policy}

Scientific information and expert communities are incorporated into multiple policy frameworks, most notably the Advocacy Coalition Framework and the subsystems and policy images of the Punctuated Equilibrium Theory. Scientific information can also be considered in isolation as an instrument with a "central role in the framing and legitimation of policy." [Ingram, Schneider, \& McDonald, 2002] So, while the importance of scientific knowledge and expertise in the policy process has been recognized, the mechanisms of how this information exerts its effects are complex. Two different classification systems have been developed to explain the factors influencing the impact of scientific expertise in the policy process.

In Nathanson's classification system [Nathanson, 2007], the ability of scientific information and experts to influence the policy process is constrained by several contingencies including:

- Characteristics of the political regime - both the scientific ideas and the experts forwarding those ideas will, in a pluralist system with both cultural and 
institutional incentives for competition, will face more challenge and skepticism than is encountered in a corporatist or hierarchical systems.

- Social and political location (status) and the framing expertise of "knowledge brokers" - incorporation of scientific knowledge or experts into the policy process (e.g., though proposed bills, hearings etc.) depends, in no small measure, on the normative beliefs of the policymakers, which is also related to how that scientific information has been presented and "framed" by knowledge brokers. These brokers, such as the media and other journalists, play a crucial role in translating this scientific information into policy images, causal stories, and socially constructed notions of who does and doesn't need or deserve protection through constructions of culturally credible risk and victimization.

- Beneficial intersections of timing and opportunity - while this contingency is typically beyond the control of policy makers, knowledge brokers, experts, or other actors in the policy process, it is nonetheless important: some ideas and arguments, no matter how sound or creative, do not resonate and so they must either change or wait until they are received more favorably.

In Weible's framework, [Weible, 2008] intended to supplement the Advocacy Coalition Framework, expert information can be used for learning, political purposes (e.g., the distortion or misrepresentation of facts), or instrumentally as part of a rational policy process to develop evidence-based policy. Further, how information is used is contingent upon the type of coalition configuration as either unitary subsystems, collaborative subsystems, or adversarial subsystem. Thus a series of propositions is forwarded on the use of expert information in subsystems:

1. The political use of expert-based information will be highest in adversarial subsystems.

2. The instrumental use of expert-based information will vary from the highest in collaborative, to an intermediate level in unitary, and to the lowest in adversarial policy subsystems.

3. Learning will occur within conditions or among experts with similar analytical approaches in all subsystems and will most likely occur across coalitions or across experts with dissimilar analytical approaches in collaborative systems.

From: [Weible, 2008]

Thus scientific information and experts is clearly important in the policy process, though how the information is used and its impact is dependent upon the context of the policy process itself. 


\subsubsection{Science and Expert Communities in Tobacco Control Policy}

The importance and role of scientific information and experts in tobacco control policy is not in dispute. The causal role of this information in changing the fundamental understanding of the problem, including the construction of risk and victimization, the policy images, the perceptions of the tobacco industry, and the social changes that this information fueled has been well documented both within the United States and globally. [Nathanson, 1999], [Nathanson, 2007], [Asbridge, 2004], [Beaglehole, 1991], [Warner, 2005], [Bayer \& Colgrove, 2002], [Mamudu, 2007] However, what has been less well understood, particularly within the public health community, is why, despite overwhelming scientific evidence, policy has not followed logically and rationally from this overwhelming scientific evidence. While some within the public health and epidemiologic communities have attempted to better understand - and modify - the approach to the intersection of science and public policy, [Savitz, Poole, \& Miller, 1999], [Brownson, Royer, Ewing, \& McBride, 2006], [Brownson, Chriqui, \& Stamatakis, 2009] a substantial proportion of the tobacco control advocacy community has and continues to respond with disbelief and frustration, viewing a "failure" to adopt the "right" or "needed" policy as a "failure" of the political system. [Larsen, 2008] The response from the political science perspective is that,

"The path from knowledge to policy is not straightforward; scientific consensus does not lead automatically to policy consensus."

From: [Nathanson, 2007]

That is, policy adoption is not a scientific exercise or process, but a political one.

\subsection{The Judiciary}

\subsubsection{An Overview of the Role of the Judiciary in Public Policy}

The description of the judiciary in the elementary school, introductory version of the threebranches-of-government form of American democracy is that the judicial branch interprets the constitution. That is, it does not function to create policy, simply to ensure that policy created in the legislative branch does not violate constitutionally protected rights. However, legal, political and policy science scholars alike have long understood the naiveté of that view of the American judiciary. Within policy frameworks, the judiciary can alternately a venue (Punctuated Equilibrium Theory), a strategic opportunity and / or resource or an external event (Advocacy Coalition Framework), or an actor within society whose actions affect the society's understanding or view of the problem (including through framing, social constructions, or causal stories), opportunities or constraints on public or private solutions to the problem or how 
resources are allocated to address the problem. Starting in the 1950s and 1960s, the courts were increasingly used as an avenue to affect social reform, and a substantial body of scholarship has developed attempting to understand and better explain how legal mobilization and the judiciary affect public policy

Legal mobilization is an umbrella-term encompassing instances when litigation - or the threat of litigation - is proactively pursued to assert rights. As has been previously described, [McCann, 2008]

- Legal mobilization begins with "non-official" legal actors, private citizens, and thus is often considered a "bottom-up" approach because it begins with those outside the legal community, often, in cases of legal mobilization seeking social reform, by those considered less powerful or socially marginalized.

- In the broadest understanding of legal mobilization, actual litigation is but part of a dynamic, complex continuum of interactions between disputing parties, ranging from filing claims or charges, negotiations, legal proceedings, and postproceeding negotiations. Thus, legal mobilization, while a strategic decision, is also a process, and the judiciary can have myriad policy-like effects at any and all stages of this process.

- The decision to employ legal mobilization is complex as are the possible outcome and thus the policy repercussions are uncertain depending upon when, how, and the form of resolution to the initiating dispute.

- There are substantial socially-derived disparities in the ability or predisposition ("legal consciousness") to employ legal mobilization as a strategy to assert rights related to the substantial capital and personnel resources needed to improve the chances of success.

Additionally and as numerous scholars have identified, the inability of the courts to enforce their decisions, termed by many as the "myth of rights", combined with the observed "countermobilization backlash" has led to the questioning of legal mobilization as a strategy to affect social change. [McCann, 2008] However, whether legal mobilization is viewed as effective or successful may depend upon the evaluation time frame selected. [Epp, 2008] The highly fragmented, federalist system in the United States creates substantial incentives for legal mobilization. However, while the inability of the courts to enforce or implement their decisions (expansion or extension of rights to a new group) is very real as is the often well orchestrated 
mobilization backlash by opponents, the "myth of rights" may be a short-term phenomenon, disappearing if a longer-term evaluation timeframe is taken. [Epp, 2008] That is, the social policy impact of the courts may be realized through processes such as those articulated by the Advocacy Coalition Framework or the Punctuated Equilibrium Theory as well as what some scholars have termed the "administrative professions": the translation of judicial decisions to real and palpable changes in [social] policy is virtually entirely dependent upon intermediaries coalitions, subsystem actors, bureaucrats, policy or cause advocates, or other motivated experts who are both aware of and insist upon the realization of legal decisions in policies, programs, and regulations and are prepared to re-engage the legal system (or threaten to do so) if their requirements are not met. [Epp, 2008]

\subsubsection{The Judiciary and Tobacco Control Policy}

Legal mobilization has been an oft employed strategy in the "war on tobacco" and the paths from the offices of tobacco control advocates and the tobacco industry to the courts are well trod. An overview of key legal cases in the decades-long efforts to enact tobacco control policies, as well as the relationships of these suits to policy, is included in Appendix 1 . In addition to the public health "three-waves" etiology, (e.g., [Douglas, Davis, \& Beasley, 2006]) there was an increase in scholarship addressing the relationship between tobacco lawsuits and tobacco control policy particularly surrounding the Master Settlement Agreement. Some of this scholarship empirically explored some of the issues discussed above specifically related to tobacco control policy including how the legal mobilization and events in the courts affected a change in the policy image sufficient to motivate the tobacco companies to compromise. [Mather, 1998] Additionally, while some of this scholarship was generally positive toward the possibility that the Master Settlement Agreement could be an exception to the generally-held belief that effective (or timely) policy does not come from the courts, [Jacobson \& Warner, 1999] other views were decidedly less favorable, considering the terms of the Master Settlement Agreement to be undemocratic, a court-imposed tax, and state "nanny-ism". [Melnick, 1999] Now, more than a decade after the enactment of the M.S.A., retrospective analyses are emerging. Clearly, the "undoing" of the tobacco industry, as predicted by some, has not materialized. [Kelder Jr. \& Daynard, 1997] Further, evaluation of policy impacts of the legal mobilization resulting in the M.S.A. is complicated because, as it has now been reasonably well documented, the states did not implement the M.S.A. homogeneously nor all not quite implemented as expected. [Jones \& Silvestri, 2010] Most notably, states have substantially diverted M.S.A. funds to uses other than tobacco control programs leaving state programs underfunded, and, with the passage of the 2009 Family Smoking Prevention and Tobacco 
Control Act, it took more than 10 years to achieve the national-level regulatory regime contained in the aborted Global Settlement Agreement. [Jones \& Silvestri, 2010] In the end, a [not so] quiet consensus that seems to emerge is that the disclosure stipulations, mandating the creation of multiple tobacco industry internal documents (now available online) and the scholarship and subsequent legal actions that this otherwise unattainable information has afforded, may ultimately have the largest and longest-lasting impact on tobacco control policy. [Miura, Daynard, \& Samet, 2006], [Givel \& Glantz, 2004]

The preponderance of scholarship on the role of litigation in tobacco control policy has been focused on the Master Settlement Agreement. Few empirical and even fewer quantitative studies have systematically investigated the effect of the larger body tobacco litigation on tobacco control policy either at the national or lower-court level. This area of inquiry is well suited for examination, especially as some policy and "legal mobilization" entrepreneurs are suggesting that the "lessons" from tobacco litigation be applied to other areas of public health, particularly obesity. [Alderman \& Daynard, 2006]

\subsection{The Political and Policy Science Perspective on Networks}

Within political and policy science, three areas of scholarship have emerged with overlapping language, definitions and constructs: epistemic communities; transnational advocacy networks (sometimes called global advocacy networks); and the Advocacy Coalition Framework. Early empirical work differentiated epistemic communities from interest groups and social movements, disciplines and professions, and legislators and bureaucrats (and bureaucracies) based on knowledge, beliefs, and interests. [Haas, 1992] According to this work,

"...it is the combination of having a shared set of causal and principled (analytic and normative) beliefs, a consensual knowledge base, and a common policy enterprise (common interests) that distinguish epistemic communities from various other groups. They differ from interest groups in that the epistemic community members have shared causal beliefs and cause-and-effect understandings...epistemic communities have exerted their influence on decision makers in a wide variety of issue-areas. Generally called upon for advice under conditions of uncertainty, they have often proved to be significant actors in shaping patterns of international policy coordination."

From: [Haas, 1992] 
In expanding the notion of epistemic communities to include individuals beyond subject specialists, advocacy networks, sometimes also discussed as coalitions, have been described as:

"Advocacy networks are significant transnationally, regionally and domestically. They may be key contributors to a convergence of social and cultural norms able to support processes of regional and international integration .... [They] are forms of organization characterized by voluntary, reciprocal and horizontal patterns of communication and exchange...Transnational advocacy networks appear most likely to emerge around those issues where: (1) channels between domestic groups and their governments are hampered or severed where such channels are ineffective for resolving a conflict, setting into motion the 'boomerang' pattern of influence characteristic of these networks; (2) activists or 'political entrepreneurs' believe that networking will further their missions and campaigns, and actively promote them; (3) international conferences and other forms of international contacts create arenas for forming and strengthening networks."

From: [Keck \& Sikkink, 1999]

In contrast to the Advocacy Coalition Framework, which emphasizes stable and enduring coalition formation around fundamental values and typically within a single subsystem, the development of epistemic communities and advocacy networks has been more functional, both arising from and focusing on what these more loosely-organized networks have accomplished. [Farquharson, 2003] Within tobacco control, the development of these networks, either within or between jurisdictions as well as globally, has been the explicit goal of, for example, the World Conferences on Tobacco or Health as well as the C.D.C.'s National Tobacco Control Program. These networks, because of their diverse membership from both technical and lay communities, likely have more theoretical grounding in global advocacy networks or the Advocacy Coalition Framework compared to epistemic communities due to the emphasis of the latter on common understandings based on similar technical expertise. [Farquharson, 2003] Studies have reported on the success of these networks in taking advantage of the multiple venues in multi-level governance arrangements to advance myriad public health policies including tobacco control policies. [Princen, 2007] Further, numerous other studies have reported on various characteristics of the network organization, including strategic membership, community involvement, and use of the media, that have facilitated network success in advancing tobacco control policies. [Chapman \& Wakefield, 2001], [Farquharson, 2003], [Farquharson, 2005], [Lewis, 2006] 
Thus these networks, whether originating from epistemic communities, loose associations locally or globally based, or more the formal and organized structures consistent with the Advocacy Coalition Framework, have and continue to be important facilitators of the policy learning and diffusion as well as policy convergence, and the social changes associated with tobacco control policy adoption. A form of institution themselves, they have become institutionalized through, for example, the C.D.C.'s N.T.C.P., and have also been able to understand and utilize existing institutional arrangements to affect change. In Donabedian parlance, these networks have become the functional structures through which the processes to change both tobacco control policy adoption and the reduction of smoking prevalence are produced.

\subsection{Chapter Summary}

This chapter has presented a review of tobacco control policy from the political and policy science perspective. This chapter has examined both the conceptual underpinnings (generally) as well as the application to tobacco control policy (more specifically) for agenda setting theories and frameworks, the role of science and expert communities, the impact of the courts and legal proceedings, the effect of the morality-policy dimension of tobacco control policy, institutions and institutionalism, the role of social change and issue framing, policy learning and diffusion, and the effects of networks on tobacco control policy learning, diffusion, transfer and convergence. As a generalization, each of these sub-fields or topic areas contributes, using a common policy science phrase, a "lens" through which various aspects of the policy adoption component of the tobacco epidemic can be organized and explained. No single "lens" is "best" or provides the "right" explanation - each emphasizes slightly different causal factors and elements of the policy process. A comprehensive understanding of the factors influencing tobacco control policy adoption requires a broad and integrated understanding of the contributions from each of these "lenses". 


\section{AN INTEGRATED POLICY HISTORY OF THE EVOLUTION OF THE TOBACCO EPIDEMIC IN THE UNITED STATES THROUGH THE LENS OF IDEAS, INTERESTS, AND INSTITUTIONS}

\subsection{Chapter Introduction \& Purpose}

In the previous two chapters, the existing tobacco epidemic and tobacco control policy literature, representing the cumulative understanding and knowledge contribution, from two very different perspectives - that of the public health community and the political and policy science community - was reviewed. From the positivist perspective, the cumulative contribution of the public health community has been substantial, particularly as regards evidence establishing the biologic and epidemiologic causality of tobacco use and deleterious health outcomes as well as the development of "evidence-based" programs and policies to prevent tobacco use and / or promote the cessation of its use. However, a considerable portion of the literature from the public health perspective has a decidedly normative viewpoint. In particular, it is this normative viewpoint that supports the outlook that, having established the harmful health effects caused by tobacco use and exposure, the untoward and shady conduct of the tobacco industry, and the effectiveness of programs and policies to abate tobacco use, these policies and programs should therefore be universally and ubiquitously adopted so as to eventually abolish all tobacco use and exposure and ultimately eliminate the tobacco industry in its entirety. That is, this dimension of the public health perspective on the tobacco epidemic is rather dogmatic and prescriptive regarding how individuals ought to behave - or at least how individuals ought to be allowed to behave. This normative stance also typically interprets the absence of the policies and programs that "should" be in place as a "failure" of the political system, usually attributable to the undue influence of the tobacco industry.

Thus, this normative dimension of the public health perspective on the tobacco epidemic is rather narrow. Most particularly, it is a very narrow construction of policy process and the factors that influence it including, for example, a population's tolerance for or acceptance of governmental paternalism, trade-offs between social goods and individual rights, the relative values of different individual rights. Further, the strong de-normalization element within the public health community is, as has been discussed by others, anti-political and anti-democratic (owing to the presumption that the tobacco industry is not legitimate and so should not be given an legitimate voice in the policy process), which is an incongruous stance given the still-legal status of the activity (tobacco use) and the industry, and the pluralist nature of most industrialized societies. Additionally, this narrow interpretation of events and the tobacco 
epidemic could also be considered unscientific. Specifically, the reluctance to pursue explanations for the pace of policy adoption beyond that of impediments imposed by the "evil tobacco industry" could be viewed as some as the collection of data to support a position rather than the more scientifically grounded collection of data to test an hypothesis. Regardless, this normative dimension of the public health perspective flounders - perhaps because it is so normative - to provide a comprehensive or inclusive explanation for the evolution of the tobacco epidemic, particularly tobacco control policy adoption.

Explanations for the adoption (or lack thereof) of tobacco control policies are, however, the strength of the political and policy science perspective. The political and policy science literature has applied and contributed multiple theories and frameworks, particularly of the policy adoption process, to the tobacco epidemic in an effort to provide explanations for the how, if, when, and where tobacco control policies are adopted. Further, while the political and policy science perspective tends to be more positivist and without the normativist dimension of the public health literature, it is also not as well developed nor with the depth of the public health literature. For example, while some of these policy process frameworks and explanations seem particularly applicable, the scholarship to systematically and comprehensively apply them to the tobacco epidemic has simply not occurred. Additionally, in focusing on policy adoption as the primary outcome, the political and policy science literature typically overlooks or ignores that which the policies affect: tobacco use. Thus, each perspective largely ignores contributions of the other and, in their own way, each perspective also discounts the populace and its use of tobacco on policy adoption of and, thus, the evolution of the tobacco epidemic.

Therefore, the intent of this empirical chapter is to incorporate the two perspectives and literatures on the tobacco epidemic into an integrated narrative on the evolution of the tobacco epidemic. The framework that will be used to organize this integrated policy history is that of ideas, interests, and institutions.

\subsection{Ideas, Interests, and Institutions}

In presenting a framework with which to understand and explain the evolution of public policy, Heclo (Heclo H. , Ideas, Interests, and Institutions, 1994) identified three fundamental and inextricably intertwined constructs: ideas, interests, and institutions.

"At this point one begins to sense the liberating effect of seeing interests, institutions, and ideas not as the proprietary battleground among different social science "approaches" but as the shared patrimony of human materials for getting a better view of the world. The interrelationships are 
complicated, to be sure, but not every complication is a contradiction. We can recognize that interests, ideas, and institutions all "matter" in a very fundamental sense without forcing ourselves to choose which type of factor is analytically precedent ...."

Further, Heclo described each of these three pillars of policy evolution as:

“...self-interest probably explains more of the variance in political affairs than any other single factor, but this does not mean it explains very much...[but] individual choices are embedded in institutional settings that privilege some options and delete others ...."

And

"...institutions are supposed to be the things that stay around, fostering continuity and a long-term view of affairs.... Institutions are the bearers of such traditions and practices...Institutions may go beyond helping individuals signal and coordinate preferences more effectively, beyond privileging or deleting options, and beyond even the historical construction of understandings that bequeath meaning to our options an practices. "

Heclo discussed the "reciprocity" between these constructs such that it is difficult to identify discrete boundaries between them:

"... it is how to follow the strands of ideas, interests, and institutions as they intertwine and enfold in dynamic processes..."

And,

"Political institutions can also provide the means for changing ideas about our interests and preferences."

Thus, Heclo advanced that understanding policy evolution required an understanding of these three interdependent, dynamic constructs. It is this lens that will be used to examine the evolution of tobacco control policy in the United States.

\subsection{Ideas}

In the 1950s, cigarettes in America were both ubiquitous and superlative symbols of freedom and Americanism. With few restrictions, smoking was common in workplaces, Congressional committee rooms, by physicians at their patient's bedside, in restaurants, theatres, and airplanes - it was everywhere, and many, if not most, people did it. As symbols of youth, freedom, and American cool, cigarettes were the perfect accessory for James Dean's jeans, white t-shirt and tosseled hair, and Joe Camel $^{\mathrm{TM}}$ and the Marlboro Man ${ }^{\mathrm{TM}}$ were iconic American brands. To evolve from products with such social prominence and acceptance to ones highly restricted and with a negative social image, ideas about cigarettes by both the 
public and policy makers alike needed to cross two specific thresholds: a) that tobacco is a "problem product" whose use has negative consequences and imposes harm and unfair costs on society, and b) because of the nature of the product, society needs to be protected from these negative consequences, harms, and costs by government action. That is, there was a needed change in the ideas about the problem, the preference for a public or private solution for the problem, fundamental values regarding public protection among other things, or some combination of these ideas. The evolution of these ideas, then, is directly related to the reframing of tobacco in general and cigarettes specifically from iconic symbols of individualism and American freedom to that of a social menace. 
Table 5-1. Smoking and Tobacco-Related Reports of the U.S. Surgeon General, 1964-2007

\begin{tabular}{|c|c|}
\hline Year & Title \\
\hline 1964 & Smoking and Health: Report of the Advisory Committee of the Surgeon General of the Public Health Service \\
\hline 1967 & The Health Consequences of Smoking, A Public Health Service Review \\
\hline 1968 & The Health Consequences of Smoking: 1968 Supplement to the 1967 Public Health Service Review \\
\hline 1969 & The Health Consequences of Smoking: 1969 Supplement to the 1967 Public Health Service Review \\
\hline 1971 & The Health Consequences of Smoking: A Report of the Surgeon General: 1971 \\
\hline 1972 & The Health Consequences of Smoking 1972 \\
\hline 1973 & The Health Consequences of Smoking 1973 \\
\hline 1974 & The Health Consequences of Smoking 1974 \\
\hline 1975 & The Health Consequences of Smoking 1975 \\
\hline 1976 & The Health Consequences of Smoking: A Reference Edition \\
\hline 1979 & Smoking and Health: A Report of the Surgeon General \\
\hline 1979 & The Health Consequences of Smoking, 1977-1978 \\
\hline 1980 & The Health Consequences of Smoking for Women: A Report of the Surgeon General \\
\hline 1981 & The Health Consequences of Smoking - The Changing Cigarette: A Report of the Surgeon General \\
\hline 1982 & The Health Consequences of Smoking - Cancer: A Report of the Surgeon General \\
\hline 1983 & The Health Consequences of Smoking - Cardiovascular Disease: A Report of the Surgeon General \\
\hline 1984 & The Health Consequences of Smoking - Chronic Obstructive Lung Disease: A Report of the Surgeon General \\
\hline 1985 & The Health Consequences of Smoking - Cancer and Chronic Lung Disease in the Workplace: A Report of the Surgeon General \\
\hline 1986 & Smoking and Health, A National Status Report: A Report to Congress \\
\hline 1986 & The Health Consequences of Involuntary Smoking: A Report of the Surgeon General \\
\hline 1986 & The Health Consequences of Using Smokeless Tobacco \\
\hline 1988 & The Health Consequences of Smoking - Nicotine Addiction: A Report of the Surgeon General \\
\hline 1989 & Reducing the Health Consequences of Smoking - 25 Years of Progress: A Report of the Surgeon General \\
\hline 1990 & The Health Benefits of Smoking Cessation: A Report of the Surgeon General \\
\hline 1992 & Smoking and Health in the Americas: A Report of the Surgeon General \\
\hline 1994 & Preventing Tobacco Use Among Young People: A Report of the Surgeon General \\
\hline 1994 & Surgeon General's Report for Kids about Smoking \\
\hline 1998 & Tobacco Use Among U.S. Racial/Ethnic Minority Groups: A Report of the Surgeon General \\
\hline 2000 & Reducing Tobacco Use: A Report of the Surgeon General \\
\hline 2001 & Women and Smoking: A Report of the Surgeon General \\
\hline 2004 & The Health Consequences of Smoking: A Report of the Surgeon General \\
\hline 2006 & The Health Consequences of Involuntary Exposure to Tobacco Smoke: A Report of the Surgeon General \\
\hline 2007 & $\begin{array}{l}\text { Children and Secondhand Smoke Exposure-Excerpts from The Health Consequences of Involuntary Exposure to Tobacco Smoke: A Report of the } \\
\text { Surgeon General }\end{array}$ \\
\hline
\end{tabular}

In 1954 when approximately 45\% of Americans smoked, only 39\% of Americans believed that smoking caused lung cancer, but by 1992, when $23 \%$ of Americans smoked, the proportion of Americans who reported that smoking caused lung cancer was $92 \%$, or a $140 \%$ increase in this 38-year time period. (Morales, L; Gallup, Inc., 2008) Likely the single biggest agent for change during this period was the continual emergence of scientific evidence identifying an ever-increasing number of diseases, risk factors, and costs associated with tobacco use. Prominent among this scientific evidence has been the U.S. Surgeon General's office which has, between 1994-2007, released 34 reports on various aspects of tobacco use, cigarette smoking, exposure to secondhand smoke, and the health and economic consequences thereof (Table 5-1). Through these reports, not only has the information from individual scientific studies been summarized, synthesized, and presented in a publicly- 
digestible and actionable format, but the Surgeon General has given the information (i.e., results from individual scientific studies) credibility and prominence not otherwise achievable.

While population surveys on the knowledge and attitudes about the harmful effects of tobacco use and cigarette smoking have not been collected with the same frequency or standardized methodological rigor as, for example, smoking prevalence, the 1989 Surgeon General's Report did summarize such results from several different sources. (U.S. Department of Health and Human Services, Office of the Surgeon General, 1989) An overview of selected results from the "Adult Use of Tobacco Survey (A.U.T.S.)" is shown in Figure 5-1. The proportion of Americans who believe that smoking is harmful to your health, and that it causes lung cancer and heart disease have all increased substantially since 1964, the year of the seminal Surgeon General's report affirming that tobacco is causative of deleterious health outcomes. (U.S. Department of Health, Education, and Welfare, 1964)

The results from the A.U.T.S. survey, the Gallup, Inc. ${ }^{\circledR}$ polls, and the decline of smoking prevalence in the absence of substantive tobacco control policies until the 1980s (discussed in the Policy Stream below) strongly suggests that the American public, and so one can only assume policy makers as well, had an increasing understanding of the negative health

Figure 5-1. Overview of Results Regarding Knowledge and Attitudes about the Harmful Effects of Smoking

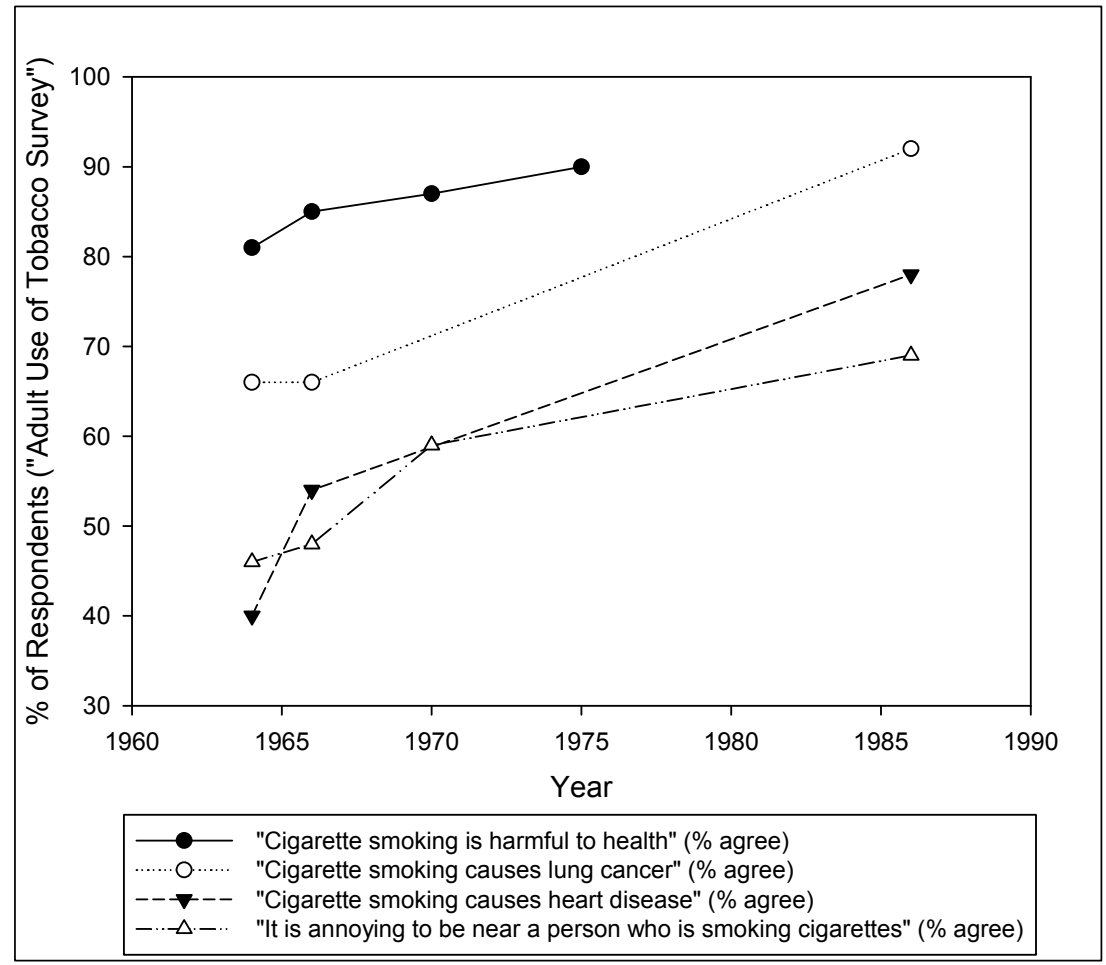

Data Source: (U.S. Department of Health and Human Services, Office of the Surgeon General, 1989)

Note: AUTS Survey Results Only 
consequences of smoking and tobacco use. However, the transformation of cigarettes from a harmful product left to strictly private decision making to a product requiring substantial government regulation and restriction was likely strongly related to three factors: 1) the emergence of evidence that secondhand smoke was also causative of deleterious health effects, 2) the rise of the non-smokers' rights movements, and 3) the demise of the tobacco industry. The 1986 Surgeon General's Report had as one of its principal conclusions that exposure to secondhand smoke (termed "involuntary smoking" in the report) caused lung cancer in healthy non-smokers. (U.S. Department of Health and Human Services, Office of the Surgeon General, 1986) Results summarized in the 1989 Surgeon General's report support the evolution of the public's view of this issue. (U.S. Department of Health and Human Services, Office of the Surgeon General, 1989) In 1974, 46\% of respondents agreed that smoking was hazardous to nonsmoker's health while $81 \%$ of respondents agreed with this statement in 1987 , though these data have different original sources. And has been discussed above, support for "totally banning" smoking in public places such as restaurants, workplaces, and hotels and motels has steadily increased from 1987-2005: for example, 17\% reported supporting a total smoking ban in restaurants in 1987 compared to 54\% in 2005 (Moore, D W; Gallup, Inc., 2005). The increasing evidence for the deleterious effects of secondhand smoke (culminating in the 1986 Surgeon General's report) was a key impetus for the formation and expansion of the nonsmokers' rights movement, which began in the 1970s and expanded rapidly thereafter. (Nathanson, 2007) These groups, such as G.A.S.P. (Groups Against Smokers' Pollution), were important agents in transforming and re-framing cigarettes, smokers, and the tobacco industry as infringing on the public's right to breathe clean air and jeopardizing the health of children, a traditionally protected social group. In any policy area, the ability to successfully link a policy image to a "right" is a powerful strategy in reframing a policy problem (Feldman \& Bayer, Unfiltered: Conflicts Over Tobacco Policy and Health, 2004) and this strategy has been successfully employed by these nonsmokers' groups.

Finally, while the favorable opinion of and prevalence of smoking had already begun to decline, another key factor has been the declining influence of the tobacco industry. Despite ample and credible scientific evidence to the contrary, including the 1988 Surgeon General's report (U.S. Department of Health and Human Services, Office of the Surgeon General, 1988), as late as 1994 tobacco industry executives testified under oath before a Congressional committee that nicotine was not addictive. This testimony was later undermined by documents from the tobacco industry itself, released as part of a settlement in a Minnesota law suit, and the 
credibility of the tobacco industry suffered substantially. Thereafter, it became far more difficult for the tobacco industry to position themselves as the "innocent victims" of aggressive targeting by zealous public health activists.

Regarding public attitudes towards tobacco control policies, these attitudes can be evaluated from different perspectives and at different levels of resolution. Unfortunately and regardless of the perspective or resolution, very little information has been systematically collected over regular, prolonged intervals and thus conclusions regarding the public ideas about and attitudes towards tobacco control policies must be inferred. At the macro-level, there have been periodic public opinion surveys regarding attitudes, defined broadly, toward restriction on smoking and tobacco sales. The 1989 Surgeon General's report summarized the results from several surveys. (U.S. Department of Health and Human Services, Office of the Surgeon General, 1989) While fully acknowledging the challenge of comparing results from different survey sources (including slightly different instruments and companies/groups administering the survey), in $196452 \%$ of all adults agreed that smoking should be allowed in fewer places than it is now compared to $70 \%$ in 1975 . In $197816 \%$ of adults favored a total ban on smoking in public places compared to $60 \%$ in 1988 , and in $196436 \%$ of adults agreed that cigarette advertising should not be permitted compared to $55 \%$ of adults in 1988 . Additionally, as was discussed above, Gallup, Inc. ${ }^{\circledR}$ has reported that, amongst adults, $17 \%$ favored total bans in restaurants and workplaces in 1987 compared to 54\% and 41\%, respectively, in 2005. (Moore, D W; Gallup, Inc., 2005) Results from individual studies also support a trend of more favorable attitudes towards restrictive tobacco control polices. In California and the U.S.A., there has been a $28.6 \%$ (from $58.5 \%$ to $75.8 \%$ ) and a $23.2 \%$ (from $46.5 \%$ to $57.3 \%$ ) respective increase in support for a smoking ban in at least four of six venue sites (restaurants, hospitals, indoor work areas, bars, indoor sports venues, indoor shopping malls). (Gilpin, Lee, \& Pierce, 2004) Finally, the National Social Climate Survey of Tobacco Control study, a recently established study based on social institutional theory, has reported similar trends: in $200061 \%$ of respondents felt that smoking should not be allowed at all in restaurants compared to $83.6 \%$ in 2008; and $59.7 \%$ of respondents in 2005 felt that people should not be allowed to smoke within twenty feet of a doorway compared to $65.1 \%$ in 2008. (American Academy of Pediatrics Julias B. Richmond Center of Excellence, 2008) Thus, based on the information from these disparate sources it is not unreasonable to infer that the social ideas have become more favorable to increasingly restrictive comprehensive tobacco control policies. 
In summary, since the early 1950 s tobacco and smoking has evolved from a widely used and widely accepted product to one which the majority of the population views unfavorably and as needing substantial regulation and restriction. While increasing knowledge about the deleterious effects of smoking and secondhand smoke has played an important role in the transformation of this issue, so too has the nonsmokers' rights movement and the actions of the tobacco industry itself. Thus, the two predominant yet diametric and competing images or "frames" regarding tobacco and smoking that currently exist are a) that cigarettes are an entirely unsafe and addictive product promoted by a deceptive and untrustworthy industry resulting in unjustifiable societal harm and cost and so should be banned outright vs. b) that provided the tobacco industry complies with existing legislation and regulation to protect those who chose not to smoke, then the government and society should leave the tobacco companies alone to sell their legal products to those who chose to exercise their right to smoke. It is clear that many ideas in the tobacco control debate have changed over time, including ideas about the health effects of smoking, the tobacco industry, and even some ideas about where it is and is not acceptable to smoke (and the subsequent support for smoking bans). However, it is less clear whether these changes in ideas are due to changes in information about tobacco use and the tobacco industry with associated changes in the understanding (construction) or risk and populations deserving protection, or if these changes in ideas are due to more fundamental changes in preferences for public vs. private solutions, or social values, which might, for example, indicate in a change in the preference or tolerance for paternalism in favor of unabridged individual rights. Neither is it clear if these ideas are distributed equally throughout a population at a given point in time (they most likely are not), their temporal distribution within a given society, or their relative distributions between societies at any given point in time. Empirical studies evaluating these questions, but could provide valuable insights into the role and importance of ideas in the adoption of tobacco control policy as well as tobacco use itself.

\subsection{Interests}

The struggle to enact tobacco control policy has, fundamentally, been a struggle between two competing interests: the interest of the state to prevent its citizens from smoking thereby improving health and avoiding unnecessary expenses, and the interests of the tobacco industry to continue to sell and profit by its legal products. The interests of the state can thus be interpreted as motivated by hard or soft paternalism and possibly (and more cynically) a desire by the bureaucracy to protect its [expanding] role in the "war on tobacco", and thus the state and other public health advocates work to support the adoption of more restrictive tobacco control 
policies. The interests of the tobacco industry can be understood as motivated by self preservation and profit, and thus in opposition to the adoption of tobacco control polices.

\subsubsection{Tobacco Industry Interests}

The opposition of the tobacco industry to regulation in any form has been well documented and specific details of activities have emerged in large measure because of the public disclosure of documents from American-based tobacco companies and, while this has clearly been a global phenomenon and strategy (Thomson \& Wilson, 2002), (Hiilamo, 2003), (Barraclough \& Morrow, 2008), (Smith \& Malone, 2006), (Smith, 2006), (Mamudu, Hammond, \& Glantz, 2008), (World Health Organization, 2008), many of the details have emerged because of the public disclosure of documents from American-based tobacco companies. The American release of these documents, which has resulted in the publication of many books and academic manuscripts as well as their warehousing on multiple websites in both the U.S. and the U.K., have had multiple sources including documents leaked from a tobacco industry insider to a university professor, as part of the disclosure and investigation for Congressional hearings, and, perhaps most significantly for both volume and impact, as part of the terms of the settlement in State of Minnesota v. Philip Morris (the State of Minnesota and Blue Cross and Blue Shield of Minnesota sued Philip Morris for conspiracy and fraud regarding the hazards of smoking, impeding the development of safer cigarettes, and intentionally targeting children as new consumers (Bero, 2003), (Public Health Law Center, 2010)), and the extension of the requirement for public disclosure of industry documents in the subsequent Master Settlement Agreement.

A substantial portion of the legacy of the disclosure of these documents has been to reveal tobacco industry strategies to defeat or impede tobacco control policies which can be categorized as: making misleading and fraudulent claims to the public and policymakers regarding both tobacco products (particularly health effects and nicotine addiction) and industry conduct; intentionally failing to disclose or hiding information regarding tobacco products and industry knowledge and strategies; creating controversies about scientific studies and public health reports, their claims, and / or their authors; extensive involvement of lawyers and a legalistic framework in scientific studies (or the critique thereof), marketing, and public relations; creation and funding of third-party groups to act as a non-partisan "front" for political lobbying, conducting scientific studies, conducting public relations campaigns, and funding public groups such as "smokers' rights" groups; global coordination amongst tobacco companies regarding strategies and tactics to counteract the public relations and legal liability of scientific evidence 
linking smoking to deleterious health effects; various tactics and strategies designed to pressure and influence other corporations and organizations into supporting tobacco industry positions; and, of particular interest to epidemiologists and public health advocates, obstruction of legislation requiring documentation of smoking on death certificates. (Bero, 2003), (Sweda Jr \& Daynard, 1996)

These now-disclosed documents have also, for example, brought "Operation Berkshire" to light, the code name for a cooperative and conspiratorial strategy amongst international tobacco companies dating back to 1977 , in attempt to counteract anti-smoking campaigns and legislation by continuing to create controversy over the veracity of study results linking smoking to morbidity and mortality and refusal to accept any such evidence as definitive "proof". (Francey \& Chapman, 2000) "Operation Berkshire" was accompanied by "Operation Mayfly", also a cooperative international effort designed to diminish the effect of the World Health Organization's report "Smoking or Health - The Choice is Yours", and involved a series of field tests and projects in Australia and New Zealand in and around 1981 to influence public opinion to be more favorable to smoking and the tobacco industry. (Francey \& Chapman, 2000) More recently, analysis of industry documents and other sources identified "Project Sunrise", a Philip Morris (U.S.A.) strategy which was started in 1995 to counter industry (and smoking) marginalization and bolster the social acceptability of smoking by "voluntarily and willingly" working with moderate tobacco control advocates while working to undermine and ostracize more strident tobacco control advocates, thus creating controversy and disagreement within the tobacco control movement in a classic divide-and-conquer approach. (McDaniel, Smith, \& Malone, 2006) Additionally, a recent report detailed how the tobacco industry was able, by providing funding to a study investigator, to obtain data from the Framingham Study in the early 1970s, now one of the most renowned and important longitudinal epidemiologic studies in American history, thus enabling a tobacco industry consultant to re-analyze the data in an effort to discredit existing Framingham-based studies on the associations between smoking and coronary heart disease (tobacco industry funding was terminated after the dataset was obtained). (Cataldo, Bero, \& Malone, 2010)

These documents have also allowed researchers to document tactics used as part of the tobacco industry's vociferous opposition to the release of the risk assessment of environmental tobacco smoke by the E.P.A., eventually released in 1993. (Muggli, Hurt, \& Repace, 2004) These tactics included: lobbying for an executive order to change the standards for risk assessments by federal agencies to create a delay in the release of the E.P.A. report; lobbying 
for an executive order to transfer jurisdiction from the E.P.A. to O.S.H.A., thereby making the E.P.A. report without weight or authority; creating controversy (and subsequent political pressure) about and discrediting the E.P.A.'s methodology and assessment procedures; working closely and directly with a single Congressman (Thomas Bliley, R-VA) to affect the policy and procedural processes from the "inside"; and finally, filing suit against the E.P.A., again in the attempt to delay or stop the release of the report, and discredit its contents before its release. While some tactics were not successful, others were - the release of the report was delayed and controversy surrounded its findings largely persisted until the tobacco industry suit against the E.P.A. was overturned by the U.S. Supreme Court, but that did not happen until 2002 (aspects of this case are discussed in more detail in the Judicial Stream below). (Muggli, Hurt, \& Repace, 2004)

Tobacco industry efforts to influence the policy process, either indirectly through contributions to political campaigns or directly through opposing ballot initiatives and taxes, have also been documented. At the central-level, a recent report documented that almost $\$ 7$ million from 17 tobacco industry political action committees was received by Congressional legislators (almost \$13,000 per member) during the period 1993-2000. (Luke \& Krauss, 2004) Further, while Republicans compared to Democrats received more money (respective mean contributions of $\$ 22,005$ vs. $\$ 6,057$ ) and were more likely to vote pro-tobacco on the 49 tobacco-related bills between 1997-2000 (73\% for Republicans vs. 23\% for Democrats), it was Democrats whose voting was more influenced by contributions compared to Republicans (Democrats were $9.8 \%$ more likely to vote pro-tobacco for every $\$ 10,000$ received compared to $3.5 \%$ more likely for every $\$ 10,000$ in contributions to Republicans). Tobacco industry contributions to legislators have also been shown to influence voting patterns in state legislatures. (Monardi \& Glantz, 1998) Also at the state-level, in 1997 the Tobacco Institute, a tobacco industry lobbying group, spent almost \$3 million on state lobbyists. (Givel \& Glantz, 2001) However, these "common wisdom" findings - that money=influence - has been challenged by a study reporting that longer-term voting patterns of U.S. Congress members were more related to political ideology, as measured by the Americans for Democratic Action voting score, than tobacco industry contributions or connections to the tobacco agricultural "bloc". (Wright, 2004) (This finding of the importance of political ideology is echoed in the findings from two Canadian studies that reported that ideology, as measured by a general orientation towards favoring government intervention in health promotion, was a significant predictor in Canadian legislators' support for tobacco control policies, though these studies were 
not assessing tobacco industry financial contributions or lobbying. (de Guia, et al., 2003), (Cohen, de Guia, Ashley, Ferrence, Northrup, \& Studlar, 2002)) Other key tactics employed by the tobacco industry at the state-level have included: lobbying and campaign contributions, particularly to those identified as "legislative leaders" regardless of their opinion toward smoking and / or the tobacco industry; gifts and honoraria; strategic alliances with like-minded or sympathetic interest groups or groups that could then work to indirectly advance the interests of tobacco (for example legislative groups); covert funding of front groups that were ostensibly unaffiliated with the tobacco industry while, in fact, being operated by the industry (for example, funding of groups who asserted to represent a restaurant or motel industry group though they were owned and funded by the tobacco industry); making every attempt to delay votes on legislation until time for the legislative session expired thus requiring the bill to be re-introduced; working to defeat or undermine legislation after enactment; and advocating for inclusion of preemption clauses in state legislation thus preventing localities from implementing stronger restrictions. (Givel \& Glantz, 2001)

In single issue areas, such as taxes, or single events, such as ballot initiatives, the tobacco industry has also been very adept at both understanding the specifics and nuances of and manipulating the process in their favor. For example, the industry has extensively funded citizen groups in order to facilitate issue re-framing favorably for the industry, such as funding groups to argue that tobacco taxes are socially unfair and regressive thereby re-framing the issue to create opposition toward increases in tobacco excise taxes. (Campbell \& Balbach, 2009) Additionally, the tobacco industry has been successful in defeating individual ballot measures when and where public health advocates have not been prepared for industry tactics including exploiting subtleties in procedural rules, developing tobacco-industry sponsored alternative ballot measures, and promulgating misinformation and voter confusion campaigns. (Tung, Hendin, \& Glantz, 2009)

The motivation for the tobacco industry to act with such vigor and with such resources is patently obvious: to protect their revenues and profits by preventing litigation, regulation, or marginalization. (Bero, 2003) Despite a decade of legal fights and a sharp increase in regulations, restrictions, and taxes, the tobacco industry continues to be very profitable. Altria, the parent company of Philip Morris, has recently reported a $27 \%$ increase in revenue, a $3.6 \%$ increase in total sales, and a $27 \%$ increase in their stock value over the past year. (Becker, $\mathrm{N}$; Dow Jones Newswire, 2010) Further, while cigarettes sales volume has decreased by $0.7 \%$, the sales volume of smokeless products has increased by $22 \%$. (Becker, N; Dow Jones 
Newswire, 2010) Each smoker represents a tremendous lifetime revenue stream for tobacco companies. For example, some authors have estimated that each smoking-addicted high school senior represents $\$ 20,000$ in lifetime revenues and that the $27 \%$ decline in the prevalence of smoking amongst high school seniors between 1997-2002 (from 36.5\% to 26.7\%) represented $\$ 4$ billion in forgone future revenues for tobacco companies. (Healton, Farrelly, Weitzenkamp, Lindsey, \& Haviland, 2006) In another series of estimates and calculations, images of smoking in movies are projected to entice 390,000 adolescents to start smokin which results in estimated lifetime revenues of $\$ 4.1$ billion and estimated lifetime profits of $\$ 894$ million for tobacco companies. (Alamar \& Glantz, 2006) Finally, as an example of the cost to the tobacco industry of comprehensive tobacco control programs, from 1989-2004 the California Tobacco Control Program was estimated to have prevented the sale of 3.6 billion packs of cigarettes representing $\$ 9.2$ billion in pre-tax revenues for the tobacco industry. (Lightwood, Dinno, \& Glantz, 2008) Thus, when such tobacco control programs are understood from this financial perspective, it is not difficult to see that, for the tobacco industry, a "few million" spent in an attempt to defeat tobacco control initiatives remains a cost effective, prudent investment.

\subsubsection{Public Health and State Advocacy Interests}

Countering the tobacco industry are anti-tobacco advocates. Groups opposing the tobacco industry have evolved substantially over time in number, focus, resources, and organization, the result of significant legal mobilization and social mobilization of interests efforts. What began as a few groups that formed in response to the mounting scientific evidence of the deleterious health effects and substantial (and avoidable) societal costs caused by tobacco products, has evolved (expansion) into a series of organizations and bureaucracies that support a (now) fairly extensive and overlapping network of coalitions. While it is beyond the scope of the present analysis to provide a detailed account of evolution of each these groups and networks, a broad overview and timeline is shown in Table 5-2. The C.D.C., the nation's leading public health agency, was established very early as a hub for the synthesis and dissemination of credible scientific information and support and technical information for groups and organizations promoting the adoption of anti-tobacco polices, including "how-to" and "best practices" for the organization, operation, and sustainability of coalitions. The C.D.C.'s promotion of a "coalition" or "network of coalitions" model is not unique to tobacco control, but rather is the most common model used by the C.D.C. and other public health agencies (e.g., the Robert Wood Johnson Foundation) in chronic disease prevention and health promotion activities. The C.D.C. regards a coalition as a group of individuals and organizations with a diverse array of skills, expertise, resources, and spheres of influence that come together to 
advance a specific cause (in this case, adoption of anti-tobacco policies) and who collectively can leverage these assets to affect change in ways the members could not individually. As discussed in Chapter 2, community-based coalitions are central to the C.D.C.'s strategy for implementing the National Tobacco Control Program. (Centers for Disease Control and Prevention, 2007)

In additional to the strategic, scientific, and financial that the C.D.C. provides to statelevel tobacco control programs and, in turn, these community-based coalition networks, the C.D.C. also provides support and advice on the structure, function, and sustainability of the community-based organizations and coalitions themselves. (Centers for Disease Control and Prevention, 2007) Many of these C.D.C. "best practice" strategies and approaches have been accumulated and assembled from the experiences - successful and otherwise - of the early anti-tobacco groups such as the Group Against Smoking Pollution (G.A.S.P.), the Action on Smoking and Health (A.S.H.), American Non-Smokers' Rights (A.N.R.), the collective experiences of the California anti-tobacco movement including the California Tobacco Control Program (widely considered to be pioneers in the anti-smoking campaign and the tobacco control policy movement), as well as from the formal, funded scientific trials assessing community-based approaches to implementing anti-tobacco policy trials such as the COMMIT, ASSIST, IMPACT, and SmokeLess States programs. In addition to these public coalitions, there are myriad other groups and coalitions, variously funded by private foundations and

Table 5-2. Overview of the Development of Anti-Tobacco Groups and Coalitions

\begin{tabular}{|c|c|c|}
\hline Era & Year & Event \\
\hline Grassroots / State Coalition & 1963 & - $\quad$ Colorado state coalition forms \\
\hline \multirow[t]{3}{*}{$\begin{array}{l}\text { Movement } \\
(1960 s-1980 s)\end{array}$} & 1965 & $\begin{array}{l}\text { - } \quad \text { CDC establishes the National Clearinghouse for Smoking and Health } \\
\text { - National Clearinghouse later becomes the Office on Smoking and Health }\end{array}$ \\
\hline & 1967 & - Action on Smoking and Health is formed \\
\hline & 1970s & - $\quad$ GASP (Group Against Smoking Pollution) networks form nationwide \\
\hline \multirow[t]{3}{*}{$\begin{array}{l}\text { National Movement } \\
\quad(1980 \mathrm{~s}-2000 \mathrm{~s})\end{array}$} & 1981 & $\begin{array}{l}\text { - Coalition on Smoking or Health forms (includes American Lung Association, } \\
\text { American Cancer Society, and the American Heart Association) }\end{array}$ \\
\hline & 1986 & - $\quad$ American's for Non-Smoker's Rights (ANR) is established \\
\hline & $1985-1993$ & $\begin{array}{l}\text { - National Cancer Institute funds the COMMIT (Community Intervention Trial for } \\
\text { Smoking Cessation) }\end{array}$ \\
\hline \multirow[t]{7}{*}{$\begin{array}{l}\text { Era of Coalition Funding } \\
\quad(1990 \text { s - Present })\end{array}$} & $1991-1998$ & $\begin{array}{l}\text { - National Cancer Institute and American Cancer Society fund ASSIST } \\
\text { (American Stop Smoking Intervention Study for Cancer Prevention) trial } \\
\text { - ASSIST is supplemented by the IMPACT (Initiative to Mobilize for the } \\
\text { Prevention and Control of Tobacco Use) trial by the CDC } \\
\text { - ASSIST and IMPACT trials later become incorporated into CDC's National } \\
\text { Tobacco Control Program }\end{array}$ \\
\hline & $1994-2000$ & $\begin{array}{l}\text { - Robert Wood Johnson Foundation in conjunction with the American Medical } \\
\text { Association fund the Smokeless States initiative }\end{array}$ \\
\hline & 1995 & $\begin{array}{l}\text { - Robert Wood Johnson Foundation launches the Center for Tobacco Free Kids } \\
\text { - This Center plays an important role in the negotiations leading up to the } \\
\text { Master Settlement Agreement }\end{array}$ \\
\hline & 1998 & $\begin{array}{l}\text { - American Legacy Foundation is created by and funded from the Master } \\
\text { Settlement Agreement }\end{array}$ \\
\hline & 1999 & - National Tobacco Control Program is launched at the CDC \\
\hline & 1999 & $\begin{array}{l}\text { - The CDC, Office on Smoking and Health, National Tobacco control Program } \\
\text { publishes the first "Best Practices for Comprehensive Tobacco Control } \\
\text { Programs" }\end{array}$ \\
\hline & 2007 & $\begin{array}{l}\text { - The CDC, Office on Smoking and Health, National Tobacco control Program } \\
\text { publishes and updated "Best Practices for Comprehensive Tobacco Control } \\
\text { Programs" }\end{array}$ \\
\hline
\end{tabular}

Source (in part): (Centers for Disease Control and Prevention, 2007) 
organizations whose mission is directly and solely tobacco-related (primary) or is also but indirectly tobacco-related (secondary), that also interact with all other types of organizations, coalitions, and networks. Based on the number of agencies who have listed themselves on the Action for Smoking and Health website, it is not unreasonable to estimate that the number of groups and individuals self-identifying as an anti-tobacco coalition (or part thereof) approaches 1,000 nationally (most states average 7-12 listed groups, but other states list many more groups - e.g., California has 69 groups and individuals listed). (Action for Smoking and Health, 2010)

Thus, the current, cumulative picture of anti-tobacco coalitions is that of a large, complex, and overlapping network of public agencies, private organizations and foundations, as well as individuals and groups at the national, state, and local levels. A schematic overview of these coalition networks and how they interact is presented in Figure 5-2. The interconnectedness, interdependence, and fluidity of these groups cannot be overemphasized. A recent social-network analysis of five C.D.C.-funded state coalitions examined how the network structure, communication style, and funding stability affects network productivity. (Krauss, Meuller, \& Luke, 2004) In addition to identifying that both communication style and funding stability were important in facilitating network productivity, the analysis illuminated the complexity of the social interactions - individuals and groups can act alone, in conjunction with

Figure 5-2. Schematic Representation of Current Anti-Tobacco Coalition Networks

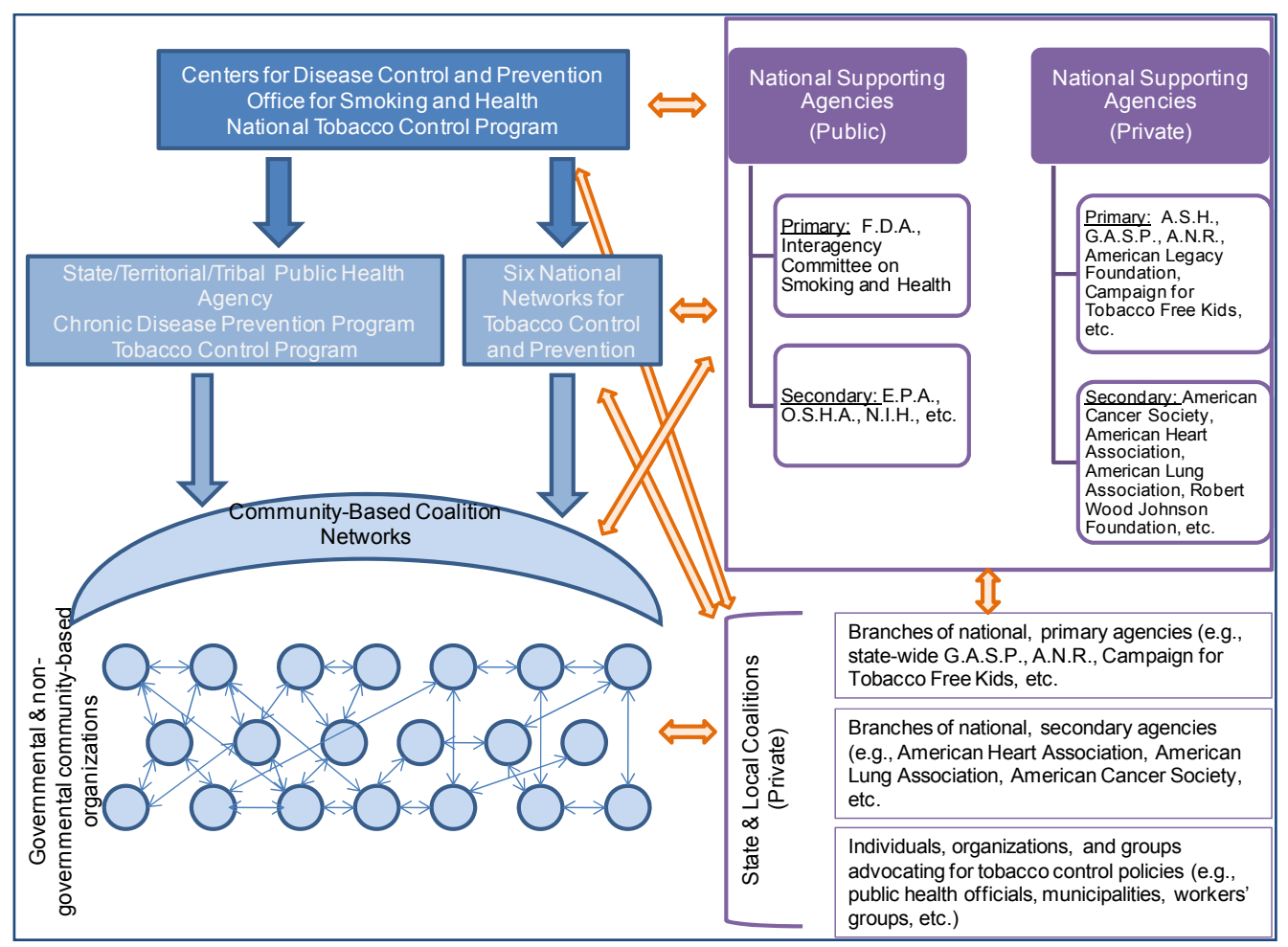


other members of a given coalition, as part of a collective coalition action, or as part of another (overlapping) coalition. (Krauss, Meuller, \& Luke, 2004) This interconnected network, then, serves not only as the functional component that implements the goals and initiatives of the C.D.C.'s National Tobacco Control Program, but also as the apparatus to counteract and oppose tobacco industry interest groups. That is, this apparatus and its constituent elements, fostered and developed as part of the National Tobacco Control Program, has evolved to be the political groups that challenge to the issue framing and interests of the tobacco industry in the public and policy arenas.

In summary, interest and advocacy groups have had substantial influence on the evolution of tobacco control issue expansion, mobilization, and counter-mobilization backlash, have most certainly affected the public's perception of tobacco and smoking as a problem (Problem Stream), opposing interest groups competing for control over issue framing, policy image, and policy subsystem at multiple venues within the American federalist structure have dominated the Politics Stream.

\subsection{Institutions}

If the starting point for the evaluation of the evolution of tobacco control policy is the 1940s-1950s, the dominant subsystem coalition (A.C.F.) or controller of the subsystem and policy image (P.E.T.) was the tobacco industry (which includes tobacco farmers). Thus, the tobacco industry, the then benefactors of the status quo, where highly motivated to maintain the policy image and venue / institutional arrangements, promote negative feedback, and prevent mobilization. In contrast, public health activists were highly motivated to impel matters in a diametrically opposite direction. As discussed above, public health advocacy networks and coalitions employed strategies such as framing and social construction, substantially aided by both scientific information and information gleaned from tobacco industry documents, to change the policy image and society's ideas about smoking and the tobacco industry in an effort to mobilize interest in order to disrupt the subsystem and pseudo-equilibrium and thereby affect policy change. An additional strategy employed by these public health advocacy networks was changing venues, thereby disrupting the institutional arrangements supporting the status quo and benefiting the tobacco industry. This strategy, implemented in numerous ways, has been greatly aided by the pluralist and federalist American system.

First, as reported by others, the primary central-level policy making venue in the tobacco industry controlled subsystem / pseudo-equilibrium was agriculturally-based committees and forums in Congress. (Baumgartner \& Jones, Agendas and Instability in American Politics, 1993), 
(Worsham, 2006) With re-framing and other efforts meant to expand the issue, public health advocacy networks and coalitions were able to gradually erode this policy monopoly and mobilize different Congressionally-based venues, such as health and welfare related committees. The ultimate result of this positive feedback was certainly the destruction of the old policy monopoly, which was institutionalized, in part, by the elimination of agricultural subsidies as part of the Master Settlement Agreement (and so agriculturally-based committees are no longer important policy making venues). Whether a new pseudo-equilibrium and policy monopoly has yet been re-established is still unclear; perhaps there will be an extended period of Weible's adversarial subsystem before a dominant coalition emerges. (Weible, Expert-based information and policy subsystems: a review and synthesis, 2008)

A second example of a venue-change strategy employed by the public health advocacy networks and coalitions has been the establishment, through the National Tobacco Control Program, of a network of community-based advocacy coalitions. In so doing, the C.D.C. compelled a change from central (national) level policy making venues to state and local policy making venues. Additionally, funding provided through the C.D.C. to state-level departments of public health has functionally institutionalized this venue change and, in so doing, has attempted to instill an oppositional voice to the tobacco industry in virtually every jurisdiction in the country.

A third and important venue-change strategy has been legal mobilization. Seminal cases in this legal mobilization are summarized in Appendix 1 (summarized in Table 5-3). As predicted by scholars of the role of the judiciary in policy, the trajectory of this mobilization has been complex, has met with much counter-mobilization backlash, and the implications for tobacco control policy are, in many instances, still uncertain. (Epp, 2008), (McCann, 2008) With the numerous different types of cases and legal bases for suits, the trajectory of this legal mobilization has not been as consistent or unidirectional - the resolution in some cases has represented advancement for tobacco control policy, while the resolution in other cases has represented clear restriction for tobacco control policy. Regardless of the ultimate resolution of a case, tobacco industry documents and scientific evidence have played increasingly important roles in cases over time, and the effective use of both internal industry documents and scientific evidence has also been an increasingly important factor in achieving a final judgment against the tobacco industry. Further, it is also clear that the tobacco companies have engage in substantial counter-mobilization backlash and have maintained their strategy of defending (or prosecuting) each case to the fullest extent possible using all means at their disposal, which are not unimposing. Given the revenue streams at stake for the tobacco companies, litigation is an 
Table 5-3. Summary of Seminal Legal Cases Discussed in Appendix 1

\begin{tabular}{|c|c|c|}
\hline Category & Example Cases & Impact on Policy \\
\hline $\begin{array}{l}\text { Class Action Suits Claiming } \\
\text { Personal Harm }\end{array}$ & $\begin{array}{l}\text { Cipollone v. Liggett Group } \\
\text { Engle v. R.J. Reynolds et al. }\end{array}$ & $\begin{array}{l}\text { - Unclear direct effects } \\
\text { - } \text { Possible secondary impacts: } \\
\text { - } \quad \text { liability and industry wrongdoing } \\
\text { - Making public previously unknown information through the } \\
\text { - } \quad \text { Product and industry framing in the Problem Stream } \\
\text { - Policy images in the Policy Stream } \\
\text { Unclear direct or secondary effects (these suits almost } \\
\text { universally unsuccessful) }\end{array}$ \\
\hline $\begin{array}{l}\text { Suits Claiming Harm from } \\
\text { Exposure to Secondhand or } \\
\text { Environmental Tobacco Smoke }\end{array}$ & $\begin{array}{l}\text { Helling v. McKinney, No. 91-1958 } \\
\text { Thaxton v Norfolk Southern Railroad Co., } 239 \mathrm{Ga} \\
\text { Gainsborough St. Realty Trust v. Haile, No. } 98- \\
02279\end{array}$ & $\begin{array}{l}\text { Direct impacts: } \\
\text { - Established the legal precedent for the harmful effects of } \\
\text { secondhand smoke } \\
\text { In establishing liability for not protecting non-smokers from } \\
\text { exposure to secondhand smoke, de facto requirements } \\
\text { (policy) for smoke-free environments created }\end{array}$ \\
\hline $\begin{array}{c}\text { Suits Seeking Reimbursement } \\
\text { for Tobacco-Attributable } \\
\text { Expenses }\end{array}$ & $\begin{array}{l}\text { Broin v. Philip Morris, Inc. et al } \\
\text { Moore v. American Tobacco, et al. } \\
\text { Case No. } 94-1429 \text {. followed by others, then the } \\
\text { Master Settlement Agreement } \\
\text { Blue Cross \& Blue Shield of N.J., Inc. v. Philip } \\
\text { Morris U.S.A Inc } \\
\text { Alabama Coushatta Tribe of Texas v. American } \\
\text { Tobacco Co.) } \\
\text { Iron Workers Local Union No. } 17 \text { Ins. Fund v. Philip } \\
\text { Morris Inc }\end{array}$ & $\begin{array}{l}\text { - } \quad \text { Complex impacts } \\
\text { The M.S.A. represented de facto policy by contractual } \\
\text { agreement with enforcement through civil contractual law } \\
\text { dispute mechanisms } \\
\text { Important secondary impacts: } \\
\text { - Establishment of the tobacco industry document library } \\
\text { - Creation of the American Legacy Foundation } \\
\text { - Controversial aspect: } \\
\text { Failure of states to use M.S.A. settlement payments to } \\
\text { adequately fund state tobacco control programs }\end{array}$ \\
\hline Suits Disputing Scope of Action & $\begin{array}{l}\text { Philip Morris v Day One } \\
\text { F.D.A. et al. v. Brown \& Williamson Tobacco Corp } \\
\text { Flue-Cured Tobacco Cooperative Stabilization } \\
\text { Corporation et al. v. the United States } \\
\text { Environmental Protection Agency No. 98-2407 } \\
\text { Lorillard Tobacco Co. et al. v. Reilly, Attorney } \\
\text { General of Massachusetts et al, No. 00-0596 } \\
\text { Commonwealth Brands, Inc., et al. v. FDA et al. } \\
\text { No. 1:09-CV-117-M } \\
\text { Smoking Everywhere, Inc., and Sottera, Inc., d/b/a } \\
\text { NJOY v. U.S. Food and Drug Administration et al. } \\
\text { Civil Case No. 09-771 (RJL)) } \\
\text { Altria Group, In., et al. v. Good et al } \\
\text { United States of America v. Philip Morris U.S.A, } \\
\text { Inc., et al. }\end{array}$ & $\begin{array}{l}\text { - Very complex, often with yet unclear impacts (cases still } \\
\text { ongoing or only recently concluded) } \\
\text { - Some actions (F.D.A. et al. v. Brown \& Williamson Tobacco } \\
\text { Corp, Lorillard Tobacco Co. et al. v. Reilly, Attorney General of } \\
\text { Massachusetts et al.) succeeded in greatly restricting } \\
\text { government scope of action that, as in the ruling in the latter } \\
\text { case on First Amendment commercial free speech standards, } \\
\text { functionally created enduring restrictions on the scope of } \\
\text { government policy } \\
\text { Some actions failed to restrict scope of government action } \\
\text { (Flue-Cured Tobacco Cooperative Stabilization Corporation et } \\
\text { al. v. the United States Environmental Protection Agency) }\end{array}$ \\
\hline
\end{tabular}

important tactic to delay implementation of a regulation or stop an industry practice thereby maintaining a revenue streams, even if temporarily while a case proceeds through the legal system.

Finally, an element of institutions that is most fundamental and also the least studied as it impacts tobacco control policy is cultural values. Cultural values are intimately intertwined with all aspects of policy making, yet little is understood about how a society's values regarding public vs. private solutions to problems, or the protection of individual human rights vs. property rights has impacted either tobacco control policy adoption or tobacco-related population health. Further, it is fairly patent that the ultimate goal of tobacco control advocates is the complete elimination of all tobacco products. The ability to attain this goal may well depend upon its 
consistency with pervading cultural values balancing individual freedoms with collective public health.

\subsection{Ideas, Interests, and Institutions and Policy Change}

In additional to Heclo's ideas, interests, and institutions, several elements of Kingdon's Multiple Streams Framework (Kingdon, 1984) supplement the understanding of the changes in tobacco control policy regimes, particularly policy entrepreneurs and policy windows which are discussed here.

\subsubsection{Focusing Events \& Policy Entrepreneurs}

Within the context of Kingdon's Multiple Streams Framework, focusing events are significant events, often "crises", that serve to focus much attention on a problem or issue and which Kingdon viewed as critical in opening the "policy window". Similarly, policy entrepreneurs are creative policy problem solvers who are able to recognize (or facilitate the creation of) a focusing event and the opening of the policy window and are able to "join" the streams in an open policy window to create policy and / or policy change.

The effort to enact comprehensive tobacco control policies has been a collection of myriad efforts, many of which have been cumulative and interdependent and pursued over the past 50-75 years. In such a long-standing, complex progression and because so many have participated, it would be tempting to list the many people and organizations who have contributed to or any event that may have impacted the evolution of tobacco control policies. However, the identification of a policy entrepreneur or focusing event is intended not to diminish the contributions of those not so designated, but rather to identify those people and events whose contributions were decisive. Therefore, five categories of policy entrepreneurs (politicians, advocacy organizations, non-governmental organizations, bureaucracies, and individuals) and three types of focusing events can be identified, each of which are discussed below.

Collectively, the Surgeon General's reports can be considered focusing events, particularly the 1964, 1986, and 1988 Surgeon General's reports (establishing that smoking causes morbidity and mortality, exposure to secondhand smoke causes morbidity and mortality, and that nicotine is addictive, respectively). While not a single event, their almost annual release and the commitment of the government to research and produce these reports on multiple different aspects of tobacco, smoking, and health, has had an unquestionable impact on the evolution of ideas about the problem. Further, as previously discussed, not only did 
these reports have the explicit endorsement of the government, but the attention they received gave prominence and attention to the findings of individual studies not otherwise obtainable, thus altering the perception of the problem and the problem image.

Also a series of events to be considered collectively, the release of tobacco industry documents from the various sources has had unquestionable effects on the evolution of ideas, interests, and institutions. The content of these documents, including the timeline of what the tobacco companies knew when, and the strategies and tactics routinely employed by the industry has had far reaching consequences that are still unfolding. In addition to influencing the image of the industry, the information gleaned from the study of these documents has had a profound impact on the outcome of myriad legal actions. Almost uniformly, these documents have greatly facilitated the ability of the government or other actors in holding the tobacco companies accountable as these documents have provided a unique form of "evidence" and "proof" of the willful actions of the tobacco companies.

Finally, the M.S.A. has also been studied by others as a focusing event. (Wood, 2006). However, given that the M.S.A. is de facto policy, it is unclear that policy itself can also be a focusing event. It is more likely that the events leading up to the M.S.A. would agree with Kingdon's conception of a focusing event. Specifically, the M.S.A., signed in 1998, can be viewed as being the culmination of a series of events over 5-7 years all of which served to focus attention on tobacco, smoking, and, perhaps more importantly, the tobacco industry. The series of events, all discussed above, in the 1990s included: the Synar Amendment in 1992; the release of the E.P.A. Risk Assessment in 1992 and the subsequent very public fight and filing of suit by the tobacco industry; the release of thousands of Brown \& Williamson internal documents and their subsequent publishing in a series of articles in the Journal of the American Medical Association in 1995 and then in book form ("The Cigarette Papers") in 1996; the announcement of the intention of the F.D.A. to regulate tobacco in 1995 and the Final Rule in 1996 followed by substantial legal action; and, also very importantly, a series of Congressional hearings conducted by Rep. Henry Waxman (D-CA) that variously summoned tobacco industry executives (who famously testified that smoking is not harmful for your health), and former tobacco-industry scientists and insiders. These events, coupled with a series of T.V. documentaries (the afore discussed "Smoke Screen" on A.B.C.'s "Day One" program) and Pulitzer Prize-winning magazine articles (Freedman, 1995), (Freedman, Philip Morris memo likens nicotine to cocaine, 1995) served to intensify scrutiny on both smoking but also the conduct of the tobacco industry. In the middle of these events, individual state Attorneys 
General began to file lawsuits on behalf of the states (Mississippi, the first state to do so, filed in 1994). The initial national settlement was announced in 1997, the McCain Bill failed in early 1998, and the M.S.A. signed in late 1998. Alternatively, then, the M.S.A. could be regarded as a needed alternate after the failure, in spite of all the attention and evidence, of the legislative process. Hence, the M.S.A. could be considered as an event that focused attention on the still powerful political influence of the tobacco industry. This time period - almost a decade-long period of sustained, multi-faceted activity and attention on this policy area - has also received substantial scholarly attention, being the subject of multiple books from both a public health and policy perspective. The 'tobacco wars' as the time period is commonly described, is widely regarded as being an extraordinary nexus of events and juncture in public policy making. This time period and these extraordinary, intertwined events are also the subject of multiple literary investigations that document and interrogate both the events and the actors in far more depth than can be discussed in this analysis.

In addition to focusing events, five categories of policy entrepreneurs are considered as being critical factors facilitating the advancement of tobacco control policies. Among politicians, Rep. Henry Waxman (D-CA), the late- Sen. Edward Kennedy (D-MA), and Sen. John McCain (R-AZ) have performed critical roles in the advancement of tobacco control policies. As the Chairman for the Subcommittee on Health and the Environment (House Committee on Energy and Commerce), Rep. Waxman was among the first to conduct hearings on tobacco issues in a Committee or setting outside of the agricultural policy subsystem (subsystems are discussed in detail in the next chapter), including the 1986 Committee hearing on the health effects of environmental tobacco smoke. In particular, the hearings conducted in 1994 (Rep. Waxman was then the ranking Majority member) with testimony from tobacco company executives and former scientists were particularly seminal. Rep. Waxman was also closely associated with the Synar Amendment and was a sponsor of the proposed Family Smoking Prevention and Tobacco Control Act of 2007, an earlier version of the Family Smoking Prevention and Tobacco Control Act enacted in 2009. Sen. John McCain worked to develop and then introduced the Universal Tobacco Settlement Act of 1997 (S.1414.PCS, also known as the "McCain Bill"), the legislation needed to enact the original 1997 proposed national settlement agreement to create a legislative framework for an aggressive, national, comprehensive tobacco control policy regime. The McCain Bill, however, did have enough votes to in the Senate and thus ultimately failed leading to the need to adopt the 1998 Master Settlement agreement, a much weaker, state-by-state, contractually-based approach to tobacco control. While postulated reasons for 
the failure of the McCain Bill have included the Senator's leadership style and legislative skills, the Bill and the Senator also had substantial opposition from within the Republican party as well as opposition from the tobacco industry. (Hook, 2000) Regardless of the outcome of the McCain Bill, many within the tobacco control advocacy community have acknowledged McCain's efforts to advance tobacco control policies. (Kranish, 2008) Finally, the late Sen. Edward Kennedy was also a long-standing proponent of tobacco control polices. Throughout his long political career, the Senator sponsored several tobacco bills, though many ultimately failed. In 2007, Kennedy introduced to the Senate the Family Smoking Prevention and Tobacco Control Act of 2007, the predecessor-bill sponsored by Rep. Waxman that ultimately became the Family Smoking Prevention and Tobacco Control Act of 2009.

Advocacy organizations have also been critical in working to draw attention to the issue and advance tobacco control policies. These groups are non-profit, independent organizations that have formed for the singular purpose of advancing tobacco control policies. Most prominently, these groups include the Action for Smoking and Health, Americans for Nonsmokers' Rights, and the Campaign for Tobacco-Free Kids, all of which formed very early in the anti-tobacco movement $(1967,1976$, and 1995 respectively) and have been active, prominent and outspoken advocates of tobacco control polices and equally outspoken opponents of "big tobacco". More recently, the American Legacy Foundation was formed pursuant to the M.S.A. and can also be considered member among this group of advocacy organizations. In addition to direct policy advocacy, these groups have functioned to continually maintain issue prominence by releasing reports and press releases, documenting events, and functioning as a source of information countervailing the messages, marketing, and tactics of "big tobacco". These groups have also frequently been involved in litigation, either as the initiators (plaintiffs), a named defendant, or author to an amicus brief in an ongoing legal proceeding. These advocacy organizations are differentiated from state-level, C.D.C.-funded tobacco coalitions by their duration and longer history of action, the independence of their funding and thus their ability to function more independently, innovatively, and vigorously to advance their organization's cause.

A similar group of advocacy organizations that have functioned as policy entrepreneurs are a group of non-governmental organizations including the American Cancer Society, the American Lung Association, the American Heart Association, and the Robert Wood Johnson Foundation. While these groups have functioned similarly to the advocacy organizations (above) as related to policy advocacy, publishing and disseminating reports and information, 
and filing amicus briefs, a fundamental difference is that these non-governmental organizations have a primary mission other than tobacco control and so tobacco control advocacy is a secondary, supportive component of their mission. This difference has had important implications for these groups, particularly as related to prioritization of resources and activities as well as engaging in activities that may jeopardize the larger mission of these groups. A secondary but important difference between these non-governmental organizations and the advocacy organizations (above) has been the functioning of these groups as grant-funding agencies. All four of these organizations have long-standing general grant programs and have, periodically, created tobacco-specific grant funding programs (e.g., the SmokeLess States program funded by the Robert Wood Johnson Foundation). Thus, these non-governmental organizations have also systematically supported the advancement of the body of scientific knowledge underpinning tobacco control policies. Both of these types of groups have had important, if slightly different, entrepreneurial roles in the advancement of tobacco control policies in large measure because of their ability, as previous studies of the entrepreneurial potential of non-governmental organizations have identified, to enlist and direct resources, including public opinion and trust, in ways that government cannot. (Magnusson, 2009)

The advocacy and non-governmental organizations are also distinguished from the government agencies and bureaucracies that have also had an important role in the advancement of tobacco control policies, including the National Cancer Institute (N.C.I.), C.D.C., F.D.A., and E.P.A. While some might question the designation as entrepreneurial for fulfilling the mission of the bureaucracy itself, the impact of the sustained efforts of these agencies cannot be in question. The C.D.C., F.D.A., and N.C.I. all reside within the Department of Health and Human Services (formerly the Department of Health, Education, and Welfare) with the N.C.I. administratively within the N.I.H. Both the N.C.I. and the C.D.C. became enmeshed in tobacco control efforts almost from the inception of this public health effort. The C.D.C. was integrally involved in all, including the early, Surgeon General's reports and, as lung cancer was the first adverse health outcome to be causally associated with smoking, the N.C.I. was also very early to adopt anti-smoking and cessation as part of their mission and agenda. Both the N.C.I. and C.D.C. have also been the leading grant-making agencies, thus being important facilitators in not only understanding the physiologic consequences of smoking but the development of efficient, effective, and evidence-based tobacco control policies, all of which have served not only to advance the knowledge of the field but have been critical in defending against the legal challenges of tobacco control legislation and regulation. The F.D.A. is notable 
because of its exclusion in the early tobacco control efforts. The announcement in 1995 by then-President Clinton and Dr. David Kessler (then-F.D.A. Commissioner, discussed below) to assume F.D.A. jurisdiction over tobacco, while ultimately overturned by the Supreme Court served to "force" a conversation within the tobacco control community, including supportive legislators, about how best to develop and implement a comprehensive, national, tobacco control policy regime in the United States. The ultimate result was the Family Smoking Prevention and Tobacco Control Act enacted in 2009, which legislated jurisdiction of tobacco regulation to the F.D.A. Finally, while the E.P.A. has had a comparatively small role in the evolution of tobacco control policy, it has been important. The E.P.A.'s insistence on proceeding with their environmental tobacco smoke risk assessment while facing substantial political, industry, and industry-supported public opposition followed by almost a decade of legal challenges served to bring substantial attention to the deleterious effects of environmental tobacco smoke. The 1992 risk assessment was ultimately upheld by the Supreme Court and, in while also being a vindication for the E.P.A., served to create a de facto requirement for smokefree environments.

Finally, there have been a series of individuals whose contributions have been entrepreneurial - innovative, creative, novel, risky, and with results that have substantially impacted the trajectory of tobacco control policy. These individuals and their contributions are identified below:

- Dr. David Kessler, a pediatrician, was the F.D.A. Commissioner from 1990-1997. With then-President Clinton, Dr. Kessler assumed F.D.A. jurisdiction over tobacco regulation and issued a Final Rule that was heavily focused on the prevention of use initiation by youth and adolescents. This strategic decision for policy focus continues to affect and influence problem and policy images and policy formulation. Although the 1996 Final Rule was eventually overturned by the Supreme Court, there is a direct connection between Dr. Kessler's actions in the early-mid 1990s and the Family Smoking Prevention and Tobacco Control Act enacted in 2009.

- Michael (Mike) Moore was the Attorney General for Mississippi from 1988-2004. He was the initiator of the state-led lawsuits against the tobacco companies seeking restitution for Medicaid expenditures for tobacco-related medical treatment. Mississippi was the first state to file their lawsuits, with other states following shortly thereafter. Moore became the de facto leader of the Attorneys General and the chief negotiator in the subsequent settlement agreement discussions. 
- Merrell Williams was working as a paralegal in 1988 for a firm in Kentucky which had a sub-contract with Brown \& Williamson to screen and code internal documents that might be damaging in a product liability suit. During the course of his work, Williams was assigned thousands of documents including documents about the company's knowledge about the health effects and addictiveness of smoking and marketing efforts aimed at children. Williams began smuggling documents out at night by strapping them to his waist under a girdle, copying them, and returning them in the morning. He kept a copy of the documents and also sent a copy to a friend in case anything happened to him. The path to the eventual release of the documents was complex, but they eventually ended up in the hands of Dr. Stanton Glantz (discussed below) - the infamous "Mr. Butts" mailing - as well as in the hands of Congress. Williams was sued by Brown \& Williamson, but eventually settled with them a sealed agreement.

- Matthew Myers has been the President of the Campaign for Tobacco-Free Kids since 2000 after being the organization's legal counsel for several years. Myers has a long history with tobacco control advocacy, including representing the Action for Smoking OR Health and being a negotiator in the 1998 M.S.A. discussions. Since the strategic decision by Kessler and the F.D.A. to focus policy on youth and adolescents, the Campaign and Myers have had increased prominence and were active in the formulation and advocacy for the Family Smoking Prevention and Tobacco Control Act of 2009.

- Dr. Jeffrey Wigand was the Vice-President of Research and Development at Brown \& Williamson in the early 1990s. Wigand became the famous "whistleblower" in the 1995 (and again in 1996) 60 Minutes (C.B.S.) documentary program on tobacco companies during which he asserted that tobacco companies were knowingly manipulating tobacco leaf blends in order to alter nicotine delivery. Wigand later made similar testimony to Congress. Wigand was the first tobacco industry "insider" to turn and testify against the tobacco companies; his story was told, in part, in the 1999 movie of the same name ("The Insider", Touchstone Pictures).

- Dr. Stanton A. Glantz is a professor of medicine at University of California San Francisco and is a well-known, long-time tobacco control activist. Currently, PubMed lists 277 publications for "Glantz SA" and, while his early publications reflect is initial training and research focus (cardiac function), as early as 1984 Dr. Glantz had begun to focus and publish on the health effects of secondhand smoke. (Glantz, What to do because evidence links involuntary (passive) smoking with lung cancer, 1984) Dr. Glantz received national attention when he became the receiver of the mailing from "Mr. Butts" 
of thousands of Brown \& Williamson documents, which he promptly published in a series of articles as well as a book (discussed above). Dr. Glantz has also been integrally involved in California's tobacco control efforts, a state known for its comprehensive policies and smoking prevalence rates among the lowest in the nation.

The above list of policy entrepreneurs is likely smaller than could be developed. Again, in any policy effort that has lasted decades countless individuals and groups will have contributed. Particularly omitted from the above list are individuals and groups that have been entrepreneurial in state-level policy activities, especially those in California and Minnesota which are widely regarded as "leader" states in the adoption of tobacco control polices. This omission is, in part, due to the focus of this analysis on national level efforts to adopt a comprehensive tobacco control policy regime.

\subsubsection{Policy Windows}

In Kingdon's Multiple Streams Framework, policy window are those unique opportunities for policy change which open infrequently and only for short periods of time. That is, policy windows are when new policy is adopted but because this can only be determined retrospectively (i.e., policy changed so a policy window must have been "open"), the Multiple Streams Framework cannot be considered true theory. However, as the present analysis is a retrospective application of the Framework its utility in understanding the trajectory of national tobacco control policy adoption in the United States is not jeopardized. Further, in a retrospective analysis, both the windows that "opened" and the windows that remained "closed" can be identified. Discussed below are the traditional policy windows that resulted in policy adoption through legislation, pseudo-policy widows that resulted in policy adoption through nonlegislative means, and failed policy windows -attempts to adopt legislation that failed.

\subsubsection{Traditional Successful Policy Windows}

These policy windows are those that resulted in policy through traditional, legislative means. These legislated Acts, as previously discussed, include:

- Comprehensive Smoking Education Act of 1984 which required warning labels on cigarette packages and the Surgeon General to report annually to Congress on the advertising practices of the tobacco industry and the health consequences of smoking; 
- Comprehensive Smokeless Tobacco Health Education Act of 1986 which required more and stronger warning labels on cigarette packages and that tobacco companies submit a list of product ingredients to the government;

- Synar Amendment to the Alcohol, Drug Abuse, and Mental Health Administration (A.D.A.M.H.A.) Reorganization Act of 1992 which required that all states adopt and enforce restrictions on the prohibition of sales of tobacco products to minors; and

- Family Smoking Prevention and Tobacco Control Act of 2009 which legislated jurisdiction of tobacco regulation to the F.D.A. and required substantial new and more restrictive regulations on the sales and marketing of tobacco products.

As also discussed above, other pieces of legislation, regulation, and Executive Order have also occurred, but the above five Acts are the most significant and those that have addressed comprehensive tobacco control.

\subsubsection{Non-Traditional, Non-Legislative Policy Windows}

These policy windows are those events that resulted in de facto tobacco control policy through non-traditional, non-legislative means. As discussed above, these events are almost exclusively related to litigation. These non-traditional, non-legislative policy windows include:

- Protection from environmental tobacco smoke. The series of individual and classaction lawsuits combined with the 1992 E.P.A. risk assessment that classified environmental tobacco smoke as a class A carcinogen (also upheld in litigation) created the expectation for smoke-free environments and liability for those not providing such environment;

- The Master Settlement Agreement of 1998. Though a contractual agreement between the tobacco companies and the individual states, these agreements created restrictions on advertising and promotion that had a comparable effect to similar restrictions that might have been enacted through legislation.

- Release of tobacco industry documents and tobacco industry practices. As has been discussed above, these documents and practices have been released through various means, almost all related to activities resulting from legal mobilization. Former tobacco industry executives and scientists have testified at Congressional hearings and as expert witnesses in legal proceedings, all of which are now part of the public record. Tobacco industry documents have been leaked directly ("Mr. Butts") as a result of legal proceeding and, most significantly, as part of the 
Minnesota settlement with the tobacco industry in 1998 and again as part of the Master Settlement Agreement of 1998. While the testimony or documents do not directly or indirectly constitute policy or even pseudo-policy, the knowledge gleaned from these sources has been critical in developing and justifying new tobacco control policies, especially in light of developments of case law and the expansion of First Amendment commercial free speech rights. In reading the full text of the Family Smoking Prevention and Tobacco Control Act of 2009 and the 2010 FDA Final rule, the importance of this information becomes manifest - it is critical in justification of the regulations and the demonstration that they have not unnecessarily or unduly infringed upon the rights of the tobacco companies.

\subsubsection{Failed Policy Windows}

Failed policy windows are attempts to achieve, through legislation or regulation, comprehensive tobacco control policy that failed. The two most patent examples of such failed policy windows are the 1996 F.D.A. Final Rule, which was overturned by the Supreme Court in 2000, and Universal Tobacco Settlement Act of 1997 (McCain Bill), which failed to clear the Senate and resulted in the failure of the 1997 proposed national settlement and the adoption instead of the Master Settlement Agreement. There were, however, many other failed legislative attempts at achieving a national comprehensive tobacco control regime. As a testament to both the challenges and complexity of achieving a national tobacco control policy regime, the THOMAS database at the Library of Congress was used to search the records from the $101^{\text {st }}-111^{\text {th }}$ Congress (January 1989 - present, the only dates available online) using the terms "tobacco prevention", "smoking prevention", and "tobacco control". (The Library of Congress, 2010) The results, after removal of duplicate records, are the 120 records representing each bill introduced into either the Senate or House of Representative summarized in the table below (Table 5-4). While it is acknowledged that each of the entries in this table are not truly independent, what is apparent in examining this table is that while some Congressional sessions have been more active than others, all Congressional sessions since 1989 have attempted to enact tobacco control policies. That is, the opponents of tobacco control policies have been comparatively successful in resisting regulation.

Table 5-4. List of Failed Tobacco Control Legislation (1989-2010)

\begin{tabular}{|c|c|c|c|}
\hline $\begin{array}{c}\text { Congress \# } \\
\text { 101st } \\
\text { (Jan. 1989-Jan. 1991) }\end{array}$ & $\begin{array}{c}\text { Title } \\
\text { Adolescent Tobacco Prevention Act of } 1989\end{array}$ & $\begin{array}{c}\text { Action } \\
\text { Introduced in Senate }\end{array}$ & $\begin{array}{l}\text { Reference } \\
{[S .1527 .1 S \text { ] }}\end{array}$ \\
\hline $101 \mathrm{st}$ & Adolescent Tobacco Prevention Act of 1989 & Introduced in Senate & [S.1528.IS ] \\
\hline 101st & Tobacco Control and Health Protection Act & Introduced in House & {$[\mathrm{H} . \mathrm{R} .5041 . \mathrm{IH}$} \\
\hline 101st & Tobacco Deregulation Act of 1990 & Introduced in House & {$[H . R .4965 .1 \mathrm{H}$} \\
\hline 101st & Tobacco Product Education and Health Protection Act of 1990 & Introduced in Senate & [S.1883.IS ] \\
\hline
\end{tabular}




\begin{tabular}{|c|c|c|c|}
\hline $\begin{array}{c}\text { Congress \# } \\
101 \mathrm{st}\end{array}$ & $\begin{array}{c}\text { Title } \\
\text { Tobacco Product Education and Health Protection Act of } 1990\end{array}$ & $\begin{array}{l}\text { Action } \\
\text { Introduced in House }\end{array}$ & $\begin{array}{l}\text { Reference } \\
{[\text { H.R.3943.IH] }}\end{array}$ \\
\hline 102nd & Adolescent Tobacco Prevention Act of 1991 & Introduced in Senate & [S.561.IS ] \\
\hline \multicolumn{4}{|l|}{ (Jan. 1991-Jan. 1993) } \\
\hline 102nd & Adolescent Tobacco Prevention Act of 1991 & Introduced in Senate & [S.560.IS ] \\
\hline 102nd & Healthy Students-Healthy Schools Act & Introduced in House & {$[H . R .4361 . I H]$} \\
\hline 102nd & Healthy Students-Healthy Schools Act & Introduced in Senate & [S.2191.IS ] \\
\hline $103 r d$ & Healthy Students-Healthy Schools Act & Introduced in Senate & [S.629.IS ] \\
\hline \multicolumn{4}{|l|}{ (Jan. 1993-Jan. 1995) } \\
\hline 103rd & Smokeless Tobacco Distribution Control Act of 1993 & Introduced in House & {$[\mathrm{H} . \mathrm{R} .3025 . \mathrm{IH}]$} \\
\hline 103rd & Women's Health Equity Act of 1993 & Introduced in House & [H.R.3075.IH] \\
\hline \multicolumn{4}{|l|}{ (Jan. 1995-Jan. 1997) } \\
\hline 104th & Women's Health Equity Act of 1996 & Introduced in House & {$[\mathrm{H} . \mathrm{R} .3178 . \mathrm{IH}]$} \\
\hline 104th & Women's Health Equity Act of 1996 & Introduced in Senate & [S.1799.IS ] \\
\hline 104th & Youth Smoking Prevention Act of 1995 & Introduced in House & {$[\mathrm{H} . R .2414 . \mathrm{IH}$} \\
\hline $\begin{array}{l}\text { 105th } \\
\text { (lan }\end{array}$ & Bipartisan NO Tobacco for Kids Act of 1998 & Introduced in House & [H.R.3868.IH] \\
\hline \multicolumn{4}{|l|}{ (Jan. 1997-Jan. 1999) } \\
\hline 105th & Bipartisan NO Tobacco for Kids Act of 1998 & Introduced in House & [H.R.3868.IH ] \\
\hline 105th & Common Sense Smoking Prevention Act of 1998 & Introduced in House & {$[\mathrm{H} . \mathrm{R} .4600 .1 \mathrm{H}$} \\
\hline 105th & $\begin{array}{c}\text { Departments of Labor, Health and Human Services, and Education, } \\
\text { and Related Agencies Appropriations Act, } 1998\end{array}$ & $\begin{array}{l}\text { Engrossed Amendment } \\
\text { as Agreed to by Senate }\end{array}$ & H.R.2264.EAS \\
\hline 105th & Drug Demand Reduction Act & Introduced in Senate & [S.2647.IS ] \\
\hline 105th & Healthy and Smoke Free Children Act & Introduced in Senate & [S.1492.IS ] \\
\hline 105th & Healthy and Smoke Free Children Act & Introduced in House & {$[$ H.R.3028.IH ] } \\
\hline 105th & Healthy Kids Act & Introduced in Senate & [S.1638.IS ] \\
\hline 105th & Healthy Kids Act & Introduced in House & {$[\mathrm{H} . \mathrm{R} .3474 . \mathrm{IH}]$} \\
\hline 105th & KIDS Act & $\begin{array}{c}\text { Placed on Calendar in } \\
\text { Senate }\end{array}$ & S.1889.PCS \\
\hline 105th & Minority Community Tobacco Reduction Act & Introduced in House & [H.R.4189.IH] \\
\hline 105th & National Tobacco Policy and Youth Smoking Reduction Act & $\begin{array}{l}\text { Senate Amendment } \\
\text { Ordered to be Printed }\end{array}$ & [S.1415.AS ] \\
\hline 105th & PAST Act & Introduced in Senate & [S.1648.IS ] \\
\hline 105th & Pregnant Mothers and Infants Health Protection Act of 1997 & Introduced in Senate & [S.938.IS ] \\
\hline 105th & PROTECT Act & Introduced in Senate & [S.1530.IS ] \\
\hline 105th & PROTECT Act & $\begin{array}{l}\text { Placed on Calendar in } \\
\text { Senate }\end{array}$ & {$[\mathrm{S} .1530 . \mathrm{PCS}$} \\
\hline 105th & Public Health and Education Resource (PHAER) Act & Introduced in Senate & [S.1343.IS ] \\
\hline 105th & Public Health and Education Resource (PHAER) Act & Introduced in House & {$[\mathrm{H} . \mathrm{R} .2764 . \mathrm{IH}$} \\
\hline 105th & Teen Tobacco Use Prevention Act of 1998 & Introduced in House & [H.R.3889.IH \\
\hline 105th & $\begin{array}{l}\text { To establish a responsible United States international tobacco policy, } \\
\text { to prevent tobacco companies from targeting tobacco products to } \\
\text { children, to ensure no government promotion of... }\end{array}$ & Introduced in House & H.R.3738.IH \\
\hline 105th & Tobacco Market Transition Act & Introduced in Senate & [S.1582.IS ] \\
\hline 105th & Tobacco Market Transition Act & Introduced in House & {$[\mathrm{H} . \mathrm{R} .3437 . \mathrm{IH}$} \\
\hline 105th & Tobacco Products Control Act of 1997 & Introduced in Senate & [S.201.IS ] \\
\hline 105th & Universal Tobacco Settlement Act & Reported in Senate & [S.1415.RS ] \\
\hline 105th & Universal Tobacco Settlement Act & Introduced in Senate & S.1415.IS ] \\
\hline 105th & Universal Tobacco Settlement Act & $\begin{array}{l}\text { Placed on Calendar in } \\
\text { Senate }\end{array}$ & {$[S .1414 . \mathrm{PCS}]$} \\
\hline 105th & Youth Smoking Prevention Act of 1997 & Introduced in House & {$[\mathrm{H} . R .516 . \mathrm{H}]$} \\
\hline 105th & Youth Tobacco Possession Prevention Act & Introduced in House & {$[\mathrm{H} . \mathrm{R} .3655 . \mathrm{IH}]$} \\
\hline $\begin{array}{l}\text { 106th } \\
\text { 106 }\end{array}$ & Child Tobacco Use Prevention Act of 2000 & Introduced in House & {$[\mathrm{H} . \mathrm{R} .4041 . \mathrm{H}]$} \\
\hline $\begin{array}{l}\text { (Jan. 1999-Jan. 2001) } \\
\text { 106th }\end{array}$ & $\begin{array}{c}\text { Children's Smoking Prevention, Health, and Learning Trust Fund Act } \\
\text { of } 1999\end{array}$ & Introduced in Senate & [S.584.IS] \\
\hline 106th & FDA Tobacco Jurisdiction Act of 2000 & Introduced in House & {$[\mathrm{H} . \mathrm{R} .4042 . \mathrm{H}$} \\
\hline 106th & KIDS Act & Introduced in Senate & [S.2379.IS] \\
\hline 106th & Safe and Drug-Free Schools and Communities Reauthorization Act & Introduced in Senate & [S.1823.IS \\
\hline 106th & Tobacco Use Prevention and Public Health Act of 1999 & Introduced in House & {$[\mathrm{H} . R .1289 .1 \mathrm{H}$} \\
\hline 106th & Youth Smoking Prevention and Public Health Protection Act & Introduced in Senate & [S.2568.IS ] \\
\hline 106th & Youth Tobacco Possession Prevention Act & Introduced in House & {$[\mathrm{H} . \mathrm{R} .144 . \mathrm{IH}$} \\
\hline 107th & Child Tobacco Use Prevention Act of 2001 & Introduced in House & H.R.1044.IH] \\
\hline \multicolumn{4}{|l|}{ (Jan. 2001-Jan. 2003) } \\
\hline 107th & FDA Tobacco Jurisdiction Act of 2001 & Introduced in House & {$[$ H.R.1043.IH] } \\
\hline 107th & KIDS Act & Introduced in Senate & [S.247.IS ] \\
\hline 107th & Leave No Child Behind Act of 2001 & Introduced in Senate & [S.940.IS ] \\
\hline 107th & Leave No Child Behind Act of 2001 & Introduced in House & [H.R.1990.IH] \\
\hline 107th & Safe and Drug-Free Schools and Communities Reauthorization Act & Introduced in Senate & [S.437.IS ] \\
\hline 107th & Tobacco Equity Elimination Act of 2002 & Introduced in House & {$[H . R .5035 .1 \mathrm{H}]$} \\
\hline 107th & $\begin{array}{l}\text { Tobacco Livelihood and Economic Assistance for our Farmers Act of } \\
\qquad 2002\end{array}$ & Introduced in House & {$[\mathrm{H} . \mathrm{R} .3940 . \mathrm{IH}$} \\
\hline 107th & $\begin{array}{l}\text { Tobacco Livelihood and Economic Assistance for Our Farmers Act of } \\
\qquad 2002\end{array}$ & Introduced in Senate & [S.2764.IS ] \\
\hline
\end{tabular}




\begin{tabular}{|c|c|c|c|}
\hline Congress \# & Title & Action & Reference \\
\hline 107th & Tobacco Market Transition Act of 2002 & Introduced in House & [H.R.4753.IH] \\
\hline 107th & Youth Smoking Prevention and Public Health Protection Act & Introduced in Senate & {$[S .2626 .1 S]$} \\
\hline $\begin{array}{l}\text { 108th } \\
\text { (Jan. 2003-Jan. 2005) }\end{array}$ & Family Smoking Prevention and Tobacco Control Act & $\begin{array}{l}\text { Engrossed as Agreed to } \\
\text { or Passed by Senate }\end{array}$ & S.2974.ES \\
\hline 108 th & Family Smoking Prevention and Tobacco Control Act & $\begin{array}{l}\text { Considered and Passed } \\
\text { by Senate }\end{array}$ & [S.2974.CPS ] \\
\hline 108th & Family Smoking Prevention and Tobacco Control Act & Introduced in Senate & [S.2461.IS ] \\
\hline 108th & Family Smoking Prevention and Tobacco Control Act & Introduced in House & {$[H . R .4433 . I H]$} \\
\hline 108th & Family Smoking Prevention and Tobacco Control Act & Introduced in Senate & [S.2461.IS ] \\
\hline 108th & HeLP America Act & Introduced in Senate & S.2558.IS \\
\hline 108th & Leave No Child Behind Act of 2003 & Introduced in Senate & [S.448.IS ] \\
\hline 108th & Leave No Child Behind Act of 2003 & Introduced in House & {$[\mathrm{H} . \mathrm{R} .936 . \mathrm{IH}]$} \\
\hline 108th & Quit Smoking Incentive and Opportunity Act of 2003 & Introduced in House & {$[\mathrm{H} . R .2876 .1 \mathrm{H}]$} \\
\hline 108th & Smuggled Tobacco Prevention Act of 2004 & Introduced in Senate & {$[S .2642 .1 S]$} \\
\hline 108th & Smuggled Tobacco Prevention Act of 2004 & Introduced in House & {$[H . R .4820 .1 \mathrm{H}]$} \\
\hline 108th & Tobacco Equity Elimination Act of 2003 & Introduced in House & [H.R.245.IH ] \\
\hline 108th & Tobacco Livelihood and Economic Assistance for our Farmers Act & Introduced in House & [H.R.140.IH] \\
\hline 108th & Tobacco Market Transition Act & Introduced in House & [H.R.986.IH] \\
\hline 108th & Tobacco Market Transition Act of 2003 & Introduced in Senate & [S.1490.IS ] \\
\hline 108th & Tobacco Market Transition Act of 2003 & $\begin{array}{l}\text { Placed on Calendar in } \\
\text { Senate }\end{array}$ & {$[S .1490 . P C S]$} \\
\hline 108th & $\begin{array}{l}\text { Tobacco Reduction, Accountability, and Community Enhancement } \\
\text { Act of } 2003\end{array}$ & Introduced in House & [H.R.3160.IH] \\
\hline 108th & Youth Smoking Prevention and State Revenue Enforcement Act & Introduced in House & {$[\mathrm{H} . R .1839 .1 \mathrm{H}]$} \\
\hline $\begin{array}{l}\text { 109th } \\
\text { (Jan. 2005-Jan. 2007) }\end{array}$ & Family Smoking Prevention and Tobacco Control Act & Introduced in Senate & [S.666.IS ] \\
\hline 109th & Family Smoking Prevention and Tobacco Control Act & Introduced in House & [H.R.1376.IH ] \\
\hline 109th & HeLP America Act & Introduced in House & H.R.5951.IH \\
\hline 109th & HeLP America Act & Introduced in Senate & [S.1074.IS ] \\
\hline 109th & Smoke Free Mothers and Babies Act of 2006 & Introduced in Senate & [S.3915.IS ] \\
\hline 109th & Smuggled Tobacco Prevention Act of 2005 & Introduced in House & {$[\mathrm{H} . \mathrm{R} .1377 . \mathrm{IH}]$} \\
\hline $\begin{array}{l}\text { 110th } \\
\text { (Jan. 2007-Jan. 2009) }\end{array}$ & Family Smoking Prevention and Tobacco Control Act & Reported in House & H.R.1108.RH \\
\hline 110th & Family Smoking Prevention and Tobacco Control Act & $\begin{array}{l}\text { Engrossed as Agreed to } \\
\text { or Passed by House }\end{array}$ & [H.R.1108.EH] \\
\hline 110th & Family Smoking Prevention and Tobacco Control Act & $\begin{array}{l}\text { Referred to Senate } \\
\text { Committee after being } \\
\text { Received from House }\end{array}$ & [H.R.1108.RFS ] \\
\hline 110th & Family Smoking Prevention and Tobacco Control Act & Introduced in Senate & [S.625.IS ] \\
\hline 110th & Family Smoking Prevention and Tobacco Control Act & Introduced in House & [H.R.1108.IH] \\
\hline 110th & HEALTH Act & Introduced in Senate & [S.1834.IS ] \\
\hline 110th & Lung Cancer Mortality Reduction Act of 2008 & Introduced in Senate & S.3187.IS ] \\
\hline 110th & Secondhand Smoke Education and Outreach Act of 2007 & Introduced in Senate & [S.2005.IS ] \\
\hline 110th & Smoke Free Mothers and Babies Act of 2007 & Introduced in Senate & [S.1013.IS ] \\
\hline 110th & Smuggled Tobacco Prevention Act of 2008 & Introduced in House & H.R.5689.IH \\
\hline 110th & $\begin{array}{l}\text { Stop Adolescent Smoking Without Excessive Bureaucracy Act of } \\
2008\end{array}$ & Introduced in House & {$[\mathrm{H} . \mathrm{R} .5513 . \mathrm{IH}$} \\
\hline $\begin{array}{l}\text { 111th } \\
\text { (Jan. 2009-Jan. 2011) }\end{array}$ & $\begin{array}{c}\text { Agriculture, Rural Development, Food and Drug Administration, and } \\
\text { Related Agencies Appropriations Act, } 2010\end{array}$ & $\begin{array}{l}\text { Engrossed as Agreed to } \\
\text { or Passed by House }\end{array}$ & [H.R.2997.EH] \\
\hline 111 th & $\begin{array}{l}\text { Agriculture, Rural Development, Food and Drug Administration, and } \\
\text { Related Agencies Appropriations Act, } 2010\end{array}$ & $\begin{array}{l}\text { Placed on Calendar in } \\
\text { Senate }\end{array}$ & [H.R.2997.PCS \\
\hline 111th & $\begin{array}{l}\text { Agriculture, Rural Development, Food and Drug Administration, and } \\
\text { Related Agencies Appropriations Act, } 2010\end{array}$ & Public Print & [H.R.2997.PP ] \\
\hline 111th & $\begin{array}{c}\text { Agriculture, Rural Development, Food and Drug Administration, and } \\
\text { Related Agencies Appropriations Act, } 2010\end{array}$ & $\begin{array}{l}\text { Engrossed Amendment } \\
\text { as Agreed to by Senate }\end{array}$ & [H.R.2997.EAS \\
\hline 111th & Family Smoking Prevention and Tobacco Control Act & Introduced in Senate & [S.982.IS ] \\
\hline 111th & Family Smoking Prevention and Tobacco Control Act & Introduced in House & {$[H . R .1256 . I H$} \\
\hline 111th & Family Smoking Prevention and Tobacco Control Act & Reported in House & [H.R.1256.RH \\
\hline 111th & Federal Tobacco Act of 2009 & Introduced in Senate & [S.579.IS ] \\
\hline 111th & Lung Cancer Mortality Reduction Act of 2009 & Introduced in Senate & [S.332.IS \\
\hline 111th & Lung Cancer Mortality Reduction Act of 2009 & Introduced in House & {$[H . R .2112 .1 \mathrm{H}]$} \\
\hline 111th & $\begin{array}{l}\text { Resolved, That the bill from the House of Representatives (H.R. } \\
\text { 1256) entitled 'An Act to protect the public health by providing the } \\
\text { Food and Drug Administration with certain authority... }\end{array}$ & $\begin{array}{l}\text { Engrossed Amendment } \\
\text { as Agreed to by Senate }\end{array}$ & [H.R.1256.EAS \\
\hline 111th & Smoke Free Mothers and Babies Act of 2009 & Introduced in Senate & [S.670.IS ] \\
\hline 111th & Smoke-Free Federal Workplace Act & Introduced in House & {$[H . R .4131 .1 \mathrm{H}]$} \\
\hline 111th & STOP Act & Introduced in Senate & [S.3288.IS ] \\
\hline 111th & STOP Act & Introduced in House & {$[\mathrm{H} . \mathrm{R} .5178 . \mathrm{IH}]$} \\
\hline 111th & $\begin{array}{l}\text { Stop Adolescent Smoking Without Excessive Bureaucracy Act of } \\
\qquad 2009\end{array}$ & Introduced in House & H.R.1432.IH] \\
\hline 111th & $\begin{array}{l}\text { To protect the public health by providing the Food and Drug } \\
\text { Administration with certain authority to regulate tobacco products, to } \\
\text { amend title 5, United States Code, to make certain... }\end{array}$ & $\begin{array}{l}\text { Enrolled as Agreed to or } \\
\text { Passed by Both House } \\
\text { and Senate }\end{array}$ & [H.R.1256.ENR \\
\hline 111th & To protect the public health by providing the Food and Drug & Placed on Calendar in & [H.R.1256.PCS ] \\
\hline
\end{tabular}




\begin{tabular}{|c|c|c|c|}
\hline Congress \# & $\begin{array}{c}\text { Title } \\
\text { Administration with certain authority to regulate tobacco products, to } \\
\text { amend title 5, United States Code, to make certain... }\end{array}$ & $\begin{array}{l}\text { Action } \\
\text { Senate }\end{array}$ & Reference \\
\hline 111th & $\begin{array}{l}\text { To protect the public health by providing the Food and Drug } \\
\text { Administration with certain authority to regulate tobacco products, to } \\
\text { amend title 5, United States Code, to make certain... }\end{array}$ & $\begin{array}{c}\text { Engrossed as Agreed to } \\
\text { or Passed by House }\end{array}$ & H.R.1256.EH \\
\hline 111th & Youth Prevention and Tobacco Harm Reduction Act & Introduced in House & {$[H . R .1261 .1 H]$} \\
\hline
\end{tabular}

\subsection{Chapter Summary \& Contribution}

Using Heclo's ideas, interest, and institutions framework, and Kingdon's Multiple Streams Framework this chapter has integrated the political and policy science viewpoint with the public health perspective on the evolution of the tobacco epidemic to provide a more comprehensive policy history analysis of critical factors in this evolution, including the adoption of tobacco control policies. A persistent observation has been the tension between oppositional forces those motivating progression towards comprehensive tobacco control policy and those forces opposing such policy adoption. The forces motivating more comprehensive policy have included the advancing knowledge of the health consequences of smoking and exposure to secondhand smoke whereas the opposing forces have included social norms and expectations for the appropriate role of government and tolerable balance between individual and property rights. Changes in the ideas and images toward smoking and the tobacco industry has motivated the adoption of more restrictive policy while opposing interest groups have vied for the attention and favor of legislators. Additionally, policy adoption has alternately been facilitated and opposed by activities resulting from legal mobilization. The ability of tobacco control advocates to achieve their ultimate goal - elimination of all tobacco products - will likely depend upon a fundamental change in pervading cultural values balancing individual freedoms with collective public health. 


\section{ASSOCIATIONS BETWEEN TOBACCO CONTROL POLICIES, PROGRAMS, AND POPULATION TOBACCO-RELATED HEALTH IN THE U.S. STATES}

\subsection{Chapter Introduction \& Purpose}

Based upon the literature reviews and analyses in the previously presented chapters, it is clear that the trajectory of the tobacco epidemic in industrialized countries is intertwined with substantial social change. This social change is particularly notable in Heclo's sphere of ideas, as discussed in the previous chapter. As social change is entwined with secular decrease in tobacco use and increase in tobacco control policy adoption, it is reasonable to inquire as to the temporal relationship between policy adoption and population-level tobacco use. The public health perspective assumes that policy drives changes in tobacco use, largely discounting the role of social change, in particular ideas and cultural values (institutions), as factors facilitating or impeding the adoption of tobacco control policy. The political and policy science perspective, despite the theoretical if not empirical understanding that smoking prevalence is an important political outcome and factor in the policy adoption process (e.g., (Marmor \& Lieberman, 2004)), in essence ignores the effect - or effectiveness - on the population on whose behalf the policies are adopted. Thus, the purpose of this chapter is to explore the nature of the temporal relationship between tobacco control policy adoption and population-level tobacco use.

\subsection{Background}

Tobacco use is widely regarded as the single most preventable cause of death worldwide. (World Health Organization, 2008) Its deleterious health effects are well known: smoking has been shown to cause almost a dozen cancers and chronic diseases such as cardio- and cerebrovascular disease, aneurysms, and periodontitis among others. (Centers for Disease Control and Prevention, 2009) Additionally, exposure to second hand smoke has been causally linked to sudden infant death syndrome, respiratory illness, lung cancer, cardiovascular disease, and low birth weight. (Centers for Disease Control and Prevention, 2009) More recently, it has also been demonstrated that exposure to the toxins in so-called "third hand smoke", the residue deposited on fabrics and surfaces by cigarette smoke and that remain after the cigarette is extinguished, causes adverse health outcomes. (U.S. Department of Health and Human Services, Office of the Surgeon General, 2006) The World Health Organization (WHO) has estimated that, by 2030 , tobacco use will cause 8 million deaths annually and result in 1 billion cumulative deaths during the $21^{\text {st }}$ century. (World Health Organization, 2008) 
The public health case, then, for enacting strict tobacco control policies or even an outright ban on tobacco is straightforward: the causal links between smoking and disease and death were definitively established in the 1960s with the publishing of the US Surgeon General's Report "Smoking and Health" (U.S. Department of Health, Education, and Welfare, 1964), and the vigor of that scientific evidence has only strengthened in time, including the expansion to non-tobacco users involuntarily exposed to second- and third-hand tobacco smoke. (U.S. Department of Health and Human Services, Office of the Surgeon General, 2006), (Centers for Disease Control and Prevention, 2009) Further, the estimated 6-8\% of all health care expenditures spent treating smoking-related diseases is entirely preventable. (Warner, The economics of tobacco: myths and realities, 2000)

The toxic contents of cigarettes are also well established. Of the 200-250 poisonous gases and chemicals in cigarettes, many are severely restricted or banned in all other applications. For example, eleven of the chemicals are classified as type 1 carcinogens (the most lethal classification), one is radioactive, and others, such as lead, are known to cause mental retardation and developmental delays in children. (U.S. Department of Health and Human Services, Office of the Surgeon General, 2006)

Finally, nicotine is a potent psychostimulant similar to amphetamines or cocaine, with a significant addictive potential. (Balfour, 2002) Research has demonstrated that the addiction is established very early - possibly as soon as the first cigarette - in use, (DiFranza, 2008) and review of tobacco industry documents has shown that cigarette contents have been intentionally manipulated in order to circumvent nicotine content regulations while increasing the addictiveness of nicotine through 'freebasing', a chemical process virtually identical to and with the analogous effects of freebasing cocaine as 'crack cocaine'. (Stevenson \& Proctor, 2008)

In their 2000 decision in the case of FDA v. Brown \& Williamson Tobacco Corp. et al, the U.S. Supreme Court agreed with almost all of the arguments regarding the toxicity and danger of cigarettes and then, ironically, denied the F.D.A. the authority to regulate cigarettes. Citing the F.D.A.'s own primary directive to assure the safety and effectiveness of products for their intended use, the Supreme Court rationalized that under these criteria the F.D.A. would be required to ban all tobacco products, which was clearly contrary to the intentions of Congress in light of the 'alternate regulatory scheme' and thus regulation of cigarettes was ruled as outside the jurisdiction of the F.D.A.. Thus, within the U.S. (and elsewhere), tobacco remains classified as a consumer product, not a drug or hazardous compound, and its regulation within the 
purview of the Congress or other legislative body. Enacting tobacco control policies, therefore, has and continues to require the action of the policy making apparatus of a given jurisdiction. The challenge in the U.S., then, as in other industrialized countries, has been to enact tobacco control policies so as to avert the substantial personal and societal costs associated with tobacco use. Despite the profound change in the information known about tobacco use and the tobacco industry as well as the associated policy images, tobacco control policy adoption, especially at the central level, has lagged. According to two models developed to characterize the tobacco epidemic, the Phases of Tobacco Control (Studlar, Tobacco Control. Comparative Politics in the United States and Canada, 2002), (Studlar, U.S. tobacco control policy: public health, political economy, or morality policy?, 2008) and the Tobacco Epidemic Model (Lopez, Collishaw, \& Piha, 1994), adoption of tobacco control policies does not begin until decades after the onset of the epidemic and well after the entrenchment of tobacco use in the society. However, as has been observed in all industrialized countries, smoking prevalence begins to decline before policy adoption, leading to the question of the temporal association and relationship between smoking prevalence, tobacco control policies, and tobacco control programs and regimes.

There is a substantial body of scientific literature that has developed the evidence base for effective tobacco control policies. (e.g., as summarized in (Levy, Chaloupka, \& Gitchell, The effects of tobacco control policies on smoking rates: a tobacco control scorecard, 2004)) Further, three large research programs contributed substantially to the knowledge base for the development of effective tobacco control programs:

- COMMIT (Community Intervention Trial for Smoking Cessation)

- Funded by the National Cancer Institute of the National Institutes of Health

- Focused on heavy smokers

- Ended in 1992

- Participating communities: Vallejo, CA , Hayward, CA, Cedar Rapids/Marion, IA, Davenport, IA, Fitchburg/Leominster, MA, Lowell, MA, Paterson, NJ, Trenton, NJ, Santa Fe, NM, Las Cruces, NM, Yonkers, NY, New Rochelle, NY, Utica, NY, Binghamton/Johnson City, NY, Raleigh, NC, Greensboro, NC, Medford/Ashland, OR, Albany/Corvallis, OR, Bellingham, WA, Longview/Kelso, WA, Brantford, Ontario, Canada, Peterborough, Ontario, Canada 
- $\quad$ ASSIST (American Stop Smoking Intervention Study)

- Funded by the National Cancer Institute of the National Institutes of Health

- Planning phase (October 1991 - October 1993) and implementation phase (November 1993 - September 1999)

- 17 participating states (Colorado, Indiana, Maine, Massachusetts, Michigan, Minnesota, Missouri, New Jersey, New Mexico, New York, North Carolina, Rhode Island, South Carolina, Virginia, West Virginia, Washington, Wisconsin)

\section{- Smokeless States}

- Funded by the Robert Wood Johnson Foundation

- 48 state-wide coalitions (plus 2 additional non-state coalitions) from 19932004

These programs were all funded by government-sponsored research funding institutes or private research foundations and the C.D.C's National Tobacco Control Program was developed using findings and recommendations from these research programs. That is, in the U.S., the central government, even though it lagged in central-level policy adoption, was instrumental in developing the multi-level network of community-based advocacy coalition structure in place in the U.S. today.

In the United States, tobacco control programs are implemented by the individual states. This organizational arrangement facilitates inter-state analyses comparing features of either tobacco control programs and / or policies implemented at the state-level and measures of state population health (e.g., smoking prevalence). California followed by Massachusetts, Arizona, Oregon, and Florida were the first states to implement state-level tobacco control programs and thus early evaluations of "state tobacco control programs" were case-study based approaches to examining the structures and processes implemented in these early-adopter states and the subsequent progress in the reduction of smoking prevalence. (Siegel, 2002), (Wakefield \& Chaloupka, Effectiveness of comprehensive tobacco control programmes in reducing teenage smoking in the USA, 2000), (Pierce, 2007) Population-based analyses have also been undertaken. (Luke, Stamatakis, \& Brownson, State youth-access tobacco control policies and youth smoking behavior in the United States, 2000), (Farrelly, Pechacek, Thomas, \& Nelson, 2008), (Tauras, et al., 2005) Generally, state spending on tobacco control programs has been reported to be statistically significantly and negatively associated with smoking prevalence. 
Interestingly, the associations were much stronger when individual-level rather than populationlevel smoking prevalence was outcome and dependent variable, thus allowing for direct adjustment for socioeconomic status and demographic variables. (Tauras, et al., 2005), (Farrelly, Pechacek, Thomas, \& Nelson, 2008) Additionally, statistical methods that allowed for weighting of previous spending on tobacco control increased the association between current spending and declines in smoking prevalence, though the authors could not determine the reason for this observation or the important (causative) aspects of a state's tobacco control program. (Farrelly, Pechacek, Thomas, \& Nelson, 2008)

A primary challenge with these studies that may account for the perhaps more tepid than expected results is the implicit assumption in the directionality of causality from tobacco control program to smoking prevalence. In other words, while it is typically assumed that comprehensive tobacco control programs cause a decrease in smoking prevalence, in fact it may be that a lower smoking prevalence, which can conceivably serve as a proxy for the social acceptability of smoking and / or socially-based institutionalized values, may precede tobacco control policy adoption and represent reduced barriers to such policy adoption. That is, some social changes may occur before policy changes, thereby creating a feedback mechanism. Any such feedback mechanism would not be detectable in a precede-proceed evaluation model or before-and-after study design. Further, these feedback mechanisms, or "social conditioning" and creation of social predispositions to tobacco control policy, may be heightened in the case of states that were early innovators and participants in the scientific studies that served as the basis for the best-practice comprehensive tobacco control programs. Therefore, the primary purpose of this study is to assess the timing of changes in smoking prevalence (social change) compared to policy change. It is hypothesized that lower prevalence in advance of policy change supports the notion that social change precedes policy change.

\subsection{Materials and Methods}

All fifty states as well as the District of Columbia were included in this study. Populationlevel smoking prevalence was used as the health outcome variable as well as a proxy variable for social changes leading to a reduction in barriers to adoption of tobacco control policy. Six tobacco control policies were selected for their range in direct impact on individual behavior and thus perceived "intrusiveness" as well as uniform data availability. The six selected policies were:

1. Smoke-free indoor air policies at government worksites

2. Smoke-free indoor air policies at private worksites 
3. Smoke-free indoor air policies at restaurants

4. State cigarette excise tax

5. Youth access to cigarette vending machine policies

6. Policies requiring licensure for tobacco retail locations

Data on state-level policy and smoking prevalence were obtained from the C.D.C's STATE data system (publicly available at www.cdc.gov). Annual smoking prevalence data were obtained from 1990 to 2009 and, to account for slight variations in year-to-year data availability, state prevalence was averaged for each state for the 5-year intervals of 1990-1994, 1995-1999, 2000-2004, and 2005-2009 (a 4-year interval but the last year for which data were available was 2009). For the six tobacco control policies, annual policy status (whether a specific policy had been adopted) was obtained from 1995 to 2004. To correspond with the 5-year intervals established for smoking prevalence, a variable was created characterizing the absolute status for each policy (whether a policy had been adopted and the type of policy adopted) for the years 1995 (the start of the study period) and 2004 (the end of the study period). For each policy for each state, an additional variable was created that categorized, for the time periods 1995-1999 and 2000-2004, whether a state had: a) no baseline policies and did not add any policies during the time period; b) no baseline policies but did add policies during the time period; c) did have baseline policies but did not add any policies during the time period; or d) did have baseline policies and added policies during the time period.

In addition to these tobacco control policy and population smoking prevalence data, data for three additional, variables were obtained: a) the percent of the state's population living below the poverty level from the 1989 and 1999 Census Abstract; b) the state's educational attainment, specifically the proportion of the population having achieve a high school education or higher, from the 1990 and 2000 Census Abstract; and c) the magnitude of the state's tobacco agricultural industry, as estimated by the number of tobacco acres harvested, from C.D.C.'s STATE data system.

All data were obtained from the aforementioned public data sources. Data were downloaded and manipulated in Microsoft Office Excel ${ }^{\circledR}$ and then exported to S.P.S.S. ${ }^{\circledR}$ (I.B.M. S.P.S.S. Statistics Version 19, I.B.M. Corporation, Somers, N.Y.) for statistical analysis. To assess whether changes in population smoking prevalence preceded or followed tobacco policy adoption, differences in the average state-level adult smoking prevalence was calculated for each type of policy adoption categories described above for the time periods before, during, and 
after the 1995-1999 and 2000-2004 policy adoption evaluation timeframe. This was assessed in univariate analysis using A.N.O.V.A.. The assessment was repeated with multivariable analysis using general linear models (G.L.M.) A.N.C.O.V.A. with the above described variables for educational attainment, poverty, and tobacco agriculture as covariates and the categorical tobacco policy adoption categorical variable as a random factor. For simplicity, in the A.N.O.V.A. and G.L.M. A.N.C.O.V.A. analysis, statistically significant differences between the mean smoking prevalence at different levels of the tobacco policy adoption categorical variable (unadjusted mean in A.N.O.V.A. analysis and covariable-adjusted estimated marginal mean in G.L.M. A.N.C.O.V.A.) was assessed using the $95 \%$ confidence intervals rather than post-hoc tests.

\subsection{Results}

The descriptive characteristics of the fifty-one jurisdictions included in this analysis are shown in Tables 6-1 and 6-2. State tobacco excise taxes were the only policies in place in all jurisdictions and were also the policies most likely to be changed (37\% of jurisdictions increased taxes in 1995-1999 and 66\% of jurisdictions increased taxes in 2000-2004). In contrast, smokefree indoor air policies for private work sites and restaurants were the least common in both time periods as well as the least likely to be adopted. Policies requiring licensure for tobacco retail sales also had a low adoption rate. For the 1995-1999 time period, the average state tobacco excise tax was $\$ 0.34 \pm 0.19$ (standard deviation) increasing to $\$ 0.55 \pm 0.36$ in $2000-20004$.

The averaged adult smoking prevalence declined from the 1990-1994 to the 2005-2009 time period: $23.27 \% \pm 2.77$ in $1990-1994,23.26 \% \pm 2.73$ in $1995-1999,22.73 \% \pm 3.01$ in $2000-$ 2004 , and $19.79 \% \pm 3.12$ in $2005-2009$.

Results from univariate A.N.O.V.A. analysis are shown in Table 6-3. All policies except for the youth access to vending machines and retail licensure policies demonstrated a statistically significant $(p<0.05)$ or a trend toward a statistically significant $(0.05<p<0.1)$ association between smoking prevalence and policy adoption category. In general, smoking prevalence was lower in all time periods, including before the policy adoption timeframe, in jurisdictions with policies at baseline and in jurisdictions that adopted policies compared to those jurisdictions either without baseline policies or that did not adopt policies during the timeframe. For example, in the 20002004 policy adoption timeframe, seven states had neither baseline nor did they adopt smokefree indoor air statues at government worksites. At the opposite end of the policy adoption categorization, seven states had both baseline policies and adopted additional government 
worksite smoke free air policies during the 2000-2004 timeframe. From 1990-1994 to 20052009, the former "policy inactive" states were observed to have an averaged adult smoking prevalence of: $25.93 \%$ (95\%Cl 23.60-28.27), 25.77\% (23.26-28.29), 25.62\% (22.99-28.25), and $22.93 \%$ (20.01-25.85), respectively. In contrast, the latter "policy active" states were observed to have an averaged adult smoking prevalence of: $22.62 \%(95 \% \mathrm{Cl} 21.01-24.24), 22.69 \%$ (21.32-24.05), 21.95\% (20.21-23.69), and 19.00\% (17.00-20.99), respectively. It is noted that, while the confidence intervals between these two groups overlap, the absolute value of the overlap is small and it is not unreasonable to attribute this to the sample size in each group $(n=7)$ and thus interpret this as a strong trend towards statistically significant differences between these groups at each timeframe. That is, there was a strong trend towards "policy active" states having lower smoking prevalence compared to "policy inactive" states before policy adoption, a difference which grew in the timeframes after policy adoption. This latter observation of a lower and growing difference in smoking prevalence implies bi-directional feedback between smoking prevalence and policy adoption.

These univariate analyses were repeated using multivariable G.L.M. A.N.C.O.V.A. analysis to assess whether the associations observed in univariate analysis would persist after accounting for other known covariates of policy adoption, educational attainment, poverty, and tobacco agriculture. No statistically significant observations were observed (results not shown). It is noted that, given the cell sample and the number of covariables, it is unclear whether these null results are attributable to the absence of reliable association or lack of sufficient statistical power.

\subsection{Discussion}

This study assessed the temporal association between smoking prevalence and tobacco control policy adoption. This association was assessed for multiple different policy types and timeframes. Results from this analysis suggest that lower smoking prevalence precedes policy adoption, increasing the likelihood of policy adoption. Policy adoption, in turn, may contribute to a differentially larger decrease in smoking prevalence in policy adopting compared to policy non-adopting states. Further, the results from this study suggest that the association between smoking prevalence and policy adoption depends upon the type of policy. Policies that have a more direct impact on individuals, such as smoke free air policies in restaurants and worksites, were observed to have a stronger association with prior population smoking prevalence compared to policies that have more indirect impacts on the majority of the population, for example retail licensure and youth access polices. 
The present analyses have several limitations and the results should be interpreted cautiously and regarded as preliminary. First, the observations from univariate analysis were not replicated in multivariable analysis. However, it is unclear whether this is the result of insufficient statistical power or errant and / or unreliable results in univariate analysis. Given, however, that univariate statistical significance was observed for multiple policy types and timeframes, this latter explanation seems less plausible than the former. Future studies should aim to increase the statistical power by increasing the number of jurisdictions and or timeframes evaluated.

An additional important limitation is the relative simplicity of the statistical models employed in this analysis. If, in fact, the temporal association between smoking prevalence and policy adoption is bidirectional and recursive, linear statistical models are likely inadequate. Future studies should incorporate more complex statistical models that reflect these complex causal associations.

Finally, the number and type of covariates included in the present analysis is likely incomplete. Future studies should attempt to include a more comprehensive set of factors associated with both policy adoption and smoking prevalence, including interactions with different jurisdictions, particularly jurisdictions with different tobacco control policy regimes.

\subsection{Chapter Summary \& Contribution}

This chapter has provided quantitative evidence that lower smoking prevalence may precede policy adoption, possibly functioning to - or signaling - lower society-originating barriers to tobacco control policy adoption. This evidence diverges from the predominant public health perspective that policy precedes prevalence reduction, and not vice versa. It is, however, consistent with the theoretical contributions of, for example, Marmor and Lieberman who asserted the interactive feedback between policy and prevalence. (Marmor \& Lieberman, 2004) The observations reported in this chapter also point to the importance of social factors in tobacco control policy adoption, factors that have been largely overlooked by both the public health and political and policy science communities. 


\begin{tabular}{|c|c|c|c|c|c|c|c|c|}
\hline & & & $\mathbf{n}$ & $\%$ & & & $\mathbf{n}$ & $\%$ \\
\hline $\begin{array}{l}\text { Smoke-free Indoor Air } \\
\text { Policies at Government } \\
\text { Worksites }\end{array}$ & $\begin{array}{l}1995,4^{\text {th }} \\
\text { Quarter }\end{array}$ & $\begin{array}{l}\text { No Provision } \\
\text { In Designated Areas } \\
\text { In Separate Ventilated Areas } \\
\text { Banned }\end{array}$ & $\begin{array}{l}10.0 \\
31.0 \\
2.0 \\
8.0\end{array}$ & $\begin{array}{c}19.6 \\
60.8 \\
3.9 \\
15.7\end{array}$ & $\begin{array}{l}\text { 2004, 4th } \\
\text { Quarter }\end{array}$ & $\begin{array}{l}\text { No Provision } \\
\text { In Designated Areas } \\
\text { In Separate Ventilated Areas } \\
\text { Banned }\end{array}$ & $\begin{array}{c}7.0 \\
24.0 \\
5.0 \\
15.0\end{array}$ & $\begin{array}{c}13.7 \\
47.1 \\
9.8 \\
29.4\end{array}$ \\
\hline Worksites & $\begin{array}{c}\text { Policy } \\
\text { Change, 1995- } \\
99\end{array}$ & $\begin{array}{l}\text { No Baseline Policies, No Change } \\
\text { No Baseline Policies, Policies Added } \\
\text { Baseline Policies, No Change } \\
\text { Baseline Policies, Policies Added }\end{array}$ & $\begin{array}{c}9.0 \\
1.0 \\
39.0 \\
2.0\end{array}$ & $\begin{array}{c}17.6 \\
2.0 \\
76.5 \\
3.9\end{array}$ & $\begin{array}{c}\text { Policy } \\
\text { Change, 2000- } \\
04\end{array}$ & $\begin{array}{l}\text { No Baseline Policies, No Change } \\
\text { No Baseline Policies, Policies Added } \\
\text { Baseline Policies, No Change } \\
\text { Baseline Policies, Policies Added }\end{array}$ & $\begin{array}{c}7.0 \\
0.0 \\
37.0 \\
7.0\end{array}$ & $\begin{array}{c}13.7 \\
0.0 \\
72.5 \\
13.7\end{array}$ \\
\hline \multirow[t]{2}{*}{ Worksites } & $\begin{array}{l}1995,4^{\text {th }} \\
\text { Quarter }\end{array}$ & $\begin{array}{l}\text { No Provision } \\
\text { In Designated Areas } \\
\text { In Separate Ventilated Areas } \\
\text { Banned }\end{array}$ & $\begin{array}{c}30.0 \\
20.0 \\
1.0 \\
0.0\end{array}$ & $\begin{array}{c}58.8 \\
39.2 \\
2.0 \\
0.0\end{array}$ & $\begin{array}{c}\text { 2004, 4th } \\
\text { Quarter }\end{array}$ & $\begin{array}{l}\text { No Provision } \\
\text { In Designated Areas } \\
\text { In Separate Ventilated Areas } \\
\text { Banned }\end{array}$ & $\begin{array}{c}24.0 \\
19.0 \\
3.0 \\
5.0\end{array}$ & $\begin{array}{c}47.1 \\
37.3 \\
5.9 \\
9.8\end{array}$ \\
\hline & $\begin{array}{c}\text { Policy } \\
\text { Change, 1995- } \\
99\end{array}$ & $\begin{array}{l}\text { No Baseline Policies, No Change } \\
\text { No Baseline Policies, Policies Added } \\
\text { Baseline Policies, No Change } \\
\text { Baseline Policies, Policies Added }\end{array}$ & $\begin{array}{c}30.0 \\
0.0 \\
21.0 \\
0.0\end{array}$ & $\begin{array}{c}58.8 \\
0.0 \\
41.2 \\
0.0 \\
\end{array}$ & $\begin{array}{c}\text { Policy } \\
\text { Change, 2000- } \\
04\end{array}$ & $\begin{array}{l}\text { No Baseline Policies, No Change } \\
\text { No Baseline Policies, Policies Added } \\
\text { Baseline Policies, No Change } \\
\text { Baseline Policies, Policies Added }\end{array}$ & $\begin{array}{c}24.0 \\
5.0 \\
17.0 \\
5.0 \\
\end{array}$ & $\begin{array}{c}47.1 \\
9.8 \\
33.3 \\
9.8 \\
\end{array}$ \\
\hline \multirow[t]{2}{*}{ Policies at Restaurants } & $\begin{array}{l}1995,4^{\text {th }} \\
\text { Quarter }\end{array}$ & $\begin{array}{l}\text { No Provision } \\
\text { In Designated Areas } \\
\text { In Separate Ventilated Areas } \\
\text { Banned }\end{array}$ & $\begin{array}{c}21.0 \\
29.0 \\
0.0 \\
1.0\end{array}$ & $\begin{array}{c}41.2 \\
56.9 \\
0.0 \\
2.0\end{array}$ & $\begin{array}{c}\text { 2004, 4th } \\
\text { Quarter }\end{array}$ & $\begin{array}{l}\text { No Provision } \\
\text { In Designated Areas } \\
\text { In Separate Ventilated Areas } \\
\text { Banned }\end{array}$ & $\begin{array}{c}19.0 \\
23.0 \\
2.0 \\
7.0\end{array}$ & $\begin{array}{c}37.3 \\
45.1 \\
3.9 \\
13.7\end{array}$ \\
\hline & $\begin{array}{c}\text { Policy } \\
\text { Change, 1995- } \\
99\end{array}$ & $\begin{array}{l}\text { No Baseline Policies, No Change } \\
\text { No Baseline Policies, Policies Added } \\
\text { Baseline Policies, No Change } \\
\text { Baseline Policies, Policies Added }\end{array}$ & $\begin{array}{c}21.0 \\
0.0 \\
29.0 \\
1.0\end{array}$ & $\begin{array}{c}41.2 \\
0.0 \\
56.9 \\
2.0\end{array}$ & $\begin{array}{c}\text { Policy } \\
\text { Change, 2000- } \\
04\end{array}$ & $\begin{array}{l}\text { No Baseline Policies, No Change } \\
\text { No Baseline Policies, Policies Added } \\
\text { Baseline Policies, No Change } \\
\text { Baseline Policies, Policies Added }\end{array}$ & $\begin{array}{c}19.0 \\
2.0 \\
23.0 \\
7.0\end{array}$ & $\begin{array}{c}37.3 \\
3.9 \\
45.1 \\
13.7\end{array}$ \\
\hline $\begin{array}{c}\text { State Cigarette Excise } \\
\text { Tax }\end{array}$ & $\begin{array}{c}\text { Policy } \\
\text { Change, 1995- } \\
99\end{array}$ & $\begin{array}{l}\text { No Baseline Policies, No Change } \\
\text { No Baseline Policies, Policies Added } \\
\text { Baseline Policies, No Change } \\
\text { Baseline Policies, Policies Added }\end{array}$ & $\begin{array}{c}0.0 \\
0.0 \\
32.0 \\
19.0\end{array}$ & $\begin{array}{c}0.0 \\
0.0 \\
62.7 \\
37.3 \\
\end{array}$ & $\begin{array}{c}\text { Policy } \\
\text { Change, 2000- } \\
04\end{array}$ & $\begin{array}{l}\text { No Baseline Policies, No Change } \\
\text { No Baseline Policies, Policies Added } \\
\text { Baseline Policies, No Change } \\
\text { Baseline Policies, Policies Added }\end{array}$ & $\begin{array}{c}0.0 \\
0.0 \\
17.0 \\
34.0 \\
\end{array}$ & $\begin{array}{c}0.0 \\
0.0 \\
33.3 \\
66.7 \\
\end{array}$ \\
\hline \multirow[t]{2}{*}{$\begin{array}{l}\text { Cigarette Vending } \\
\text { Machine Policies }\end{array}$} & $\begin{array}{l}1995,4^{\text {th }} \\
\text { Quarter }\end{array}$ & $\begin{array}{l}\text { No Restrictions } \\
\text { Limited Restrictions and No Supervision } \\
\text { Not Allowed in Youth-Accessible Areas } \\
\text { Unless Supervised and-or Locked } \\
\text { Banned from Youth-Accessible Areas }\end{array}$ & $\begin{array}{c}16.0 \\
1.0 \\
18.0 \\
16.0\end{array}$ & $\begin{array}{c}31.4 \\
2.0 \\
35.3 \\
31.4\end{array}$ & $\begin{array}{l}\text { 2004, 4th } \\
\text { Quarter }\end{array}$ & $\begin{array}{l}\text { No Restrictions } \\
\text { Limited Restrictions and No Supervision } \\
\text { Not Allowed in Youth-Accessible Areas } \\
\text { Unless Supervised and-or Locked } \\
\text { Banned from Youth-Accessible Areas }\end{array}$ & $\begin{array}{r}4.0 \\
1.0 \\
14.0 \\
32.0\end{array}$ & $\begin{array}{c}7.8 \\
2.0 \\
27.5 \\
62.7\end{array}$ \\
\hline & $\begin{array}{c}\text { Policy } \\
\text { Change, 1995- } \\
99\end{array}$ & $\begin{array}{l}\text { No Baseline Policies, No Change } \\
\text { No Baseline Policies, Policies Added } \\
\text { Baseline Policies, No Change } \\
\text { Baseline Policies, Policies Added }\end{array}$ & $\begin{array}{c}8.0 \\
8.0 \\
27.0 \\
8.0\end{array}$ & $\begin{array}{l}15.7 \\
15.7 \\
52.9 \\
15.7\end{array}$ & $\begin{array}{c}\text { Policy } \\
\text { Change, 2000- } \\
04\end{array}$ & $\begin{array}{l}\text { No Baseline Policies, No Change } \\
\text { No Baseline Policies, Policies Added } \\
\text { Baseline Policies, No Change } \\
\text { Baseline Policies, Policies Added }\end{array}$ & $\begin{array}{c}4.0 \\
3.0 \\
43.0 \\
1.0\end{array}$ & $\begin{array}{c}7.8 \\
5.9 \\
84.3 \\
2.0\end{array}$ \\
\hline $\begin{array}{l}\text { Policies Requiring } \\
\text { Licensure for Tobacco } \\
\text { Retail Locations }\end{array}$ & $\begin{array}{l}1995,4^{\text {th }} \\
\text { Quarter }\end{array}$ & $\begin{array}{l}\text { No Retail Licensing Requirements } \\
\text { Retail Licensing for Vending Machines } \\
\text { Only } \\
\text { Licensing for Over-the-Counter Retail }\end{array}$ & $\begin{array}{c}16.0 \\
4.0 \\
1.0\end{array}$ & $\begin{array}{c}31.4 \\
7.8 \\
2.0\end{array}$ & $\begin{array}{c}\text { 2004, 4th } \\
\text { Quarter }\end{array}$ & $\begin{array}{l}\text { No Retail Licensing Requirements } \\
\text { Retail Licensing for Vending Machines } \\
\text { Only } \\
\text { Licensing for Over-the-Counter Retail }\end{array}$ & $\begin{array}{l}9.0 \\
3.0\end{array}$ & $\begin{array}{c}17.6 \\
5.9\end{array}$ \\
\hline & & Sales Only & & & & Sales Only & & \\
\hline
\end{tabular}


n

Retail Licensing Required for Over-the-

58.8

Retail Licensing Required for Over-the-

$37.0 \quad 72.5$

Change, 1995- No Baseline Policies, Policies Added

No Baseline Policies, Policies
Baseline Policies, No Change

Baseline Policies, Policies Added

$\begin{array}{cc}12.0 & 23.5 \\ 4.0 & 7.8 \\ 33.0 & 64.7 \\ 2.0 & 3.9\end{array}$

23.5
7.8
64.7
3.9

Policy

Counter and Vending Machine Sales

No Baseline Policies, No Change

$9.0 \quad 17.6$

Change, 2000-

$9.0 \quad 17.6$

Baseline Policies, No Change

Baseline Policies, Policies Added

$\begin{array}{cc}2.0 & 3.9 \\ 40.0 & 78.4\end{array}$




\begin{tabular}{|c|c|c|c|c|c|c|c|}
\hline & $\mathbf{n}$ & Missing & Mean & Median & Std. Dev. & Minimum & Maximum \\
\hline State Cigarette Excise Tax, 1990 & 51 & 0 & 0.21 & 0.20 & 0.09 & 0.02 & 0.40 \\
\hline State Cigarette Excise Tax, 1995 & 51 & 0 & 0.30 & 0.27 & 0.17 & 0.03 & 0.75 \\
\hline State Cigarette Excise Tax, 2000 & 51 & 0 & 0.42 & 0.34 & 0.28 & 0.03 & 1.11 \\
\hline State Cigarette Excise Tax, 04 & 51 & 0 & 0.74 & 0.60 & 0.48 & 0.03 & 2.05 \\
\hline State Cigarette Excise Tax, State Average for 1995-99 & 51 & 0 & 0.34 & 0.32 & 0.19 & 0.03 & 0.75 \\
\hline State Cigarette Excise Tax, State Average for $2000-04$ & 51 & 0 & 0.55 & 0.44 & 0.36 & 0.03 & 1.34 \\
\hline Adult Smoking Prevalence, 1990 & 45 & 6 & 23.99 & 23.60 & 2.78 & 17.10 & 29.50 \\
\hline Adult Smoking Prevalence, 1995 & 50 & 1 & 22.78 & 22.45 & 2.81 & 13.20 & 27.90 \\
\hline Adult Smoking Prevalence, 2000 & 51 & 0 & 22.85 & 23.30 & 3.01 & 12.90 & 30.50 \\
\hline Adult Smoking Prevalence, 2005 & 51 & 0 & 21.02 & 20.60 & 3.13 & 11.50 & 28.70 \\
\hline Adult Smoking Prevalence, State Average for $1990-94$ & 51 & 0 & 23.37 & 22.74 & 2.77 & 15.48 & 29.93 \\
\hline Adult Smoking Prevalence, State Average for 1995-99 & 51 & 0 & 23.26 & 23.30 & 2.73 & 14.20 & 30.16 \\
\hline Adult Smoking Prevalence, State Average for $2000-04$ & 51 & 0 & 22.73 & 22.42 & 3.01 & 12.28 & 30.48 \\
\hline Adult Smoking Prevalence, State Average for 2005-09 & 51 & 0 & 19.79 & 19.48 & 3.12 & 10.40 & 27.32 \\
\hline Agricultural Acres Harvested, 1990 & 49 & 2 & 14965.51 & 0.00 & 49590.28 & 0.00 & 284200.00 \\
\hline Agricultural Acres Harvested, 1995 & 49 & 2 & 13541.33 & 0.00 & 44725.50 & 0.00 & 261100.00 \\
\hline Agricultural Acres Harvested, 2000 & 49 & 2 & 9580.00 & 0.00 & 31023.38 & 0.00 & 167400.00 \\
\hline Agricultural Acres Harvested, 2005 & 46 & 5 & 6478.70 & 0.00 & 22021.53 & 0.00 & 126000.00 \\
\hline Agricultural Acres Harvested, Average for 1990-94 & 50 & 1 & 14830.60 & 0.00 & 48719.64 & 0.00 & 268720.00 \\
\hline Agricultural Acres Harvested, State Average for $1995-99$ & 49 & 2 & 14684.06 & 0.00 & 48903.60 & 0.00 & 265840.00 \\
\hline Agricultural Acres Harvested, State Average for $2000-04$ & 49 & 2 & 8769.06 & 0.00 & 28973.96 & 0.00 & 162640.00 \\
\hline Agricultural Acres Harvested, State Average for $2005-2008$ & 46 & 5 & 7348.97 & 0.00 & 26274.47 & 0.00 & 157275.00 \\
\hline Educational Attainment of High School or More (Census), 1990 & 51 & 0 & 76.22 & 76.70 & 5.59 & 64.30 & 86.60 \\
\hline Educational Attainment of High School or More (Census), 2000 & 51 & 0 & 81.87 & 82.13 & 4.37 & 72.86 & 88.33 \\
\hline Percent Below Poverty Level (Census), 1989 & 51 & 0 & 13.14 & 12.42 & 4.13 & 6.42 & 25.21 \\
\hline Percent Below Poverty Level (Census), 1999 & 51 & 0 & 12.11 & 11.42 & 3.31 & 6.55 & 20.22 \\
\hline
\end{tabular}




\begin{tabular}{|c|c|c|c|c|c|c|c|c|c|c|c|c|c|c|}
\hline & & & \multicolumn{6}{|c|}{$\begin{array}{c}\text { Policy Adoption Timeframe } \\
1995-99 \\
\end{array}$} & \multicolumn{6}{|c|}{$\begin{array}{l}\text { Policy Adoption Timeframe } \\
2000-04\end{array}$} \\
\hline & & & $\mathbf{n}$ & Mean & $\begin{array}{l}\text { Std. } \\
\text { Dev. }\end{array}$ & $\begin{array}{l}95 \% \mathrm{Cl} \\
\text { (Lower) }\end{array}$ & $\begin{array}{l}95 \% \mathrm{Cl} \\
\text { (Upper) }\end{array}$ & $\begin{array}{l}\text { Stat. } \\
\text { Sig. }\end{array}$ & $\mathbf{n}$ & Mean & $\begin{array}{l}\text { Std. } \\
\text { Dev. }\end{array}$ & $\begin{array}{l}95 \% \mathrm{Cl} \\
\text { (Lower) }\end{array}$ & $\begin{array}{l}95 \% \mathrm{Cl} \\
\text { (Upper) }\end{array}$ & $\begin{array}{l}\text { Stat. } \\
\text { Sig. }\end{array}$ \\
\hline \multirow{15}{*}{$\begin{array}{l}\text { Smoke-free } \\
\text { Indoor Air } \\
\text { Policies at } \\
\text { Government } \\
\text { Worksites }\end{array}$} & $\begin{array}{l}\text { Adult Smoking } \\
\text { Prevalence, State }\end{array}$ & $\begin{array}{l}\text { No Baseline Policies, No Change } \\
\text { No Baseline Policies, Policies Added }\end{array}$ & $\begin{array}{l}9 \\
1\end{array}$ & $\begin{array}{l}25.25 \\
20.46\end{array}$ & 2.66 & 23.21 & 27.29 & 0.100 & $\begin{array}{l}7 \\
0\end{array}$ & 25.93 & 2.52 & 23.60 & 28.27 & 0.026 \\
\hline & Average for $1990-94$ & Baseline Policies, No Change & 39 & 23.08 & 2.71 & 22.20 & 23.96 & & 37 & 23.02 & 2.76 & 22.10 & 23.94 & \\
\hline & & Baseline Policies, Policies Added & 2 & 21.98 & 0.79 & 14.86 & 29.10 & & 7 & 22.63 & 1.75 & 21.01 & 24.25 & \\
\hline & Adult Smoking & No Baseline Policies, No Change & 9 & 25.32 & 2.52 & 23.38 & 27.26 & 0.035 & 7 & 25.77 & 2.72 & 23.26 & 28.29 & 0.028 \\
\hline & Prevalence, State & No Baseline Policies, Policies Added & 1 & 19.36 & & & & & 0 & & & & & \\
\hline & Average for $1995-99$ & Baseline Policies, No Change & 39 & 22.96 & 2.61 & 22.11 & 23.80 & & 37 & 22.89 & 2.70 & 21.99 & 23.79 & \\
\hline & & Baseline Policies, Policies Added & 2 & 21.76 & 0.82 & 14.39 & 29.13 & & 7 & 22.69 & 1.47 & 21.32 & 24.05 & \\
\hline & Adult Smoking & No Baseline Policies, No Change & 9 & 25.49 & 2.48 & 23.58 & 27.39 & 0.010 & 7 & 25.62 & 2.84 & 22.99 & 28.25 & 0.020 \\
\hline & Prevalence, State & No Baseline Policies, Policies Added & 1 & 19.68 & & & & & & & & & & \\
\hline & Average for $2000-04$ & Baseline Policies, No Change & 39 & 22.30 & 2.84 & 21.38 & 23.22 & & 37 & 22.33 & 2.96 & 21.34 & 23.32 & \\
\hline & & Baseline Policies, Policies Added & 2 & 20.26 & 1.39 & 7.81 & 32.71 & & 7 & 21.95 & 1.88 & 20.21 & 23.69 & \\
\hline & Adult Smoking & No Baseline Policies, No Change & 9 & 23.04 & 2.75 & 20.93 & 25.15 & 0.003 & 7 & 22.93 & 3.16 & 20.01 & 25.85 & 0.013 \\
\hline & Prevalence, State & No Baseline Policies, Policies Added & 1 & 16.46 & & & & & 0 & & & & & \\
\hline & Average for $2005-09$ & Baseline Policies, No Change & 39 & 19.23 & 2.80 & 18.32 & 20.14 & & 37 & 19.35 & 2.98 & 18.36 & 20.35 & \\
\hline & & Baseline Policies, Policies Added & 2 & 17.83 & 1.63 & 3.22 & 32.44 & & 7 & 19.00 & 2.16 & 17.00 & 20.99 & \\
\hline \multirow{16}{*}{$\begin{array}{l}\text { Smoke-free } \\
\text { Indoor Air } \\
\text { Policies at } \\
\text { Private } \\
\text { Worksites }\end{array}$} & Adult Smoking & No Baseline Policies, No Change & 30 & 23.96 & 2.80 & 22.92 & 25.01 & 0.065 & 24 & 24.38 & 2.86 & 23.17 & 25.59 & 0.085 \\
\hline & Prevalence, State & No Baseline Policies, Policies Added & 0 & & & & & & 5 & 22.44 & 2.13 & 19.80 & 25.09 & \\
\hline & Average for $1990-94$ & Baseline Policies, No Change & 21 & 22.51 & 2.56 & 21.35 & 23.67 & & 17 & 22.26 & 2.69 & 20.87 & 23.64 & \\
\hline & & Baseline Policies, Policies Added & 0 & & & & & & 5 & 23.19 & 1.78 & 20.98 & 25.40 & \\
\hline & Adult Smoking & No Baseline Policies, No Change & 30 & 23.93 & 2.59 & 22.96 & 24.89 & 0.035 & 24 & 24.30 & 2.69 & 23.16 & 25.43 & 0.060 \\
\hline & Prevalence, State & No Baseline Policies, Policies Added & 0 & & & & & & 5 & 22.13 & 1.42 & 20.37 & 23.89 & \\
\hline & Average for $1995-99$ & Baseline Policies, No Change & 21 & 22.30 & 2.69 & 21.08 & 23.53 & & 17 & 22.13 & 2.91 & 20.64 & 23.63 & \\
\hline & & Baseline Policies, Policies Added & 0 & & & & & & 5 & 23.21 & 1.41 & 21.45 & 24.96 & \\
\hline & Adult Smoking & No Baseline Policies, No Change & 30 & 23.52 & 2.82 & 22.47 & 24.58 & 0.024 & 24 & 23.87 & 2.80 & 22.68 & 25.05 & 0.074 \\
\hline & Prevalence, State & No Baseline Policies, Policies Added & 0 & & & & & & 5 & 21.62 & 2.67 & 18.30 & 24.94 & \\
\hline & Average for $2000-04$ & Baseline Policies, No Change & 21 & 21.60 & 2.98 & 20.24 & 22.96 & & 17 & 21.54 & 3.23 & 19.88 & 23.20 & \\
\hline & & Baseline Policies, Policies Added & 0 & & & & & & 5 & 22.45 & 2.05 & 19.90 & 25.00 & \\
\hline & Adult Smoking & No Baseline Policies, No Change & 30 & 20.70 & 3.06 & 19.56 & 21.84 & 0.012 & 24 & 20.91 & 2.98 & 19.65 & 22.17 & 0.099 \\
\hline & Prevalence, State & No Baseline Policies, Policies Added & 0 & & & & & & 5 & 19.20 & 3.49 & 14.86 & 23.54 & \\
\hline & Average for $2005-09$ & Baseline Policies, No Change & 21 & 18.50 & 2.80 & 17.23 & 19.77 & & 17 & 18.52 & 3.05 & 16.96 & 20.09 & \\
\hline & & Baseline Policies, Policies Added & 0 & & & & & & 5 & 19.35 & 2.51 & 16.23 & 22.47 & \\
\hline \multirow{8}{*}{$\begin{array}{l}\text { Smoke-free } \\
\text { Indoor Air } \\
\text { Policies at } \\
\text { Restaurants }\end{array}$} & Adult Smoking & No Baseline Policies, No Change & 21 & 24.19 & 2.47 & 23.07 & 25.32 & 0.093 & 19 & 24.23 & 2.51 & 23.02 & 25.44 & 0.336 \\
\hline & Prevalence, State & No Baseline Policies, Policies Added & & & & & & & 2 & 23.88 & 2.97 & -2.80 & 50.56 & \\
\hline & Average for $1990-94$ & Baseline Policies, No Change & 29 & 22.90 & 2.84 & 21.82 & 23.98 & & 23 & 22.65 & 3.11 & 21.31 & 24.00 & \\
\hline & & Baseline Policies, Policies Added & 1 & 19.42 & & & & & 7 & 23.23 & 1.97 & 21.41 & 25.05 & \\
\hline & Adult Smoking & No Baseline Policies, No Change & 21 & 24.34 & 2.30 & 23.29 & 25.38 & 0.013 & 19 & 24.42 & 2.41 & 23.26 & 25.58 & 0.121 \\
\hline & Prevalence, State & No Baseline Policies, Policies Added & & & & & & & 2 & 23.60 & 0.40 & 20.04 & 27.16 & \\
\hline & Average for $1995-99$ & Baseline Policies, No Change & 29 & 22.65 & 2.70 & 21.63 & 23.68 & & 23 & 22.50 & 3.08 & 21.17 & 23.83 & \\
\hline & & Baseline Policies, Policies Added & 1 & 18.08 & & & & & 7 & 22.50 & 1.60 & 21.02 & 23.99 & \\
\hline
\end{tabular}




\begin{tabular}{|c|c|c|c|c|c|c|c|c|c|c|c|c|c|c|}
\hline & & & \multicolumn{6}{|c|}{$\begin{array}{c}\text { Policy Adoption Timeframe } \\
1995-99\end{array}$} & \multicolumn{6}{|c|}{$\begin{array}{l}\text { Policy Adoption Timeframe } \\
2000-04\end{array}$} \\
\hline & & & $\mathbf{n}$ & Mean & $\begin{array}{l}\text { Std. } \\
\text { Dev. }\end{array}$ & $\begin{array}{l}95 \% \mathrm{Cl} \\
\text { (Lower) }\end{array}$ & $\begin{array}{l}95 \% \mathrm{Cl} \\
\text { (Upper) }\end{array}$ & $\begin{array}{l}\text { Stat. } \\
\text { Sig. }\end{array}$ & $\mathbf{n}$ & Mean & $\begin{array}{l}\text { Std. } \\
\text { Dev. }\end{array}$ & $\begin{array}{l}95 \% \mathrm{Cl} \\
\text { (Lower) }\end{array}$ & $\begin{array}{l}95 \% \mathrm{Cl} \\
\text { (Upper) }\end{array}$ & $\begin{array}{l}\text { Stat. } \\
\text { Sig. }\end{array}$ \\
\hline & Adult Smoking & No Baseline Policies, No Change & 21 & 24.17 & 2.72 & 22.93 & 25.41 & 0.002 & 19 & 24.19 & 2.79 & 22.84 & 25.53 & 0.035 \\
\hline & Prevalence, State & No Baseline Policies, Policies Added & & & & & & & 2 & 24.01 & 2.84 & -1.53 & 49.55 & \\
\hline & Average for $2000-04$ & Baseline Policies, No Change & 29 & 21.90 & 2.70 & 20.88 & 22.93 & & 23 & 21.82 & 3.09 & 20.48 & 23.15 & \\
\hline & & Baseline Policies, Policies Added & 1 & 16.48 & & & & & 7 & 21.40 & 1.88 & 19.66 & 23.14 & \\
\hline & Adult Smoking & No Baseline Policies, No Change & 21 & 21.54 & 3.06 & 20.15 & 22.93 & 0.001 & 19 & 21.48 & 3.04 & 20.01 & 22.95 & 0.006 \\
\hline & Prevalence, State & No Baseline Policies, Policies Added & & & & & & & 2 & 22.14 & 4.41 & -17.50 & 61.78 & \\
\hline & Average for $2005-09$ & Baseline Policies, No Change & 29 & 18.72 & 2.48 & 17.78 & 19.66 & & 23 & 18.69 & 2.84 & 17.46 & 19.92 & \\
\hline & & Baseline Policies, Policies Added & 1 & 14.26 & & & & & 7 & 18.18 & 1.45 & 16.84 & 19.51 & \\
\hline \multirow{8}{*}{$\begin{array}{l}\text { State } \\
\text { Cigarette } \\
\text { Excise Tax }\end{array}$} & Adult Smoking & Baseline Policies, No Change & 32 & 23.92 & 2.68 & 22.95 & 24.89 & 0.062 & 17 & 24.10 & 2.59 & 22.77 & 25.43 & 0.183 \\
\hline & $\begin{array}{l}\text { Prevalence, State } \\
\text { Average for 1990-94 }\end{array}$ & Baseline Policies, Policies Added & 19 & 22.43 & 2.74 & 21.11 & 23.75 & & 34 & 23.00 & 2.82 & 22.01 & 23.98 & \\
\hline & Adult Smoking & Baseline Policies, No Change & 32 & 23.98 & 2.41 & 23.11 & 24.84 & 0.013 & 17 & 23.62 & 2.69 & 22.24 & 25.00 & 0.506 \\
\hline & $\begin{array}{l}\text { Prevalence, State } \\
\text { Average for } 1995-99\end{array}$ & Baseline Policies, Policies Added & 19 & 22.05 & 2.87 & 20.67 & 23.43 & & 34 & 23.08 & 2.77 & 22.11 & 24.04 & \\
\hline & Adult Smoking & Baseline Policies, No Change & 32 & 23.72 & 2.42 & 22.84 & 24.59 & 0.002 & 17 & 23.51 & 3.14 & 21.90 & 25.12 & 0.194 \\
\hline & $\begin{array}{l}\text { Prevalence, State } \\
\text { Average for 2000-04 }\end{array}$ & Baseline Policies, Policies Added & 19 & 21.07 & 3.24 & 19.51 & 22.63 & & 34 & 22.34 & 2.92 & 21.32 & 23.36 & \\
\hline & Adult Smoking & Baseline Policies, No Change & 32 & 20.91 & 2.63 & 19.97 & 21.86 & 0.001 & 17 & 20.65 & 3.19 & 19.00 & 22.29 & 0.170 \\
\hline & $\begin{array}{l}\text { Prevalence, State } \\
\text { Average for 2005-09 }\end{array}$ & Baseline Policies, Policies Added & 19 & 17.91 & 3.04 & 16.45 & 19.38 & & 34 & 19.37 & 3.04 & 18.31 & 20.43 & \\
\hline \multirow{16}{*}{$\begin{array}{l}\text { Youth } \\
\text { Access to } \\
\text { Cigarette } \\
\text { Vending } \\
\text { Machine } \\
\text { Policies }\end{array}$} & Adult Smoking & No Baseline Policies, No Change & 8 & 23.51 & 2.21 & 21.66 & 25.35 & 0.920 & 4 & 22.65 & 2.16 & 19.21 & 26.08 & 0.761 \\
\hline & Prevalence, State & No Baseline Policies, Policies Added & 8 & 23.92 & 1.86 & 22.36 & 25.47 & & 3 & 23.73 & 2.14 & 18.40 & 29.05 & \\
\hline & Average for $1990-94$ & Baseline Policies, No Change & 27 & 23.14 & 3.38 & 21.80 & 24.48 & & 43 & 23.35 & 2.89 & 22.46 & 24.24 & \\
\hline & & Baseline Policies, Policies Added & 8 & 23.42 & 1.88 & 21.85 & 24.99 & & 1 & 25.98 & & & & \\
\hline & Adult Smoking & No Baseline Policies, No Change & 8 & 23.79 & 2.29 & 21.87 & 25.70 & 0.891 & 4 & 22.83 & 1.42 & 20.57 & 25.08 & 0.948 \\
\hline & Prevalence, State & No Baseline Policies, Policies Added & 8 & 23.58 & 1.47 & 22.35 & 24.80 & & 3 & 24.00 & 2.88 & 16.85 & 31.15 & \\
\hline & Average for $1995-99$ & Baseline Policies, No Change & 27 & 23.00 & 3.33 & 21.68 & 24.32 & & 43 & 23.23 & 2.87 & 22.35 & 24.12 & \\
\hline & & Baseline Policies, Policies Added & 8 & 23.27 & 1.97 & 21.63 & 24.92 & & 1 & 23.88 & & & & \\
\hline & Adult Smoking & No Baseline Policies, No Change & 8 & 23.72 & 2.88 & 21.31 & 26.13 & 0.747 & 4 & 22.76 & 2.92 & 18.12 & 27.40 & 0.658 \\
\hline & Prevalence, State & No Baseline Policies, Policies Added & 8 & 22.82 & 1.64 & 21.45 & 24.19 & & 3 & 23.77 & 2.77 & 16.88 & 30.66 & \\
\hline & Average for $2000-04$ & Baseline Policies, No Change & 27 & 22.37 & 3.56 & 20.96 & 23.78 & & 43 & 22.58 & 3.08 & 21.63 & 23.53 & \\
\hline & & Baseline Policies, Policies Added & 8 & 22.87 & 2.29 & 20.96 & 24.78 & & 1 & 26.02 & & & & \\
\hline & Adult Smoking & No Baseline Policies, No Change & 8 & 21.15 & 3.37 & 18.34 & 23.97 & 0.566 & 4 & 20.17 & 2.75 & 15.79 & 24.55 & 0.311 \\
\hline & Prevalence, State & No Baseline Policies, Policies Added & 8 & 19.42 & 1.70 & 17.99 & 20.84 & & 3 & 20.75 & 3.60 & 11.81 & 29.68 & \\
\hline & Average for $2005-09$ & Baseline Policies, No Change & 27 & 19.42 & 3.44 & 18.06 & 20.78 & & 43 & 19.57 & 3.10 & 18.61 & 20.52 & \\
\hline & & Baseline Policies, Policies Added & 8 & 20.09 & 2.93 & 17.64 & 22.54 & & 1 & 25.26 & & & & \\
\hline \multirow{7}{*}{$\begin{array}{l}\text { Policies } \\
\text { Requiring } \\
\text { Licensure } \\
\text { for Tobacco } \\
\text { Retail } \\
\text { Locations }\end{array}$} & Adult Smoking & No Baseline Policies, No Change & 12 & 23.15 & 2.66 & 21.46 & 24.84 & 0.794 & 9 & 22.85 & 2.30 & 21.08 & 24.62 & 0.800 \\
\hline & Prevalence, State & No Baseline Policies, Policies Added & 4 & 22.17 & 1.57 & 19.67 & 24.67 & & 2 & 22.90 & 4.92 & -21.32 & 67.12 & \\
\hline & Average for $1990-94$ & Baseline Policies, No Change & 33 & 23.60 & 2.99 & 22.54 & 24.66 & & 40 & 23.50 & 2.84 & 22.60 & 24.41 & \\
\hline & & Baseline Policies, Policies Added & 2 & 23.13 & 2.22 & 3.18 & 43.08 & & 0 & & & & & \\
\hline & Adult Smoking & No Baseline Policies, No Change & 12 & 23.44 & 2.97 & 21.55 & 25.33 & 0.566 & 9 & 23.24 & 2.31 & 21.46 & 25.01 & 0.935 \\
\hline & Prevalence, State & No Baseline Policies, Policies Added & 4 & 21.53 & 1.55 & 19.06 & 23.99 & & 2 & 22.56 & 6.34 & -34.36 & 79.48 & \\
\hline & Average for $1995-99$ & Baseline Policies, No Change & 33 & 23.33 & 2.80 & 22.33 & 24.32 & & 40 & 23.30 & 2.72 & 22.43 & 24.17 & \\
\hline
\end{tabular}




\begin{tabular}{|c|c|c|c|c|c|c|c|c|c|c|c|c|c|}
\hline & & \multicolumn{6}{|c|}{$\begin{array}{c}\text { Policy Adoption Timeframe } \\
1995-99\end{array}$} & \multicolumn{6}{|c|}{$\begin{array}{l}\text { Policy Adoption Timeframe } \\
2000-04\end{array}$} \\
\hline & & $\mathbf{n}$ & Mean & $\begin{array}{l}\text { Std. } \\
\text { Dev. }\end{array}$ & $\begin{array}{l}95 \% \mathrm{Cl} \\
\text { (Lower) }\end{array}$ & $\begin{array}{l}95 \% \mathrm{Cl} \\
\text { (Upper) }\end{array}$ & $\begin{array}{l}\text { Stat. } \\
\text { Sig. }\end{array}$ & $\mathbf{n}$ & Mean & $\begin{array}{l}\text { Std. } \\
\text { Dev. }\end{array}$ & $\begin{array}{l}95 \% \mathrm{Cl} \\
\text { (Lower) }\end{array}$ & $\begin{array}{l}95 \% \mathrm{Cl} \\
\text { (Upper) }\end{array}$ & $\begin{array}{l}\text { Stat. } \\
\text { Sig. }\end{array}$ \\
\hline & Baseline Policies, Policies Added & 2 & 24.48 & 0.71 & 18.13 & 30.83 & & 0 & & & & & \\
\hline Adult Smoking & No Baseline Policies, No Change & 12 & 22.78 & 3.28 & 20.69 & 24.86 & 0.743 & 9 & 22.53 & 2.29 & 20.78 & 24.29 & 0.832 \\
\hline Prevalence, State & No Baseline Policies, Policies Added & 4 & 21.72 & 2.44 & 17.83 & 25.61 & & 2 & 21.57 & 7.20 & -43.10 & 86.24 & \\
\hline Average for $2000-04$ & Baseline Policies, No Change & 33 & 22.72 & 3.09 & 21.62 & 23.81 & & 40 & 22.83 & 3.03 & 21.86 & 23.80 & \\
\hline & Baseline Policies, Policies Added & 2 & 24.68 & 0.11 & 23.66 & 25.70 & & 0 & & & & & \\
\hline Adult Smoking & No Baseline Policies, No Change & 12 & 20.35 & 3.69 & 18.01 & 22.69 & 0.486 & 9 & 19.85 & 2.59 & 17.86 & 21.84 & 0.995 \\
\hline Prevalence, State & No Baseline Policies, Policies Added & 4 & 19.28 & 3.01 & 14.49 & 24.07 & & 2 & 19.61 & 7.57 & -48.37 & 87.59 & \\
\hline Average for $2005-09$ & Baseline Policies, No Change & 33 & 19.48 & 2.99 & 18.42 & 20.54 & & 40 & 19.79 & 3.11 & 18.80 & 20.78 & \\
\hline & Baseline Policies, Policies Added & 2 & 22.66 & 0.59 & 17.32 & 28.00 & & 0 & & & & & \\
\hline
\end{tabular}




\section{TOBACCO CONTROL POLICY AND RELATED POPULATION HEALTH OUTCOMES IN THE EUROPEAN UNION: ASSESSING THE IMPACT OF E.U. ACCESSION ON POPULATION HEALTH}

\subsection{Chapter Introduction \& Purpose}

The previous chapter provided quantitative evidence for the importance of lower smoking prevalence in facilitating tobacco control policy adoption, leading to additional reduction in tobacco use. These observations point to the importance of social factors and changes in both policy adoption and reduced tobacco use. However, the necessity of these social factors and changes in the successful abatement of tobacco use is unclear and the effect of international efforts such as the F.C.T.C. is predicated on their non-requirement. The purpose of this chapter is to assess the impact of tobacco control policies on societies that have not undergone social changes to the same degree as in industrialized countries, specifically the mostly ex-Soviet bloc countries that acceded to the E.U. in 2004 and 2007.

\subsection{Background}

The deleterious health effects of primary and secondary exposure to tobacco smoke, including almost a dozen cancers and chronic diseases such as cardio- and cerebrovascular disease, are well known. While tobacco use is the second leading cause of death worldwide, predicted to cause one billion cumulative deaths during the $21^{\text {st }}$ century, is it also the most preventable cause of death. (World Health Organization, 2008) As the cost of treating and caring for those afflicted by tobacco use or exposure continues to rise and place enormous burdens on societal resources, reducing tobacco use and its subsequent adverse health consequences through tobacco control policies (T.C.P.) is paramount.

Though causal links between smoking and health were definitively established in the 1960s, (U.S. Department of Health, Education, and Welfare, 1964) T.C.P. did not proliferate in industrialized countries until the mid-1980s after a sustained period of "policy hesitancy" (Studlar, Tobacco Control. Comparative Politics in the United States and Canada, 2002) whilst smoking prevalence and consequent health effects reached epidemic proportions. The barriers to implementing effective T.C.P. in the industrialized world, often supported by the tobacco industry, (Bero, Implications of the tobacco industry documents for public health and policy, 2003) have been formidable, though they are slowly being overcome and more restrictive policies are garnering public support and being implemented. As comprehensive T.C.P. are gradually enacted and the societal benefits progressively realized in industrialized countries, 
public health efforts are increasingly focused on the developing world: the tobacco epidemic in the industrialized world has unfolded over almost three quarters of a century, but is it possible for the policy and public health lessons learned in industrialized countries to be transferred to developing countries, truncating the duration of the epidemic and forgoing some of the enormous societal costs in countries least able to absorb such avoidable costs? (Jha, Chaloupka, Corrao, \& Jacob, 2006)

The Tobacco Epidemic Model (T.E.M.) is a four-stage natural history model that characterizes the tobacco epidemic based on trends and progression in smoking prevalence (male and female), smoking related mortality, and tobacco control policies. (Lopez, Collishaw, \& Piha, 1994) While smoking prevalence is low in early stages, it rises sharply to a peak before it declines, with prevalence in men peaking before prevalence in women. Due to a prolonged latency period, smoking-attributable mortality rates lag that of prevalence, not peaking until well after prevalence has begun to decline. Tobacco control efforts are nascent until the final stages of this model, when they become more organized, successful, and comprehensive.

An implicit public health goal for T.C.P. transfer, then, is reducing the 30-50 year lag (as characterized by the T.E.M.) between the initial stages of the tobacco epidemic and adoption of comprehensive T.C.P.. A substantial body of scientific evidence exists regarding the effectiveness of specific T.C.P. elements (Jha, Chaloupka, Corrao, \& Jacob, 2006), (Levy, Chaloupka, \& Gitchell, The effects of tobacco control policies on smoking rates: a tobacco control scorecard, 2004) and policy learning and diffusion has emerged as a key mechanism for the trans-jurisdictional adoption of similar policy elements as well as the knowledge about needed infrastructure and strategies to make the T.C.P. successful. (Rose, 2007), (Dolowitz \& Marsh, 1996) International treaties and transnational tobacco control agreements have become important instruments in policy learning and diffusion, thus aspiring to facilitate international convergence of T.C.P., the most prominent example of which is the W.H.O. Framework Convention on Tobacco Control (F.C.T.C.). However, while the treaty has in excess of 160 signatories, it is yet unclear how successful the F.C.T.C. will be in implementing common, effective policies throughout the diverse membership. Further, the F.C.T.C. process remains the target of intense tobacco industry efforts to weaken its success. (Mamudu, Hammond, \& Glantz, Tobacco industry attempts to counter the World Bank report Curbing the Epidemic and obstruct the WHO framework convention on tobacco control, 2008) 
A second example of facilitated international policy diffusion is the European Union (E.U.) T.C.P. acquis communautaire, the common laws and policies in effect throughout members of the E.U.. Until 1987, member states of the E.U. were individual actors in T.C.P., each having exclusive authority over its own domestic policy. The E.U. T.C.P. acquis communautaire establishes minimum policy requirements which all members must adopt, though individual members may adopt more restrictive policies in a process of multilevel governance. (Hooghe \& Marks, 2001) The Single European Act of 1987 was the first expansion of E.U. jurisdiction into public health, with the justification that health is important to economic integration. This expanded in 1993 in the Treaty of the European Communities (Maastricht). Development of the E.U. T.C.P. acquis communautaire started in 1989 with a directive banning T.V. advertising and has grown to also include: 1989 and 1992 directives on product labeling; a 1990 directive on maximum tar levels; and three directives on minimum tax levels in 1992 (2) and 1995. The most comprehensive directive, a virtual ban on direct and indirect advertising, started development 1989 and was eventually implemented in 1997 after much debate, controversy, and compromise. This directive was immediately challenged by Germany in the European Court of Justice, which annulled it in 2001 . The E.U. subsequently adopted a narrower directive in 2002, which banned only direct cross-border advertising. (Duina \& Kurzer, 2004)

E.U. accession is an elaborate process, leading from formal application to acceptance of candidacy status, negotiations regarding progression toward membership requirements in different policy areas, formal votes on entrance by E.U. institutions, and formal votes within individual candidate countries. (Glenn, 2004), (Grabbe, 2003) For the twelve countries acceding to the E.U. in 2004/2007, most applied for candidacy between 1994-1996, meaning a ten-year period in which to absorb and adopt the E.U. T.C.P. acquis communautaire. The E.U. T.C.P. acquis communautaire would be expected to have considerably more influence on policy adoption and population health outcomes in newly joining members without a substantial history and infrastructure in this policy area. Thus it is hypothesized that, by both proximity and the process of E.U. accession, the E.U. could be an obvious source of policy learning and diffusion for accession countries to abbreviate stages of the T.E.M..

The purpose of the present study is to:

1. Assess the extent to which T.C.P. convergence has taken place coincident with the 2004/2007 accession and characterize the nature of convergence, if any; 
2. Assess the extent to there has been convergence in tobacco-related population health outcomes, specifically prevalence of smoking, tobacco consumption, and mortality from smoking-related causes;

3. Extend the understanding of the accession process on T.C.P. adoption and related population health, if any, by comparing accession countries to Europeanneighborhood countries on the same indicators.

\subsection{Materials and Methods}

All fifteen "existing countries" 1 (members of the E.U. before 2004) and twelve "accession countries" 2 (those acceding to the E.U. in 2004 or 2007) were included in this study except Cyprus, excluded due to the absence of data for almost all indicators at all time points. The four non-E.U. "European-neighborhood" comparison countries selected based on both cultural similarity and data availability were Russia, Ukraine, Turkey, and Albania. Donabedian's structure-process-outcome conceptual model (Donabedian, 1966) guided the selection of variables for this study. Selected outcome variables were smoking prevalence (percent of population aged 15+ years that were regular daily smokers; total, female, and male population), consumption (number of cigarettes per person per year; total population), and smoking-related mortality (standardized death rate from selected smoking-related causes per 100,000; total, female, and male population). Selected process variables included the price of cigarettes (2001 only), and an assessment of the number, timing, and type of T.C.P. instrument adoption (described below). Finally, structural variables were real GDP (rGDP; \$PPP, USD), and spending on health care as a percent of G.D.P..

Data were obtained from common, publicly available data sources assembled and maintained by the W.H.O. Regional Office for Europe (European Health for All database, (World Health Organization, 2009) and the Tobacco Control database (World Health Organization, 2009). Data were downloaded and reconstituted in a Microsoft Office Access ${ }^{\circledR}$ database for manipulation and processing, then exported into S.P.S.S. ${ }^{\circledR}$ (formerly S.P.S.S., Chicago, IL; now I.B.M. S.P.S.S. Statistics, I.B.M. Corporation, Somers, N.Y.) for statistical analysis. To compensate for different collection and reporting years in different countries, values were averaged across five year intervals for each country. The period 1990/94 was the baseline time

\footnotetext{
${ }^{1}$ Belgium, Luxembourg, Netherlands, France, Italy, Germany, Denmark, Ireland, UK, Greece, Portugal, Spain, Finland, Austria, Sweden

${ }^{2}$ Czech Republic, Estonia, Hungary, Latvia, Lithuania, Malta, Poland, Slovakia, Slovenia, Romania, Bulgaria
} 
period as it corresponded with time of application for accession for several countries and the first time period for which complete data were available. The subsequent time periods of 1995/99, 2000/04 and 2005/07 (the last year for which data, though not from all countries, were available) were also considered.

Countries were grouped aggregately as "existing" or "accession" countries. While variation in all indicators exists within these groups, the primary goal of this analysis was assessing the convergence of accession countries to the average, established community standard. One-way ANOVA analysis was used to determine the presence of statistically significant differences between existing and accession countries at each time period. Within each country group, paired-sample t-tests were used to determine if there had been a statistically significant change between the baseline and the final, full-data time period (2000/04). For each indicator, the rate of change within country group was determined using simple regression, where the selected indicator was the dependent variable and time was the independent variable. The estimated $\beta$ coefficients for existing and accession countries were compared using Student's t-test.

Information about T.C.P. status and activity was obtained from the W.H.O.-Europe Tobacco Control Policy database. (World Health Organization, WHO Regional Office for Europe, 2009) Five policy areas were included: direct advertising (6 specific topics), indirect advertising (2), product distribution (3), smoke-free public spaces (7), and smoke-free public transit (4). A simple score (T.C.P.-s) was calculated that assigned 0.5 points if the specific topic was addressed by a policy restriction and 1.0 points if the specific topic was addressed by a policy ban. A total of 22 points - one for each policy element - were possible. A country's T.C.P-s (a score out of 22) was calculated for each of the four study time periods. The duration of T.C.P. activity was calculated for each country by subtracting the year of the first policy element listed from 2007. The number of unique legislative events was determined as the number of unique times that tobacco control legislation was enacted (which could include a single or multiple policy elements). The authors acknowledge that other scores for this purpose have been developed, specifically the Tobacco Control Scale (T.C.S.). (Joossens \& Raw, 2006) It is not our intent to replace or improve upon the T.C.S., but because the T.C.S. was calculated from non-publicly available data sources and for a short time period, we developed an alternate score that would allow us to quantify policy and policy change over time including in jurisdictions not included in the T.C.S.. Additionally, while the price of cigarettes is an acknowledged important element of TCP, taxes were excluded from the current study because most accession 
countries received derogations (delays) on tax harmonization upon their entry into E.U. membership. (European Commission, 2004)

\subsection{Results}

The selected structural variables for existing and accession countries are compared in Table 7-1. As anticipated, existing countries had higher rG.D.P. and spent more on health care at each time point than did accession countries. Both existing and accession countries had statistically significant change (growth) in both variables between 1990/94 and 2000/04. The rate of growth of rG.D.P. was statistically significant in both existing and accession countries, though the rate of growth of rG.D.P. in existing countries approached being statistically significantly larger than the growth of rG.D.P. in accession countries ( $p$ for Student's t-test for difference between simple regression $\beta=0.064$ ). Finally, while the rate of growth in health care spending was statistically significant in existing countries, it was not in accession countries ( $p$ for simple regression $\beta=0.099$ ).

Results for the comparisons of prices and T.C.P.-s between existing and accession countries are shown in Table 7-2. Price for the cheapest/most popular brand of cigarettes was statistically significantly lower in accession compared to existing countries, though there was no difference in the 2001 price of the most popular international brand. For the T.C.P.-s, comparisons showed that existing countries had implemented more total policy elements during the baseline time period, but for the remaining study time periods there was no difference in score between existing and accession countries. Further, while both country groups had a statistically significant increase in T.C.P.-s during the study period and a statistically significant rate of change in T.C.P.-s, the rate of change for adoption of policy elements was statistically significantly higher in accession countries. Existing countries had a longer history of T.C.P. activity, including more unique legislative events, likely related to a longer history of policies establishing smoke free public areas and advertising restrictions.

Table 7-3 summarizes results from comparisons in the selected measures of population health outcomes. Our analysis suggested that there was neither difference between nor change within country groups in per capita cigarette consumption. Neither were there any differences in the overall population smoking prevalence (except for the 2005/07 time period where existing countries had an approaching-significantly lower prevalence $(p=0.079)$, though it should be noted that data were available for fewer countries during that time period). And, while there was a statistically significant decrease in the within-group prevalence for both country groups, the rate of change in prevalence was not significant for either country group. Different patterns, 
however, were noted for gender-specific smoking prevalence. For all time periods, the prevalence of female smoking in accession countries was statistically significantly lower than that in existing countries (except in the last time period, though the same, previous caveats regarding data availability apply). The results suggest that female smoking prevalence remained "flat" in both country groups (statistically not significant within-group change or rate of change) throughout the study time periods. A statistically significantly lower proportion of men (or approaching statistical significance) in existing countries smoked compared to men in accession countries, though there was a statistically significant within-group reduction in male smoking prevalence in both country groups. However, neither the within-group rate of change nor the between-group rate of change comparison was statistically significant.

The estimated standardized mortality rates for selected smoking-related causes for the total population, female population, and male population were lower at all study time periods in existing compared to accession countries. Both the within-group change and rate of change in smoking-related mortality decreased statistically significantly in existing countries for all population strata (total, female, male). In accession countries, there was a statistically significant decrease in the within-group mortality rates (all population strata) but not in the rate of change in mortality rates. It is noted that variance estimates for mortality rate parameters in the accession countries were substantially larger than for existing countries.

In Figure $7-1$, the percent change in smoking prevalence from 1990/94 to $2000 / 04$ is shown for individual countries in both country groups, where a negative percent change corresponds to a decrease in smoking prevalence and a positive percent change to an increased smoking prevalence. While most countries, both existing and accession, showed decreased smoking prevalence, some countries from both groups demonstrated increased smoking prevalence during the study period. Within existing countries, Belgium had increases in total and female smoking prevalence, Luxembourg in total and male smoking prevalence, and Italy, France, and Spain in female smoking prevalence. Within accession countries, Latvia and Lithuania had increases in smoking prevalence in all population strata (total, female, male) with particularly high increases in female smoking prevalence. Slovakia, Estonia, and Romania also experienced increases in total smoking prevalence (Slovakia) and female smoking prevalence (Estonia, Romania).

Comparisons between existing, accession, and European-neighborhood countries are shown in Figure 7-2. Existing E.U. countries had substantially larger and increasing rG.D.P. 
compared to both accession and European-neighborhood countries; accession countries were indistinguishable from European-neighborhood countries during the baseline time period but had modestly higher rG.D.P. (but still substantially lower than existing countries) by 2005/07. It is clear that the period 1990/94 to $1995 / 99$ was a time of T.C.P. adoption for most countries, with existing countries, as previously discussed, having more policies (higher T.C.P.-s) in place during the baseline time period. However, it appears that existing, accession, and the Ukraine continued to adopt T.C.P. after 1995/99, whereas Turkey did not and Russia did not adopt new policies after 2000/04. Albania had the lowest T.C.P.-s and lags substantially behind all other countries. Russia and Albania had similar smoking prevalence to existing and accession countries during the baseline period, but a trend of increasing prevalence throughout the remaining study time periods. Turkey and Ukraine, while having a higher smoking prevalence than either existing or accession countries throughout the study time periods, had lower smoking prevalence during the final study time period compared to their population smoking prevalence during the baseline time period (though still higher than E.U. existing or accession countries). Mortality rates for smoking-related causes were only available for Ukraine and Albania. While smoking-related mortality rates in both existing and accession decreased during the study period, tobacco-related mortality increased from the baseline study period through two additional study time periods in both Ukraine and Albania. While mortality rates were lower in Albania compared to accession countries at all study time periods (and existing countries at the baseline time period), mortality rates in Ukraine were higher than those in existing or accession countries at all study time periods.

\subsection{Discussion}

This study assessed convergence between E.U. existing and accession countries on measures of T.C.P. and related population health outcomes and the extent to which any convergence may be attributable to the E.U. accession process. Results from this study support the ability of the E.U. and E.U. accession to support and accelerate T.C.P. adoption, with subsequent benefits to related population health outcomes.

Accession countries, while more similar to European-neighborhood countries in rG.D.P., were more similar to existing than European-neighborhood countries in the other parameters studied here. There was clear convergence between existing and accession countries in the number and type of T.C.P.; only Ukraine demonstrated a similar pattern of sustained T.C.P. adoption. Consistent with a priori expectations, existing countries had more policies in place during the study baseline period, but there was no difference in the number of polices for the 
remainder of the study time periods. Results suggested that baseline differences were related to a longer history with T.C.P. activity, especially restrictions and bans on smoking in public areas and direct advertising. Also, while existing, accession, and two European-neighborhood countries had similar total population smoking prevalence at the baseline time period, only existing and accession countries demonstrated a consistent decline in smoking prevalence throughout the study time periods. Evaluation of individual country results showed Latvia and Lithuania as consistent laggards in reductions in smoking prevalence. Likewise, only existing and accession countries realized a decline in smoking-related mortality throughout all study time periods.

The tendency to policy convergence across E.U. member states over time has come be called "Europeanization" (Radaelli, 2003), (Bulmer \& Lequesne, 2005) and results from this study support the role of the E.U. as a policy transfer platform, allowing progressive countries to influence E.U. policies through uploading and laggard states to catch-up (converge) through policy downloading. (Borzel, 2002) Given that most accession countries had no or only very few T.C.P. during the baseline time period, the process of E.U. accession was a de facto mandatory policy diffusion (download) of the E.U. tobacco acquis communautaire to acceding countries, permitting these countries to at least shorten the extended periods of nascent and ineffective T.C.P. advocacy and implementation as predicted by the T.E.M..

An additional important finding tentatively supported by the current study's results is the ability of such "mandatory" policy adoption to influence population behavior in the unclear presence of considerable public support for such policies. The trajectory of enacting restrictive T.C.P. in Western democracies, and the basis for predictions in the T.E.M., has historically been that T.C.P. are implemented in an atmosphere of permissive consensus, with politicians only acting when it is "safe" to do so. (Studlar, U.S. tobacco control policy: public health, political economy, or morality policy?, 2008) Public support for T.C.P. has been demonstrated to be related to both the implementation and enforcement of restrictive and comprehensive T.C.P. (Hyland, et al., 2009) in Western democracies. Further, particularly well documented and discussed in the United States, public support for such T.C.P. has been built primarily by the work of advocacy groups through a sustained effort to reframe T.C.P. partially on the basis of the arguments of morality policy and de-normalizing the product, act of smoking, and sometimes even the tobacco industry itself. (Studlar, U.S. tobacco control policy: public health, political economy, or morality policy?, 2008) For many accession countries, this prolonged period of advocacy and de-normalization, with subsequent change in societal attitudes towards smoking 
and T.C.P., was likely not present. Of the twelve countries acceding to the E.U. in 2004/2007, ten were Central and Eastern Europe (C.E.E.) countries emerging from collapsed communist regimes and decades of social, political, and economic oppression. Thus E.U. accession represented a way to advance and stabilize democracy and free markets, as well as advance public health, standards of living, and quality of life. In pre-collapse communist societies, the tobacco market was typically a monopoly of a domestic producer, and tobacco advertising was virtually immaterial, as was advertising for any consumer good. The government-controlled the price of the cigarettes, the revenue stream from which was not insignificant, and smoking was a nearly ubiquitous cultural norm, especially for men. As late as 1983 in Poland, cigarettes were included as rations with worker paychecks, and while early official statistics are difficult to find, some have estimated that 65-75 percent of men in Poland smoked. (Zatonski, 2003) Further, the health care system, health information, and the public health agenda were controlled by the government, and while it was not forbidden for physicians or other public health or policy makers to discuss an alternate agenda, such groups and messages received little if any reinforcement, and the impact from any such campaign was minimal. In the societal vacuum left by the departure of the communist regimes in C.E.E., Western-based transnational tobacco companies, concurrently pressured by shrinking markets in the West, saw tremendous market potential. Research based on tobacco industry documents have reported the many strategies employed by the industry to exploit these markets, including the explosion of advertising, often targeted at women and children, in societies previously unaccustomed to the promotion of consumer goods. (Zatonski, 2003), (Lipand, A; for the World Health Organization Tobacco Free Initiative, 2007), (Szilagyi, 2006) Thus, in societies where advocacy and de-normalization had likely not yet taken root, results from this study suggest that changes in population behavior patterns may have been driven by T.C.P. implementation. This directionality (policy $\rightarrow$ social change) is opposite to that previously argued, that T.C.P. adoption reflects social change and a population willing to accept such mandated behavioral restrictions. (Nathanson, Disease Prevention as Social Change: The State, Society and Public Health in the United States, France, Great Britain, and Canada, 2007)

The limitations of this study are threefold. First, as this study used an epidemiologic approach with cross-sectional data, the reported results represent associations and not causality. Second, publicly available data were used and so results are only as reliable as the data reported to and data compilation procedures of these sources. Finally, the present study assessed only enacted policies, not policy enforcement. While the authors acknowledge that 
differences between enacted legislation and on-the-ground policy enforcement exist within the E.U. (Nathanson, Disease Prevention as Social Change: The State, Society and Public Health in the United States, France, Great Britain, and Canada, 2007) and that these differences impact the realization of policy effectiveness, it was beyond the scope of the present study to determine T.C.P. enforcement over time and in all the jurisdictions included in this study.

\subsection{Chapter Summary \& Contribution}

This results reported in this chapter provide prima facie support for the ability of the E.U. and the E.U. accession process, as a de facto mandatory policy diffusion, to advance population health and shorten phases in the tobacco epidemic. That is, this chapter provided quantitative evidence that both policy adoption and reductions in population-level tobacco use can occur absent substantial social changes. This is oppositional to the findings reported in the previous chapter, thus highlighting the bi-directional nature of the relationship between policy adoption and tobacco use. These seemingly-contradictory findings also likely highlight both the complexity and the importance of contextual factors in understanding the dynamic between tobacco use and policy adoption.

Specifically regarding this study, results suggest that the challenge particularly for accession countries will be to continue to foster healthy public policy advocacy to entrench new normative behavior. 
Table 7-1. Comparisons and Changes in Structural and Institutional Metrics (1990/1994 to 2000/2004) in Existing E.U. Countries and 2004 \& 2007 E.U. Accession Countries

\begin{tabular}{|c|c|c|c|c|}
\hline & & $\begin{array}{c}\text { Existing E.U. Countries } \\
\text { (n / Mean } \pm \text { Std. Error) }\end{array}$ & $\begin{array}{l}\text { Accession Countries } \\
(\mathrm{n} / \text { Mean } \pm \text { Std. Error) }\end{array}$ & Statistical Difference \\
\hline \multirow[t]{4}{*}{ Real G.D.P. } & $1990-1994$ & $15 / 17244.7 \pm 1079.1$ & $11 / 6705.4 \pm 744.9$ & $\mathrm{p}_{\mathrm{F}}<0.0001$ \\
\hline & 1995-1999 & $15 / 22241.2 \pm 1388.0$ & $11 / 8746.0 \pm 1157.9$ & $\mathrm{p}_{\mathrm{F}}<0.0001$ \\
\hline & $2000-2004$ & $15 / 28606.24 \pm 2435.14$ & $11 / 12227.6 \pm 1169.7$ & $\mathrm{p}_{\mathrm{F}}<0.0001$ \\
\hline & 2005-2007 & $15 / 32564.1 \pm 2285.1$ & $11 / 15574.1 \pm 1283.2$ & $\mathrm{p}_{\mathrm{F}}<0.0001$ \\
\hline \multirow{4}{*}{$\begin{array}{l}\% \text { of G.D.P. as Health Care } \\
\text { Expenditure }\end{array}$} & $1990-1994$ & $15 / 7.7 \pm 0.3$ & $9 / 5.2 \pm 0.5$ & $\mathrm{p}_{\mathrm{F}}<0.0001$ \\
\hline & 1995-1999 & $15 / 8.0 \pm 0.3$ & $10 / 6.1 \pm 0.5$ & $\mathrm{p}_{\mathrm{F}}=0.001$ \\
\hline & $2000-2004$ & $15 / 8.6 \pm 0.3$ & $10 / 6.4 \pm 0.5$ & $\mathrm{p}_{\mathrm{F}}<0.0001$ \\
\hline & $2005-2007$ & $15 / 9.2 \pm 0.3$ & $9 / 6.4 \pm 0.5$ & $\mathrm{p}_{\mathrm{F}}<0.0001$ \\
\hline \multirow[t]{2}{*}{ Within Country Change } & Real G.D.P. & $15 / 11361.6 \pm 1627.3 / p<0.0001$ & $11 / 5522.3 \pm 549.27 / p<0.0001$ & -- \\
\hline & $\begin{array}{l}\% \text { of G.D.P. as Health Care } \\
\text { Expenditure }\end{array}$ & $15 / 1.0 \pm 0.2 / p=0.001$ & $8 / 1.0 \pm 0.3 / p=0.014$ & -- \\
\hline
\end{tabular}




\begin{tabular}{|c|c|c|c|c|c|}
\hline & & & $\begin{array}{c}\text { Existing E.U. Countries } \\
\text { (n / Mean } \pm \text { Std. Error })\end{array}$ & $\begin{array}{l}\text { Accession Countries } \\
(\mathrm{n} / \text { Mean } \pm \text { Std. Error) }\end{array}$ & $\begin{array}{l}\text { Statistical } \\
\text { Difference }\end{array}$ \\
\hline \multirow{2}{*}{$\frac{d}{0.0}$} & $\begin{array}{c}\text { Retail Price of Cheapest/Most Popular } \\
\text { Domestic Brand }\end{array}$ & USD, PPP\$, 2001 & $15 / 4.1 \pm 0.4$ & $11 / 2.6 \pm 0.3$ & $\mathrm{p}_{\mathrm{F}}=0.006$ \\
\hline & $\begin{array}{c}\text { Retail Price of Most Popular } \\
\text { International Brand }\end{array}$ & USD, PPP\$, 2001 & $15 / 4.8 \pm 0.3$ & $11 / 4.7 \pm 0.6$ & $\mathrm{p}_{\mathrm{F}}=0.81$ \\
\hline \multirow{3}{*}{$\begin{array}{l}0 \\
0 \\
0 \\
0\end{array}$} & \multirow{3}{*}{$\begin{array}{c}\text { T.C.P.-s Score } \\
\text { ( \# of Policy Elements - } 22 \text { Total } \\
\text { Possible) }\end{array}$} & $1990-1994$ & $15 / 8.4 \pm 1.3$ & $11 / 2.5 \pm 1.3$ & $p_{F}=0.004$ \\
\hline & & 1995-1999 & $15 / 10.5 \pm 1.3$ & $11 / 11.4 \pm 1.6$ & $p_{F}=0.67$ \\
\hline & & $2005-2007$ & $15 / 16.1 \pm 1.0$ & $11 / 16.2 \pm 0.8$ & $\mathrm{p}_{\mathrm{F}}=0.95$ \\
\hline \multirow{5}{*}{ 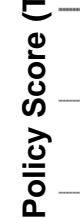 } & \multirow[t]{2}{*}{ All Policy Areas } & Duration of Policy Activity (Yrs) & $15 / 27.4 \pm 3.3$ & $11 / 13.8 \pm 2.4$ & $\mathrm{p}_{\mathrm{F}}=0.005$ \\
\hline & & \# Unique Legislative Events & $15 / 4.9 \pm 0.5$ & $11 / 3.6 \pm 0.5$ & $p_{F}=0.05$ \\
\hline & \multirow[t]{2}{*}{ Smoke Free Public Areas } & Duration & $15 / 19.8 \pm 3.2$ & $10 / 10.7 \pm 1.6$ & $p_{F}=0.04$ \\
\hline & & \# Unique Legislative Events & $15 / 2.1 \pm 0.3$ & $10 / 1.9 \pm 0.3$ & $p_{F}=0.69$ \\
\hline & Smoke Free Public Transportation & Duration & $15 / 17.5 \pm 3.4$ & $11 / 12.3 \pm 2.5$ & $\mathrm{p}_{\mathrm{F}}=0.27$ \\
\hline \multirow{7}{*}{ 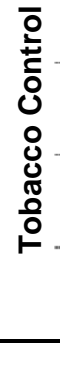 } & & \# Unique Legislative Events & $15 / 1.3 \pm 0.2$ & $11 / 1.2 \pm 0.1$ & $\mathrm{p}_{\mathrm{F}}=0.75$ \\
\hline & & \# Unique Legislative Events & $15 / 2.1 \pm 0.3$ & $11 / 1.6 \pm 0.3$ & $p_{F}=0.30$ \\
\hline & Indirect Advertising Policies & Duration & $15 / 13.5 \pm 2.5$ & $11 / 7.6 \pm 1.4$ & $\mathrm{p}_{\mathrm{F}}=0.08$ \\
\hline & & \# Unique Legislative Events & $14 / 1.6 \pm 0.2$ & $11 / 1.4 \pm 0.2$ & $\mathrm{p}_{\mathrm{F}}=0.44$ \\
\hline & Distribution Policies & Duration & $15 / 12.0 \pm 2.4$ & $11 / 10.4 \pm 1.2$ & $p_{F}=0.62$ \\
\hline & & \# Unique Legislative Events & $15 / 2.0 \pm 0.2$ & $11 / 1.7 \pm 0.2$ & $\mathrm{p}_{\mathrm{F}}=0.41$ \\
\hline & Within Country Change & \# of Policy Elements & $15 / 5.3 \pm 1.1 / p_{\beta}<0.0001$ & $11 / 12.3 \pm 1.6 / p_{\beta}<0.0001$ & -- \\
\hline
\end{tabular}


Table 7-3. Comparisons and Changes in Population Health Outcome Metrics (1990/1994 to 2000/2004) in Existing E.U. Countries and 2004 \& 2007 E.U. Accession Countries

\begin{tabular}{|c|c|c|c|c|}
\hline & & $\begin{array}{c}\text { Existing E.U. Countries } \\
(\mathrm{n} / \text { Mean } \pm \text { Std. Error })\end{array}$ & $\begin{array}{l}\text { Accession Countries } \\
(\mathrm{n} / \text { Mean } \pm \text { Std. Error })\end{array}$ & $\begin{array}{l}\text { Statistical } \\
\text { Difference }\end{array}$ \\
\hline \multirow{3}{*}{$\begin{array}{c}\text { Annual Cigarette Consumption } \\
\text { (per Capita) }\end{array}$} & 1990-1994 & $14 / 1753.0 \pm 74.7$ & $6 / 1956.5 \pm 195.2$ & $p=0.244$ \\
\hline & 1995-1999 & $14 / 1636.8 \pm 122.6$ & $9 / 1951.0 \pm 124.5$ & $p=0.101$ \\
\hline & $2000-2004$ & $14 / 1659.3 \pm 164.1$ & $6 / 1933.8 \pm 246.4$ & $p=0.370$ \\
\hline \multirow{4}{*}{$\begin{array}{c}\text { Smoking Prevalence (Total } \\
\text { Population) }\end{array}$} & $1990-1994$ & $14 / 30.2 \pm 1.4$ & $11 / 30.6 \pm 1.6$ & $p=0.840$ \\
\hline & 1995-1999 & $15 / 29.4 \pm 1.4$ & $10 / 30.1 \pm 1.3$ & $p=0.723$ \\
\hline & $2000-2004$ & $13 / 28.0 \pm 1.4$ & $11 / 27.9 \pm 1.2$ & $p=0.942$ \\
\hline & $2005-2007$ & $11 / 23.3 \pm 1.1$ & $5 / 27.4 \pm 2.1$ & $p=0.079$ \\
\hline \multirow[t]{4}{*}{ Smoking Prevalence (Female) } & 1990-1994 & $14 / 24.4 \pm 1.5$ & $10 / 18.5 \pm 2.5$ & $p=0.045$ \\
\hline & 1995-1999 & $15 / 24.3 \pm 1.6$ & $10 / 18.4 \pm 1.4$ & $p=0.015$ \\
\hline & $2000-2004$ & $13 / 24.1 \pm 1.1$ & $10 / 19.3 \pm 1.4$ & $p=0.013$ \\
\hline & 2005-2007 & $11 / 19.7 \pm 1.2$ & $5 / 18.3 \pm 1.9$ & $p=0.544$ \\
\hline \multirow[t]{4}{*}{ Smoking Prevalence (Male) } & 1990-1994 & $14 / 36.3 \pm 1.9$ & $10 / 41.8 \pm 2.1$ & $p=0.070$ \\
\hline & 1995-1999 & $15 / 34.8 \pm 1.8$ & $10 / 41.9 \pm 2.3$ & $p=0.025$ \\
\hline & $2000-2004$ & $13 / 32.1 \pm 2.0$ & $10 / 38.1 \pm 2.3$ & $p=0.067$ \\
\hline & 2005-2007 & $11 / 27.2 \pm 1.6$ & $5 / 38.5 \pm 4.1$ & $p=0.007$ \\
\hline \multirow{4}{*}{$\begin{array}{l}\text { S.D.R. Smoking-Related Causes } \\
\text { (Total Population) }\end{array}$} & $1990-1994$ & $15 / 300.2 \pm 16.4$ & $11 / 514.6 \pm 43.8$ & $p<0.0001$ \\
\hline & 1995-1999 & $15 / 269.4 \pm 13.3$ & $11 / 477.7 \pm 38.7$ & $p<0.0001$ \\
\hline & $2000-2004$ & $14 / 232.6 \pm 10.8$ & $11 / 429.0 \pm 33.2$ & $p<0.0001$ \\
\hline & 2005-2007 & $13 / 199.8 \pm 9.0$ & $10 / 398.0 \pm 38.4$ & $p<0.0001$ \\
\hline \multirow{4}{*}{$\begin{array}{l}\text { S.D.R. Smoking-Related Causes } \\
\text { (Female) }\end{array}$} & 1990-1994 & $15 / 208.2 \pm 14.1$ & $11 / 374.0 \pm 36.1$ & $p<0.0001$ \\
\hline & 1995-1999 & $15 / 187.0 \pm 12.4$ & $11 / 348.8 \pm 32.6$ & $p<0.0001$ \\
\hline & $2000-2004$ & $14 / 165.4 \pm 10.6$ & $11 / 312.6 \pm 26.7$ & $p<0.0001$ \\
\hline & 2005-2007 & $13 / 142.3 \pm 9.2$ & $10 / 286.2 \pm 30.0$ & $p<0.0001$ \\
\hline \multirow{4}{*}{$\begin{array}{l}\text { S.D.R. Smoking-Related Causes } \\
\text { (Male) }\end{array}$} & $1990-1994$ & $15 / 427.3 \pm 21.3$ & $11 / 716.7 \pm 61.4$ & $p<0.0001$ \\
\hline & 1995-1999 & $15 / 381.8 \pm 16.0$ & $11 / 663.8 \pm 52.3$ & $p<0.0001$ \\
\hline & $2000-2004$ & $14 / 321.7 \pm 11.9$ & $11 / 597.5 \pm 46.0$ & $p<0.0001$ \\
\hline & $2005-2007$ & $13 / 274.9 \pm 9.8$ & $10 / 560.7 \pm 53.9$ & $\mathrm{p}<0.0001$ \\
\hline \multirow[t]{7}{*}{ Within Country Change } & Cigarette Consumption & $14 /-93.7 \pm 121.5 / p_{t}=0.454$ & $4 /-107.0 \pm 293.8 / p_{t}=0.74$ & -- \\
\hline & Prevalence (Total) & $12 /-3.0 \pm 0.8 / p_{t}=0.004$ & $11 /-2.7 \pm 1.2 / p_{t}=0.052$ & -- \\
\hline & Prevalence (Female) & $12 /-1.6 \pm 1.0 / p_{t}=0.134$ & $9 / 0.2 \pm 1.6 / p_{t}=0.912$ & -- \\
\hline & Prevalence (Male) & $12 /-4.3 \pm 1.0 / p_{t}=0.001$ & $9 /-5.4 \pm 1.5 / p_{t}=0.006$ & -- \\
\hline & Mortality (Total) & $14 /-71.4 \pm 8.2 / p_{t}<0.0001$ & $11 /-85.6 \pm 21.7 / p_{t}=0.003$ & -- \\
\hline & Mortality (Female) & $14 /-47.1 \pm 5.8 / p_{t}<0.0001$ & $11 /-61.4 \pm 18.1 / p_{t}=0.007$ & -- \\
\hline & Mortality (Male) & $14 /-108.4 \pm 12.6 / p_{t}<0.0001$ & $11 /-119.2 \pm 29.5 / p_{t}=0.002$ & -- \\
\hline
\end{tabular}




\begin{tabular}{cccc}
\hline Dependent Variable & Existing E.U. Countries & Accession Countries & Statistical Difference \\
\hline Real G.D.P. & $\beta=1136.2 \pm 242.7, p_{\beta}<0.0001$ & $\beta=552.2 \pm 145.9, p_{\beta}=0.001$ & $p_{\mathrm{t}}=0.064$ \\
\% of G.D.P. as Health Care Expenditure & $\beta=0.097 \pm 0.042, p_{\beta}=0.027$ & $\beta=0.1 \pm 0.07, p_{\beta}=0.099$ & $p_{\mathrm{t}}=0.793$ \\
\# of Policy Elements & $\beta=0.5 \pm 0.2, \mathrm{p}_{\beta}=0.004$ & $\beta=1.2 \pm 0.2, \mathrm{p}_{\beta}<0.0001$ & $\mathrm{p}_{\mathrm{t}}=0.007$ \\
Cigarette Consumption & $\beta=-9.5 \pm 17.6, \mathrm{p}_{\beta}=0.6$ & $\beta=-2.3 \pm 26.8, \mathrm{p}_{\beta}=0.9$ & $\mathrm{p}_{\mathrm{t}}=0.780$ \\
Prevalence (Total) & $\beta=-0.2 \pm 0.2, \mathrm{p}_{\beta}=0.3$ & $\beta=-0.3 \pm 0.2, \mathrm{p}_{\beta}=0.2$ & $\mathrm{p}_{\mathrm{t}}=0.842$ \\
Prevalence (Female) & $\beta=-0.02 \pm 0.2, \mathrm{p}_{\beta}=0.9$ & $\beta=0.08 \pm 0.2, \mathrm{p}_{\beta}=0.7$ & $\mathrm{p}_{\mathrm{t}}=0.748$ \\
Prevalence (Male) & $\beta=-0.4 \pm 0.3, \mathrm{p}_{\beta}=0.1$ & $\beta=-0.4 \pm 0.3, \mathrm{p}_{\beta}=0.2$ & $\mathrm{p}_{\mathrm{t}}=0.919$ \\
Mortality (Total) & $\beta=-6.8 \pm 1.9, \mathrm{p}_{\beta}=0.001$ & $\beta=-8.6 \pm 5.4, \mathrm{p}_{\beta}=0.1$ & $\mathrm{p}_{\mathrm{t}}=0.728$ \\
Mortality (Female) & $\beta=-4.3 \pm 1.8, \mathrm{p}_{\beta}=0.019$ & $\beta=-6.1 \pm 4.4, \mathrm{p}_{\beta}=0.2$ & $\mathrm{p}_{\mathrm{t}}=0.670$ \\
Mortality (Male) & $\beta=-10.5 \pm 2.4, \mathrm{p}_{\beta}<0.0001$ & $\beta=-11.9 \pm 7.5, \mathrm{p}_{\beta}=0.1$ & $\mathrm{p}_{\mathrm{t}}=0.843$ \\
\hline
\end{tabular}


Figure 7-1. Range of the Percent Change in Smoking Prevalence from 1990-94 to 2000-04 in Individual Existing and Accession E.U. Countries

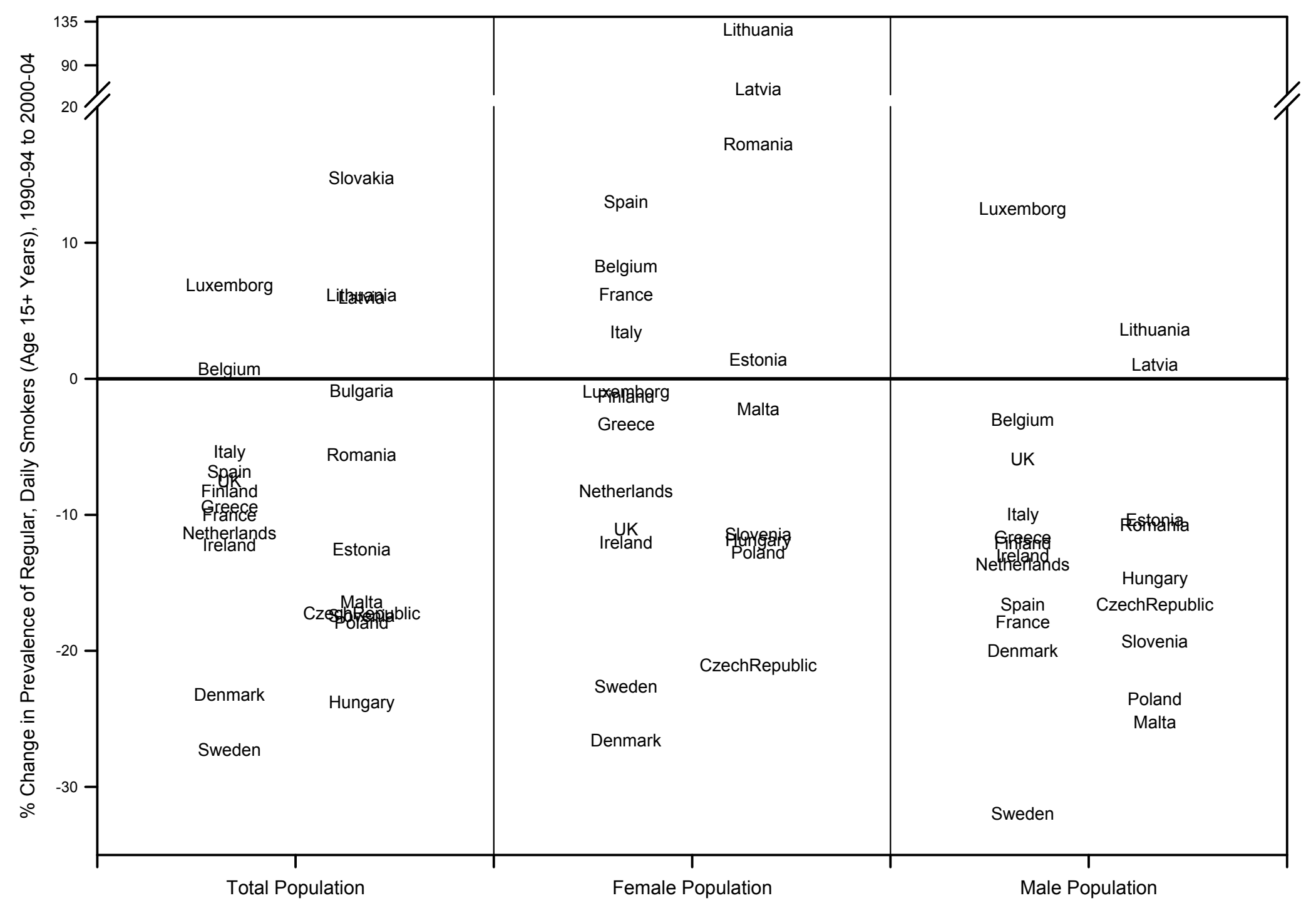




\section{Panel A: Real GDP}

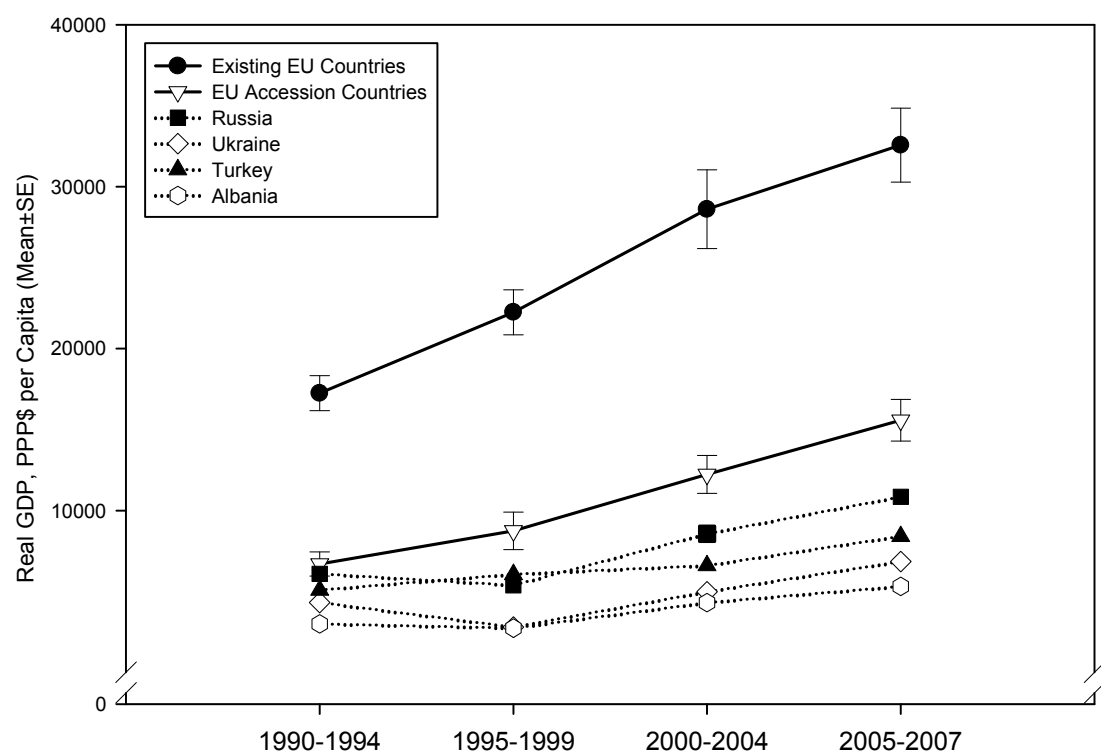

Panel C: Smoking Prevalence (Total Population)

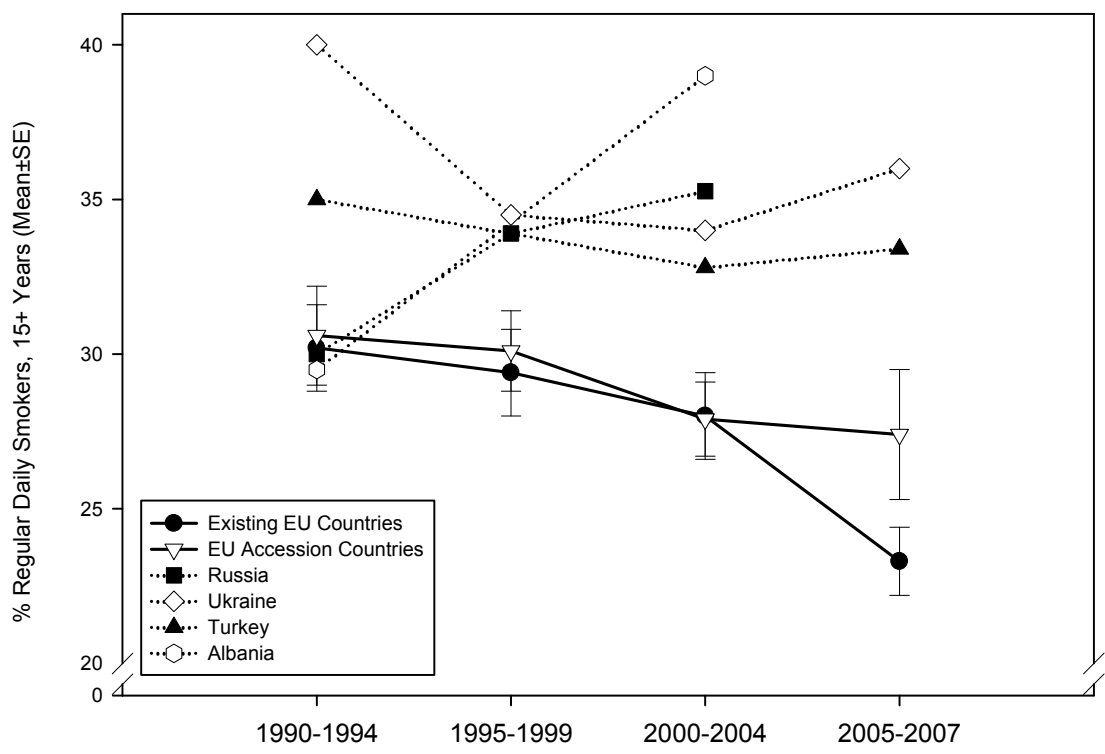

Panel B: Tobacco Control Policy Elements (TCP-s)

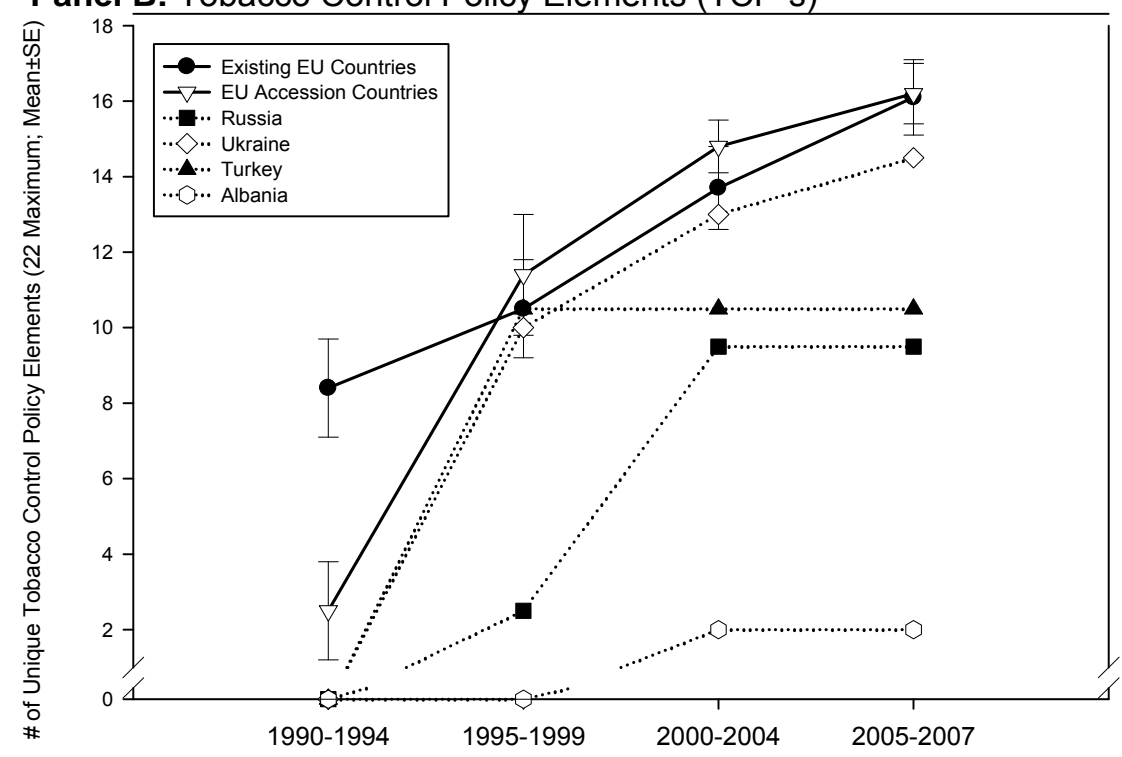

Panel D: Tobacco-Related Mortality (Standardized Death Rate per 100,000)

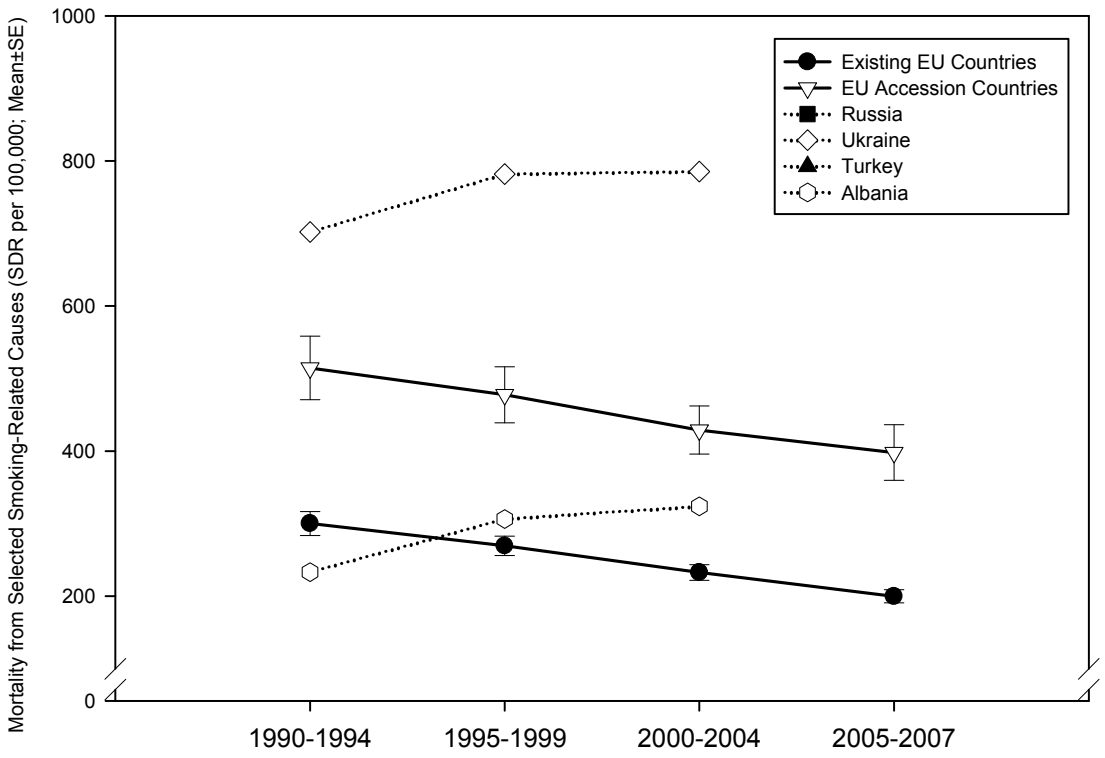




\section{CONCLUSION (AND A CONCEPTUAL MODEL FOR UNDERSTANDING TOBACCO CONTROL POLICY AND TOBACCO-RELATED POPULATION HEALTH)}

\subsection{Chapter Introduction \& Purpose}

The previous chapters have presented an overview of the tobacco epidemic, a review of two very different literatures with very different perspectives on the tobacco epidemic (the public health literature and the political and policy science literature), an empirical analysis integrating the political and policy science viewpoint with the public health perspective on the evolution of the tobacco epidemic, and two quantitative analyses alternately supporting the interdependence and complex temporal relationship between tobacco control policy adoption and population health outcomes as well as the importance of societally-derived factors in the evolution of the tobacco epidemic. The ultimate objective has been to identify key elements and forces in the tobacco epidemic and, more precisely, the processes of tobacco control policy adoption so as to present an integrated conceptual model based on the causal loops of tobacco control policy and tobacco-related population health. This model is now presented and each element discussed, with suggestions for quantification and future research questions. 


\subsection{An Conceptual Model for Integrating the Social and Political Forces Affecting Policy Adoption and Population Health: A Causal Loop}

Figure 8-1. Causal Loop Diagram

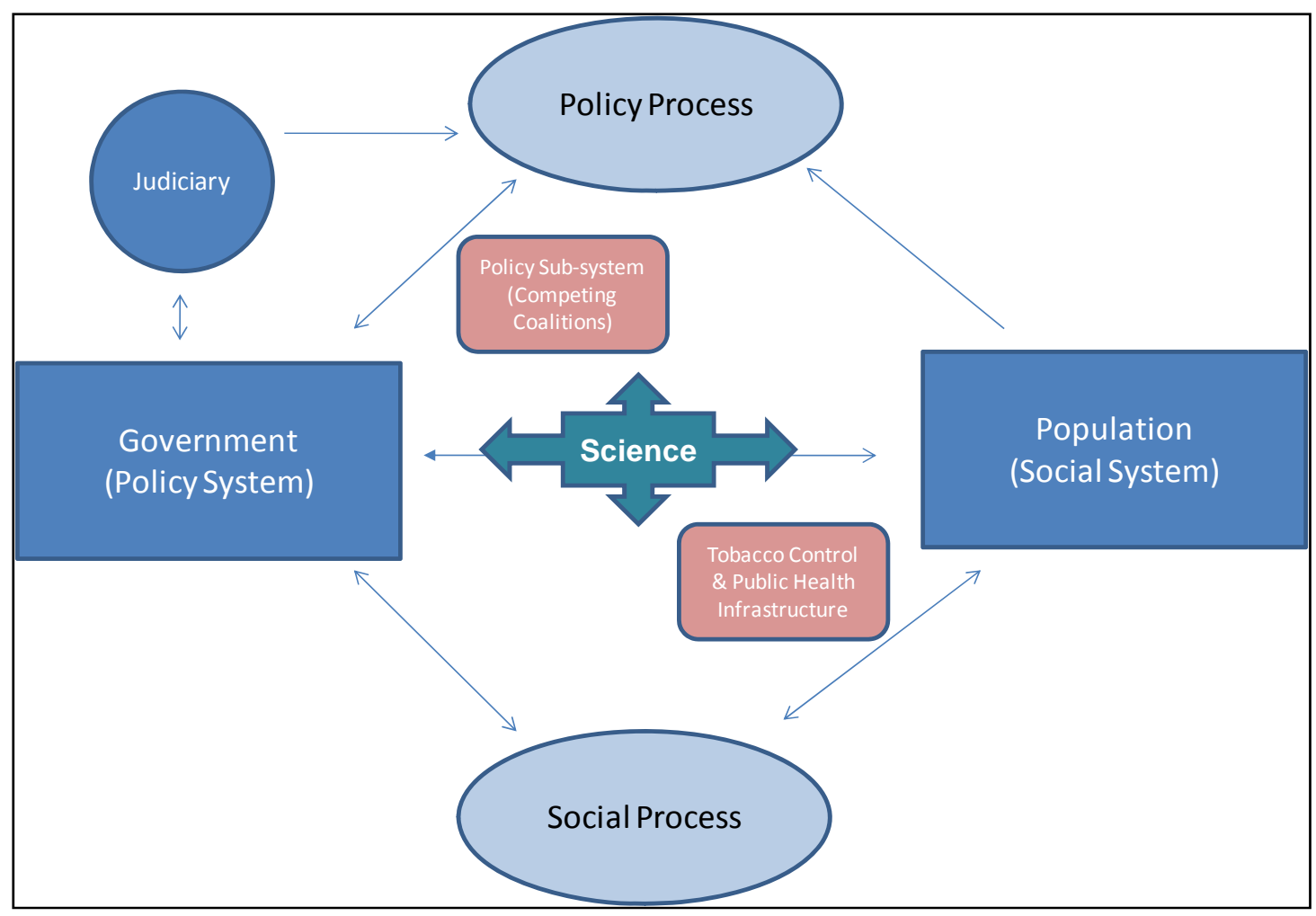

\subsection{Elements of the Causal Loop Diagram}

\subsubsection{Population (Social System)}

Abatement of the effects of the tobacco epidemic in society (the population) is the primary focus of the public health community. The overwhelming majority of research and measurement efforts are directed toward quantifying tobacco use, the health effects of such use, and the costs, both direct and indirect, of tobacco use and tobacco-related health effects. However, neither the public health community nor the political or policy science community has comprehensively assessed the influence of factors within this sphere on tobacco control policy adoption. For example, it is unclear how - or if - fundamental societal values regarding libertarian vs. paternalistic perspectives on the balance between individual choice and public health meaningfully affect the likelihood, pace, or types of tobacco control policy adoption. A research agenda integrating the political and policy science and public health perspectives on the influence of this sphere on the evolution of the tobacco epidemic would include assessment and measurement of knowledge, attitudes, an behaviors related to not only tobacco use, but 
also regarding the tobacco industry, and the role of government in regulating individual behavior. More specifically, suggested metrics and constructs in a comprehensive and integrated research framework might include:

- Knowledge and attitudes regarding the health effects of tobacco use, including understanding and conception of "risk"

- Knowledge and attitudes regarding conduct by the tobacco industry

- Tobacco use and consumption

- Fundamental preferences and values for private vs. public solutions to problems

- Fundamental preferences, values, and tolerance for paternalism and protection vs. perceived infringement of individual rights (and the distinction between those 2 constructs)

Key research questions in a comprehensive and integrated research framework might include:

- To what extent, if any, does social change precede policy adoption?

- How do fundamental values affect opposition or support for tobacco control policies?

- Are effects and associations uniform throughout the population or do they differ between specific strata?

- What is the quantitative nature of the interaction between social structural variables, especially the values and expectations regarding the role of government, affect a) policy outcomes and b) population health outcomes?

\subsubsection{Government (Policy System)}

Understanding how government structures, functions, and aspects of the policy process influence tobacco control policy adoption has been the primary focus of the political and policy science community. This sphere, however, has been too narrowly construed and thus understudied by the public health community. Further, neither the political and policy science nor the public health communities have undertaken study of how policy adoption in the governmental sphere is affected by population-level tobacco use and vice versa. A research agenda integrating the political and policy science and public health perspectives on the influence of this sphere on the evolution of the tobacco epidemic would include mechanisms to account for this interrelated and temporal dynamic. Key metrics in a comprehensive and integrated research framework might include: 
- Form of government (e.g., federalism) and degree of pluralism

- Existing social and social welfare policy regimes

- Existing tobacco control policy regime, including institutional arrangements for regulatory vs. prevention functions

- Obligations or constraints as required by treaties or other forms of multi-level governance

- Competition vs. coordination between different venues and "levels" in a federalist system

- Responsiveness of policy system to social system or to policy system at different "levels" in a federalist system

Key research questions in a comprehensive and integrated research framework might include:

- What is the interaction between social and policy systems as related to tobacco control policy and tobacco-related health outcomes?

- Are tobacco control policy regimes related to / affected by other aspects of social welfare or health regimes?

- What are the important / most effective elements of the institutional arrangements for regulation and prevention?

- Do the number of policy venues affect in any meaningful way either policy or population health outcomes?

\subsubsection{Judiciary}

The judiciary has had undeniable impacts on the evolution of the tobacco epidemic, including tobacco control policy. However, except for the most high profile cases, usually in the Supreme Court, the impact of the judiciary has not been routinely or systematically studied in either the political and policy science or public health communities. A research agenda integrating the political and policy science and public health perspectives on the influence of this sphere on the evolution of the tobacco epidemic would attempt to articulate and systematically quantify the effects of the judiciary on tobacco control policy adoption or tobacco-related population health outcomes.

Key research questions in a comprehensive and integrated research framework might include:

- How have the courts been used, which courts, how often, and for what? 
- What have been the rulings in the lower courts?

- How has judicial activity (rulings, case law) quantitatively affected policy outcomes (at the state- or national-level)?

- Is there a pattern or relationship between either the use of the courts (legal mobilization) or the rulings of the courts to tobacco control policy or tobaccorelated population health (implying a social effect of the judiciary as well)?

\subsubsection{Tobacco Control and Public Health Infrastructure vs. Tobacco Industry (Competing Coalitions)}

These are the "opposing forces" in the tobacco epidemic, competing for the policy monopoly, to control the subsystem, and to be able to define the policy image. Both coalitions are institutionalized. The Advocacy Coalition Framework or global advocacy networks would seem ideal theoretical frameworks with which to systematically and quantitatively assess the impact of these coalitions, though few studies to date have attempted to do so. Key research questions in a comprehensive and integrated research framework might include:

- What are the resources and strategies of each coalition?

- How do the structural and resource characteristics of coalitions affect their ability to influence the policy subsystem?

- How do the coalitions interact with other venues or the policy or social systems?

- What policy images are the coalitions promoting and how it being advanced?

\subsubsection{Scientific, Expert, and Epistemic Communities}

These communities have pervasive effects, interacting with all the other actors in the system. While it is understood that these communities have had an effect on the tobacco epidemic and tobacco control policy adoption, much less is known about how these effects have been exerted. Key research questions in a comprehensive and integrated research framework might include:

- What is the relationship between "scientific knowledge" and "issue understanding" in either the policy or social systems?

- What is the status of these communities?

- What is their role, formal or informal, in the policy subsystem?

\subsection{Conclusions: Submissions to Political and Policy Science, and Public Health}

The primary aim of this work has been to integrate the two very different perspectives from the political and policy science and public health communities as regards the evolution of 
the tobacco epidemic. An integrated conceptual model based on the causal loops of tobacco control policy and tobacco-related population health has been presented that incorporates the realms of population, governmental, judicial, public health, tobacco industry and other subsystems, and scientific communities. This framework, as well as the identification of its constituent elements and the dynamic interrelationship between social factors and policy adoption, is submitted as the novel contributions of this work. However, while this framework does assimilate the key elements and forces elucidated during the course of this work and integrates the political and policy science with the public health perspective, in truth this framework likely elicits more questions than it answers. The research questions and agendas and metrics proposed in this chapter highlight both the strengths and deficiencies of the two perspectives. For the political and policy science community, development of a comprehensive and integrated research framework implies building on the existing explanatory frameworks of the policy process to incorporate additional spheres such as the judiciary and, in particular, socially-driven factors influencing policy adoption. For the public health community, development of a comprehensive and integrated research framework entails building upon existing strengths in the measurements and assessment of tobacco use within the population and developing and incorporating a more sophisticated understanding of the factors affecting the policy adoption process. It is likely that this more sophisticated, comprehensive, and integrated understanding of the tobacco epidemic, including the dynamics of tobacco use and tobacco control policy adoption, will be required if the goals of, for example the F.C.T.C. and other international efforts, are to be achieved and the tobacco epidemic in the developing world substantially curtailed. 


\section{LIST OF APPENDICES}

Summary of Key Legal Cases and Events

Curriculum Vitæ (Frisbee, Stephanie J) 


\section{REFERENCES}

Action for Smoking and Health. (2010). US Anti-Smoking Organizations. Retrieved April 25, 2010, from Action for Smoking and Health: http://ash.org

Alamar, B., \& Glantz, S. A. (2006). Tobacco industry profits from smoking images in the movies. Pediatrics , 117;1462.

Albuja, S., \& Daynard, R. A. (2009). The FCTC and the adoption of domestic tobacco control policies: the Ecuadorian experience. Tobacco Control , 18(1):18-21.

Alciati, M. H., Frosh, M., Green, S. B., Brownson, R. C., Fisher, P. H., Hobart, R., et al. (1998). State laws on youth access to toacco in the United States: measuring their extensiveness with a new rating system. Tobacco Control , 7:345-352.

Alderman, J., \& Daynard, R. A. (2006). Applying lessons from tobacco litigation to obesity lawsuits. American Journal of Preventive Medicine , 30(1):82-88.

American Academy of Pediatrics Julias B. Richmond Center of Excellence. (2008). 2008 National Social Climate Survey of Tobacco Control. Retrieved April 23, 2010, from Social Climate Website: www.socialclimate.org

American Cancer Society Cancer Action Network, American Heart Association, American Lung Association, Robert Wood Johnson Foundation, Campaign for Tobacco-Free Kids, with funding from the Robert Wood Johnson Foundation. (2009). Deadly in Pink: Big Tobacco Steps Up Its Targeting of Women and Girls. Washington, DC: Campaign for Tobacco-Free Kids.

American Lung Association. (2009). State of Tobacco Control 2009. Washington, DC: American Lung Association.

Anonymous. (1996). FDA regulations restricting the sale and distribution of cigarettes and smokeless tobacco to protect children and adolescents (executive summary). Tobacco Control, 5:236-246.

Anonymous. (1993). Respiratory health effects of passive smoking: lung cancer and other disorders. Tobacco Control , 2:71-79.

Arabi, Z. (2007). An epidemic that deserves more attention: epidemiology, prevention, and treatment of smokeless tobacco. Southern Medical Journal , 100(9):890-894.

Arabi, Z. (2006). Metabolig and cardiovascular effects of smokeless tobacco. Journal of the Cardiometabolic Syndrome , 1(5):345-350.

Armour, B. S., Finkelstein, E. A., \& Fielbelkorn, I. C. (2009). State-level Medicaid expenditures attributable to smoking. Preventing Chronic Disease: Public Health Research, Practice, and Policy, 6(3):A84. 
Armour, B. S., Pitts, M., \& Lee, C.-W. (2008). Cigarette smoking and food insecurity among lowincome families in the United States, 2001. American Journal of Health Promotion , 22(6):386392.

Asare, B., Cairney, P., \& Studlar, D. T. (2009). Fedearlism and multilevel governance in tobacco policy: the European Union, the United Kingdom, and devolved UK institutions. Journal of Public Policy , 29(1):79-102.

Asbridge, M. (2004). Public place restrictions on smoking in Canada: assessing the role of the state, media, science and public health advocacy. Social Science and Medicine , 58:13-24.

Associated Press. (1995, August 23). Judge once worked as tobacco lobbyist. New York Times , p. Section D; Page 3; Column 3; Business/Financial Desk.

Assunta, M., \& Chapman, S. (2005). Health treaty dilution: a case study of Japan's influence on the language of the WHO Framework Convention on Tobacco Control. Journal of Epidemiology and Community Health , 60:751-756.

Bachrach, P., \& Baratz, M. S. (1962). Two faces of power. American Political Science Review , 56(4):947-952.

Balfour, D. J. (2002). The neurobiology of tobacco dependence: a commentary. Respiration , 69:7-11.

Barbeau, E. M., Leavy-Sperounis, A., \& Balbach, E. D. (2004). Smoking, social class, and gender: what can public health learn from the tobacco industry about disparities in smoking? Tobacco Control , 13:115-120.

Barnes, D. E., Hanauer, P., Slade, J., Bero, L. A., \& Glantz, S. A. (1995). Environmental tobacco smoke. The Brown and Williamson documents. Journal of the American Medical Association , 274(3):248-253.

Barraclough, S., \& Morrow, M. (2008). A grim contradiction: the practice and consequences of corporate social responsibility by British American Tobacco in Malaysia. Social Science \& Medicine , 66:1784-1796.

Baumgartner, F., \& Jones, B. D. (1993). Agendas and Instability in American Politics. Chicago, IL: University of Chicago Press.

Baumgartner, F., \& Jones, B. D. (1993). Agendas and Instability in Americn Politics. Chicago, IL: University of Chicago Press.

Baumgartner, F., \& Jones, B. D. (2007). Punctuated Equilibrium Theory: Explaining Stability and Change in Public Policymaking. In P. A. Sabatier, Theories of the Policy Process (pp. 155-188). Boulder, CO: Westview Press.

Bayer, R., \& Colgrove, J. (2002). Science, politics, and ideology in the campaign against environmental tobacco smoke. American Journal of Public Health , 92(6):949-954. 
Bayer, R., Gostin, L. O., Jarvin, G. H., \& Brandt, A. (2002). Tobacco advertising in the United States, a proposal for a constitutionally acceptable form of regulation. Journal of the American Medical Association , 287(22):2990-2995.

Beaglehole, R. (1991). Science, advocacy and health policy: lessons from the New Zealand tobacco wars. Journal of Public Health Policy, Summer:175-183.

Becker, G. S., Grossman, M., \& Murphy, K. M. (1994). An empirical analysis of cigarette addiction. American Economic Review , 84(3):396-418.

Becker, N; Dow Jones Newswire. (2010, April 21). Altria 1Q Profit Jumps 38\%; Revenue, Smokeless Volume Up. Wall Street Journal .

Bell, K., Salmon, A., Bowers, M., Bell, J., \& McCullough, L. (2010). Smoking, steigman and tobacco 'denormalization': Further reflections on the use of stigma as a public health tool. A commentary on Social Science \& Medicine's Stigma, Prejudice, Discrimination and Health Special Issue (67:3). Social Science and Medicine , 70:795-799.

Bennett, C. J. (1991). Review article: what is policy convergence and what causes it? British Journal of Political Science , 21:215-233.

Bennett, C. J. (1997). Understanding ripple effects: the cross-national adoption of policy instruments for bureaucratic accountability. Governance , 10:223-233.

Bero, L. (2003). Implications of the tobacco industry documents for public health and policy. Annual Review of Public Health , 24:267-288.

Bero, L., Barnes, D. E., Hanauer, P., Slade, J., \& Glantz, S. A. (1995). Lawyer control of the tobacco industry's external research program. The Brown and Williamson documents. Journal of the American Medical Association , 274(3):241-247.

Berry, F. S. (1994). Sizing up state policy innovation research. Policy Studies Journal , 22(3):442.

Berry, F. S., \& Berry, W. D. (2007). Innovation and Diffusion Models in Policy Research. In P. A. Sabatier, Theories of the Policy Process (pp. 223-260). Boulder, CO: Westview Press.

Berry, F. S., \& Berry, W. D. (2007). Innovation and Diffusion Models in Policy Research. In P. A. Sabatier, Theories of the Policy Process, 2nd Edition. Boulder, CO: Westview Press.

Berry, F. S., \& Berry, W. D. (1990). State lottery adoptions as policy innovations: an event history analysis. American Political Science Review , 395-415.

Best, A., Tenaski, R., Trochim, W., Lau, F., Holmes, B., Huerta, T., et al. (2006). Systematic transofmational change in tobacco control: an overview of the Initiative for the Study and Implementation of Systems (ISIS). In A. L. Casebeer, A. Harrison, \& A. L. Mark, Innovations in Health Care: A Reality Check (pp. 189-205). Houndsmills, UK: Palgrame MacMillan. 
Blackman, V. S. (2005). Putting policy theory to work: tobacco control in California. Policy and Politics in Nursing Practice , 6:148-155.

Blackwell, J. R. (2010, January 6). Judge upholds most tobacco advertising restrictions. Richmond Times-Dispatch, p. Business Section.

Boffetta, P., Hecht, S., Gray, N., Gupta, P., \& Straif, K. (2008). Smokeless tobacco and cancer. Lancet Oncology , 9(7):667-675.

Bolleyer, N., \& Borzel, T. A. (2010). Non-hierarchical policy coordination in multilevel systems. European Political Science Review , 2(2):157-185.

Borland, R., Yong, H. H., King, B., Cummings, K. M., Fong, G. T., Elton-Marshall, T., et al. (2004). Use of and beliefs about light cigarettes in four countries: findings from the International Tobacco Control Policy Evaluation Survey. Nicotine and Tobacco Research , 6 (Suppl 3):S311S321.

Borzel, T. A. (2002). Pace-setting, foot-dragging, and fence-sitting: member state responses to Europeanization. Journal of Common Market Studies , 40:193-214.

Brownson, R. C., Chriqui, J. F., \& Stamatakis, K. A. (2009). Understanding evidence-based public health policy. American Journal of Public Health , 99(9):1576-1583.

Brownson, R. C., Royer, C., Ewing, R., \& McBride, T. D. (2006). Researchers and policymakers. Travelers in parallel universes. American Journal of Preventive Medicine , 30(2):164-172.

Bulmer, S. J. (1994). The governance of the European Union: a new institutionalist approach. Journal of Public Policy , 13(4):351-380.

Bulmer, S., \& Lequesne, C. (2005). The Member States of the European Union. New York, NY: Oxford University Press.

Byrd, J. C., Shapiro, R. S., \& Schiedermayer, D. L. (1989). Passive smoking: a review of medical and legal issues. American Journal of Public Health , 79(2):209-215.

Cairney, P. (2009). The role of ideas in policy transfer: the case of UK smoking bans since devolutoin. Journal of European Public Policy , 16(3):471-488.

Cairney, P. (2007). Using devolution to set the agenda? Venue shift and the smoking ban in Scotland. British Journal of Politics and International Relations , 9:73-89.

Campbell, R. B., \& Balbach, E. D. (2009). Building alliances in unlikely places: progressive allies and the Tobacco Institute's coalition strategy on cigarette excise taxes. American Journal of Public Health , 99(7):1188-1196.

Cappuccio, F. P. (2004). Commentary: epidemiologic transition, migration, and cardiovascular disease. International Journal of Epidemiology , 33:387-388. 
Carver, V., Reinert, B., \& Range, L. M. (2007). Sustaining tobacco control coalitions amid declining resources. Health Promotion and Practice , 8(3):292-298.

Castles, F. G., \& Obinger, H. (2008). Worlds, families, regimes: country clusters in European and OECD area public policy. West European Politics , 31(1-2):321-344.

Cataldo, J. K., Bero, L. A., \& Malone, R. E. (2010). "A delicate diplomatic situation": tobacco industry efforts to gain control of the Framingham Study. Journal of Clinical Epidemiology , 63:841-853.

Centers for Diseaes Control and Prevention. (2009, August 14). Interagency Committee on Smoking and Health. Retrieved July 8, 2010, from Centers for Disease Control and Prevention, Office on Smoking and Health, National Center for Chronic Disease Prevention and Health Promotion.

Centers for Disease Control and Prevention. (2007). Best Practices for Comprehensive Tobacco Control Programs -- 2007. Atlanta, GA: Department of Health and Human Services, Centers for Disease Control and Prevention, National Center for Chronic Disease Prevention and Health Promotion, Office on Smoking and Health.

Centers for Disease Control and Prevention. (2007). Best Practices User Guide: Coalitions State and Community Intervention. Atlanta, GA: U.S. Department of Health and Human Services, Centers for Disease Control and Prevention, National Center for Chronic Disease Prevention and Health Promotion, Office on Smoking and Health.

Centers for Disease Control and Prevention. (2010). Best Practices User Guide: Youth Engagement -- State and Community Intervention. Atlanta, GA: U.S. Department of Health and Human Services, Centers for Disease Control and Prevention, National Center for Chronic Disease Prevention and Health Promotion, Office on Smoking and Health.

Centers for Disease Control and Prevention. (2009, September 16). Betel Quid with Tobacco (Gutka). Retrieved July 5, 2010, from Centers for Disease Control and Prevention, Office on Smoking and Health, National Center for Chronic Disease Prevention and Health Promotion.

Centers for Disease Control and Prevention. (2007). Charter, Interagency Committee on Smoking and Health. Atlanta, GA: Department of Health and Human Services, Pubic Health Service, Centers for Disease Control and Prevention.

Centers for Disease Control and Prevention. (2009, May 29). Economic Facts about U.S. Tobacco Use and Tobacco Production. Retrieved April 13, 2010, from Centers for Disease Control and Prevention, National Center for Chronic Disease Prevention and Health Promotion, Office on Smoking and Health.

Centers for Disease Control and Prevention. (2010, April 30). Fast Facts. Retrieved July 11, 2010, from Centers for Disease Control and Prevention, Office on Smoking and Health, National Center for Disease Prevention and Health Promotion. 
Centers for Disease Control and Prevention. (2009, September 14). Global Tobacco Surveillanc System (GTSS). Retrieved June 12, 2010, from Centers for Disease Control and Prevention, Office on Smoking and Health, National Center for Chronic Disease Prevention and Health Promotion.

Centers for Disease Control and Prevention. (2009, December 1). Health Effects of Cigarette Smoking. Retrieved April 13, 2010, from Centers for Disease Control and Prevention, National Center for Chronic Disease Prevention and Health Promotion, Office on Smoking and Health.

Centers for Disease Control and Prevention. (2010, February 9). Legislation: Selected Action of the U.S. Government Regarding the Regulation of Tobacco Sales, Marketing, and Use (excluding laws pertaining to agriculture or excise tax). Retrieved April 20, 2010, from Centers for Disease Control and Prevention, National Center for Chronic Disease Prevention and Health Promotion, Office on Smoking and Health.

Centers for Disease Control and Prevention. (2010, February 8). National Tobacco Control Program. Retrieved June 10, 2010, from Centers for Disease Control and Prevention, National Center for Chronic Disease Prevention and Health Promotion, Office on Smoking and Health, State and Community Resources.

Centers for Disease Control and Prevention. (2009, May 29). Office on Smoking and Health (OSH). Retrieved April 25, 2010, from Centers for Disease Control and Prevention, Office on Smoking and Health, National Center for Chronic Disease Prevention and Health Promotion.

Centers for Disease Control and Prevention. (2009, May 29). Regulation: Selected Actions of the U.S. Government Regarding the Regulation of Tobacco Sales, Marketing, and Use (excluding laws pertaining to agriculture or excise tax). Retrieved April 20, 2010, from Centers for Disease Control and Prevention, National Center for Chronic Disease Prevention and Health Promotion, Office on Smoking and Health.

Centers for Disease Control and Prevention. (2010, January 15). Secondhand Smoke (SHS). Retrieved April 13, 2010, from Centers for Disease Control and Prevention, National Center for Chronic Disease Prevention and Health Promotion, Office on Smoking and Health.

Centers for Disease Control and Prevention. (2009, September 16). Smokeless Tobacco Facts. Retrieved July 5, 2010, from Centers for Disease Control and Prevention, Office on Smoking and Health, National Center for Chronic Disease Prevention and Health Promotion.

Centers for Disease Control and Prevention. (2010). State cigarette excise taxes - United States, 2009. Morbidity and Mortality Weekly Report , 59(13):385-411.

Centers for Disease Control and Prevention. (2010). Tobacco Control State Highlights, 2010. Atlanta, GA: U.S. Department of Health and Human Services, Centers for Disease Control and Prevention, National Center for Chronic Disease Prevention and Health Promotion, Office on Smoking and Health. 
Centers for Disease Control and Prevention. (2010). Tobacco Control State Highlights, 2010. Atlanta, GA: U.S. Department of Health and Human Services, Centers for Disease Control and Prevention, National Center for Chronic Disease Prevention and Health Promotion, Office on Smoking and Health.

Centers for Disease Control and Prevention. (2009, September 16). Tobacco-Related Mortality. Retrieved April 13, 2010, from Centers for Disease Control and Prevention, National Center for Disease Prevention and Health Promotion, Office for Smoking and Health.

Centers for Disease Control and Prevention. (2009, May 29). Trends in Current Cigarette Smoking Among High School Students and Adults, United States, 1965-2007. Retrieved July 5, 2010, from Centers for Disease Control and Prevention, Office on Smoking and Health, National Center for Chronic Disease Prevention and Health Promotion.

Centers for Disease Control and Prevention, National Center for Chronic Disease Prevention and Health Promotion, Office on Smoking and Health. (2010). CDC Vitalsigns (TM), September 2010. Atlanta, GA: Centers for Disease Control and Prevention.

Centers for Disease Control and Prevention, Office on Smoking and Health, Division of Adolescent and School Health, National Center for Chronic Disease Prevention and Health Promotion . (2008). Cigarette use among high school students -- United States, 1991-2007. Morbidity and Mortality Weekly Report , 57(25):686-688.

Chaloupka, F. J., \& Saffer, H. (1992). Clean indoor air laws and the demand for cigarettes. Contemporary Policy Issues , 10(2):72-83.

Chapman, S., \& Wakefield, M. (2001). Tobacco control advocacy n Australia: reflections on 30 years of progress. Health Education and Behavior , 28:274-289.

Coggon, J. (2009). Public health, responsibility and English law: are there such things as no smoke without ire or needless clean needles? Medical Law Review , 17:127-139.

Cohen, J. E., de Guia, N. A., Ashley, M. J., Ferrence, R., Northrup, D. A., \& Studlar, D. T. (2002). Predictors of Canadian legislators' support for tobacco control policies. Social Science and Medicine , 55:1069-1076.

Cohen, M. D., March, J. G., \& Olsen, J. P. (1972). A "garbage can" model of organizational choice. Administrative Sciences Quarterly, 17:1-5.

Collin, J., Lee, K., \& Bissell, K. (2002). The framework convention on tobacco control: the politics of global health governance. Third World Quarterly , 23(2):265-282.

Congressional Research Service. (2009). Bill Summary and Status 111th Congress (20092010) H.R. 1256 CRS Summary. Washington, DC: The Library of Congress, THOMAS Search Engine, Congressional Research Service.

Crow, M. E. (2004). Smokescreens and state responsibility: using human rights strategies to promote global tobacco control. Yale Journal of International Law , 29:209-250. 
Crow, M. E. (2005). The human rights responsibilities of multinational tobacco companies. Tobacco Control , 14(Supp.II_ii14-ii18.

Cummings, K. M., \& Pollay, R. W. (2002). Exposing Mr Butts' tricks of the trade. Tobacco Control , 11(Suppl1):i1-i4.

Cummings, K. M., Hyland, A., Bansal, M. A., \& Giovino, G. A. (2004). What do Marlboro Lights smokers konw about low-tar cigarettes? Nicotine and Tobacco Research , 6 (Suppl 3):S323S332.

Curfman, G. D., Morrissey, S., \& Drazen, J. M. (2009). Tobacco, public health, and the FDA. N Engl J Med , 361(4):402-403.

Daynard, R. A., Bates, C., \& Francey, N. (2000). Tobacco litigation worldwide. BMJ , 320:111113.

de Guia, N. A., Cohen, J. E., Ashley, M. J., Ferrence, R., Rehm, J., Studlar, D. T., et al. (2003). Dimensions underlying legislatory support for tobacco control policies. Tobacco Control , 12:133-139.

Department of Health and Human Serivces, Centers for Medicaid and Medicare Services. (2010, August 24). Press Release: HHS Announces Medicare Expands Coverage of Tobacco Cessation Counseling. Retrieved October 27, 2010, from Centers for Medicaid and Medicare Servces Press Releases.

Department of Health and Human Services, Food and Drug Administration. (1995). Analysis regarding the Food and Drug Administration's jurisdiction over nicotine-containing cigarettes and smokeless tobacco products. Federal Register , 60(155):41453.

Derthick, M. (2001). Federalism and the politics of tobacco. Publius , 31(1):47-63.

DiClemente, C. C., Delahanty, J. C., \& Fiedler, R. M. (2010). The journey to the end of smoking. A personal and population perspective. American Journal of Preventive Medicine , 38(3S):S418S428.

DiFranza, J. (2008). Hooked from the first cigarette. Scientific American, May.

Dolowitz, D., \& Marsh, D. (1996). Who learns what from whom: a review of the policy transfer literature. Political Studies , 44:343-357.

Donabedian, A. (1966). Evaluating the quality of of medical care. Millbank Quarterly , 44:166203.

Douglas, C. E., Davis, R. M., \& Beasley, J. K. (2006). Epidemiology of the third wave of tobacco litigation in the United States, 1994-2005. Tobacco Control , 15(Suppl IV):iv9-iv16.

Downs, A. (1972). Up and down with ecology -- the "issue attention cycle". Public Interest , 28:38-50. 
Dressler, C., \& Marks, S. (2006). The emerging human right to tobacco control. Human Rights Quarterly , 28:599-651.

Dube, S. R., Asman, K., Malarcher, A., \& Carabollo, R. (2009). Cigarette smoking among adults and trends in smoking cessation -- United States, 2008. Morbidity and Mortality Weekly Report , 58(44):1227-1232.

Dugas, E., Tremblay, M., Low, N. C., Cournoyer, D., \& O'Loughlin, J. (2010). Water-pipe smoking among North American youths. Pediatrics , 125(6):1184-1189.

Duina, F., \& Kurzer, P. (2004). Smoke in your eyes: the struggle over tobacco control in the European Union. Journal of European Public Policy , 11(1):57-77.

Easton, D. (1957). An approach to the analysis of political systems. World Politics , 9(3):383400.

Eckhart, D. (2004). The Tobacco Master Settlement Agreement: Enforcement of Marketing Restrictions. St. Paul, MN: Tobacco Control Legal Consortium.

Editorial, New York Daily News. (1995, August 23). ABCs of a smoke screen. New York Daily News , p. 24.

Environmental Protection Agency. (2009, August 12). EPA Designates Passive Smoking a "Class A" or Known Human Carcinogen. Retrieved May 12, 2010, from Environmental Protection Agency History.

Epp, C. R. (2008). Law as an Instrument of Social Reform. In K. E. Whittington, R. D. Kellemen, \& G. A. Caldeira, The Oxford Handbook of Law and Policy. New York, NY: Oxford University Press.

Epsing-Andersen, G. (1990). The Worlds of Welfare Capitalism. Oxford, UK: Polity Press.

Etter, J.-F. (2010). Electronic cigarettes: a survey of users. BMC Public Health , 10:231.

European Commission. (2004). Tobacco or Health in the European Union: Past, Present and Future. Luxembourg: Office for Official Publications of the European Commission.

Farm Service Agency. (2005, March). Fact Sheet: Tobacco Transition Payment Program. Retrieved November 29, 2010, from United States Department of Agriculture Farm Service Agency.

Farquharson, K. (2005). A different kind of snowball: identifying key policymakers. International Journal of SOcial Research Methodology , 8(4):345-353.

Farquharson, K. (2003). Influencing policy transnationally: pro- and anti-tobacco global advocacy networks. Australian Journal of Public Administration , 62(4):80-92.

Farrelly, M. C., \& Engelen, M. (2008). Cigarette prices, smoking, and the poor, revisited. American Journal of Public Health , 98(4):582-583. 
Farrelly, M. C., Pechacek, T. F., Thomas, K. Y., \& Nelson, D. (2008). The impact of tobacco control programs on adult smoking. American Journal of Public Health , 98:304-309.

Feldman, E. A. (2001). A comparative look at tobacco control: the law, politics and ethics of smoking in the US and Japan. Review of Asian and Pacific Studies , 22:1-15.

Feldman, E. A. (2009). The bioethics of tobacco. Penn Center Guide to Bioethics, Chpt. 54.

Feldman, E. A., \& Bayer, R. (2004). Unfiltered: Conflicts Over Tobacco Policy and Health. Cambridge, MA: Harvard University Press.

Fellows, J. L., Trosclair, A., Adams, E. K., \& Rivera, C. C. (2002). Annual smoking-attributable mortality, years of potential life lost, and economic costs -- United States, 1995-1999. Morbidity and Mortality Weekly Report , 51(14):300-303.

Ferkeitch, A. K., Liber, A., Pennell, M., Nealy, D., Hammer, J., \& Berman, M. (2010). Clean indoor air ordinance coverage in the Appalachian region of the United States. American Journal of Public Health , 100(7):1313-1318.

Fiore, M. C., Keller, P. A., \& Baker, T. B. (2005). The Justice Department's case against the tobacco companies. New England Journal of Medicine , 353:10.

Fong, G T; Cummings, K M; Shopland, D R; for the ITC Collaboration. (2006). Building the evidence base for effective tobacco control policies: the International Tobacco Control Policy Evaluation Project (the ITC Project). Tobacco Control , 15(Siii):Siii1-Siii2.

Fong, G. T., Cummings, R. M., Borland, R., Hastings, G., Hyland, A., Giovino, G. A., et al. (2006). The conceptual framework of the International Tobacco Control (ITC) Policy Evaluation Project. Tobacco Control , 15(Siii):Siii3-Siii11.

Fox, F. J., \& Katz, J. E. (2005). Individual and human rights in tobacco control: help or hindrance? Tobacco Control , 14(Suppl II):ii1-ii2.

Framework Convention Alliance. (2010, June 7). Framework Convetion Alliance Updated Status of the WHO FCTC: Ratification and Accession by Countrie. Retrieved July 10, 2010, from The Framework Convention Alliance.

Francey, N., \& Chapman, S. (2000). "Operation Berkshire": the international tobacco companies' conspiracy. British Medical Journal , 321:371-374.

Franks, P., Jerant, A. F., Leigh, J. P., Lee, D., Chiem, A., Lewis, I., et al. (2007). Cigarette prices, smoking, and the poor: implications of recent trends. American Journal of Public Health , 97(10:1873-1877.

Franz, G. A. (2008). Price effects on the smoking behaviour of adult age groups. Public Health , 122(12):1343-1348. 
Freedman, A. M. (1995, October 18). 'Impact Booster'. Tobacco firm shows how amonia spurs delivery of nicotine -- Brown \& Williamson papers claim wide industry use of additive in cigarettes -- inside 'the Soul of Marlboro'. Wall Street Journal , p. A1.

Freedman, A. M. (1995, December 8). Philip Morris memo likens nicotine to cocaine. Wall Street Journal , p. B1.

Freeman, B., \& Chapman, S. (2010). British American Tobacco on Facebook: undermining Article 13 of the global World Health Organization Framework Convention of Tobacco Control. Tobacco Control , April 15 [Epub ahead of print].

Frieden, T. R., \& Blakeman, D. E. (2005). The dirty dozen: 12 myths than undermine tobacco control. American Journal of Public Health , 95(9):1500-1505.

Frisbee, S. J., Studlar, D. T., \& Christensen, K. (2010). Assessing the Tobacco Control Scale: association with measures of population smoking and health. [In preparation] .

Frisbee, S. J., Studlar, D. T., \& Christensen, K. (2010). Tobacco control policy in Europe: assessing the impact of the 2004 and 2007 EU accession. [In preparation] .

Funston, R. (1975). The double standard of consitutional protection in the era of the welfare state. Political Science Quarterly, 90(2):261-287.

Gable, L. (2007). The proliferation of human rights in global health governance. Journal of Law, Medicine, and Ethics , 35(4):534-544.

Gartner, C. E., Hall, W. D., Vos, T., Bertram, M. Y., Wallace, A. L., \& Lim, S. S. (2007). Assessment of Swedish snus for tobacco harm reduction: an epidemiological modelling study. Lancet , 369:2010-2014.

Gilpin, E. A., Lee, L., \& Pierce, J. P. (2004). Changes in population attitudes about where smoking should not be allowed: California versus the rest of the USA. Tobacco Control , 13:3844.

Givel, M. (2008). Assessing material and symbolic variations in Punctuated Equilibrium and public policy output patterns. Review of Policy Research , 25(6):547-561.

Givel, M. (2006). Punctuated Equlibrium in limbo: the tobacco lobby and U.S. state policymaking from 1990 to 2003. Policy Studies Journal , 34(3):405-418.

Givel, M. S., \& Glantz, S. A. (2001). Tobacco lobby political influence on US state legislatures in the 1990s. Tobacco Control , 10:124-134.

Givel, M., \& Glantz, S. A. (2004). The "Global Settlement" with tobacco industry: 6 years later. American Journal of Public Health , 94(2):218-224.

Glantz, S. A. (1984). What to do because evidence links involuntary (passive) smoking with lung cancer. Western Journal of Medicine , 40(4):636-637. 
Glantz, S. A., Barnes, D. E., Bero, L. A., Hanauer, P., \& Slade, J. (1995). Looking through a keyhole at the tobacco industry. The Brown and Williamson documents. Journal of the American Medical Association , 274(3):219-224.

Glantz, S. A., Slade, J., Bero, L. A., Hanauer, P., \& Barnes, D. E. (1996). The Cigarette Papers. Berkely, CA, USA: University of California Press.

Glenn, J. K. (2004). From nation-states to member states: accession negotiations as an instrument of Europeanization. Comparative European Politics , 2:3-28.

Global Tobacco Surveillance System Collaboration Group. (2005). Global Tobacco Surveillance System (GTSS): purpose., production, and potential. Journal of School Health , 75(1):15-24.

Godlee, F. (2000). WHO faces up to its tobacco links. British Medical Journal , 321:314-315.

Gordon, R., McDermott, L., Stead, M., \& Angus, K. (2006). The effectiveness of social marketing intervetions for health improvement: What's the evidence? Public Health , 120:11331139.

Gospodinov, N., \& Irvine, I. (2009). Tobacco taxes and regressivity. Journal fo Health Economics , 28:375-384.

Gostin, L. G. (2002). Corporate speech and the Constitution: the deregulation of tobacco advertising. American Journal of Public Health , 92(3):352-355.

Gostin, L. O. (2009). FDA regulation of tobacco. Politics, law and the public's health. Journal of the American Medical Association , 302(13):1459-1460.

Gostin, L. O., \& Hodge, J. J. (2007). Global health law, ethics, and policy. Journal of Law, Medicine and Ethics , 35(4):519-525.

Government of Bhutan. (2009, July 10). News in Detail: NC decides to revoke tobacco ban (Source: kuenselonline.com). Retrieved July 10, 2010, from Government of Butan, National Portal of Bhutan: http://www.bhutan.gov.bt/government/newsDetail.php?id=1331 \& cat=5

Grabbe, H. (2003). Europeanization Goes East: Power and Uncertainty in the EU Accession Process. In K. Featherstone, \& C. M. Radaelli, The Politics of Europeanization. Oxford, UK: Oxford University Press.

Greathouse, L. W., Hahn, E. J., Okoli, C. T., Warnick, T. A., \& Riker, C. A. (2005). Passing a smoke-free law in a pro-tobacco culture; a Multiple Streams approach. Policy and Politics in Nursing Practice, 6:211-220.

Greenhouse, L. (2001, June 29). The Supreme Court: Supreme Court roundup; Justices rein in local regulation of tobacco ads. New York Times , p. Sectoin A; Column 3; National Desk; Pg. 1.

Greenland, K. J., Liu, K., Kiefe, C. I., Yunis, C., Dyer, A. R., \& Burke, G. L. (1995). Impact of father's education and parental smoking status on smoking behavior in young adults. The 
CARDIA study. Coronary Artery Risk Development in Young Adults. American Journal of Epidemiology , 142(10):1029-1033.

Grier, S., \& Bryant, C. A. (2005). Social marketing in public health. Annual Review of Public Health , 26:319-339.

Grossman, M., \& Chaloupka, F. J. (1997). Cigarette taxex: the straw to break the camel's back. Public Health Reports , 112(4):290-297.

Haas, P. M. (1992). Epistemic communities and international policy coordination. International Organization , 46(1):1-35.

Hall, W., \& Gartner, C. (2009). Supping with the Devil? The role of law in promoting tobacco harm reduction using low nitrosamine smokeless tobacco products. Public Health , 123:287291.

Hammond, D., Fong, G. T., Zanna, M. P., Thrasher, J. F., \& Borland, R. (2006). Tobacco denormalization and industry beliefs among smokers from four countries. American Journal of Preventive Medicine , 31(3):225-232.

Hanauer, P., Slade, J., Barnes, D. E., Bero, L., \& Glantz, S. A. (1995). Lawyer control of internal scientific research to protect against product liability lawsuits. The Brown and Williamson documents. Journal of the American Medical Association , 274(3):234-240.

Harris, J. K., Luke, D. A., Burke, R. C., \& Meuller, N. B. (2008). Seeing the forest for the trees: using network analysis to develop an organizational blueprint of state tobacco control systems. Social Science and Medicine , 67:1669-1678.

Hatsukami, D. K., Slade, J., Benowitz, N. L., Giovino, G. A., Gritz, E. R., Leischow, S., et al. (2002). Reducing tobacco harm: research challenges and issues. Nicotine and Tobacco Research, Suppl.:S89-S101.

Hayashida, K., Imanaka, Y., Murakami, G., Takahashi, Y., Nagai, M., Kuriyama, S., et al. (2010). Differences in medical expenditures between male smokers and non-smokers. Health Policy , 94:84-89.

Healton, C., \& Nelson, K. (2004). Reversal of misfortune: viewing tobacco as a social justice issue. American Journal of Public Health , 94(2):186-191.

Healton, C., Farrelly, M. C., Weitzenkamp, D., Lindsey, D., \& Haviland, M. L. (2006). Youth smoking prevention and tobacco industry revenue. Tobacco Control , 15:103-106.

Heclo, H. H. (1972). Policy analysis. British Journal of Political Science , 2:83-108.

Heclo, H. (1994). Ideas, Interests, and Institutions. In L. C. Dodd, \& C. Jillson, The Dynamics of American Politics, Approaches and Interpretations (pp. 366-392). Boulder, CO: Westview Press.

Heclo, H. (1994). Ideas, Interests, and Institutions. In L. C. Dodd, \& C. Jillson, The Dynamics of American Politics, Approaches and Interpretations. Boulder, CO: Westview Press. 
Hiilamo, H. (2003). Tobacco industry strategy to undermine tobacco control in Finland. Tobacco Control , 12:414-423.

Hodgson, T. A. (1992). Cigarette smoking and lifetime medical expenditures. Milbank Quarterly, 70(1):81-125.

Hooghe, L., \& Marks, G. (2001). Multi-level Governance and European Integration. Lanham, MD: Rowman and Littlefield.

Hook, J. (2000, February 26). Failed tobacco bill illustrates McCain's leadership style. Los Angeles Times , p. Collections Section; Republican Party.

Hooker, C., \& Chapman, S. (2006). Structural elements in achieving legislative tobacco control in NSW, 1955-1995: political reflections and implications. Australian and New Zealand Journal of Public Health , 30(1):10-15.

Hospers, J. (1980). Libertarianism and legal paternalism. Journal of Libertarian Studies , 4(3):255-265.

Hurt, R. D., Ebbert, J. O., Muggli, M. E., Lockhart, N. J., \& Robertson, C. R. (2009). Open doorway to truth: legacy of the Minnesota tobacco trial. Mayo Clinical Proceedings , 84(5):446456.

Hyland, A., Bauer, J. E., Li, Q., Abrams, S. M., Higbee, C., Peppone, L., et al. (2005). Higher cigarette prices influence cigarette purchase patterns. Tobacco Control , 14(2):86-92.

Hyland, A., Higbee, C., Borland, R., Travers, M., Hastings, G., Fong, G. T., et al. (2009). Attitudes and beliefs about secondhand smoke and smoke-free policies in four countries: findings from the International Tobacco Control Four Country Survey. Nicotine and Tobacco Research , 11(6):642-649.

Immergut, E. M. (2006). Institutional Constraints on Policy. In M. Moran, M. Rein, \& R. E. Goodin, The Oxford Handbook of Public Policy. Oxford, UK: Oxford University Press.

Ingram, H., Schneider, A. L., \& Deleon, P. (2007). Social Construction and Policy Design. In P. A. Sabatier, Theoris of the Policy Process (pp. 93-128). Boulder, CO: Westview Press.

Ingram, H., Schneider, A., \& McDonald, B. (2002). The Political Invasion of Science: How Policy Constructs Boundaries and Meanings. Annual American Political Science Association Meeting. Boston, MA.

Jacobson, P. D., \& Banerjee, A. (2005). Social movements and human rights rhetoric in tobacco control. Tobacco Control , 14(Suppl II):ii45-ii49.

Jacobson, P. D., \& Warner, K. E. (1999). Litigation and public health policy making: the case of tobacco control. Journal of Health Politics Policy and Law , 24(4):769-804.

Janofsky, M. (1993, June 23). Tobacco grops sue to void rule on danger in secondhand smoke. New York Times , p. Section A; Page 1; Column 4; National Desk. 
Jha, P. (2009). Avoidable global cancer deaths and total deaths from smoking. Nature Reviews Cancer, 9:655-664.

Jha, P., Chaloupka, F. J., Corrao, M., \& Jacob, B. (2006). Reducing the burden of smoking world-wide: effectiveness of interventions and their coverage. Drug and Alcohol Reviews , 25:597-609.

Jones, C. O. (1997). An Introduction to the Study of Public Policy, 3rd ed. Orlando, FL: Harcourt Brace \& Co.

Jones, J M; Gallup, Inc. (2009, June 22). Majority Disapproves of New Law Regulationg Tobacco. Retrieved June 23, 2010, from Gallup.com: www.gallup.com

Jones, J M; Gallup, Inc. (2006, July 18). Smoking Habits Stable; Most Would Like to Quit. Retrieved June 8, 2010, from Gallup, Inc.: www.gallup.com

Jones, W. J., \& Silvestri, G. A. (2010). The Master Settlement Agreement and its impact on tobacco use 10 years later. Chest , 137(3):692-700.

Joosens, L. (2009). Theoretically an option, but an enforcement nightmare. Tobacco Control , 18:5.

Joosens, L., \& Raw, M. (2008). Avancees du control du tabac dans 30 pay euopeens, de 2005 a 2007 (Progress in tobacco control in 30 European countries, 2005 to 2007). Bulletin Epedemiologique Hebdomadaire (Thematique Journee Mondiale sans Tabac 2008) , 2122:198-200.

Joossens, L., \& Raw, M. (2006). The Tobacco Control Scale: a new scale to measure country activity. Tobacco Control , 15:247-253.

Kane, C. (2001, June 29). Tobacco industry wins ad victorty; Justices reject Mass. effort to go beyond federal curbs. Washington Post, p. A Section; Pg. A01.

Kaplan, D. A., \& Isikoff, M. (1995, November 20). Smoke gets in CBS's eye. Newsweek , p. 96.

Katz, J. E. (2006). Tobacco control policies. Society , 43(3):25-32.

Keck, M. E., \& Sikkink, K. (1999). Transnational advocacy networks in international and regional politics. International Social Science Journal , 51(159):89-101.

Kelder Jr., G. E., \& Daynard, R. A. (1997). Judicial approaches to tobacco control: the third wave of tobacco litigation as a tobacco control mechanism. Journal of Social Issues , 53(1):169186.

Kelemen, R. D. (2000). Regulatory federalism: EU environmental regulation in comparative perspective. Journal of Public Policy , 20(2):133-167. 
Kenworthy, T., \& Brown, D. (1993, June 23). Tobacco firms sue EPA on cancer ruling: secondhand-smoke studies based on fudged data, industry alleges. Washington Post, p. First Section; Page A1.

Kessler, D. A. (1995). Nicotine addiction in young people. New England Journal of Medicine , 333(3):186-189.

Kessler, D. A., Natanblut, S. L., Wilkenfeld, J. P., Lorraine, C. C., Mayl, S. L., Bernstein, I. B., et al. (1997). Nicotine addiction: a pediatric disease. Journal of Pediatrics , 130:518-524.

Kessler, D. A., Wilkenfeld, J. P., \& Thompson, L. J. (1997). The Food and Drug Administration's Rule on tobacco: blending science and the law. Pediatrics , 99:884-887.

Kessler, D. A., Witt, A. M., Barnett, P. S., Zeller, M. R., Natanblut, S. L., Wilkenfeld, J. P., et al. (1996). The Food and Drug Administration's regulation of tobcco products. New England Journal of Medicine , 335(13):988-994.

Kingdon, J. W. (1984). Agenda, Alternative, and Public Policy. Boston, MA: Little Brown.

Kinney, E. D. (2001). The internationl human right to health: what does this mean for our nation and world? Indiana Law Review , 34:1457-1475.

Klonoff, E. A., Landrine, H., Alcaraz, R., Campbell, R. R., Lang, D. L., McSwan, K. L., et al. (1998). An instrument for assessing the quality of tobacco-control policies: the ACT-L Scale. Preventive Medicine , 27: 808-814.

Knishkowy, B., \& Amitai, Y. (2005). Water-pipe (narghile) smoking: an emerging health risk behavior. Pediatrics , 116(1):e113-e119.

Koch, W. (1998, July 20). Court stings anti-smoke movement. USA Today, p. News; Page 1A.

Koop, C. E., \& Kessler, D. A. (1997). Final report of The Advisory Committee on Tobacco Policy and Public Health. Tobacco Control , 6:254-261.

Kranish, M. (2008, March 26). McCain's stand on tobacco is put to test, Senator steps back on oversight measure. Boston Globe , p. News Section; National.

Krauss, M., Meuller, N., \& Luke, D. (2004). Interorganizational relationships within state tobacco control networks: a social network analysis. Prev Chronic Dis , 1(4):1-25.

Kurdle, R. T., \& Marmor, T. R. (1981). The Development of Welfare States in North America. In P. Flora, \& A. J. Heidenheimer, The Development of Welfare States in Europe and America. New Brunswick, NJ: Transaction Books.

Kurtz, H. (1995, November 10). '60 Minutes' kills piece on tobacco industry; CBS fears lawsuit, cites ABC settlment. The Washington Post, p. A03.

Lambe, M. (2007). Swedish snus for tobacco harm reduction (Letter). Lancet, 370:1206. 
Larsen, L. T. (2010). Framing knowledge and innocent victims. Europe bans smoking in public places. Critical Discourse Studies , 7(1):1-17.

Larsen, L. T. (2008). The political impact of science: is tobacco control science- or policy-driven. Science and Public Policy , 35(10):757-769.

Leu, R. E., \& Schaub, T. (1983). Does smoking increase medical expenditures? Social Science and Medicine , 17:1907-1914.

Levy, D. T., Bauer, J. E., \& Hye-ryeon, L. (2006). Simulation modeling and tobacco control: creating more robust public health policies. American Journal of Public Health , 96(3):494-498.

Levy, D. T., Chaloupka, F., \& Gitchell, J. (2004). The effects of tobacco control policies on smoking rates: a tobacco control scorecard. Journal of Public Health Management and Practice , 10(4):338-353.

Levy, D. T., Cho, S., Kim, Y. M., Park, S., Suh, M. K., \& Kam, S. (2010). SimSmoke model evaluation of the effect of tobacco control policies in Korea: the unknown success story. American Journal of Public Health , 100(7):1267-1273.

Levy, D. T., Mabry, P. L., Graham, A. L., Orleans, T., \& Abrams, D. B. (2010). Reaching Healthy People 2010 by 2013. American Journal of Preventive Medicine , 38(3S):S373-S381.

Lewis, J. M. (2006). Being around and knowing the players: networks of influence in health policy. Social Science and Medicine , 62:2125-2136.

Licari, M. J., \& Meier, K. J. (1997). Regulatory policy when behavior is addictive: smoking, cigarette taxes and bootlegging. Political Research Quarterly , 50(1):5-24.

Licari, M. J., \& Meier, K. J. (1997). Regulatory policy when behavior is addictive: smoking, cigarette taxes, and bootlegging. Political Research Quarterly , 50(1):5-24.

Lightwood, J. M., Dinno, A., \& Glantz, S. A. (2008). Effect of the California Tobacco Control Program on personal health care expenditures. PLOS Medicine , 5(8):e178.

Lipand, A; for the World Health Organization Tobacco Free Initiative. (2007). Successful Use of Smoke-free Policies in Tobacco Control in Estonia. Geneva, Switzerland: World Health Organization.

Lipand, A; for the World Health Organization Tobacco Free Initiative. (2007). Successful Use of Smoke-free Policies in Tobacco Control in Estonia. Geneva, Switzerland: World Health Organization.

Lopez, A. D., Collishaw, N. E., \& Piha, T. (1994). A descriptive model of the cigarette epidemic in developed countries. Tobacco Control , 3:242-247.

Lowi, T. J. (1964). American business, public policy, case studies and political theory. World Politics , 16:677-715. 
Luke, D. A., \& Krauss, M. (2004). Where there's smoke there's money: tobacco industry campaign contributions and U.S. Congressional voting. American Journal of Preventive Medicine , 27(5):363-372.

Luke, D. A., Stamatakis, K. A., \& Brownson, R. C. (2000). State youth-access tobacco control policies and youth smoking behavior in the United States. American Journal of Preventive Medicine , 19(3):180-187.

Lyon, L. (2008, January 2). The Rising Allure -- and Danger -- of Hookah. US News , p. Health Section.

Mabry, P. L., Marcus, S. E., Clark, P. I., Leischow, S. J., \& Mendez, D. (2010). Systems science: a revolution in public health policy research. American Journal of Public Health , 100(7):1161-1163.

Magnusson, R. (2009). Can NGOs and INGOs be public health policy entrepreneurs? Diabetes Voice , 54(3):34-37.

Mamudu, H. M. (2007). Epistemic Communities and Global Tobacco Control Policy Making. Western Political Science Association Meeting. Las Vegas, NV.

Mamudu, H. M., \& Studlar, D. T. (2009). Multilevel governance and shared sovereignty: European Union, member states, and the FCTC. Governance , 22(1):73-97.

Mamudu, H. M., Hammond, R., \& Glantz, S. A. (2008). Project Cerberus: tobacco industry strategy to create an alternative to the Framework Convention on Tobacco Control. American Journal of Public Health , 98(9):1630-1642.

Mamudu, H. M., Hammond, R., \& Glantz, S. A. (2008). Tobacco industry attempts to counter the World Bank report Curbing the Epidemic and obstruct the WHO framework convention on tobacco control. Social Science and Medicine , 67(11):1690-1699.

Mamudu, H. M., Hammond, R., \& Glantz, S. (2008). Tobacoc industry attempts to counter the World Bank report "Curbing the Epidemic" and obstruct the WHO Framework Convention on Tobacco Control. Social Science and Medicine , 67:1690-1699.

Manning, W. G., Keeler, E. B., Newhouse, J. P., Sloss, E. M., \& Wasserman, J. (1989). The taxes of sin. Do smokersand drinkers pay their way? Journal of the American Medical Association , 261(11):1604-1609.

March, J. G., \& Olsen, J. P. (1984). The new institutionalism: organizational factors in political life. American Political Science Review , 78(3):734-749.

Marcus, S. E., Leischow, S. J., Mabry, P. L., \& Clark, P. I. (2010). Lessons learned from the application of systems science to tobacco control at the National Cancer Institute. American Journal of Public Health , 100(7):1163-1165. 
Marmor, T. R., \& Lieberman, E. S. (2004). Tobacco Control in Comparative Perspective: Eight Nations in Search of and Explanation. In E. A. Feldman, \& R. Bayer, Unfiltered: Tobacco Policy, Politics and Public Health in Eight Industrialized Nations (pp. 275-291). Cambridge, MA: Harvard University Press.

Martin, E. G., Warner, K. E., \& Lantz, P. M. (2004). Tobacco harm reduction: what do the experts think? Tobacco Control , 13(2):123-128.

Mather, L. (1998). Theorizing about trial courts: lawyers, policymaking, and tobacco litigation. Law and Social Inquiry , 23(4):897-940.

Max, W. (2001). The financial impact of smoking on health-related costs: a review of the literature. American Journal of Health Promotion , 15(5):321-331.

McCann, M. (2008). Litigation and Legal Mobilization. In K. E. Whittington, R. D. Kellemen, \& G. A. Caldeira, The Oxford Handbook of Law and Politics. New York, NY: Oxford University Press.

McDaniel, P. A., \& Malone, R. E. (2005). Understanding Philip Morris's pursuit of US government regulation of tobacco. Tobacco Control , 14:193-200.

McDaniel, P. A., Smith, E. A., \& Malone, R. E. (2006). Philip Morris's Project Sunrise: weakening tobacco control by working with it. Tobacco Control , 15:215-223.

McKee, M., \& Gilmore, A. (2007). Swedish snus for tobacco harm reduction (Letter). Lancet , 370:1206.

McKinlay, J. B., \& Marceau, L. D. (2000). Upstream healthy public policy: lessons from the battle of tobacco. International Journal of Health Services , 30(1):49-69.

McKinlay, J., \& Marceau, L. (2000). US public health and the 21st century: diabetes mellitus. Lancet , 356(9231):757-761.

Meier, B. (1998, July 20). Judge voids study linking cancer to secondhand smoke. New York Times , p. Sectoin A; Page 12; Column 1; National Desk.

Meier, B. M. (2005). Breathing life into the Framework Convention on Tobacco Control: smoking cessation and the right to health. Yale Journal of Policy, Law and Ethics, 117:137-192.

Meier, B. M., \& Shelley, D. (2006). The Fourth Pillar of the Framework Convention on Tobacco Control: harm reduction and the international human right to health. Public Health Reports , 121:494-500.

Meier, K. J. (1999). Drugs, sex, rock, and roll: a theory of morality politics. Policy Studies Journal , 27(4):681-695.

Meija, R., Schoj, V., Barnoya, J., Flores, M. L., \& Perez-Stable, E. J. (2008). Tobacco industry strategies to obstruct the FCTC in Argentina. CVD Prevention and Control , 3:173-179. 
Mejia, A. B., \& Ling, P. M. (2010). Tobacco industry consumer research on smokeless tobacco users and product development. American Journal of Public Health , 100(1):78-87.

Mejia, A. B., Ling, P. M., \& Glantz, S. A. (2010). Quantifying the effects of promoting smokeless tobacco as a harm reduction strategy in the USA. Tobacco Control, June 27 [Epub ahead of print].

Melnick, R. S. (1999). Tobacco litigaion: good for the body but not the body politic. Journal of Health Politics Policy and Law , 24(4):805-810.

Mendez, D. (2010). A systems approach to a complex problem. American Journal of Public Health , 100(7):1160.

Milio, N. (1985). Health policy and the emerging tobacco reality. Social Science and Medicine , 21(6):603-613.

Miura, M., Daynard, R. A., \& Samet, J. M. (2006). The role of litigatin in tobacco control. Salud Publica de Mexico , 48(Suppl 1):S121-S136.

Moe, T. M. (2006). Power and Political Institutions. In I. Shapiro, S. Skowronek, \& D. Galvin, Rethinking Political Institutions: The Art of the State. New York, NY: New York University.

Monardi, F., \& Glantz, S. A. (1998). Are tobacco industry campaign contributions influencing state legislative behavior? American Journal of Public Health , 88(6):918-923.

Mooney, C. Z. (2000). The decline of federalism and the rise of morality-policy conflict in the United States. Publius , 30(1-2):171-188.

Moore, D W; Gallup, Inc. (2005, July 20). Increased Support for Smoking Bans in Public Places. Retrieved April 13, 2010, from Gallup.com.

Morales, L; Gallup, Inc. (2008, July 28). Most Americans Consider Smoking Very Harmful. Retrieved April 13, 2010, from Gallup.com.

Muggli, M. E., Forster, J. L., Hurt, R. D., \& Repace, J. L. (2001). The smoke you dont' see: uncovering tobacco industry scientific strategies aimed against environmental tobacco smoke policies. American Journal of Public Health , 91(9):1419-1423.

Muggli, M. E., Hurt, R. D., \& Repace, J. (2004). The tobacco industry's political efforts to derail the EPA report on ETS. American Journal of Public Health , 26(2):167-177.

Muggll, M. E., \& Hurt, R. D. (2003). Tobacco industry strategies to undermine the 8th World Conference on Tobacco or Health. Tobacco Control , 12:195-202.

Mumford, E. A., Levy, D. T., Gitchell, J. G., \& Blackman, K. O. (2005). Tobacco control policies and the concurrent use of smokeless tobacco and cigarettes among men, 1992-2002. Nicotine and Tobacco Research , 7(6):891-900. 
Nadelmann, E. A. (1990). Global prohibition regimes: the evolution of norms in international society. International Organization , 44(4):479-526.

Nathanson, C. A. (2005). Collective actors and corporate targets in tobacco control: a crossnational comparison. Health education and behavior , 32(3):337-354.

Nathanson, C. A. (2007). Disease Prevention as Social Change: The State, Society and Public Health in the United States, France, Great Britain, and Canada. New York, New York: Russell Sage Foundation.

Nathanson, C. A. (1999). Social movements as catalysts for policy change: the case of smoking and guns. Journal of Health Politics, Policy, and Law , 24(3):421-488.

Nathanson, C. A. (2007). The contingent power of experts: public health policy in the United States, Britain, and France. Journal of Policy History , 19(1):71-94.

National Cancer Institute. (2004, August 17). Factsheet. The Truth About "Light" Cigarettes: Questions and Answers. Retrieved May 16, 2010, from National Cancer Institute.

National Cancer Institute. (2007). Greater than the Sum: Systems Thinking in Tobacco Control. Bethesda, MD: US Department of Health and Human Services, National Institutes of Health, National Cancer Institute (NIH Publication 06-6085).

National Networks for Tobacco Control and Prevention. (n.d.). National Networks for Tobacco Control and Prevention. Retrieved July 7, 2010, from National Networks for Tobacco Control and Prevention: http://www.tobaccopreventionnetworks.org/

National Research Council, National Academy of Sciences. (1986). Environmental Tobacco Smoke: Measuring Exposures and Assessing Health Effects. Washington, DC: National Academy Press.

News Staff, American Academy of Family Practitioners. (2010, March 3). FDA Fighting for Authority to Regulate Electronic Cigarettes, Appeals Court Order Stays Lower Court Ruling in Favor of e-Cigarette Distributors. Retrieved July 19, 2010, from American Academy of Family Practitioners News Now.

Niemantsverdriet, T. (2007, November 20). Snuffed out. Probing the myth that "light" cigarettes are better for you. Newsweek, p. ID 71494.

Offe, C. (2006). Political Institutions and Social Power: Conceptual Explorations. In I. Shapiro, S. Skowronek, \& D. Galvin, Rethinking Political Institutions: The Art of the State. New York, NY: New York University Press.

Oliver, T. R. (2006). The politics of public health policy. Annual Review of Public Health , 27:195-233.

Olsen, J. P. (2001). Garbage cans, new instititionalism and the study of politics. American Political Science Review , 95(1):191-198. 
Olstrom, E. (2007). Instititional Rational Choice: An Assessment of the Institutional Analysis and Development Framework. In P. A. Sabatier, Theories of the Policy Process (pp. 21-64). Boulder, CO: Westview Press.

Ontario Tobacco Strategy Advisory Group. (2010). Building on Our Gains, Taking Action Now: Ontario's Tobacco Control Strategy for 2011-2016, A Report from the Tobacco Strategy Advisory Group to the Minister of Health Promotion and Sport. Toronto, ON: Minstry of Health Promotion and Sport, Government of Ontario.

Opinion, New York Times. (2006, August 20). Tobacco racketeers get off easy. New York Times , p. Opinion.

Oriola, T. A. (2009). Ethical and legal analyses of policy prohibiting tobacco smoking in enclosed public spaces. Journal of Law, Medicine and Ethics , 37(4):828-840.

Otanez, M. G., Mamudu, H. M., \& Glantz, S. A. (2009). Tobacco companies' use of developing countries' economic reliance on tobacco to lobby against global tobacco control: the case of Malawi. American Journal of Public Health , 99(10):1759-1771.

Owusu-Dabo, E., McNeill, A., Lewis, S., Gilmore, A., \& Britton, J. (2010). Status of implementation of Framework Convention on Tobacco Control (FCTC) in Ghana: a qualitative study. BMC Public Health , 10:1 doi: 10..1186/1471-2485-10-1.

Pacific Institute for Research and Evaluation. (n.d.). The Pacific Institute for Research and Evaluation. Retrieved 6 2010, June, from www.pire.org

Paul, C. L., Ross, S., Bryant, J., Hill, W., Bonevski, B., \& Keevy, N. (2010). The social context of smoking: a qualitative study comparing smokers of high versus low socioeconomic position. BMC Public Health , 10:211.

Pellegrini, F. (2001, July 17). From Big Tobacco, a Smoking Gun that Saves Money. Time .

Pierce, J. P. (2007). Tobacco industry marketing, population-based tobacco control, and smoking behavior. American Journal of Preventive Medicine , 33(6S):S327-S334.

Pope, T. M. (2000). Balancing public health against individual liberty: the ethics of smoking regulations. University of Pittsburgh Law Review , 61:419-498.

Powell, J. L. (1982). Carolene Products revisited. Columbia Law Review , 82(6):1087-1092.

Princen, S. (2007). Advocacy coalitions and the internationalization of public health policies. Journal of Public Policy , 27(1):13-33.

Princen, S. (2004). No smoking. Venue choice and the Europeanisation of anti-smoking policy. Second Pan-European Conference on the European Union. Bologna, Italy.

Public Health Law Center. (2010). Minnesota Litigation and Settlement. Retrieved April 24, 2010, from Public Health Law Center: www.publichealthlawcenter.org 
Public Health Law Center. (2010). United States v. Philip Morris (D.O.J. Lawsuit). Retrieved May 16, 2010, from Public Health Law Center: www.publichealthlawcenter.org

Radaelli, C. M. (2003). The Europeanization of Public Policy. In K. Featherstone, \& C. M. Radaelli, The Politics of Europeanization. Oxford, UK: Oxford University Press.

Rasmussen, S. R., Prescott, E., Sorensen, T. I., \& Sogaard, J. (2004). The total lifetime costs of smoking. European Journal of Public Health , 14(1):95-100.

Rasmussen, S. R., Prescott, E., Sorensen, T. I., \& Sogaard, J. (2005). The total lifetime health cost savings of smoking cessation to society. European Journal of Public Health , 15(6):601606.

Redhead, C. S. (1999). CRS Report for Congress. Tobacco Master Settlement Agreement (1998): Overview, Implementation by States, and Congressional Issues. Washington, DC: Congressional Research Service, The Library of Congress (Order Code RL30058).

Redhead, C. S., \& Burrows, V. K. (2009). FDA Tobacco Regulation: The Family Smoking Prevention and Tobacco Control Act of 2009. Washington, DC: Congressional Research Service (7-5700, R40475).

Redhead, C. S., \& Burrows, V. K. (2009). FDA Tobacco Regulation: The Family Smoking Prevention and Tobacco Control Act of 2009. Washington, DC: Congressional Research Service (7-5700, R40475).

Regidor, E., Pascual, C., \& Gutierrez-Fisac, J. L. (2007). Increasing the price of tobacco: economically regressive today and probably ineffective tomorrow. European Journal of Cancer Prevention , 16(4):380-384.

Remler, D. K. (2004). Poor smokers, poor quitters, and cigarette tax regressivity. American Journal of Public Health, 94(2):22-229.

Rigotti, N. A., \& Tindle, H. A. (2004). The fallacy of "light" cigarettes, low tar is not low risk. BMJUSA , 4:75-76.

Rodu, B., \& Godshall, W. T. (2006). Tobacco harm reduction: an alternative cessation strategy for inveterate smokers. Harm Reduction Journal , 3:37.

Roemer, R., Taylor, A., \& Lariviere, J. (2005). Origins of the WHO Framework Convention on Tobacco Control. American Journal of Public Health , 95(6):936-938.

Rose, R. (2007). Learning from Comparative Public Policy, a Practical Guide. New York, NY: Taylor \& Francis Group.

Rudder, C. E., \& Fritschler, A. L. (2009). U.S.A. tobacco control: six lessons in public policy for medical and science professionals. World Medical and Health Policy , 1(1):19-34.

Sabatier, P. A. (2007). Theories of the Policy Process. Boulder, CO: Westview Press. 
Sabatier, P. A., \& Weible, C. M. (2007). The Advocacy Coalition Framework: Innovations and Clarifications. In P. A. Sabatier, Theories of the Policy Process (pp. 189-222). Boulder, CO: Westview Press.

Sabatier, P. H., \& Jenkins-Smith, H. C. (1999). The Advocacy Coalition Framework: An Assessment. In P. A. Sabatier, Theories of the Policy Process. Boulder,CO: Westview Press.

Samet, J., Wipfli, H., Perez-Padilla, R., \& Yach, D. (2006). Mexico and the tobacco industry: doing the wrong thing for the right reason? British Medical Journal , 333:353-354.

Sato, H., Araki, S., \& Yokoyama, K. (2000). Policy functions of smoking control in Japan. Environmental Health and Preventive Medicine , 4:156-164.

Sato, J. (1999). The Advocacy Coalition Framework and the policy process analysis: the case of smoking control in Japan. Policy Studies Journal , 27(1):28-44.

Savitz, D. A., Meyer, R. E., Tanzer, J. M., Mirvish, S. S., \& Lewin, F. (2006). Public health implications of smokeless tobacco use as a harm reduction strategy. American Journal of Public Health , 96(11):1934-1939.

Savitz, D. A., Poole, C., \& Miller, W. C. (1999). Reassessing the role of epidemiology in public health. American Journal of Public Health , 89(8):1158-1161.

Schattschneider, E. E. (1960). The Semisovereign People; A Realist's View of Democracy in America. New York, NY: Holt, Rinehart \& Winston.

Schneider, A., \& Ingram, H. (1993). Social construction of target populations: implications for politics and policy. American Political Science Review , 87(2):334-347.

Schneider, A., \& Ingram, H. (1993). Social construction of target populations: implications for politics and policy. American Political Science Review , 87(2):334-347.

Selznick, P. (1996). Institutionalism "old" and "new". Administrative Sciences Quarterly , 41(2):270-277.

Shaffer, E. R., Brenner, J. E., \& Houston, T. P. (2005). International trade agreements: a threat to tobacco control policy. Tobacco Control , 14(Suppl II):ii19-ii25.

Shepard, A. C. (1995). Up in smoke: ABC's "Day One" story on tobacco was flawed, but its apology to Philip Morris has overshadowed the fact that its central theme was on target and fuels the drive to regulate tobacco products as drugs. American Journalism Review , 17:28-33, 47 .

Shipan, C. R., \& Volden, C. (2006). Bottom-up federalism: the diffusion of antismoking policies from U.S. cities to states. American Journal of Political Science , 50(4):825-843.

Shipan, C. R., \& Volden, C. (2008). The mechanisms of policy diffusion. American Journal of Political Science , 52(4):840-857. 
Siahpush, M., Wakefield, M. A., Spittal, M. J., Durkin, S. J., \& Scollo, M. M. (2009). Taxation reduces social disparities in adult smoking prevalence. American Journal of Preventive Medicine , 36(4):285-291.

Siegel, M. (2002). The effectiveness of state-level tobacco control interventions: a review of program implementation and behavioral outcomes. Annual Review of Public Health , 23:45-71.

Siegel, M., \& Biener, L. (1997). Evaluating the impact of statewide anti-tobacco campaigns: the Massachusetts and California tobacco control programs. Journal of Social Issues , 53(1):147168.

Singh, G. K., Siahpush, M., \& Kogan, M. D. (2010). Disparities in children's exposure to environmental tobacco smoke in the United States, 2007. Pediatrics , 126(1):4-13.

Slade, J., Bero, L. A., Hanauer, P., Barnes, D. E., \& Glantz, S. A. (1995). Nicotine and addiction. The Brown and Williamson documents. Journal of the American Medical Association , 274(3):225-233.

Sleiman, M., Gundel, L. A., Pankow, J. F., Jacob, 3. P., Singer, B. C., \& Destaillats, H. (2010). Formation of carcinogens indoors by surface-mediated reactions of nicotine with nitrous acid, leading to potential thirdhand smoke hazards. Proceedings of the National Academy of Sciences, USA , Feb 8 (Epub ahead of print).

Smith, E. A. (2006). 'It's interesting how few people die from smoking': Tobacco industry efforts to minimize risk and discredit health promotion. European Journal of Public Health , 17(2):162170.

Smith, E. A., \& Malone, R. E. (2009). "Everywhere the soldier will be": wartime tobacco promotion in the US military. American Journal of Public Health , 99(9):1595-1602.

Smith, E. A., \& Malone, R. E. (2006). 'We will speak as the smoker': the tobacco industry's smokers' rights groups. European Journal of Public Health , 17(3):306-313.

Smith, K. B. (2002). Typologies, taxonomies, and the benefits of policy classification. Policy Studies Journal , 30(3):379-395.

Smith, K. E., Gilmore, A. B., Fooks, G., Collin, J., \& Weishaar, H. (2009). Tobacco industry attempts to undermine Article 5.3 and the "good governance" trap. Tobcco Control , 18:509-511.

State of California Department of Justice, Attorney General's Office. (2010). Tobacco Litigation \& Enforcement, Highlights. Retrieved May 16, 2010, from State of California Attorney General's Office.

Steinmo, S. H. (1994). American Exceptionalism Reconsidered: Culture or Institutions? In L. C. Dodd, \& C. Jillson, The Dynamics of American Politics, Approaches \& Interpretations. Boulder, CO: Westview Press. 
Stevenson, T., \& Proctor, R. N. (2008). The secret soul of Marlboro: Phillip Morris and the origins, spread, and denial of nicotine freebasing. American Journal of Public Health , 98(7):1184-1194.

Stokes, K. W. (2007). Policy diffusion, policy transfer and comparative case studies: the case for tobacco regulation in the US and EU. 2007 Annual Meeting of the American Political Science Association, (pp. 1-34). Chicago, IL.

Stone, D. A. (1989). Causal stories and the formation of policy agendas. Political Science Quarterly , 104(2):281-300.

Stoner, W. I., \& Foley, B. X. (2006). Current tobacco control policy trends in the United States. Clinical Occupational and Environmental Medicine , 5(1):85-99.

Studlar, D. T. (1999). Diffusion of tobacco control in North American. ANNALS of the American Academy of Political Science, 566:68-79.

Studlar, D. T. (2007). Ideas, institutions and diffusion: what explains tobacco control poly in Australia, Canada, and New Zealand? Commonwealth \& Comparative Politics , 45(2):164-184.

Studlar, D. T. (2005). The political dynamics of tobacco control in Australia and New Zealand: explaining policy problems, instruments, and patterns of adoption. Australian Journal of Political Science , 40(2):255-274.

Studlar, D. T. (2009). Tobacco Control Policy in Western Europe: A Case of Protracted Paradigm Change. In G. Capano, \& M. Howlett, The Dynamics and Drivers of Policy: European and North American Experiences of Policy Change (pp. 71-90). London, UK: Routledge.

Studlar, D. T. (2006). Tobacco control policy instruments in a shrinking world: how much policy learning? International Journal of Public Administration , 29:367-396.

Studlar, D. T. (2002). Tobacco Control. Comparative Politics in the United States and Canada. Peterborough, Ontario: Broadview Press.

Studlar, D. T. (2008). U.S. tobacco control policy: public health, political economy, or morality policy? Review of Policy Research , 25(5):393-410.

Studlar, D. T. (2010). What explains the paradox of tobacco control policy under federalism in the U.S. and Canada? Comparative federalism theory vs. multi-level governance. Publius , Epub ahead of print, 1-23.

Studlar, D. T., Christensen, K., \& Frisbee, S. J. (2009). The impact of tobacco control polices in the EU: comparing old and new member states. European Union Studies Association 11th Biennial International Conference. Los Angeles, CA: Proceedings from the European Union Studies Association 11th Biennial International Conference (Available at: http://www.unc.edu/euce/eusa2009/papers/studlar_07B.pdf). 
Studlar, D. T., Christensen, K., \& Frisbee, S. J. (2009). The impact of tobacco control polices in the EU: comparing old and new member states. Proceedings from the European Union Studies Association 11th Biennial International Conference. Los Angeles, CA.

Studlar, D. T., Christensen, K., \& Sitasari, A. (2011). Tobacco control in the EU-15: the role of member states and the European Union. Journal of European Public Policy , In Press.

Sullum, J. (1998). For Your Own Good. The Anit-Smoking Crusade and the Tyranny of Public Health. New York, NY: The Free Press, Simon \& Schuster, Inc.

Sweda Jr, E. L., \& Daynard, R. A. (1996). Tobacco industry tactics. British Medical Bulletin , 52(1):183-192.

Szilagyi, T. (2006). Hungry for Hungary: Examples of Tobacco Companies' Expansionism. Case Studies from Hungary. Erd, Hungary: Health 21 Hungarian Foundation.

Talley, L. A. (2002). CRS Report for Congress. Federal Excise Taxes on Tobacco Products: Rates and Revenues. Washington, DC: Congressional Research Service, The Library of Congress (Order Code RS20343).

Tatalovich, R; Daynes, B W; (Eds.). (1998). Moral Controversies in American Politics. New York, NY: M.E. Sharpe.

Tauras, J. A. (2004). Public policy and smoking cessation among young adults in the United States. Health Policy , 68(3):321-332.

Tauras, J. A., Chaloupka, F. J., Farrelly, M. C., Giovino, G. A., Wakefield, M., Johnston, L. D., et al. (2005). State tobacco control spending and youth spending. American Journal of Public Health , 95(2):338-344.

Taylor, A. L. (2004). Governing the globalization of public health. Journal of Law, Medicine and Ethics , 32(3):500-508.

Tengs, T. O., Osgood, N. D., \& Chen, L. L. (2001). The cost-effectiveness of intensive national school-based anti-tobacco education: results from the Tobacco Policy Model. Preventive Medicine , 33:558-570.

Tengs, T. O., Osgood, N. D., \& Lin, T. H. (2001). Public health impact of changes in smoking behavior. Results from the Tobacco Policy Model. Medical Care , 39(10):1131-1141.

The Cochrane Collaboration. (n.d.). The Cochrane Library. Retrieved 6 2010, June, from The Cochrane Library: www.thecochranelibrary.com

The GTSS Collaborative Group. (2006). The Global Tobacco Surveillance System. Tobacco Control , 15(Sii):Sii1-Sii3.

The Library of Congress. (2010). The Library of Congress THOMAS. Retrieved May 18, 2010, from The Library of Congress: http://thomas.loc.gov/ 
Thomas, C., \& Weber, M. (2004). The politics of global health governance: whatever happened to "Health for All by the Year 2000"? Global Governance , 10:187-205.

Thomas, S., Fayter, D., Misso, K., Ogilvie, D., Petticrew, M., Sowden, A., et al. (2008). Population tobacco control interventions and their effects on social inequalities in smoking: systematic review. Tobacco Control , 17(4):230-237.

Thompson, M. E., Fong, G. T., Hammond, D., Boudreau, C., Driezen, P., Hyland, A., et al. (2006). Methods of the International Tobacco Control (ITC) four country survey. Tobacco Control , 15(Siii):Siii12-Siii18.

Thomson, G., \& Wilson, N. (2002). The Tobacco Industry in New Zealand: A Case Study of the Behaviour of Multinational Companies. Public Health Monograph Series No. 6. Wellington, NZ: Department of Public Health, Wellington School of Medicine and Health Sciences.

Thyrian, J. R., \& John, U. (2006). Measuring activities in tobacco control across the EU. The MAToC. Substance Abuse Treatment, Prevention, and Policy , doi: 10.1 1186/1747-597X-1-9.

Thyrian, J. R., Panagiotakos, D. B., Polychronopoulos, E., West, R., Zatonski, W., \& John, U. (2008). The relationship between smokers' motivation to quit and intensity of tobacco control at the population level: a comparison of five European countries. BMC Public Health , doi: 10.1 186/1471-2458-8-2.

Tran, K. (2009, July). Tax Rates Across Canada: Comparative Tax Rates for the 2009 Tax Year (Updated July 2009). Retrieved April 20, 2010, from Nova Scotia Department of Finance.

Tung, G. J., Hendin, Y. H., \& Glantz, S. A. (2009). Competing initiatives: a new tobacco industry strategy to oppose statewide clean indoor air ballot measures. American Journal of Public Health , 99(3):430-439.

Tworek, C., Yamaguchi, R., Kloska, D. D., Emery, S., Barker, D. C., Giovino, G. A., et al. (2010). State-level tobacco control policies and youth smoking cessation measures. Health Policy , 97:136-144.

Tynan, M., Pechacek, T., McKenna, M., Ashley, D., Deyton, L., Briss, P., et al. (2010). CDC Grand Rounds: Current opportunities in tobacco control. Morbidity and Mortality Weekly Report , 59(16):487-492.

U.S. Department of Health and Human Services, Office of the Surgeon General. (1989). Reducing the Harmful Consequences of Smoking: 25 Years of Progress. A Report of the Surgeon General. Atlanta, GA: U.S. Department of Health and Human Services, Public Health Service, Centers for Disease Control and Prevention, Center for Chronic Disease Prevention and Health Promotion, Office on Smoking and Health (DHHS Publication NO. (CDC) 89-8411).

U.S. Department of Health and Human Services, Office of the Surgeon General. (2006). The Health Consequences of Involuntary Exposure to Tobacco Smoke: A Report of the Surgeon General. Atlanta, GA: U.S. Department for Health and Human Services, Centers for Disease 
Control and Prevention, Coordinating Center for Health Promotion, National Center for Chronic Disease Prevention and Health Promotion, Office for Smoking and Health.

U.S. Department of Health and Human Services, Office of the Surgeon General. (1986). The Health Consequences of Involuntary Smoking: A Report of the Surgeon General. Atlanta, GA: U.S. Department for Health and Human Services, Centers for Disease Control and Prevention, Coordinating Center for Health Promotion, National Center for Chronic Disease Prevention and Health Promotion, Office for Smoking and Health.

U.S. Department of Health and Human Services, Office of the Surgeon General. (1988). The Health Consequences of Smoking - Nicotine Addiction: A Report of the Surgeon General. Atlanta, GA: U.S. Department for Health and Human Services, Centers for Disease Control and Prevention, Coordinating Center for Health Promotion, National Center for Chronic Disease Prevention and Health Promotion, Office for Smoking and Health.

U.S. Department of Health, Education, and Welfare. (1964). Smoking and Health: Report of the Advisory Committee of the Surgeon General of the Public Health Service. Washington, DC: U.S. Department of Health, Education, and Welfare, Public Health Service (PHS Publication No. 1103).

U.S. Department of Justice, Civil Division. (2007, September 14). Litigagtion Against Tobacco Companies. Retrieved May 16, 2010, from U.S. Department of Justice.

U.S. Environmental Protection Agency. (1992). Respiratory Health Effects of Passive Smoking: Lung Cancer and Other Disorders (EPA/600/6-90/006F). Washington, DC: Office of Health and Evironmental Assessment, Office of Research and Development, U.S. Environmental Protection Agency.

U.S. Food and Drug Administration. (2010, March 18). Frequently Asked Questions: Protecting Kids from Tobacco. Regulations Restricting the Sale and Distribution of Cigarettes and Smokeless Tobacco to Protect Children and Adolescents. Retrieved May 14, 2010, from U.S. Food and Drug Administration, Tobacco Products.

U.S. Food and Drug Administration. (2009, August 20). Public Health Focus, Electronic Cigarettes. Retrieved July 19, 2010, from U.S. Food and Drug Administration.

U.S. Food and Drug Administration. (2010). Regulations restricting the sale and distribution of cigarettes and smokeless tobacco to protect children and adolescents, Final Rule (FDA-1995-N0259). Federal Register , 75(53):13225-13232.

U.S. Food and Drug Administration. (1996). Regulations restricting the sale and distribution of cigarettes and smokeless tobacco to protect children and adolescents; Final Rule. Federal Register, August 28 / 61(168):44396.

U.S. Food and Drug Administration. (2010). Request for comment on implementation of the Family Smoking Prevention and Tobacco Control Act, Advance notice of proposed rulemaking. Federal Register , 75(53):13241. 
U.S. Food and Drug Administration. (2010). U.S. Food and Drug Administration Center for Tobacco Products 2009-2010: Inaugural Year in Review. Washington, DC: U.S. Food and Drug Administration, Department of Health and Human Services.

U.S. Senate Committee on Health, Education, Labor and Pensions. (2009, June 1). U.S. Senate Republican Policy Committee Legislative Notice, S.982 -- The Family Smoking Prevention and Tobacco Control Act. Retrieved May 13, 2010, from U.S. Senate Republican Policy Committee.

United Nations General Assembly. (1989). Convention on the Rights of the Child. GA res. 44/25, annex, 44 UN GAOR Supp. (No. 49) at 167, U.N. Doc. A/44/49 (1989); 1577 UNTS 3; 28 ILM 1456 (1989) . United Nations High Commissioner for Human Rights (http://www2.ohchr.org/english/law/crc.htm).

United Nations Office of the High Commissioner for Human Rights. (1966). International Covenant on Economic, Social and Cultural Rights. GA res. 2200A (XXI), 21 UN GAOR Supp. (No. 16) at 49, UN Doc. A/6316 (1966); 993 UNTS 3; 6 ILM 368 (1967). Office of the High Commisioner for Human Rights (http://www2.ohchr.org/english/law/cescr.htm).

United Nations Office of the High Commissioner for Human Rights. (1948). The Universal Declaration of Human Rights. GA res. 217A (III), UN Doc A/810 at 71 (1948). Office of the High Commissioner for Human Rights (http://www.ohchr.orgEN/UDHR/Pages/SearchByLang.aspx).

United States v. Carolene Products Company, 304 U.S. 144 (1938).

Variety Wire Serivces. (1994, March 25). Firm hauls ABC's butt into court. Daily Variety , p. 1.

Viscusi, W. K. (1995). Cigarette taxation and the social consequences of smoking. Tax Policy and the Economy, 9:51-101.

Wakefield, M., \& Chaloupka, F. (2000). Effectiveness of comprehensive tobacco control programmes in reducing teenage smoking in the USA. Tobacco Control , 9:117-186.

Wakefield, M., \& Chaloupka, F. (2000). Effectiveness of comprehensive tobacco control programmes in reducing teenage smoking in the USA. Tobacco Control , 9:177-186.

Warner, K. E. (2003). The costs of benefits: smoking cessation and health care expenditures. American Journal of Health Promotion , 18(2):123-124.

Warner, K. E. (2000). The economics of tobacco: myths and realities. Tobacco Control , 9:7889.

Warner, K. E. (2008). The Framework Convention on Tobacco Control: opportunities and issues. Salud Publica de Mexico , 50(S3):S283-S291.

Warner, K. E. (2005). The role of research in international tobacco control. American Journal of Public Health , 95(6):976-984.

Warner, K. E., Hodgson, T. A., \& Carroll, C. E. (1999). Medical costs of smoking in the United States: estimates, their validity, and their implications. Tobacco Control , 8:290-300. 
Warren, C. W., Jones, N. R., Peruga, A., Chauvin, J., Baptiste, J.-P., de Silva, V. C., et al. (2008). Global youth tobacco surveillance, 2000-207. Morbidity and Mortality Weekly Report, 57(SS-1):1-28.

Warren, C. W., Lee, J., Lea, V., Goding, A., O'Hara, B., Carlberg, M., et al. (2009). Evolution of the Global Tobacco Surveillance System (GTSS) 1998-2008. Global Health Promotion , 16(S2):3-37.

Weaver, R. K., \& Rockman, B. A. (1995). Assessing the Effects of Institutions. In R. K. Weaver, \& B. A. Rockman, Do Institutions Matter? Washington, DC: The Brookings Institution.

Weible, C. M. (2008). Expert-based information and policy subsystems: a review and synthesis. Policy Studies Journal , 36(4):615-635.

Weible, C. M., Sabatier, P. A., \& McQueen, K. (2009). Themes and variations: taking stock of the Advocacy Coalition Framework. Policy Studie Journal , 37(1):121-140.

Weiss, S. M., \& Smith-Simone, S. Y. (2010). Consumer health literacy. The need to better design tobacco-cessation product packaging, labels, and inserts. American Journal of Preventive Medicine , 38(3S):S403-S413.

Wilson, D. (2010, January 6). Judge lifts some tobacco ad limits. New York Times , p. Business Section.

Wilson, D. (2010, June 28). Supreme Court Rejects Appeals of Tobacco Ruling. The New York Times.

Wilson, D. (2009, June 16). Tobacco regulation is expected to face free-speech challenge. New York Times, p. Business Section.

Wilson, N., \& Thomson, G. (2005). Tobacco taxation and public health: ethical problems, policy responses. Social Science and Medicine , 61(3):649-659.

Wilson, N., Weerasakera, D., Peace, J., Edwards, R., Thomson, G., \& Delvin, M. (2009). Misperceptions of the "light" cigarettes abound: national survey data. BMC Public Health , $9: 126$.

Wipfli, H. L., Fujimoto, K., \& Valente, T. W. (2010). Global tobacco control diffusion: the case of the Framework Convention on Tobacco Control. American Journal of Public Health , 100(7):1260-1266.

Wipfli, H. L., Fujimoto, K., \& Valente, T. W. (2010). Global tobacco control diffusion: the case of the Framework Convention on Tobacco Control. American Journal of Public Health , 100(7):1260-1266.

Wisotzky, M., Albuquerque, M., Pechacek, T. F., \& Park, B. Z. (2004). The National Tobacco Control Program: focusing on policy to broaden impact. Public Health Reports, 119:303-310. 
Womach, J. (2005). CRS Report for Congress. Tobacco Price Support: An Overview of the Program. Washington, DC.: Congressional Research Service, The Library of Congress (Order Code 95-129).

Wood, R. S. (2006). Tobacco's tipping point: the 419-Master Settlement Agreement as a focusing event. Policy Studies Journal , 34(3):419-436.

World Health Organization. (2009). European Health for All Database (HFA-DB). Copenhagen, Denmark: WHO Regional Office for Europe.

World Health Organization. (2004). Tobacco and Poverty: A Vicious Circle. Geneva, Switzerland: World Health Organization.

World Health Organization. (2001). Tobacco and the Rights of the Child. Geneva, Switzerland: World Health Organization.

World Health Organization. (2009). Tobacco Control Database. Copenhagen, Denmark: WHO Regional Office for Europe.

World Health Organization. (2008). Tobacco Industry Interference with Tobacco Control. Geneva, Switzerland: World Health Organization.

World Health Organization. (2003). WHO Framework Convention on Tobacco Control. Geneva, Switzerland: World Health Organization (Full text available at: www.fctc.org).

World Health Organization. (2008). WHO Report on the Global Tobacco Epidemic, 2008: The MPower Package. Geneva, Switzerland: World Health Organization.

World Health Organization. (2009). WHO Report on the Global Tobacco Epidemic, 2009: Implementing Smoke-free Environments. Geneva, Switzerland: World Health Organization.

World Health Organization. (2010). Working groups established by the Conference of the Parties. Retrieved June 13, 2010, from World Health Organizatoin Framework Convention for Tobacco Control.

World Health Organization, WHO Regional Office for Europe. (2009). European Health for All Database (HFA-DB). Copenhagen, Denmark.

World Health Organization, WHO Regional Office for Europe. (2009). Tobacco Control Database. Copenhagen, Denmark.

World Heath Organization. (2010). WHO Framework Convention on Tobacco Control. Retrieved May 21, 2010, from World Health Organization: www.who.int/fctc/en

Worsham, J. (2006). Up in smoke: mapping subsystem dynamics in tobacco policy. Policy Studies Journal , 34(3):437-452.

Wright, J. (2004). Campaign contributions and congressional voting on tobacco policy, 19802000. Business and Politics , 6(3):1-26. 
Zahariadis, N. (1998). Comparing three lenses of policy choice. Policy Studies Journal , 26(3):434-448.

Zahariadis, N. (2007). The Multiple Streams Framework: Structure, Limitations, Prospects. In P. A. Sabatier, Theories of the Policy Process (2nd Ed.) (pp. 65-92). Boulder, CO: Westview Press.

Zatonski, W. (2003). Democracy is Healthier: A Nation's Recovery -- Tobacco Control in Poland. Warsaw, Poland: Health Promotion Foundation.

Zeller, M; Hatsukami, D; and the Strategic Dialogue on Tobacco Harm Reduction Group. (2009). The Strategic Dialogue on Tobacco Harm Reduction: a vision and blueprint for action in the US. Tobacco Control , 18:234-332. 


\section{APPENDIX 1: SUMMARY OF KEY LEGAL CASES AND EVENTS}

\subsection{Introduction}

Events within the judiciary, specifically the rulings and opinions on the cases and lawsuits within it, have alternately worked to impede and advance tobacco control policy in the United States. Many of these events have taken years to come to resolution and are complex proceedings, with many motions, rulings on motions, appeals of these motions, certification followed by de-certification as class status, etc., followed by a lengthy appeal process of the verdict in the initial case itself. These lawsuits have been filed in both state and federal courts and several have proceeded to the Supreme Court. It is beyond the scope of the present analysis to provide a detailed evaluation of each case. Rather, seminal cases and events will be described as they relate to the evolution of tobacco control policy.

These events have frequently been described as having occurred in three waves: the first wave from 1954-1973 consisting of individuals suing tobacco companies for negligence; the second wave from 1983-1992 starting with the Cipollone v. Liggett Group (discussed in detail below); and the third wave starting in 1994-present consisting of individual plaintiffs, class action suits, and third-party health care cost recovery suits. (Douglas, Davis, \& Beasley, 2006) However, because the purpose here is to better understand how activity in the judiciary has impacted the evolution of the tobacco epidemic generally and tobacco control policy specifically in the United States, the following categorizations have been developed based on the type of legal activity and its relationship to said epidemic and policy evolution:

- Suits brought against tobacco companies by individuals claiming personal harm;

- Suits brought against tobacco companies by groups of individuals (class actions) claiming personal harm;

- Suits brought by individuals or groups against various parties claiming harm, or demanding protection from harm, from environmental tobacco smoke;

- Suits brought by groups, including governments or those representing groups, against tobacco companies seeking reimbursement of expenses attributable to the harm caused by cigarettes; and

- Suits disputing scope of action, including those brought by the tobacco industry against the government claiming action without jurisdiction and so seeking to limit the scope of government action, and suits pursued by government or other 
agencies claiming actions not permitted under existing statutes, agreements, or case law and so seeking to limit the scope of action of the tobacco industry.

The legal basis for the suits and the defenses against them have changed over time based on the evolution of the "problem" of tobacco use - of particular importance have been the 1964, 1986, and 1988 Surgeon General's reports (definitively establishing that smoking causes morbidity and mortality, exposure to secondhand smoke causes morbidity and mortality, and that nicotine is addictive, respectively) and the public disclosure of tobacco industry documents. Regardless of the type of legal action, it is superfluous to convey that the tobacco industry has fought all cases with any and all legal strategies and procedural tactics at its disposal. Frequently referred to as "scorched earth litigation tactics", these have included filing multiple motions and exhausting appeals of all motions, taking extensive depositions and investigations, and other delaying and stalling tactics, all intended to prolong the procedures and increase the complexity (and cost) for plaintiffs. This strategy has been notoriously summarized with a quotation taken directly from tobacco industry documents: "The way we won these cases, to paraphrase Gen. Patton, is not by spending all of Reynolds' money, but by making the other son of a bitch spend all of his." (Extracted from filings as part of Haines $v$ Liggett Group, Inc, quoted from (Daynard, Bates, \& Francey, 2000)) An additional, important legal strategy of the tobacco industry has been to first fight the legitimacy of a suit filed in state courts based on central-level pre-emption language in existing, central-level statutes. That is, before a case has proceeded to trial, such an action by tobacco companies would first require the plaintiff(s) to defend that the state law providing the legal basis for their claim (e.g., misleading advertising) was a legitimate law not preempted by a central-level statute. These strategies and tactics have been effective deterrents to filing suits, particularly with individual plaintiffs and those from small jurisdictions (e.g., municipalities).

\subsection{Suits with Individual Plaintiffs Claiming Personal Harm}

In the first category of cases to be discussed in this analysis, individual lawsuits claiming personal harm began as early as the 1950s and new suits continue to be filed. While details are case-dependent, typically the plaintiff has been an ill current or former smoker (or their surviving spouse, heir, or estate) seeking damages from a tobacco company. Early suits of this type typically claimed that cigarettes were either faulty or that tobacco companies didn't adequately warn consumers about the risks of smoking. For their defense, tobacco companies have denied that cigarettes were harmful, claimed that the illnesses cited had other causes, or, after the Federal Cigarette Labeling and Advertising Act of 1965, that smokers did know the risk but in 
deciding to smoke regardless, knowingly assumed the risks thus alleviating the tobacco companies of liability. These early, individual cases were all successfully defended by the tobacco companies. The legal arguments forwarded by both the plaintiffs and the defense (tobacco industry) evolved over time with additional scientific information and the public disclosure of the tobacco industry documents. For individual smokers, evidence of nicotine's addictive nature, and later that tobacco companies were fully aware but concealed this, made the "free will" defense by tobacco companies much more difficult. However, prior to 2000 only a few verdicts were decided in favor of the plaintiffs and all were overturned on appeal (e.g., Cipollone v. Liggett Group; initial verdict was for the plaintiff - the first ever finding for a plaintiff - was overturned on appeal then appealed to the U.S. Supreme Court, but eventually dropped 9 years after the initial filing of the suit due in part to expenses incurred by the plaintiff).

\subsubsection{Engle and Engle Progeny Cases}

Since 2000 and the extensive study of the millions of pages of tobacco industry documents released as part of the Minnesota trial and then the Master Settlement Agreement, verdicts against tobacco companies have become more common, though trials and appeals remain long and complex. Most recently, a series of cases in Florida have been making their way through the state court system, with the majority of the now-individual cases being decided in favor of the plaintiffs. In Engle v. R.J. Reynolds et al., the original case was certified as a class action on behalf of smokers in Florida with the initial verdict and a huge damage award $\$ 145$ billion in punitive damages and $\$ 2.7$ million in compensatory damages - in favor of the plaintiffs. However, the Florida Appeals Court threw out the verdict and decertified the class but importantly allowed individual cases to proceed while using the carry-over findings of the jury in the original case of multiple wrongdoings by the tobacco industry. These individual cases, variously estimated to number at $4000-8000$, are sometimes referred to as the "Engle offspring" or "Engle progeny" cases and are now proceeding. Of the jury verdicts reached so far in 13 cases, 11 have been decided for the plaintiffs, though appeals in all are pending. A significant challenge in proving individually-based suits remains establishing individual smoking attributable, proximal causality for the plaintiff, which is different and a larger burden than demonstrating statistical causality and disease probability within a population.

\subsubsection{Summary}

It is unclear how these individual-plaintiff cases have directly affected the adoption of comprehensive tobacco control policies. These cases have likely had secondary impacts, including establishing precedent and case law particularly related to liability and industry 
wrongdoing, as well as making public previously unknown information through the discovery process. Further, this category of cases may have impacted product and industry framing and policy images, though these possible associations have not been systematically evaluated.

\subsection{Class Action Suits Claiming Personal Harm}

The second category of cases is class action suits claiming personal harm from cigarette smoke. Though class action suits filed by smokers have proceeded, the challenge of these suits is illustrated by the Florida case above (Engle v. R.J. Reynolds et al.). As it is considered a strategic advantage for tobacco companies to require that each case be tried separately, tobacco companies have fought class certification vigorously. Generally, class action lawsuits by smokers against tobacco companies have been unsuccessful regardless of the time period as courts have generally held that both causation and damage have to be demonstrated individually.

\subsection{Suits Claiming Harm from Exposure to Secondhand or Environmental Tobacco Smoke}

In the third category of cases, claims of harm from exposure to secondhand or environmental tobacco smoke, suits have been brought by a broad array of plaintiffs against an equally broad array of defendants.

\subsubsection{Individually-Based Suits}

In individually-based suits, there have been multiple cases that have upheld a nonsmoker's right to a smoke-free environment and the obligations for such an environment to be ensured. For example, the U.S. Supreme Court upheld the decision of a lower court which had ruled that a nonsmoking inmate housed with a smoker (or otherwise involuntarily subjected to forced exposure to secondhand smoke) had the right to petition for relief on the grounds that such forced exposure constituted cruel and unusual punishment, an $8^{\text {th }}$ Amendment violation, and failure to consider such a petition showed deliberate indifference to future health consequences of such exposure (Helling v. McKinney, No. 91-1958). As an example of an occupationally-based case, a lifelong nonsmoking railroad worker who was required to sleep in company-provided bunk cars with smoking co-workers contracted lung cancer for which he claimed his employer was liable (he subsequently died, prematurely, at aged 40 years). After his death, his widow continued the case and eventually settled with the railroad company (Thaxton v Norfolk Southern Railroad Co., 239 Ga.). Additionally, lawsuits have helped to establish the obligation of landlords, under covenants of habitability, to adequately protect 
tenants from exposure to secondhand smoke (e.g., Gainsborough St. Realty Trust v. Haile, No. 98-02279).

\subsubsection{Class-Action Suits}

In addition to individually-based suits, class action suits have also been filed by those affected by secondhand smoke. Most prominently, nonsmoking flight attendants who were occupationally (and involuntarily) exposed to environmental tobacco smoke filed suit against several tobacco companies claiming, among other things, that tobacco companies knew about the harmful effects of tobacco smoke but withheld this from the public thereby preventing employers from protecting their workers and leading to unnecessary and involuntary harm. In this particular case (Broin v. Philip Morris, Inc. et al.), and as a departure from all previous cases that had been vigorously contended to completion, the tobacco companies agreed to a partial settlement which, among other agreed-to terms, allowed claims for damages to proceed on a individual-case basis.

\subsubsection{Summary}

In contrast to personal-harm suits brought by smokers, these individual or class action suits by nonsmokers seeking relief or compensation for harm from exposure to secondhand smoke have had a far more direct impact on policy. First, they have established the legal precedent for the harmful effects of secondhand smoke. Second, by establishing liability for not protecting non-smokers from exposure to secondhand smoke, these activities have served to establish a requirement for employers and landlords, among others, to develop practices that protect nonsmokers. That is, these activities established de facto requirements (policy) for smoke-free environments.

\subsection{Suits Seeking Reimbursement for Tobacco-Attributable Expenses}

In the fourth category of cases, a creative and novel approach to litigation against the tobacco companies emerged beginning in the 1990s. To avoid the need to prove, as was required in individually-based suits, that the proximal, causal mechanism for illness was smoking, lawsuits emerged seeking reimbursement for expenses incurred attributable to smoking within a population. These lawsuits were able to capitalize on both the additional scientific evidence that had emerged since the early, individual-based lawsuits, additional release of tobacco industry documents revealing their awareness and concealment of the dangers of smoking and more sophisticated epidemiologic methods that could much more accurately identify smoking-attributable morbidity, mortality, and expense in a population than in an individual. That is, these suits sued not for punitive damages for harm caused by tobacco 
products (and thus did not have to prove that the harm in an individual was caused by tobacco products) but rather sued for the statistically-determined expense of treating that harm within a given population.

\subsubsection{The States Attorneys' General and the Master Settlement Agreement}

In 1994, the first of these cases was filed by the Attorney General for the State of Mississippi (Michael Moore) suing on behalf of the taxpayers of Mississippi seeking restitution for the costs to the state Medicaid fund for treating smoking-related illnesses (Moore $v$. American Tobacco, et al. Case No. 94-1429). The states of Florida, Minnesota (with Minnesota Blue Cross/Blue Shield as co-plaintiff), and Texas followed, and eventually the Attorneys General for the remaining 46 states had filed similar suits. Rather than defend lawsuits in all 50 states, the tobacco companies sought to enter into an agreement with the Attorneys General and thus began a long, complex, and contentious negotiation process which is beyond the scope of the present analysis to describe in detail save three key milestones: the 1997 proposed agreement (sometimes referred to as the national settlement agreement, the global settlement agreement, or the 1997 national settlement proposal); the McCain Bill; and the

Table 10-1. Summary of Key Components of the Master Settlement Agreement

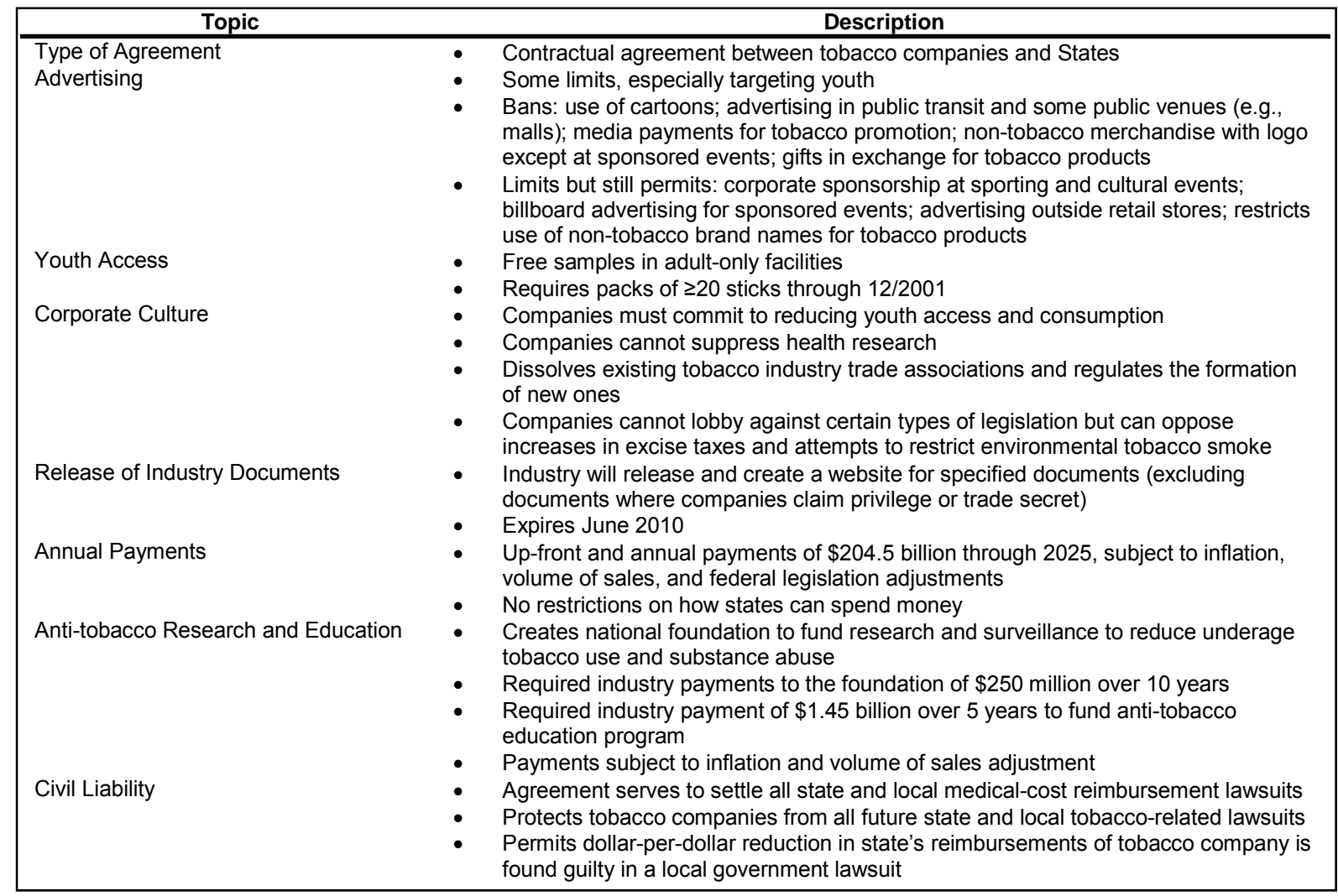

Source: (Redhead, 1999) 
Master Settlement Agreement of 1998 (also known as the Multi-State Agreement or M.S.A.).

The first settlement proposal was forwarded in 1997 and required legislation in order to be enacted. In November 1997, Senator John McCain (R-AZ) introduced the Universal Tobacco Settlement Act (the "McCain Bill) which incorporated terms of the 1997 settlement proposal but increased the sum of the annual payments, payments for research, and included stricter tobacco company reporting requirements. After revision by the Commerce Committee, the McCain Bill was introduced to the Senate where it was eventually defeated in June 1998. Negotiations after the defeat of the McCain Bill resulted in a settlement agreement that did not require Congressional action. The M.S.A., signed in November 1998, was a series of contractual agreements between the signatory tobacco companies and 46 individual states. A summary of the main components of the M.S.A. are shown in Table 10-1. There were important differences between the M.S.A. and the original 1997 proposed national settlement agreement and the McCain Bill. Importantly, the M.S.A. was structured as a contractual agreement to be managed by the National Association of Attorneys General and not the legislative framework for comprehensive tobacco control policy as was provided in the McCain Bill. Additional differences included: fewer restrictions on advertising (the McCain Bill, for example, also restricted print and internet advertising); fewer and weaker restrictions to prevent youth access to tobacco products (e.g., the M.S.A. did not include the restriction on vending machines and mail order sales that were part of the McCain Bill); no enforcement of minimum-age sales through retailer licensing (these provisions were included in the McCain Bill); no provisions or restrictions on how states could use settlement funds; and finally, no provision for the F.D.A. to regulate tobacco products, stipulations included in both the original 1997 proposed national settlement and the McCain Bill. The four states that were not party to the M.S.A. - Minnesota, Texas, Florida, and Mississippi - negotiated separate, individual-state settlements with the tobacco companies that were similar in content and implementation date to the M.S.A..

The most important difference between these separately negotiated state settlements and the M.S.A. was the Minnesota agreement, specifically the document warehouse created as part of the Minnesota settlement. In particular, Minnesota requested and eventually obtained, after multiple appeals of trial orders, access to thousands of pages of supplementary pages of internal documents that the tobacco industry had been previously shielding under the auspices of attorney-client privilege. (Hurt, Ebbert, Muggli, Lockhart, \& Robertson, 2009) The Minnesota depository contains more than 60 million pages of documents and more than 20,000 other 
materials. Combined with the materials released as part of the M.S.A., these documents have transformed the legal landscape for tobacco companies.

Within a similar timeframe as the states filed suits and the M.S.A. settlement, other groups filed similar reimbursements lawsuits. Specifically, third-party payor insurance companies (e.g., Blue Cross \& Blue Shield of N.J., Inc. v. Philip Morris U.S.A Inc.), tribal health funds from a variety of Native American tribes (e.g., Alabama Coushatta Tribe of Texas $v$. American Tobacco Co.), and labor union health funds (e.g., Iron Workers Local Union No. 17 Ins. Fund v. Philip Morris Inc.) filed suits against tobacco companies to recover the costs expended to treat smokers. In general, these lawsuits were either unsuccessful or dismissed on the grounds that third-party claims are too remote for the relief sought.

\subsubsection{Master Settlement-Emulating Suits}

Additionally related to the M.S.A., the Agreement has spawned a series of derivative lawsuits. In the first type, lawsuits have been filed designed to capture part of the settlement funds for a particular group (e.g., Brown v. Philip Morris, et.al; Table Bluff Reservation (Wiyot Tribe) et al. v. Philip Morris, Inc. et al.). These suits have been unsuccessful and the National Association of Attorneys General has retained control of the administration of the M.S.A. funds. In the second type, a series of lawsuits have been filed, either by governments or tobacco companies contesting the terms or interpretation of the terms of the M.S.A.

\subsubsection{Master-Settlement Agreement Interpretation and Enforcement Suits}

There have also been a series of legal cases pursuant to the M.S.A. as a mechanism to either determine the limits or interpretation of or enforce the terms of the M.S.A. In accordance with the M.S.A., the Attorneys General, collectively and within their own state, are responsible for enforcing the terms of the M.S.A. Within in a year of the completion of the M.S.A., the National Association of Attorneys General established the Tobacco Enforcement Committee in order to coordinate M.S.A. enforcement activities within and between the M.S.A. states. (Eckhart, 2004) Within the first four years of the M.S.A., this national-level committee has reported initiating more than twenty actions related to reported tobacco company M.S.A. violations including tobacco company activities related to misrepresenting the health effects of smoking, targeting youth in magazine advertising, providing samples and substantial advertising at N.A.S.C.A.R. and N.H.R.A. auto racing events, and providing free samples by mail. (Eckhart, 2004) Many issues brought to the attention of the Attorneys General have also reached litigation. For example, the Office of the California Attorney General lists dozens of governmentinitiated cases within the State of California and beyond, many of which reached adjudication in 
the state's Supreme Court on issues ranging from the use of cartoons, health claims, brand name sponsorship, distribution of free samples, action against retailers for selling tobacco to minors, and enforcement of M.S.A. settlement payments. (State of California Department of Justice, Attorney General's Office, 2010) Tobacco companies have also filed suit against state governments based on the terms of the M.S.A. In Lorillard Tobacco Co. V. American Legacy Foundation, the plaintiffs filed suit in Delaware claiming that the M.S.A.-created advocacy group violated the terms of the M.S.A. with their series of "edgy" anti-tobacco ads. In July 2006, the Delaware Supreme Court upheld the ruing of a lower which stated that the ads had not violated the terms of the M.S.A. and the ads could proceed (Lorillard Tobacco Company v. American Legacy Foundation, No. 579, 2005).

\subsubsection{Summary}

The impact of these reimbursement-seeking suits on tobacco control policy is not straightforward. As a contractual agreement, the M.S.A. did impose de facto policy but not through traditional legislative means (the contractual agreement was necessary due to a failure in traditional legislative mechanisms). Components of the M.S.A. were clearly based upon evidence-based tobacco control policy instruments, but enforcement of the agreement is dependent upon the resolution of contractual law disputes between the settling parties. Likely the components of the M.S.A. with the most enduring impact on tobacco control policy, though indirect, was the establishment, building on the achievement in the Minnesota trial, of the tobacco industry document library and the creation of the American Legacy Foundation, a national tobacco control advocacy organization which, with the Campaign for Tobacco Free Kids, are two of the most nationally prominent and active anti-tobacco interest groups. One of the most controversial legacies of the M.S.A. has been the settlement payments and how states have an have not used these funds, with most states not allocating recommended proportions of their Settlement funds to tobacco control activities.

\subsection{Suits Disputing Scope of Action}

In the final category of legal activities to be described in the current analysis, are suits brought by either governments (federal or state) or the tobacco industry itself claiming violation of existing statutes or procedural rules, case law, or the constitution and so seeking to limit the scope of action of the other. For suits of this kind brought by tobacco companies, four are seminal:

- A libel suit brought against a broadcasting company based on the contents of a documentary on the tobacco industry; 
- The action brought against the government's planned regulation of tobacco by the F.D.A.;

- Action brought against the government and the E.P.A. regarding the E.P.A.'s risk assessment report on environmental tobacco smoke;

- Various actions brought against the government(s) claiming advertising restriction violation of First Amendment rights;

- Action already filed by tobacco companies and non-tobacco companies seeking to limit the actions of the F.D.A. under the Family Smoking Prevention and Tobacco Control of 2009.

For suits of this kind brought by the government against tobacco companies, two are seminal:

- Suits claiming faulty use of the term "light" cigarettes; $f$

- The Department of Justice's civil claim seeking relief under the federal Racketeer Influenced and Corrupt Organizations Act (R.I.C.O.). These cases are described below.

\subsubsection{Suits Brought by Tobacco Companies}

\subsubsection{Suit Against A.B.C.'s "Day One” Documentary}

In February 1994, A.B.C. in its T.V. news-magazine documentary program "Day One" aired a feature titled "Smoke Screen", which focused on tobacco industry practices as related to the nicotine content of cigarettes. Specifically, the program investigated the industry practice of using re-constituted tobacco to make cigarettes, a process wherein parts from tobacco plants are homogenized using water and the ingredients removed during this process, nicotine among them, are later sprayed back onto the homogenate using a liquid syrup or extract. The implication in part, from the perspective of industry regulation, was whether this practice constituted intentional manipulation of a drug (nicotine) content of a product which could then be interpreted as being within the jurisdiction of the F.D.A. Whether the A.B.C. program used faulty investigative techniques or whether they reported incorrect facts or facts incorrectly has been the subject of debate, but the controversy over the approximately 20 -minute story seems to have revolved around sensationalized promotion of the program, the creative editing of clips of "Deep Cough" (a former R.J. Reynolds employee that, in disguise, detailed on-camera these industry practices but did not agree that they industry was "boosting" nicotine content merely keeping it consistent; A.B.C. included the former clips in the aired version of the program but not the latter), and the use of the word "spiking" to describe the industry's practices. (Shepard, 
1995) Philip Morris, Inc. filed a $\$ 10$ billion libel and defamation suit against A.B.C., the "Day One" reporter (Walter Bogdanich) and the "Day One" producer (John Martin) in March 1994.. (Variety Wire Serivces, 1994) A.B.C. agreed to a pre-trial settlement the terms of which included, among other things, a financial settlement (estimated to be $\$ 15$ million in legal fees) and that A.B.C. issue an apology, which it did, and while the apology was narrowly construed and technical, the typical approach to reporting the episode in the media was along the lines of 'A.B.C. admits wrongdoing and apologizes to Philip Morris'. (Editorial, New York Daily News, 1995), (Shepard, 1995) The consequences of this episode, either short-term or long-term, are likely mixed. In the short-term, Philip Morris capitalized on the publicity and the aftermath, particularly the financial settlement, allegedly intimidated at least one other broadcaster from airing an industry exposé-type documentary. (Shepard, 1995), (Kaplan \& Isikoff, 1995), (Kurtz, 1995) The long-term effects of this episode have been conjectured to be more detrimental to the tobacco industry. The documentary itself won the 1994 George Polk award for network television reporting and the award committee, in a post-apology review of the award, upheld its decision based on the substantial truth and importance of the documentary's contents. (Shepard, 1995) Further, others have cited the prominence of both the original documentary and the aftermath as being critical from an agenda-setting perspective and it is difficult to overlook that within a year of the settlement (two years from the airing of the documentary), President Clinton and David Kessler had announced their intention for the F.D.A. to regulate cigarettes (discussed further below). (Shepard, 1995), (Editorial, New York Daily News, 1995)

\subsubsection{Suit Against F.D.A.'s Assertion Over Regulation of Tobacco}

The tobacco companies have also used the legal system to prevent, delay, discredit, or deter government activity intended to expand tobacco control policy activities, regulations, or bureaucratic jurisdiction thereof. In February 1994, the same month as the airing of A.B.C.'s "Smoke Screen", then-President Clinton and then-F.D.A. Commissioner Dr. David Kessler announced that the government, through the F.D.A., was considering the regulation of tobacco products with the rationale that nicotine was a drug already tightly regulated by the F.D.A. when occurring in products such as trans-dermal patches and gum and, thus, cigarettes were merely drug-delivery devices. (Kessler, et al., 1996) The F.D.A. then undertook an extensive study and review of existing evidence on the physiologic effects of nicotine, among other things, and in August 1995 issued a report for public comment on the findings of their review. (Department of Health and Human Services, Food and Drug Administration, 1995) The F.D.A. issued their Final Rule in August 1996, with the first provisions taking effect in February 1997. (U.S. Food 
and Drug Administration, 1996), (Anonymous, 1996) The logical argument (and subsequent legal arguments) for F.D.A. regulation of cigarettes was developed around several premises: a) the physiologic and psychoactive properties of nicotine, including its addictive properties, met existing, internal F.D.A. standards for the definition of a drug; b) cigarettes and other tobacco products were intended by the industry to be simply the mechanisms for delivery of that drug; $c$ ) that smoking caused substantial public harm; and d) the best strategy to reducing this public harm was to break the cycle of tobacco use by designing policies that focused on the reduction of use initiation in children and adolescents. (Kessler, et al., 1996) The Final Rule forwarded a series of policies designed to restrict access of tobacco products from those $<18$ years of age, including requiring photo identification to purchase tobacco (for those <26 years of age), substantial restrictions on vending machines, promotional materials, and advertising. (Kessler, et al., 1996)

The 1996 F.D.A. Final Rule has had a profound impact on the trajectory of tobacco control policy in the United States that remains detectable still. Between the 1995 interim report and the August 1996 announcement of the Final Rule, the F.D.A. published a series of carefully constructed peer-reviewed articles, augmented by the final report from the Advisory Committee on Tobacco Policy and Public Health, which served to outline the scientific basis for the components of the Final Rule. (Kessler, et al., 1997), (Kessler, Nicotine addiction in young people, 1995), (Kessler, Wilkenfeld, \& Thompson, The Food and Drug Administration's Rule on tobacco: blending science and the law, 1997), (Kessler, et al., 1996), (Koop \& Kessler, 1997) Of particular import has been the framing of smoking and nicotine addiction as a "pediatric disease". The F.D.A. used as the scientific and logical justification for this focus, as outlined in the peer-reviewed articles accompanying the Final Rule, the evidence of susceptibility and special need for protection in this population based on epidemiologic evidence for tobacco use experimentation and development of addiction in this age group, and because of its target for such initiation through the advertising and promotional practices of the tobacco industry itself. The F.D.A. also rationalized that, given the level of addiction existing within the population, an outright ban would not be reasonable and create too much hardship on those already addicted, thus policy should aim to reduce and eliminate future addiction. It is also reasonable to presume that the F.D.A. was not unaware of the political and practical barriers to imposing a complete ban on all tobacco products, the more favorable social construction of children as needing - and deserving - protection (Schneider \& Ingram, 1993) and thus the greater likelihood for the acceptance of policies based in "soft paternalism" (discussed previously) to 
protect this population, nor is it possible to overlook the not unlikely coincidence that Dr. Kessler is, by training, a pediatrician.

For support of the other critical premises for F.D.A.'s assertion of its jurisdiction over the regulation of tobacco, namely the addictive nature of nicotine and the intentional manipulation of these addictive properties by the tobacco companies, the series of peer-reviewed articles (and the text of the Final Rule itself) carefully detailed the scientific evidence for the addictive properties of nicotine, and that tobacco companies were manipulating the nicotine content of both cigarettes and other tobacco products fully aware of the role of cigarettes as the vehicle to deliver a tightly controlled dose of nicotine, an addictive drug. In making the case for the latter, the tobacco companies' knowledge and intention with regard to using cigarettes to deliver a dose of nicotine, the F.D.A.'s burden was greatly lessened by a series of events that happened in a very similar timeframe as the F.D.A.'s activities. In 1994, Rep. Henry Waxman, (D-CA) as the Chair of the House Subcommittee on Health and the Environment, conducted a series of hearings on the health effects of smoking. In early April 1994, the Presidents/CEOs for seven American tobacco companies infamously testified under oath to this committee that smoking was neither addictive nor did it cause disease. Less than two weeks after this testimony, two former Philip Morris scientists (Drs. Victor DeNoble and Paul C. Mele) testified to this same committee that Philip Morris suppressed, through threat of legal action, the publication of their work on the addictive properties of nicotine. Further, these scientists testified that some of their additional research projects for the company included the development or identification of a substitute for nicotine that had the same psychoactive but not cardio-active properties. Additionally, in a separate incident in May 1994, a mailing received by a tobacco researcher (Dr. Stanton A. Glantz) with the return service address of "Mr. Butts" contained several thousand pages of Brown \& Williamson Tobacco Company internal documents. (Cummings \& Pollay, 2002) While the identity of "Mr. Butts", the original source of the documents, was the subject of litigation surrounding the unauthorized copying of the documents (Brown \& Williamson Tobacco Corp. v. Williams, Maddox v. Williams), the damaging effect of the documents to the tobacco industry could not be undone (among other things, the documents revealed that, as early as 1963, tobacco companies were aware of the harmful health effects of cigarettes). The researcher and his team subsequently published summary findings of these documents first in the scientific literature and then in book-form. (Glantz, Barnes, Bero, Hanauer, \& Slade, 1995), (Barnes, Hanauer, Slade, Bero, \& Glantz, 1995), (Bero, Barnes, Hanauer, Slade, \& Glantz, 
1995), (Hanauer, Slade, Barnes, Bero, \& Glantz, 1995), (Slade, Bero, Hanauer, Barnes, \& Glantz, 1995), (Glantz, Slade, Bero, Hanauer, \& Barnes, 1996)

While the testimony from the former Philip Morris scientists and evidence from released internal tobacco industry documents substantially supported the F.D.A.'s quest to demonstrate both industry knowledge and intent in the dosage manipulation and delivery of nicotine, and the targeting of children and adolescents, the 1996 F.D.A. Final Rule would ultimately fail. The tobacco companies objected to both the regulations and the expansion of the F.D.A.'s jurisdiction and filed suit against the F.D.A. on the basis that Congress had not authorized the F.D.A. to regulate tobacco products (F.D.A. et al. v. Brown \& Williamson Tobacco Corp.). The F.D.A.'s authority to regulate tobacco was upheld by the District Court but overturned by the Circuit Court. On appeal to the U.S. Supreme Court, in a famous 5-4 decision in 2000, the Supreme Court upheld the Circuit Court's ruling that Congress had not so authorized or intended the F.D.A.'s jurisdiction over tobacco under the existing Food, Drug, and Cosmetic Act, citing as support internal F.D.A. stating that it did not have authority to regulate tobacco, that Congress had developed a regulatory scheme for tobacco outside the F.D.A., and that despite repeated opportunities to do so, Congress had not explicitly authorized the F.D.A. to regulate tobacco. It was almost 10 years after this Supreme Court decision that Congress legislated this jurisdiction to the F.D.A. under the Family Smoking Prevention and Tobacco Control Act of 2009. (Curfman, Morrissey, \& Drazen, 2009)

\subsubsection{Suit Against E.P.A. for Report on Environmental Tobacco Smoke Risk Assessment}

The tobacco industry's legal action against the U.S. Environmental Protection Agency (E.P.A.) is another occurrence wherein the court system was employed as a strategy to prevent, delay, discredit, or deter government activity in tobacco control activities. In the late 1970s and into the 1980s, increasing scientific evidence emerged implicating exposure to secondhand smoke as part of the causal mechanism for multiple morbidities and mortalities. These scientific studies culminated in the reports from both the National Academy of Sciences and the Surgeon General's Office that reviewed and synthesized the existing evidence linking exposure to secondhand smoke to disease and mortality in nonsmokers. (U.S. Department of Health and Human Services, Office of the Surgeon General, 1986), (National Research Council, National Academy of Sciences, 1986) In particular, the Surgeon General's report had as a primary conclusion that involuntary smoking causes disease, including lung cancer, in nonsmokers. Under the authority of the 1986 "Radon Gas and Indoor Air Quality Research Act" in which Congress directed the E.P.A. to develop a comprehensive indoor air quality research and 
information dissemination program, in 1988 the E.P.A. began studying the implications for indoor air quality of environmental, or secondhand, smoke. (Environmental Protection Agency, 2009) An environmental tobacco smoke risk assessment report was drafted in June 1990 which then, per internal E.P.A. regulations, was required to be reviewed by the E.P.A. Science Advisory Board, an internal independent board that reported directly to the E.P.A. Administrator (then William Reilly) comprised of nine standing members and nine members selected from consultants and scientists based on content-expertise appointed on a report-specific basis. (Muggli, Hurt, \& Repace, 2004) The tobacco industry employed both political strategies to delay or prevent the release of the report, dubbed "sand in the gears" (Muggli, Hurt, \& Repace, 2004) as well as scientific strategies, dubbed "keep the controversy alive", which included sponsoring scientific studies with "neutral" results and sponsoring scientists to attend national and international meetings and conduct symposia highlighting "neutral" or "confounding" study results. (Muggli, Forster, Hurt, \& Repace, 2001) However, for a variety of reasons and circumstances, these efforts were largely unsuccessful. The E.P.A., after review by the Scientific Advisory Board, released a draft report for public comment in May 1992 and the final report in December 1992 ("signed" in January 1993, thus the sometimes conflicting dates for the report). The final report, a total of 530 pages, concluded that environmental tobacco smoke is a known human carcinogen in adults, responsible for an estimated 3,000 adult deaths annually, and increases the risk for lower respiratory tract and ear infections, among others, and asthma in children. (Anonymous, 1993), (U.S. Environmental Protection Agency, 1992) In June 1993, the major tobacco companies filed suit against the E.P.A. in Federal District Court in Greensboro, NC seeking injunctive relief and that the court declare the E.P.A.'s risk assessment report "wrong as a matter of law and science". (Janofsky, 1993), (Kenworthy \& Brown, 1993) The industry's complaint against the E.P.A. alleged that the E.P.A. had violated the Radon Act by not properly constituting its Scientific Advisory Board, had not complied with its own risk assessment guidelines, and that the classification of secondhand smoke was "capricious" based on the decision to use a $90 \%$ confidence interval as the standard for establishing association between exposure and disease rather than the more customary 95\% confidence interval (FlueCured Tobacco Cooperative Stabilization Corporation et al. v. the United States Environmental Protection Agency No. 98-2407). In July 1998, District Judge William Osteen Jr. cited multiple procedural and scientific mistakes, including that the E.P.A. was "committed to a conclusion before the research had begun", and vacated most of the conclusions in the E.P.A.'s report, which created concern for both municipalities citing the report as support for pending antismoking bylaws as well as for pending environmental tobacco smoke lawsuits. (Meier, 1998), 
(Koch, 1998) The E.P.A. appealed the decision and it was later reported that Judge Osteen had previous experience as a tobacco industry lobbyist (Associated Press, 1995), though this had little impact on the legal proceedings. In June 1999 the appeal was argued before the U.S. $4^{\text {th }}$ Circuit Court of Appeals and, in December 2002, the court ruled unanimously to overturn Judge Osteen's ruling. In their decision, the Circuit Court cited that the E.P.A.'s report carried no legal or regulatory authority and that the report was not a reviewable agency action; the Circuit Court did not rule on the other elements of either the initial complaint or Judge Osteen's ruling (FlueCured Tobacco Cooperative Stabilization Corporation et al. v. the United States Environmental Protection Agency No. 98-2407). The tobacco industry did not appeal the Circuit Court's ruling. While pioneering in 1992/1993, by 2002 there had been substantial additional scientific studies conducted adding to the body of evidence causally linking exposure to tobacco smoke to a multitude of diseases and mortality. Thus, a single E.P.A. report was no longer material; the tobacco industry had to concede this battle.

\subsubsection{Suits Claiming Infringement of First Amendment Rights}

Unlike the tobacco industry's legal actions against the F.D.A. and E.P.A., which appealed to technical and procedural standards to challenge agency authority to act or regulate, tobacco industry suits fighting advertising bans have been based on appeals of direct violation of existing case law and / or violation of Constitutional protections, specifically First Amendment rights to free speech. Federal regulation of tobacco advertising started in 1965, the year after the seminal Surgeon General's report asserting a causal association between tobacco use and morbidity and mortality, with the Federal Cigarette Labeling and Advertising Act of 1965 (P.L. 89-92) which required a warning label on cigarette packages but not on advertising. The Public Health Cigarette Smoking Act of 1969 strengthened the language of the package warning label and banned tobacco advertising on radio and television. The package warning label was changed to a set of four rotating labels and the requirement was extended to print advertising in the Comprehensive Smoking Education Act of 1984. These early statutes received no legal challenges because it was not until 1975 that the Court ruled, in a non-tobacco case, that First Amendment protections extended to commercial speech. (Gostin, 2002) In the 1980 ruling in Central Hudson Gas v. Public Service Commission, also a non-tobacco case, the U.S. Supreme Court created a 4-part standard by which to assess constitutional constraint of First Amendment commercial free speech and which remains the precedent case law standard. (Bayer, Gostin, Jarvin, \& Brandt, 2002) Known as the Central Hudson test, the four components are: a) only advertising for lawful products or activities that are truthful and not deceptive or misleading are 
extended protection; b) the government's interest in curtailing the commercial speech must be substantial; c) the regulation (curtailment of commercial free speech) must materially and directly advance the public's interest; and d) the restriction is only as extensive as necessary to advance the public's interest. The 1996 Final Rule from the F.D.A. included substantial regulations limiting tobacco product promotion and advertising including: prohibition on billboard advertisement within 1,000 feet of an elementary or secondary or a playgroups; requirement that all advertising be limited to black text on a white background (the so-called "tombstone" format); prohibition of the sales and / or distribution of non-tobacco items with tobacco product branding of any form; and prohibition of tobacco company sponsorship of sporting and cultural events, race cars or other teams or entries into sporting or other events, or any other event wherein the brand name of a tobacco company or product would appear. (Anonymous, 1996) While the F.D.A. anticipated First Amendment challenges (unfair restriction of commercial speech) for these advertising and promotion regulations and included justification and support addressing the four Central-Hudson tenets in the Final Rule (Anonymous, 1996), the Court never actually reviewed these regulations as the Final Rule was challenged on, and the Court ruled on, the jurisdiction of the F.D.A. to regulate tobacco (FDA et al. v. Brown \& Williamson Tobacco Corp.). In 2000 when the U.S. Supreme Court ruled to overturn the 1996 F.D.A. Final Rule judging that Congress never intended the F.D.A. to have jurisdiction over tobacco, the advertising regulations within the Final Rule became immaterial. The Master Settlement Agreement of 1998, a substantially less-restrictive version of the failed original 1997 national settlement agreement and the McCain Bill, did contain some advertising restrictions including (from Table 10-1 above): limits in advertising to youth; prohibition of the use of cartoons, advertising in certain public areas (malls, public transit), and payments to media for product promotion; and limits but not prohibition of sponsorship (and advertising at) sporting and cultural events. However, because the M.S.A. was a contractual agreement between the settling parties and not a legislated restriction, these advertising and promotion restrictions were also not subject to First Amendment challenges though, as discussed above, there has been litigation to determine the interpretation of these M.S.A. advertising restrictions.

Massachusetts was signatory to the 1998 M.S.A. However, in January 1999 then-state Attorney General Scott Harshbarger forwarded a series of additional regulations, as part of the consumer protection statute Massachusetts General Laws ch. 93A $\S 2$, with the intent to eliminate deceptive and unfair practices in the marketing and distribution of cigarettes so as to prevent the recruitment of new customers from among the minors in the state. These 
regulations were broader and more restrictive than the regulations agreed upon in the M.S.A., and were instead more similar to those included in the 1996 F.D.A. Final Rule. Before the regulations took effect, four tobacco companies sued the Attorney General on multiple grounds including that the regulations were preempted by the Federal Cigarette Labeling and Advertising Act of 1965 and that the regulations violated their First Amendment protections of commercial free speech (Lorillard Tobacco Co. et al. v. Reilly, Attorney General of Massachusetts et al, No. 00-0596). After mixed rulings in federal Circuit and Appellate Courts, the case was appealed to the U.S. Supreme Court. In a complex and split ruling in June 2001, the Supreme Court ruled that the state's regulations were preempted by the Federal statute and, in applying the CentralHudson four part test, that the regulations, particularly those banning advertising within 1,000 feet of schools and in-store displays below the height of 5 feet, met three but failed the fourth standard (the restrictions were more extensive than necessary) (Lorillard Tobacco Co. et al. v. Reilly, Attorney General of Massachusetts et al, No. 00-0596). So, while the Court acknowledged the legitimacy of the state's interest in preventing smoking initiation by minors, the ruling was widely regarded as a victory for the tobacco industry and placed doubt on the future of similar local statutes in effect in New York, Chicago, and Baltimore. (Greenhouse, 2001), (Kane, 2001)

\subsubsection{Suit Seeking to Limit the Family Smoking Prevention and Tobacco Control Act of 2009}

As discussed previously, the Family Smoking Prevention and Tobacco Control Act of 2009 that legislated the regulation of tobacco to the jurisdiction the F.D.A. included multiple provisions for package labeling and also required that the F.D.A. reissue the 1996 Final Rule that was overturned by the U.S. Supreme Court in FDA v. Brown and Williamson Tobacco Corp. (Gostin L. O., 2009), (U.S. Senate Committee on Health, Education, Labor and Pensions, 2009), (Redhead \& Burrows, FDA Tobacco Regulation: The Family Smoking Prevention and Tobacco Control Act of 2009, 2009) Issued in March 2010 and to take effect on June 22, 2010 (one year after the bill was signed by President Obama), the reinstated advertising regulations include: a ban on sporting and all cultural event sponsorship; a ban of free samples or nontobacco product giveaways or promotions linked to the purchase of a tobacco product; a ban on small-sized packs (usually <20 sticks); a ban on music and sound effects in audio advertising; a ban on color and graphics in video ads, which become restricted to static black text on a white background; and the "tombstone provision", which requires package labels and advertising be limited to black text on a white background. (U.S. Food and Drug Administration, 2010) Additionally, the 2009 Act provided that package and warning labels become one of nine 
rotating text warnings to appear on the upper $50 \%$ of the top front and rear panels of packages and occupy $20 \%$ of the total area of an advertisement (Public Law 111-31-June 22, 2009 Family Smoking Prevention and Tobacco Control Act §201), with the provision that the F.D.A. has the authority to adjust the nature and content of the warnings to, for example, graphic color warnings (Public Law 111-31-June 22, 2009 Family Smoking Prevention and Tobacco Control Act §202). Given recent case law development, the F.D.A. has deferred implementation of the regulations on outdoor advertising, instead initiating a period of further review, including formal public comment, before issuing a Final Rule on this provision. (U.S. Food and Drug Administration, 2010)

In light of previous legal challenges and Court rulings, both Congress and the F.D.A. expected legal challenges to any new regulations and the text of the Family Smoking Prevention and Tobacco Control Act of 2009 and the 2010 F.D.A. Final Rule were drafted to reflect this. Both included extensive sections detailing the scientific evidence, particularly that which has emerged since the 1996 Final Rule, that materially supports the articles and regulations. As anticipated, multiple tobacco companies filed suit in District Court in Kentucky in 2009. The Plaintiffs in this still-ongoing case include a series of tobacco companies and retailers, though not Philip Morris or its parent company Altria. As discussed previously, Philip Morris has declared its support for the 2009 Act and F.D.A. regulation of cigarettes. Thus while it has been reported that the company feels the regulations are a violation of First Amendment protected commercial free speech, Philip Morris did not enlist as a plaintiff in this lawsuit. (Wilson, Tobacco regulation is expected to face free-speech challenge, 2009) The suit challenged almost all aspects of the 2009 Act (the 2010 F.D.A. Final Rule had not yet been issued at the time the suit was filed), including the component of the 1996 F.D.A. Final Rule banning outdoor advertising and billboards, as violating their First Amendment rights of commercial free speech and their Fifth Amendment rights of due process (Commonwealth Brands, Inc., et al. v. FDA et al. No. 1:09-CV-117-M). In his January 5, 2010 opinion, Judge J.H. McKinley, Jr. refused to rule on the ban on outdoor and billboard advertising declaring it "unripe" in light of the fact that this component was not included in the 2010 F.D.A. Final Rule and the F.D.A.'s active "Request for Comment" on this stipulation of the 2009 Act. (U.S. Food and Drug Administration, 2010) Further, the court overturned all aspects of the challenge except the black-and-white-text only ("tombstone") package label requirement and a provision disallowing tobacco companies claiming "safer" products in light of F.D.A. regulation; all other aspects of the 2009 Act, including the graphic warning label provisions, sponsorship bans, bans on promotional materials, and the 
removal of advertising preemption, were upheld by the Court. (Commonwealth Brands, Inc., et al. v. FDA et al. No. 1:09-CV-117-M), (Wilson, 2010), (Blackwell, 2010) The Court did grant injunctive relief to the tobacco companies as regards the "tombstone" labeling requirements, meaning that the F.D.A. cannot implement these provisions. The F.D.A. filed an appeal on March 8, 2010, and the tobacco companies have also filed an appeal of the decision. As this litigation is not yet complete, the final impact on tobacco control policy is not yet known.

The F.D.A., including the 2009 Act, is also currently being challenged by companies outside the traditional tobacco industry: Smoking Everywhere, Inc. and NJOY, makers of electronic cigarettes. In September and October 2008, the F.D.A. first held then detained two shipments of electronic cigarettes being imported by Smoking Everywhere, Inc. Between fall 2008 and spring 2009, the F.D.A. undertook a series of regulatory procedures and actions to list electronic cigarettes from a series of manufacturers, mostly based in China, as unapproved or misbranded drugs and so subject to immediate seizure. As series of shipments of NJOY products were seized in April 2009. In April 2009, Smoking Everywhere, Inc. (NJOY subsequently joined as a plaintiff) filed suit and a request for injunctive relief in the U.S. District Court in the District of Columbia. (Smoking Everywhere, Inc., and Sottera, Inc., d/b/a NJOY v. U.S. Food and Drug Administration et al. Civil Case No. 09-771 (RJL)) At the onset of the suit, the 2009 Act had not yet been implemented, though the FDA did file a supplemental brief on July 10, 2009. (U.S. Food and Drug Administration, 2009) On January 14, 2010, District Judge Richard J. Leon granted the Plaintiff's request for injunctive relief, meaning that the F.D.A. must allow these companies to import and sell their products. (Smoking Everywhere, Inc., and Sottera, Inc., d/b/a NJOY v. U.S. Food and Drug Administration et al. Civil Case No. 09-771 $(R J L))$ However, the F.D.A. filed an appeal of this ruling and a request for an immediate stay of the order for injunctive relief in February 2010, which was granted by the U.S. Court of Appeals for the District of Columbia in March 2010. (Smoking Everywhere, Inc., and Sottera, Inc., d/b/a NJOY v. U.S. Food and Drug Administration et al. No. 10-5032, 1:09-cv-00771-RJL) Thus, the current status of this case is that the F.D.A. may, at least temporarily, block the importation and sale of the electronic cigarettes. As this case proceeds, it is unclear whether the F.D.A. will ultimately seek to regulate electronic cigarettes as "reduced harm" tobacco products under the scope and authority of the Family Smoking Prevention and Tobacco Control of 2009 or as a drug / drug delivery device under the scope and authority of the broader Food, Drug, and Cosmetic Act as other nicotine-replacement products currently are regulated (News Staff, American Academy of Family Practitioners, 2010), or how the current product testing and 
analysis activities in which the F.D.A. is currently engaged will affect the final outcome of this case. (U.S. Food and Drug Administration, 2009)

\subsubsection{Suits Brought by the Government Against Tobacco Companies}

\subsubsection{Suits Challenging "Light" Cigarette Claims}

In contrast to cases where industry is seeking to limit the scope of government action through the courts, there are also cases in which individuals or governments are seeking to limit the scope of industry action through the courts. In a set of legal cases that involve package and advertising claims, are cases brought against tobacco companies based on the use of the terms "light" and "low tar" in the marketing and packaging of cigarettes. At issue has been "light", "low tar", and "ultralight" cigarettes, available since the late 1960s, that yield lower tar (7-14 mg and $<7 \mathrm{mg}$, respectively, compared to $22 \mathrm{mg}$ of tar per stick) per Federal Trade Commission mechanical smoking machine tests (under the Federal Cigarette Labeling and Advertising Act of 1965, the Federal Trade Commission is the federal agency responsible for package labeling standards) and which tobacco companies have implicitly marketed as being safer and assisting in cessation. (Rigotti \& Tindle, 2004) However, substantial scientific evidence has emerged identifying that the lower tar yield in "light" cigarettes is a function of the physical characteristics of these cigarettes (esp. position of microholes in the filter paper) that affect test results from mechanical smoking machine tests but are far less relevant in human use because smoker compensation (the statistically significant tendency of smokers of "light" cigarettes to inhale more deeply, puff more frequently, and smoke more often) results in the tendency of smokers of "light" cigarettes to have exposure to a higher - not lower - dose of tobacco-related carcinogens (Rigotti \& Tindle, 2004), (National Cancer Institute, 2004) despite the widespread belief by smokers of these products were reducing their risk. (Wilson, Weerasakera, Peace, Edwards, Thomson, \& Delvin, 2009), (Borland, et al., 2004), (Cummings, Hyland, Bansal, \& Giovino, 2004) Further, testimony during a recent Senate committee hearing highlighted an internal tobacco company memo from 1975 that discussed the inaccurate tar estimates from smoking machine tests and the understanding that smokers of "light" cigarettes were receiving the same if not higher dose of tar and nicotine. (Niemantsverdriet, 2007) Individual and class suits brought against tobacco companies for medical harm done based on the health claims of "light" cigarettes have typically been unsuccessful as tobacco companies have defended themselves against liability based primarily on the presence of package warning labels. However, a class suit filed in federal district court in Maine, Altria Group, In., et al. v. Good et al., sought economic damages (refund for products purchased plus putative damages and attorneys' fees) based on 
fraudulent advertising claims, not medical damages, under a state Unfair Trade Practices law. The tobacco companies sought to have the case dismissed, claiming that the state law was preempted by the Federal Cigarette Labeling and Advertising Act of 1965 and, as the companies had complied with relevant federal regulations, were thus protected from any claims based on state law. In December 2008, the U.S. Supreme Court upheld a lower court ruling that the state Unfair Trade Practices law was not expressly preempted by the federal law and remanded the case to lower court for trial. The full impact of this case on tobacco control policy remains unclear as Altria v. Good is not yet complete. However, the Supreme Court ruling is expected to result in multiple, subsequent suits seeking restitution for the economic - not health - damages of the fraudulent packaging claims of "light" cigarettes.

\subsubsection{Suit Brought by the Department of Justice}

The final case to be discussed is the very complex Department of Justice suit against the tobacco industry, United States of America v. Philip Morris U.S.A, Inc., et al., is the largest civil action in U.S. history. Originally filed in 1999 and supported by then-President Clinton, the suit lasted ten years including nine months of direct trial, hundreds of motions, multiple related rulings, thousands of orders, dozens of appeals, testimony from hundreds of expert witnesses, and countless millions of pages of filings, discovery documents, and supporting evidence. With such length and complexity, the details and case proscribe succinct summary. However, there were five critical aspects and rulings in the case (summarized from: United States of America $v$. Philip Morris U.S.A, Inc., et al., and (Fiore, Keller, \& Baker, 2005), (U.S. Department of Justice, Civil Division, 2007), (Public Health Law Center, 2010)). First, the main case was heard by a single Federal Judge, Judge Gladys Kessler. Second, the original suit was filed to seek restitution for tobacco-related Medicare expenses but, in an early ruling, the medical-expenses restitution component was disallowed though the Department of Justice was allowed to proceed under the Racketeer Influenced and Corrupt Organizations (RICO) Act. Third, the Department of Justice proceeded with the case constructed around the "seven pillars of fraud" enumerated as: a) Denying adverse health effects of cigarettes and exposure to environmental tobacco smoke; b) Perpetrating the deception that tobacco-industry sponsored research was independent; c) Denying that nicotine is addictive; d) Intentionally manipulating cigarette contents in order to maximize the delivery of a nicotine dose in order to create and sustain addiction; e) Intentionally marketing "light" cigarettes with knowing deception; f) Intentionally marketing to young people despite assertions and agreements to the contrary; and $\mathrm{g}$ ) Intentionally refusing to acknowledge or release knowledge about the health hazards of 
smoking. Fourth, in 2006 in an almost-1700 page opinion, Judge Kessler ruled that the Government had made its case, namely that the tobacco companies were guilty of knowingly perpetuating a 50-year fraud including the frauds outlined in the government's "seven pillars". Judge Kessler's ruling was unanimously upheld in May 2009 by a three-judge appeal panel. Fifth, despite a finding of guilt, Judge Kessler did not award any monetary damages to the government in light of an intermediary ruling that the R.I.C.O. statute only permits forwardlooking (to prevent and restrain future violations of the Act) and not backward-looking (putative damages or forfeit of ill-gotten gains) remedies. Thus, the only sanction imposed by Judge Kessler was the prohibition of any further use of deceptive marketing practices, including the use of the term "light", "low-tar", and to issue a series of public statements acknowledging their fraud and the health hazards of smoking. Finally, while both sides appealed both the verdict (tobacco companies) and penalties (government) to the U.S. Supreme Court, in June 2010 the U.S. Supreme Court declined to hear the case functionally signifying the end of the case. (Wilson D. , Supreme Court Rejects Appeals of Tobacco Ruling, 2010)

The case has not been without controversy, including accusations and suppositions that the Department of Justice's strategies and vigor were, at times, influenced by unclear political pressures. (Fiore, Keller, \& Baker, 2005) And, in the end, it is entirely unclear the effects that the ruling will have on either tobacco companies or tobacco control policy. Other than a tersely worded opinion, a Court record-of-facts, and the ruling that the First Amendment does not protect fraudulent claims, the inability of the Court to impose sanction other than something tantamount to a public apology has left some to question if the government's victory might be limited to a moral one. (Opinion, New York Times, 2006) 
11 APPENDIX 2: CURRICULUM VITAE (FRISBEE, STEPHANIE J) 


\title{
STEPHANIE J FRISBEE, MSc, MA, PhD (Cand.)
}

ADDRESS

West Virginia University School of Medicine

Robert C. Byrd Health Sciences Center

1 Medical Center Drive - PO Box 9105

Morgantown, WV 26506-9105

Phone: 304-293-6552 • FAX: 304-293-5513 - E-Mail: sfrisbee@hsc.wvu.edu

\section{CURRENT PROFESSIONAL POSITION}

Primary Appointment

2010 - Present

Research Instructor

Adjunct Appointment

2007 - Present

Additional Affiliation

2004 - Present

Additional Duties

2010 - Present
Department of Community Medicine, West Virginia University School of Medicine

Clinical Assistant Professor

Department of Dental Practice \& Rural Health, West Virginia University School of Dentistry

Center for Cardiovascular and Respiratory Sciences

Assistant Copy Editor

Microcirculation (Wiley-Blackwell Publishing, John Wiley \& Sons, Inc.)

\section{PREVIOUS PROFESSIONAL POSITIONS}

\author{
$2006-2010$ \\ $2004-2006$ \\ $2002-2004$ \\ $2000-2002$ \\ $1999-2000$ \\ $1997-1999$ \\ Research Instructor \\ Department of Community Medicine, West Virginia University School of Medicine \\ Morgantown, WV \\ Research Instructor \\ Department of Pediatrics, West Virginia University School of Medicine \\ Morgantown, WV \\ Outcomes Manager \\ Outcomes Department, Children's Hospital of Wisconsin \& \\ National Outcomes Center, Inc., Children's Hospital and Health System \\ Milwaukee, WI \\ Outcomes Coordinator \\ Quality and Outcomes Management, Children's Hospital of Wisconsin \\ Milwaukee, WI \\ Outcomes Research Analyst \\ Center for Outcomes Research and Quality Management, Children's Hospital of \\ Wisconsin \\ Milwaukee, WI \\ Research \& Administrative Assistant \\ Department of Pediatrics (Emergency Medicine), Medical College of Wisconsin \\ Milwaukee, WI \\ 1997 \\ Program Manager \\ Department of Bioengineering, University of Washington \\ Seattle, WA
}




\section{EDUCATION}

2006 - Present

2009

1996

1994
Doctorate in Philosophy, Public Policy Analysis

Policy Field of Emphasis: Health Policy

Dissertation Title: "Comprehensive Tobacco Control Policy Regimes and

Population Health: Assessing Causal Loops"

Department of Political Science, West Virginia University, Morgantown, WV

(Candidate 2009; Anticipated Graduation 2010)

Master of Arts, American Public Policy \& Politics

Department of Political Science, West Virginia University, Morgantown, WV

Master of Science, Consumer Policy \& Affairs

University of Guelph, Guelph, Ontario

Thesis Title: "An Economic Analysis of the Factors Affecting the Demand for Skiing by Two Adult Canadian Households"

Bachelor of Science, Honors Biomedical Sciences

University of Guelph, Guelph, Ontario

\section{CONTINUING EDUCATION AND PROFESSIONAL DEVELOPMENT}

2007

2004

2003

American Heart Association

$33^{\text {rd }} 10-$ Day Seminar on the Epidemiology and Prevention of Cardiovascular Disease

July 29 - August 10, 2007

Tahoe City, CA

MRA Management Association, Waukesha, WI

- Principles of Management Certificate Series (Managing Relationships and Building Trust; Delegation and Motivation Techniques; Effective Communication and Performance Management; Dealing with Difficult People and Discipline; Problem Solving Skills, Training and Coaching)

- Effective Hiring and Interviewing Techniques

- Facilitation Skills

- Project Management: The Human and Technical View

- Emotional Leadership: The Overlooked Element

MRA Management Association, Waukesha, WI

- Leading Effective Teams Certificate Series (Foundation for Leading Teams; Communicating with Your Teammates; Keeping Your Teammates on Track; Managing Conflict in Your Team)

- Supervisor and the Law

Franklin Covey Training Seminars

- FOCUS Time Management Seminar

\section{PROFESSIONAL MEMBERSHIPS}

2009 - Present

2004 - Present

$2004-2006$
American Political Science Association

- Section on Health Politics and Policy, Section on Public Administration, Section on Comparative Politics, Section on Canadian Politics

American Heart Association (Professional)

- Council on Epidemiology and Prevention, Council on Quality of Care \& Outcomes Research

North American Society for the Study of Obesity (Professional)

\section{AWARDS AND SCHOLARSHIPS}

2010

Five Year Service Award

West Virginia University, Morgantown, WV 
2004

2002

2002

1998

$1994-1996$

$1994-1996$

1991

$1990-1993$

1990

1990 - 1994

\section{TEACHING}

2010

2010

2010

Key Contribution Award

Children's Hospital of Wisconsin, Milwaukee, WI

Award of Merit for "Children's Hospital of Wisconsin Heart Center Outcomes Report"

Wisconsin Healthcare Public Relations and Marketing Society

Key Contribution Award

Children's Hospital of Wisconsin, Milwaukee, WI

Best Paper Award for: "Frisbee SJ and Frisbee WR. The demand for skiing among working two-adult households."

Tourism and Hospitality Management Division, Administrative Sciences Association of Canada Annual Meeting, Saskatoon, Saskatchewan, 1998

University of Guelph Dorothy Britton Memorial Graduate Scholarship

University of Guelph Graduate Student Assistantship

Natural Science and Engineering Research Council Summer Research Scholarship

Natural Science and Engineering Research Council Canada Scholarship

Easter Seals Research Institute Summer Research Studentship

University of Guelph President's Scholarship

PUBH691 Bioinformatics and Personalized Medicine

Fall 2010

West Virginia University School of Medicine, Department of Community Medicine

- Lecturer (2-lecture series "Biomarkers for Risk Assessment of Environmental Exposure"); Lan Guo, PhD, Instructor of Record and Course Coordinator

PUBH7062 Current Research Issues

Fall 2010

West Virginia University School of Medicine, Department of Community Medicine

- Lecturer (1 lecture "Overview of Ongoing Research Foci"); Rachel Abraham, $M D, M P H$, Instructor of Record and Course Coordinator

PUBH630 Policy \& the Health System

Spring 2010

West Virginia University School of Medicine, Department of Community Medicine

- Instructor (Instructor of Record, sole \& lead instructor), curriculum development

\section{SERVICE}

Students Supervised

$2007-2008$

Babina Gosinga MBBS

- Member, MPH Practicum Committee

$2007-2008$

Miriam Mutambudzi, BA

- Ad Hoc Advisor, MPH Practicum

\section{Editorial Duties}

2010 - Present

Wiley-Blackwell Publishing, John Wiley \& Sons, Inc.

Hematology Journals Group (British Journal of Hematology, International Journal of Laboratory Hematology, Haemophilia, Vox Sanguinis, Microcirculation, Transfusion Medicine)

- Statistical Review Editor 


$$
2010 \text { - Present }
$$

\section{Manuscript Reviewer} 2010

2010

2010

2010

2009 - Present

2009 - Present

2009 - Present

2007 - Present

2006 - Present

2004 - Present

Institutional

2008

2007

2005

1998

\section{Community}

$2001-2004$
Microcirculation

- Member, Editorial Board

Journal of Primary Care and Community Health

Diabetes / Metabolism Research and Reviews

Environmental Science and Technology

European Journal of Public Health

Metabolism Clinical and Experimental

Journal of Dental Research

Diabetic Medicine

Microcirculation

Diabetes Care

Injury Prevention

2008 WVU Health Sciences Center E. J. Van Liere Research Day

- Judge, Poster Presentations

2007 WVU Health Sciences Center E. J. Van Liere Research Day

- Judge, Poster Presentations

Health Sciences and Technology Academy (HSTA) $11^{\text {th }}$ Annual Science Symposium

- Presider, Oral Presentations

Medical College of Wisconsin, Department of Pediatrics Website Development Committee

- Programmer, Emergency Medicine Section Website

Fight Asthma Milwaukee - Allies Coalition

- Co-Chair, Surveillance and Evaluation Committee

\section{FUNDED GRANTS AND CONTRACTS}

\section{Grants}

2010-2012

2009

$2008-2010$
National Institutes of Health, National Institute of Environmental Health Sciences, Centers for Children's Environmental Health \& Disease Prevention Research 1R21ES019236 "Associations between Non-8-Carbon-Chain Perfuoroalkyl Acids and Serum Lipid, Liver, and Kidney Parameters in Children"

- Principal Investigator

West Virginia University School of Dentistry Seed Grant

"Analyses of Inflammatory Markers Among Older Adults in West Virginia"

Bei Wu, PhD, Principal Investigator

- Co-Investigator

West Virginia University

Faculty Senate Award R-08-004

"Does the Perceived Quality of Life and Health State Utility Predict Treatment Adherence and Outcome in Patients with Coronary Artery Disease?"

Maurice Moffett, PhD, Principal Investigator

- Co-Investigator

[Note: Grant relinquished 8-2008 when PI relocated another institution.] 
$2007-2011$

$2005-2006$

$2003-2004$

$2003-2004$

$2003-2004$

$2002-2004$

$2001-2004$

$2000-2003$

\section{Contracts}

$2006-2008$

$2006-2007$

$2006-2007$
American Heart Association

National Center Established Investigator Award 0740129N

"Hypercholesterolemia and Microvascular Rarefaction: Translational Initiative from Mice to Humans"

Jefferson C. Frisbee, PhD, Principal Investigator

- Co-Investigator

Centers for Disease Control and Prevention

Special Interest Project Competitive Supplement "9-2005: Network for Cardiovascular Health Intervention Research and Translation NetworkCollaborating Center"

- $\quad$ Project Director

Commonwealth Fund \& Robert Wood Johnson Foundation

"Parent Mentors and Reducing Childhood Asthma Morbidity"

Glenn Flores, MD, Principal Investigator and Project Director

- Sub-contract: cost analysis

Agency for Health Care Research and Quality

"Bar Coding Technology and Patient and Employee Safety"

Ben-Tzion Karsh, MD, Principal Investigator and Project Director

- Sub-contract: data collection

Children's Hospital and Health System Foundation Grants

- "Quality of Life After Pediatric Trauma" (Andrea Winthrop, MD, Project Director)

- "Acupuncture Treatment for Fibromyalgia" (Lynn Rusy, MD, Project Director)

- "Extubation in Patients with Altered Mental Status" (Kelly Tieves, MD, Project Director)

- Sub-contracts for all projects: data collection, management, and statistical analysis

Robert Wood Johnson Foundation and American Academy of Allergy, Asthma and Immunology

"Emergency Department Allies: Managing Pediatric Asthma"

Kevin J. Kelly, MD, Principal Investigator and Project Director

- Sub-contract: study design, quality control, and analysis

Robert Wood Johnson

"Milwaukee Allies Against Asthma"

John R. Meurer, MD, MM, Principal Investigator and Project Director

- Sub-contract: study design, data quality control and analysis, community disease burden surveillance

Department of Health and Human Services Maternal Child Health Bureau "An EMSC-Based Violence Intervention/Prevention Program Evaluation with Cost-Benefit Implications"

Marlene Melzer, MD, Principal Investigator

- $\quad$ Sub-contract: biostatistician, study design, quality control, and analysis

Brookmar Inc., C8 Health Project Settlement Fund "WVU C8 Health Project Data Hosting"

- Project Manager, Scientist

Brookmar Inc., C8 Health Project Settlement Fund

"Chronicle and Public Opinion Services for Brookmar C8 Health Project"

- $\quad$ Project Coordinator, Analyst

Brookmar Inc., C8 Health Project Settlement Fund

"Description and Estimated Population Health Impact of Medical Surveillance"

- Project Coordinator, Analyst 


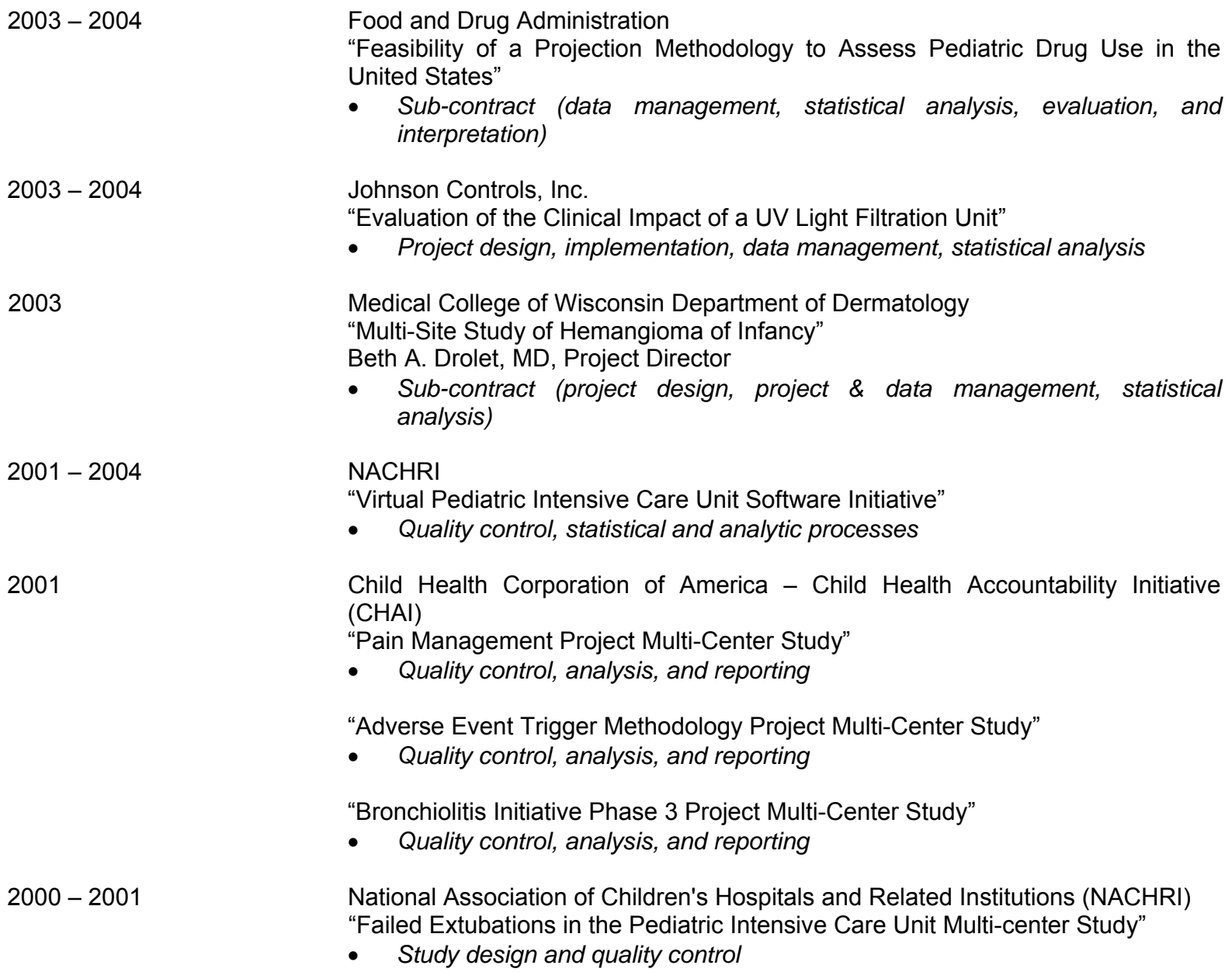

Child Health Corporation of America - Child Health Accountability Initiative (CHAI)

"Pain Management Project Multi-Center Study"

- Quality control, analysis, and reporting

"Adverse Event Trigger Methodology Project Multi-Center Study"

- Quality control, analysis, and reporting

"Bronchiolitis Initiative Phase 3 Project Multi-Center Study"

- Quality control, analysis, and reporting

National Association of Children's Hospitals and Related Institutions (NACHRI)

"Failed Extubations in the Pediatric Intensive Care Unit Multi-center Study"

- Study design and quality control

\section{INVITED PRESENTATIONS External \\ 2010}

2009

2009

2008
"Correlations between chronic depression and peripheral vascular function: a translational approach" with Beckett JAL [Presenter], Stapleton PA, Goodwill AG, d'Audiffret AC, Frisbee SJ, Frisbee JC. June 16-18, 2010, Bethesda, MD

NIH, NCRR $3^{\text {rd }}$ Biennial National IDeA Symposium of Biomedical Research Excellence (NISBRE)

"Health Care Policy Forum" October 21, 2009, Morgantown, WV WVU Young Democrats and WVU Student Government Association; Forum Panelist \& Speaker

"Misconceptions about the US and Canadian Health Care Systems" September 25, 2009, Morgantown, WV 2009 Conference of the West Virginia Political Science Association, West Virginia Chapter of the APSA, and the West Virginia University MPA Students; Panel on "The National Healthcare Dilemma"; Forum Panelist \& Speaker

"The C8 Health Project: How a Class Action Law Suit Can Interact with Public Health - History of Events"

May 7, 2008, Morgantown, WV

Community Medicine Public Health Grand Rounds; Speaker 
"The Epidemiology of Cardiovascular Disease Risk Factors in West Virginia School Children: Results from the CARDIAC Project"

National Institute for Occupational Safety and Health, Morgantown, WV Invited Presentation Speaker

"Relationship between economic conditions and cardiovascular disease risk factors in West Virginia school children: Results from the CARDIAC Project" with Frisbee SJ [Presenter], Cottrell L, Elliott E, Minor V, Spangler-Murphy E, Neal WA.

American Heart Association 2005 Scientific Sessions Meeting Dallas, TX Special Emphasis Panel - "Measures and Models: Health Policy and Outcomes Research"

"Correlations Between Peripheral Vascular Function, Inflammation, and Depression in Human Subjects" with Stapleton PA [Presenter], d'Audiffret AC, Goodwill AG, Frisbee SJ, Frisbee JC.

West Virginia University School of Dentistry / West Virginia Association of Academic Dental Research Sixteenth Annual Research Day; Invited Poster Presentation

"Peripheral Vascular Dysfunction, Systemic Inflammation and Markers of Clinical Depression in Human Subjects" with Stapleton PA [Presenter], d'Auddifret AC, Goodwill AG, James ME, Frisbee SJ, Frisbee JC.

West Virginia University School of Medicine van Liere Research Day 2009; Invited Poster Presentation

"Social Choices in Health \& Health Care: Comparing Canada and the United States"

West Virginia University School of Medicine, Department of Community Medicine - PUBH617 Ethical \& Legal Issues in Public Health, Section on Justice \& Health Care; Invited Lecturer \& Panel Discussant

"Chronic Inflammation, Cardiovascular Disease, and Dental Health: Developing Community-Based Translational Research Projects"

West Virginia University School of Dentistry / West Virginia Association of Academic Dental Research Twelfth Annual Research Day; Invited Presentation

"Factors Influencing the Development of Cardiovascular Disease in West Virginia Children"

West Virginia University School of Medicine, Center for Interdisciplinary Research in Cardiovascular Sciences; Monthly Seminar Series

"Outcomes Measurement, Evaluation and Research at Children's Hospital of Wisconsin"

Medical College of Wisconsin, Department of Pediatrics (Urology); Invited Presentation Speaker

"Designing a Clinical Research Study" Children's Hospital of Wisconsin, Cardiovascular Research Focus Meeting; Invited Presentation Speaker

"Statistical Design and Analysis"

Children's Hospital of Wisconsin, Nursing Research Interest Group; Invited Presentation Speaker 


\section{PEER-REVIEWED PUBLICATIONS}

\section{Conference Abstracts, Posters, and Oral \& Paper Presentations}

Kini NM, Meurer J, Malloy ME, Frisbee SJ, Siewert J. After hours nurse triage system identifies inner-city children who are in need of a medical home. Pediatric Academic Societies' 1998 Annual Meeting. New Orleans, LA: May 1998. [Poster]

Kini NM, Robbins JM, Kotagal RU, Kirschbaum MS, Frisbee SJ, for the Child Health Accountability Initiative. Inpatient care for uncomplicated bronchiolitis: comparison to Milliman \& Robertson recommendations. Year 2000 Pediatric Academic Societies and American Academy of Pediatrics Joint Meeting. Boston, MA: May 2000. [Poster]

Sachdeva RC, Tweddell JS, Mussatto KA, Frisbee SJ, Otto M, Pelech AN, Litwin SB. The use of PRISM score to predict outcomes for pediatric patients with right ventricular outflow tract homograft valve replacement. Midwest Pediatric Cardiology Society Meeting. Milwaukee, WI: June 2000. [Poster]

Sachdeva RC, Frisbee SJ, Stahovic LL, Wegner C, Rice TB. Quality of life measurements in technologically dependent children with special health care needs. 22nd Annual Meeting of the Society for Medical Decision Making. Cincinnati, OH: September 2000. [Poster]

Rice TB, Frisbee SJ, Wegner C, Stahovic LL, Sachdeva RC. Risk factors for long-term outcomes in pediatric patients with tracheostomy. CHEST 2000 Annual Meeting. San Francisco, CA: October 2000. [Poster]

Fedderly RT, Whitstone BN, Frisbee SJ, Tweddell JS, Litwin SB. Factors related to pleural effusions after the Fontan procedure in the era of fenestration. American Heart Association 73rd Scientific Sessions. New Orleans, LA: November 2000. (Circulation. 2000;102(Suppl II):745.) [Poster]

Rice TB, Frisbee SJ, Wegner C, Stahovic LL, Sachdeva RC. Outcomes for a trach/vent program: a 23year experience. American Academy of Pediatrics 2000 Annual Meeting. Chicago, IL: November 2000. [Poster]

Mussatto KA, Tweddell JS, Frisbee SJ, Sachdeva RC, Emmons V, Pelech AN, Litwin SB. The use of PedsQL to assess health related quality of life in pediatric patients with right ventricular outflow tract homograft valve replacement. Society of Critical Care Medicine 30th International Educational and Scientific Symposium. San Francisco, CA: February 2001. [Poster]

Sachdeva RC, Tweddell JS, Mussatto KA, Frisbee SJ, Otto M, Pelech AN, Litwin SB. The use of PRISM-II score to predict outcomes for pediatric patients with right ventricular outflow tract homograft valve replacement. Society of Critical Care Medicine 30th International Educational and Scientific Symposium. San Francisco, CA: February 2001. [Poster]

Sachdeva RC, Twedell JS, Frisbee SJ, Mussatto KA, Emmons V, Pelech AN, Litwin SB. Evaluation of a quality of life technique to evaluate outcomes of children with right ventricular outflow tract homograft valve replacement. Society of Critical Care Medicine 30th International Educational and Scientific Symposium. San Francisco, CA: February 2001. [Poster]

Wegner C, Sachdeva RC, Stahovic LL, Frisbee SJ, Rice TB. The family of a child with technology dependence: an outcomes study using the Impact on Family Scale. Society for Pediatric Nurses Annual Conference. New Orleans, LA: April 2001. [Poster]

Berger S, Whitstone BN, Frisbee SJ, Bauer K, Dhala A, Ellis D, Pirallo RG, Pukansky L, Wolkenheim BJ, Sachdeva RC. A cost-effectiveness analysis of Project A.D.A.M. (Automatic Defibrillators in Adam's Memory) for high schools in the Milwaukee Public School District. The 3rd World Congress of Pediatric Cardiology and Cardiac Surgery (PCCS 2001). Toronto, Ontario: May 2001. [Poster]

Whitstsone BN, Frommelt MA, Brosig C, Frisbee SJ, Leuthner S. The impact of prenatal versus postnatal diagnosis on psychological distress in parents of children with severe congenital heart disease. The 3rd World Congress of Pediatric Cardiology and Cardiac Surgery (PCCS 2001). Toronto, Ontario: May 2001.

Rudd NA, Zlotocha JR, Mussatto KA, Frisbee SJ, Pelech AN, Frommelt PC. Growth velocity of infants with hypoplastic left heart syndrome: a comparison of enteral feeding strategies. The 3rd World Congress of Pediatric Cardiology and Cardiac Surgery (PCCS 2001). Toronto, Ontario: May 2001. [Poster]

Brosig C, Whitstone B, Frommelt M, Frisbee SJ, Leuthner S. Psychological distress in parents of children with severe congenital heart disease: the impact of prenatal versus postnatal diagnosis. Great Lakes Regional Meeting on Child Health Psychology. Milwaukee, WI: May 2002. [Poster]

Weisman SJ, Currier KL, Frisbee SJ, Throop C, Sachdeva RC. Pediatric pain management: effective practices in a multi-site collaborative for post-surgical patients. International Association for the Study of Pain 10th World Congress. San Diego, CA: August 2002. [Poster]

Meurer JR, Kramer K, Allerson L, Frisbee SJ, Ebert DA, Urban M, Carr R, Navon L, Fiore B. Appropriate asthma medication use by children in Wisconsin Medicaid. Wisconsin Public Health and Health Policy Institute 4th Conference. Madison, WI, October 2003. [Poster]

Winthrop AL, Brasel KJ, Stahovic L, Paulson J, Schneeberger B, Kuhn E, Frisbee SJ. Quality of life and functional outcome after pediatric trauma. J Trauma. 2004; 57(2):\#446. [Poster]

Rice TB, Frisbee SJ, Sachdeva RC. Information systems build capacity to improve patient care. NACHRI 2004 Annual Meeting. Fort Lauderdale, FL: October 2004. [Poster] 
McGrosky M, Frisbee SJ, Neal WA. Office-based obesity prevention program: West Virginia Providers on the Move. American Heart Association 45th Annual Conference on Cardiovascular Disease Epidemiology and Prevention. Washington, DC: April 2005. Circulation. 2005; 111: e184-e296. [Poster]

Frisbee SJ, Cottrell L, Elliott E, Minor V, Spangler-Murphy E, Neal WA. Epidemiology of obesity, hypertension, hyperlipidemia and insulin resistance in West Virginia school children: six years of the CARDIAC Project. American Heart Association 45th Annual Conference on Cardiovascular Disease Epidemiology and Prevention. Washington, DC: April 2005. Circulation. 2005; 111: e184-e296. [Poster]

Frisbee SJ, Cottrell L, Elliot E, Minor V, Spangler-Murphy E, Neal WA. Relationship of birthweight to obesity, hypertension, and dyslipidemia in pre-adolescents: results from the CARDIAC Project. North American Association for the Study of Obesity (NAASO) Annual Meeting, Vancouver, BC, October 2005. [Poster]

Frisbee SJ, Cottrell L, Elliot E, Minor V, Spangler-Murphy E, Neal WA. Obesity, hypertension, and dyslipidemia, and the metabolic syndrome in West Virginia school children: 7 years of the CARDIAC Project. North American Association for the Study of Obesity (NAASO) Annual Meeting, Vancouver, BC, October 2005. [Poster]

Cottrell LA, Minor V, Spangler Murphy E, Tillis G, Frisbee SJ, Nicholson P, Neal WA. The power of perception: parental estimates of their children's weight, their perceived abilities, and opportunities. North American Association for the Study of Obesity (NAASO) Annual Meeting, Vancouver, BC, October 2005. [Poster]

Frisbee SJ, Cottrell L, Elliott E, Minor V, Spangler-Murphy E, Neal WA. Relationship between economic conditions and cardiovascular disease risk factors in West Virginia school children: Results from the CARDIAC Project. American Heart Association Annual Scientific Sessions Meeting, Dallas, TX, November 2005. [Oral Presentation, Panel: "Measures and Models: Health Policy and Outcomes Research"]

Frisbee SJ, Goodwill AG, Boegehold MA, Neal WA, Frisbee JC. Altered patterns of inflammatory marker expression in plasma of obese vs dyslipidemic humans. North American Association for the Study of Obesity (NAASO) 2006 Annual Meeting, Boston, MA, October 2006. [Poster]

Frisbee SJ, Halverson JA, Neal WA. Changes in obesity and factors related to its increase in West Virginia school children. North American Association for the Study of Obesity (NAASO) 2006 Annual Meeting, Boston, MA, October 2006. [Poster]

Frisbee SJ, Leyden KM. Neighborhood characteristics and overweight in families in rural communities. North American Association for the Study of Obesity (NAASO) 2006 Annual Meeting, Boston, MA, October 2006. [Poster]

Frisbee SJ. Self esteem, self and body image, quality of life and overweight in children in rural communities. North American Association for the Study of Obesity (NAASO) 2006 Annual Meeting, Boston, MA, October 2006. [Poster]

Frisbee JC, Goodwill AG, Frisbee SJ. Inflammation, nitric oxide bioavailability and the metabolic syndrome: interactions leading to microvascular rarefaction. Workshop on Mathematical Modeling of Microcirculation; Mathematical Biosciences Institute, Ohio State University, Columbus, OH, October 2007. [Poster]

Frisbee SJ, d'Audiffret A, Frisbee JC. The relationship between depressive symptoms, cardiovascular disease risk factors, and inflammation in rural communities. American Heart Association, 47th Annual Conference on Cardiovascular Disease Epidemiology and Prevention in association with the Council on Nutrition, Physical Activity, and Metabolism, Orlando, FL, Feb. 2007. Circulation. 2007;115:e214-e301 (P256). [Poster]

Frisbee SJ, Muller-Delp JM, Goodwill AG, Frisbee JC. Influences of Age and Gender on Cardiovascular Disease Risk Factor Associated Inflammation. American Heart Association, 47th Annual Conference on Cardiovascular Disease Epidemiology and Prevention in association with the Council on Nutrition, Physical Activity, and Metabolism, Orlando, FL, Feb. 2007. Circulation. 2007;115:e214-e301 (P117). [Poster]

Chambers CB, Frisbee SJ, Frisbee JC, Crout RJ. Dental health, cardiovascular disease and inflammation in adults and children. International Association for Dental Research and American Association for Dental Research 87th General Session and Exhibition, New Orleans, LA, March 2007. [Oral Presentation, Panel: "Oral Health and Quality of Life Issues"]

Mujuru P, Frisbee SJ, Dey RD. Relationship between lung function, obesity, and systemic inflammation in a rural community cohort. American Thoracic Society 2007 International Conference. San Francisco, CA, May 2007. [Poster Presentation, Session: "Poster Discussion Session A23 - Obesity and Pediatric Respiratory Disease"]

Frisbee SJ, Mujuru P, Dey RD. Relationship between depressive symptoms and lung function in a rural community cohort. American Thoracic Society 2007 International Conference. San Francisco, CA, May 2007. [Poster]

Frisbee JC, James ME, Muller-Delp JM, Frisbee SJ. HMG-CoA reductase inhibitors improve microvascular outcomes in the metabolic syndrome independent of plasma cholesterol profile. Federations for the American Societies of Experimental Biology (FASEB) Annual Experimental Biology 2007 Meeting. Washington, DC, April 2007. FASEB Journal. 2007;21:742.5. [Poster]

Frisbee SJ, Chambers CB, Frisbee JC, Goodwill AG, Crout RJ. Dental habits related to adult cardiovascular disease and systemic inflammation. American Association for Dental Research 37th Annual Meeting and Exhibition, Dallas, TX, April 2008. [Poster] 
Chambers CB, Frisbee SJ, Frisbee JC, Goodwill AG, Crout RJ. Dental health, cardiovascular disease risk, and systemic inflammation in children. American Association for Dental Research 37th Annual Meeting and Exhibition, Dallas, TX, April 2008. [Oral Presentation, Panel: "Oral and Systemic Health"]

Frisbee JC, Goodwill AG, Stapleton PA, James ME, Bryner RW, Frisbee SJ. Metabolic syndrome and microvascular rarefaction: contributions from nitric oxide and inflammation. $25^{\text {th }}$ Conference of the European Society for Microcirculation, Budapest, Hungary, August 2008. [Poster]

Frisbee JC, Goodwill AG, James ME, Bryner RW, Frisbee SJ. Microvascular adaptations to obesity and the metabolic syndrome. 2008 American Physiologic Society Intersociety Meeting: The Integrative Biology of Exercise V, Hilton Head, SC, September 2008. The Physiologist, December 2008. [Poster]

Frisbee JC, Goodwill AG, James ME, Brock RW, Hollander JM, Frisbee SJ. Development of a predictive model for negative microvascular outcomes in the metabolic syndrome. Federations for the American Societies of Experimental Biology (FASEB) Annual Experimental Biology 2009 Meeting. New Orleans, LA, April 2009. FASEB Journal. 2009;23:594.11. [Poster]

Stapleton PA, d'Audiffret AC, Frisbee SJ, Goodwill AG, James ME, Frisbee JC. Correlations between peripheral vascular function, inflammation, and depression in human subjects. Federations for the American Societies of Experimental Biology (FASEB) Annual Experimental Biology 2009 Meeting. New Orleans, LA, April 2009. FASEB Journal. 2009;23:795.3. [Oral Presentation]

Studlar DT, Christensen K, Frisbee SJ. The impact of tobacco control polices in the EU: comparing old and new member states. Proceedings from the European Union Studies Association $11^{\text {th }}$ Biennial International Conference, Los Angeles, April 2009. Available at: http://www.unc.edu/euce/eusa2009/papers/studlar 07B.pdf. [Paper Presentation]

Mujuru P, Salana HK, Frisbee SJ. Does biomechanical body structures of weight in obese subjects impede physiological breathing patterns? A cross-sectional study. $137^{\text {th }}$ American Public Health Association Annual Meeting, Philadelphia, PA, November 2009. [Oral Presentation, Section 5156.0 Epidemiology of Obesity]

Goodwill AG, Stapleton PA, Frisbee SJ, James ME, Frisbee JC. Increased vascular generation of thromboxane $A_{2}$ : an initiating condition for microvascular rarefaction in obese Zucker rats? Federations for the American Societies of Experimental Biology (FASEB) Annual Experimental Biology 2010 Meeting. Anaheim, CA, April 2010. FASEB J. 24: 774.19. [Poster]

Frisbee SJ, Studlar DT. Is U.S. tobacco control policy really bottom-up? Federal aid for local tobacco control coalitions. American Political Science Association 2010 Annual Meeting and Exhibition. Washington, DC, September 2010. [Poster]

Goodwill AG, Stapleton PA, Frisbee SJ, Frisbee JC. Obesity-induced increased vascular thromboxane $A_{2}$ generation: an initiating stimulus for microvascular rarefaction? $9^{\text {th }}$ World Congress for Microcirculation. Paris, France, September 2010. [Poster]

Frisbee JC, Goodwill AG, Stapleton PA, Frisbee SJ, d'Audiffret AC. Aspirin resistance with genetic dyslipidemia: contribution of vascular thromboxane generation. $9^{\text {th }}$ World Congress for Microcirculation. Paris, France, September 2010. [Poster] [Subsequently selected for featured oral presentation]

\section{Manuscripts}

Frisbee SJ, Frisbee WR. The demand for skiing among working two-adult households. Proceedings of the Administrative Sciences Association of Canada. 1998.

Hennes H, Frisbee SJ, Paddon KJ, Walsh-Kelly CM. Current income profile for academic pediatric emergency medicine faculty in the United States. Pediatric Emergency Care. 1999;15(5):350-354.

Frisbee SJ, Hennes H. Infant back carriers: A potential risk for injury. Injury Prevention. 2000;6:56-58.

Fedderly RT, Whitstone BN, Frisbee SJ, Tweddell JS, Litwin SB. Factors related to pleural effusions after the Fontan procedure in the era of fenestration. Circulation. 2001;104(12 Suppl 1):I148-I151.

Frisbee SJ, Malloy ME, Meurer J, Kuhagen KA, Kini NM. Urban Wisconsin pediatric patients using an after-hours telephone triage service: outcomes and compliance. Wisconsin Medical Journal. 2001;100(5):55-58.

Kini NM, Robbins JM, Kirschbaum MS, Frisbee SJ, Kotagal UR for the Child Health Accountability Initiative. Inpatient care for uncomplicated bronchiolitis: comparison to Milliman and Robertson guidelines. Archives of Pediatrics and Adolescent Medicine. 2001;155(12):1323-1327.

Tweddell JS, Hoffman GM, Mussatto KA, Fedderly RT, Berger S, Jaquiss RDB, Ghanayem NS, Frisbee SJ, Litwin SB. Improved survival of patients undergoing palliation of hypoplastic left heart syndrome: lessons learned from 115 consecutive patients. Circulation. 2002 Sep 24;106(12 Suppl 1):I82-9.

Ghanayem NS, Hoffman GM, Mussatto KA, Cava JR, Frommelt PC, Rudd NA, Steltzer MM, Bevandic SM, Frisbee SS, Jaquiss RD, Litwin SB, Tweddell JS. Home surveillance program prevents interstage mortality after the Norwood procedure. Journal of Thoracic and Cardiovascular Surgery. 2003 Nov;126(5):1367-77.

Beger S, Whitstone BN, Frisbee SJ, Miner JT, Dhala A, Pirrallo RG, Sachdeva RC. Cost-effectiveness of Project ADAM: a project to prevent sudden cardiac death in high school students. Pediatric Cardiology. 2004 Jan 28. 
Brosig CL, Whitstone BN, Frommelt MA, Frisbee SJ, Leuthner SR. Psychological distress in parents of children with severe congenital heart disease: the impact of prenatal versus postnatal diagnosis. Journal of Perinatology. 2007; Aug 23.

Velan SS, Said N, Durst C, Frisbee S, Frisbee J, Raylmann RR, Thomas MA, Rajendran VM, Spencer RG, Alway SE. Distinct patterns of fat metabolism in skeletal muscle of normal-weight, overweight, and obese humans. American Journal of Physiology - Regulatory, Integrative, and Comparative Physiology. 2008;295(4):R10601065.

Goodwill AG, Frisbee SJ, Stapleton PA, James ME, Frisbee JC. Impact of chronic anti-cholesterol therapy on development of microvascular rarefaction in the metabolic syndrome. Microcirculation. 2009;16(8):667-684.

Steenland K, Tinker S, Frisbee S, Ducatman A, Vaccarino V. Association of perfluorooctanic acid (PFOA) and perfluoroctanesulfonate (PFOS) with serum lipids among adults living near a chemical plant. American Journal of Epidemiology. 2009;170(10):1268-1278.

Frisbee SJ, Brooks AP, Maher A, Flensborg P, Arnold S, Fletcher T, Steenland K, Shankar A, Knox SS, Pollard C, Halverson JA, Vieira VM, Jin C, Leyden KM, Ducatman AM. 2009. The C8 Health Project: Design, Methods, and Participants. Environmental Health Perspectives. 2009;117(12):1873-1882.

d'Audiffret AC, Frisbee SJ, Stapleton PA, Goodwill AG, Isingrini E, Frisbee JC. Depressive behavior and vascular dysfunction: a link between clinical depression and vascular disease? Journal of Applied Physiology. 2010;108:1041-1051. [Selected for highlighted editorial focus in both the Journal of Applied Physiology and Physiology]

Frisbee SJ, Shankar A, Knox SS, Steenland K, Fletcher T, Savitz DA, Ducatman AM. Perfluorooctanoic acid, perfluorooctanesulfonate, and serum lipids in children and adolescents: results from the C8 Health Project. Archives of Pediatrics and Adolescent Medicine. 2010;164(9):860-869. [Selected for editorial focus]

Frisbee JC, Goodwill AG, Stapleton PA, Frisbee SJ, d'Audiffret AC. Aspirin resistance with genetic dyslipidemia: contribution of vascular thromboxane generation. Physiological Genomics. 2010;42(3):331-341.

Frisbee SJ, Chambers C, Frisbee JC, Goodwill AG, Crout RJ. Self-Reported Dental Hygiene and Health, Obesity, and Systemic Inflammation in a Pediatric Rural Community Cohort. BMC Oral Health. 2010;10 (Sept 18):21.

Nurkiewicz TR, Porter DW, Hubbs AF, Stone S, Moseley AM, Cumpston JL, Goodwill AG, Frisbee SJ, Perrotta PL, Brock RW, Frisbee JC, Boegehold MA, Frazer DG, Chen BT, Castranova V. Pulmonary particulate matter and systemic microvascular dysfunction. Health Effects Institute. [Accepted, 2009.]

Frisbee SJ, Chambers C, Frisbee JC, Goodwill AG, Crout RJ. Association Between Dental Hygiene, Cardiovascular Disease Risk, and Systemic Inflammation in Rural Adults. Journal of Dental Hygiene. [Accepted, 2010.]

\section{In Review}

Abstracts In Review

Frisbee SJ, Shankar A, Knox SS, Ducatman AM. Associations between non-8-carbon-chain perfuoroalkyl acids and cholesterol in children. American Heart Association Nutrition, Physical Activity and Metabolism / Cardiovascular Disease Epidemiology and Prevention 2011 Scientific Sessions. [Submitted, 2010]

Frisbee SJ, Frisbee JC, Shankar A, Knox SS, Ducatman AM. Contribution of dyslipidemia vs. obesity to inflammation in children. American Heart Association Nutrition, Physical Activity and Metabolism / Cardiovascular Disease Epidemiology and Prevention 2011 Scientific Sessions. [Submitted, 2010]

Frisbee SJ, Shankar A, Knox Ss, Ducatman AM. Associations between obesity and obesity-related systemic inflammation and markers of immune function in children. American Heart Association Nutrition, Physical Activity and Metabolism / Cardiovascular Disease Epidemiology and Prevention 2011 Scientific Sessions. [Submitted, 2010]

Frisbee SJ, Studlar DT. Scientific communities, local tobacco control coalitions, and tobacco control policy: investigating bottom-up influences on social change and the policy process. $69^{\text {th }}$ Annual Midwest Political Science Association Annual Conference. [Submitted, 2010]

\section{Manuscripts In Review}

Knox SS, Jackson T, Javins B, Frisbee SJ, Shankar A, Ducatman AM. Implications of early menopause in women exposed to perfluorocarbons. Journal of Clinical Endocrinology Metabolism. [In Review, 2010]

Mujuru P, Salana HK, Frisbee SJ, Dong L. Overweight and obesity impacts pulmonary function: A cross-sectional study in respiratory asymptomatic adults in small rural communities. Journal of Primary Care and Community Health. [In Review, 2010] 